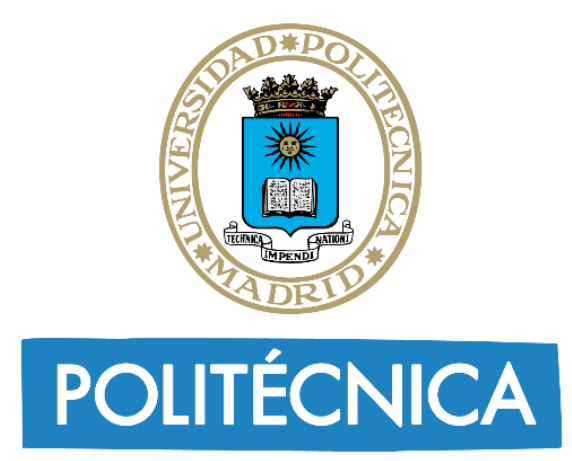

Universidad Politécnica de Madrid

Escuela Técnica Superior de Ingenieros Industriales

\title{
Desarrollo de un instrumento MAX-DOAS para medidas urbanas de calidad del aire y de gases traza en la atmósfera polar
}

\author{
Tesis Doctoral
}

Nuria Benavent Oltra, MSc.

Director:

Prof. Alfonso Saiz López

2020 

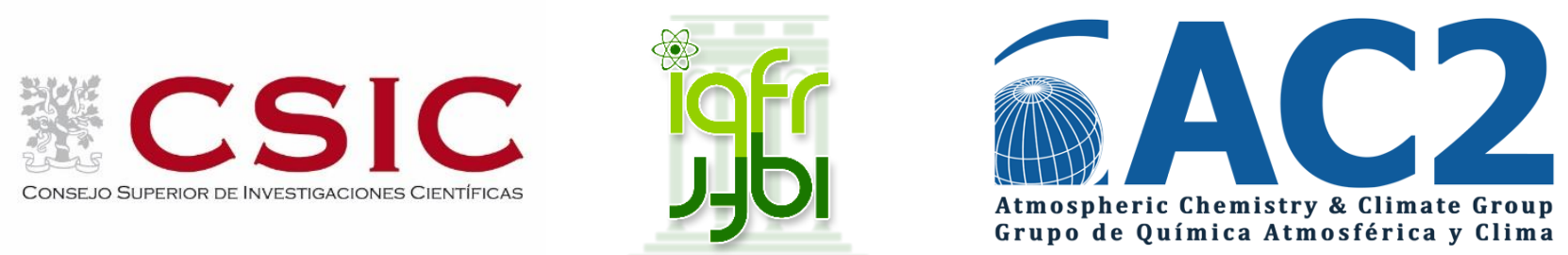

Instituto de Química Física Rocasolano (CSIC)

Grupo de Química Atmosférica y Clima

\section{Desarrollo de un instrumento MAX-DOAS}

para medidas urbanas de calidad del aire

\section{y de gases traza en la atmósfera polar}

Tesis Doctoral

Nuria Benavent Oltra, MSc.

Director:

Prof. Alfonso Saiz López 

Título:

Desarrollo de un instrumento MAX-DOAS para medidas urbanas de calidad del aire y de gases traza en la atmósfera polar.

Autora:

Nuria Benavent Oltra, MSc.

Supervisor:

Prof. Alfonso Saiz López.

Tribunal nombrado por el Mgfco. Y Excmo. Sr. Rector de la Universidad Politécnica de Madrid, el día de de 2020

Presidente D.
Vocal D.
Vocal D.
Vocal D.
Secretario D.
Suplente D.
Suplente D.

Realizado el acto de defensa y lectura de la Tesis Doctoral el de de 2020.

Calificación:
El presidente
El secretario
Los vocales 

A mis abuelas, Adela y Carmen, por cuidar siempre de mí. 



\section{Agradecimientos}

En primer lugar, quiero agradecer a mi director de tesis Prof. Alfonso Saiz López, por el apoyo y dedicación que ha ofrecido a este trabajo; por la dirección y el rigor científico que ha facilitado en esta tesis. Gracias por la confianza depositada desde que llegué al grupo, por la oportunidad de aprender tanto y vivir experiencias inolvidables.

También, agradecer a mi tutor Prof. Rafael Borge la ayuda, asistencia y el soporte científico aportado.

A Dr. Gonzalo González Abad y al Prof. Kelly Chance por darme la oportunidad de pasar dos meses en su centro y aprender de ellos.

A la gente que hace posible que existan estaciones de investigación en sitios remotos como es el caso de Station Nord. A Bjarne Jensen y Henrik Skov, gracias por la oportunidad y la ayuda en la instalación del instrumento MAX-DOAS. Y a los militares que están allí durante todo el año y se han encargado del mantenimiento del instrumento. Al mismo tiempo agradecer a la gente que organiza campañas como el ACE y a todos los que estuvieron ayudándonos en la campaña CINDI-2, en especial a Mónica, Cristina, Olga y Marga, gracias.

Asimismo, a todos mis compañeros del grupo de Química Atmosférica y Clima, a los que han pasado y a los que están todavía en el grupo: María, Caterina, Nando, Manolo, David Armenteros, Leti, Vega, Alba, Dani, Mónica, Noemí, Roberto, Ángel, Nani, Carlos, Jesús, Qinyi, Paul, Shiney, Anoop, Rafa. Gracias por la ayuda recibida y por los buenos momentos durante todos estos años. También a Nacho y José de taller mecánico, sin su ayuda esta tesis no hubiera sido posible. 
A David, mi compañero de despacho, de medidas y de cálculos, gracias por el apoyo incondicional durante todos estos años, por todos los momentos y anécdotas. Bien sabes todo el esfuerzo, constancia y trabajo que hay detrás de estas tesis.

A mis compañeras de piso María y Alicia, y a mis amigas Neus, Carla B., Laia, Nuria, Gema, Rosa y Carla G., gracias.

Por último, a los que siempre están a mi lado, a toda mi familia, en especial a mis padres, Mari Carmen y Emilio por ayudarme, apoyarme y cuidarme durante todos estos años y a mi hermano, Emilio. "Gràcies a tots per l'ajuda inestimable i el recolzament moral i humà que tant necessari és en els moments més difícils". No querría terminar esta parte sin acordarme de mis abuelos, sé que estarían orgullosos de ver este trabajo.

A todos, muchas gracias. 


\title{
Table of contents
}

\author{
Abstract
}

Resumen

Resum

1 MOTIVATION AND OBJECTIVES...................................................29

2 INTRODUCTION TO THE ATMOSPHERE OF THE EARTH.................31

2.1 Brief introduction to atmospheric composition.................................31

2.2 Layers of the atmosphere ...................................................................

2.3 General atmospheric circulation system...........................................36

2.4 Brief introduction to general ozone chemistry...............................38

3 HALOGEN CHEMISTRY IN THE POLAR BOUNDARY LAYER............41

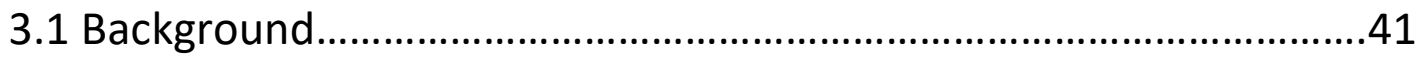

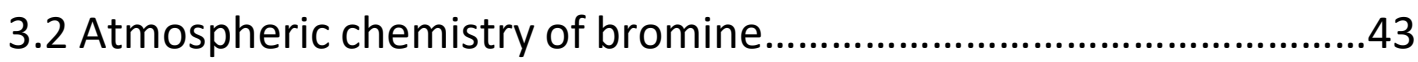

3.3 Atmospheric chemistry of iodine........................................................4 


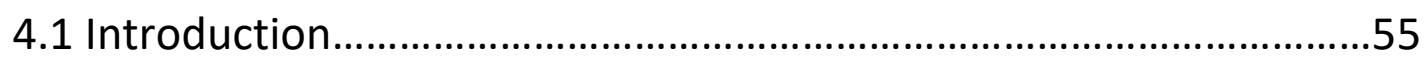

4.2 Solar radiation and Fraunhofer structures........................................57

4.3 Atmospheric interaction with radiation .............................................60

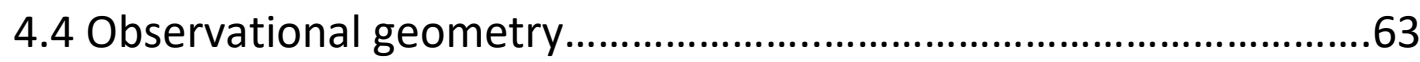

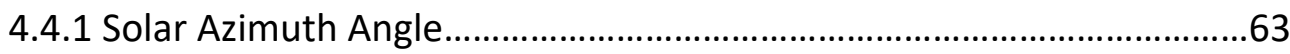

4.4.2 Solar Zenith Angle......................................................................................

4.4.3 Viewing Azimuth Angle..............................................................................64

4.4.4 Elevation Viewing Angle..........................................................................64

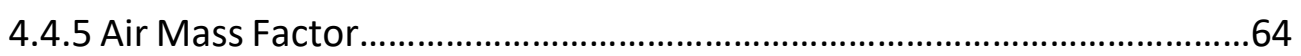

\section{DIFFERENTIAL OPTICAL ABSORPTION SPECTROSCOPY.................67}

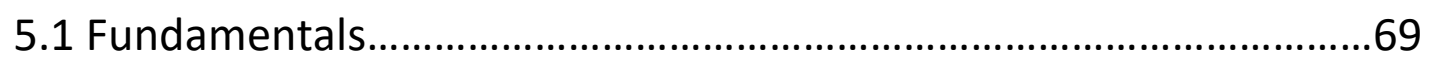

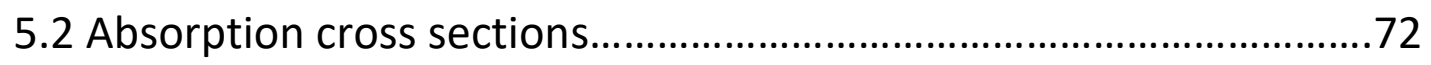

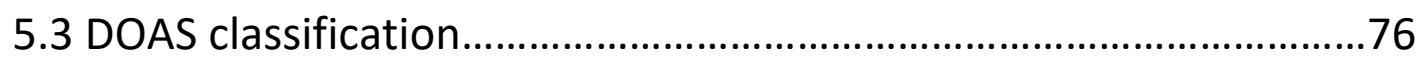

5.4 Multi-AXis Differential Optical Absorption Spectroscopy..................77

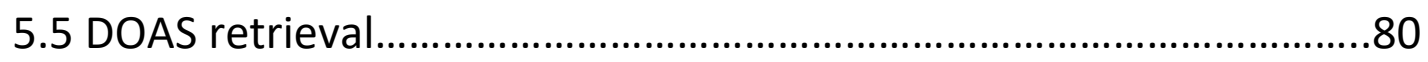

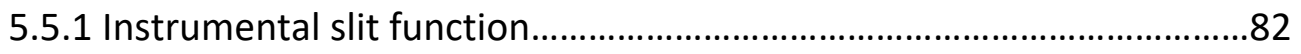

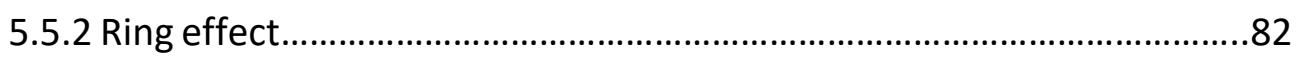

5.6 Background measurements and instrumental effects.......................85

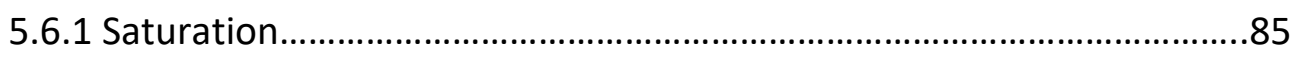

5.6.2 Electronic offset and dark current.........................................................

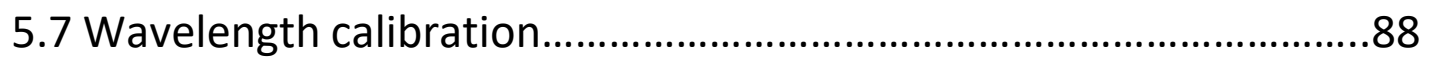

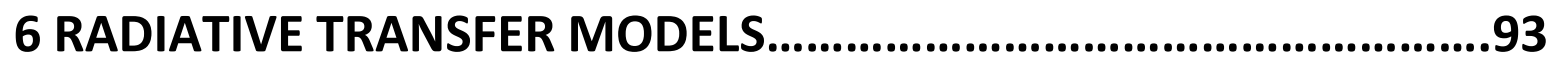

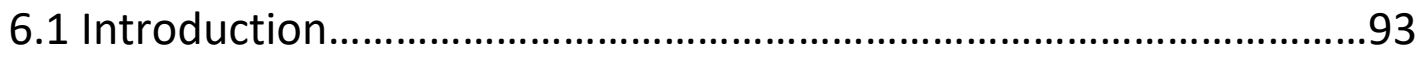


6.2 The forward model and its matrix notation......................................96

6.3 Aerosol extinction and trace gas profile retrieval.............................100

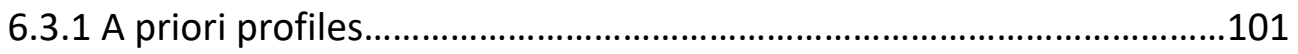

6.4 Radiative Transfer Model of the Atmospheric Chemistry and Climate

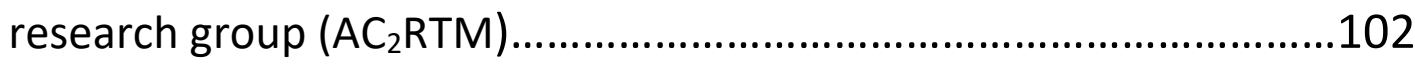

6.4.1 In-scattering and out-scattering...........................................................102

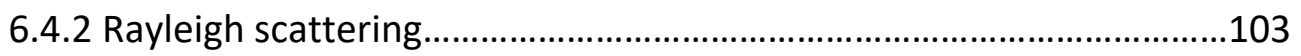

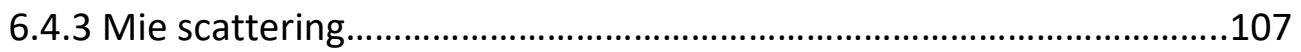

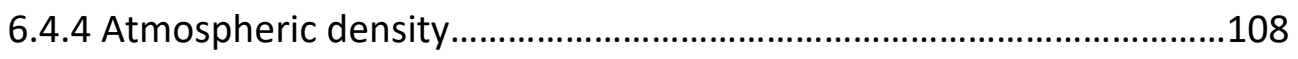

6.4.5 Aerosol extinction..................................................................................109

6.4.6 Integrating over light paths...................................................................112

6.4.7 Scattering weights...................................................................................113

6.4.8 Multiple scattering and albedo...........................................................115

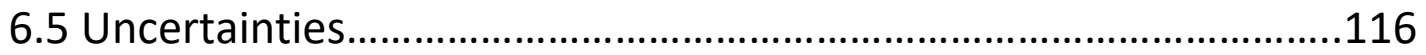

\section{DEVELOPMENT OF A NEW MAX-DOAS FOR POLAR OBSERVATIONS...................................................................................117}

7.1 Instrument description.................................................................117

7.1.1 External Unit...................................................................................118

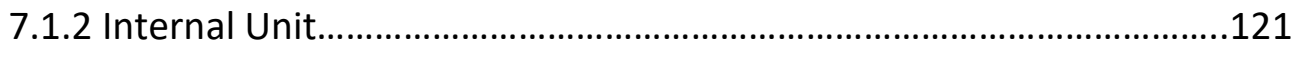

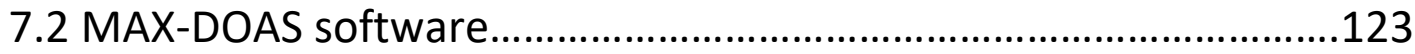

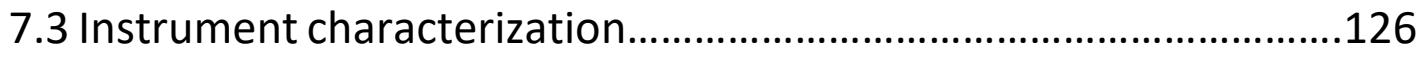

7.3.1 Cloud Index calculation...........................................................................126

7.3.2 Weather proof tests.............................................................................127

7.4 Arctic installation and measurement site.........................................129 


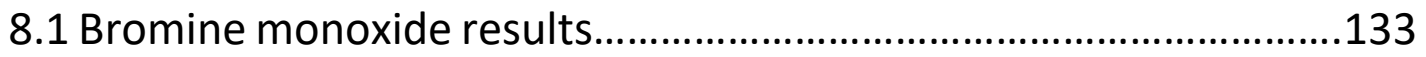

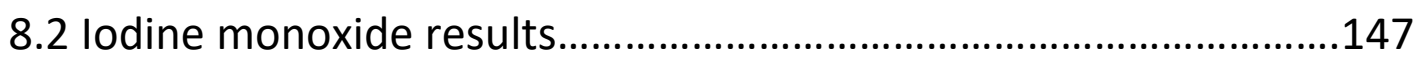

8.3 Impact of bromine and iodine on Arctic ozone loss.........................155

9 MAX-DOAS HALOGEN MEASUREMENTS IN ANTARCTICA..........157

9.1 Antarctic Circumnavigation Expedition (ACE).................................157

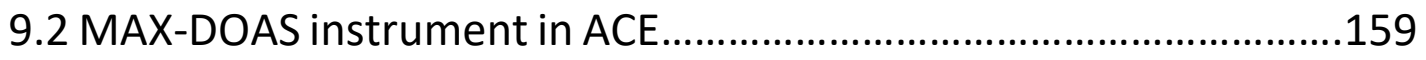

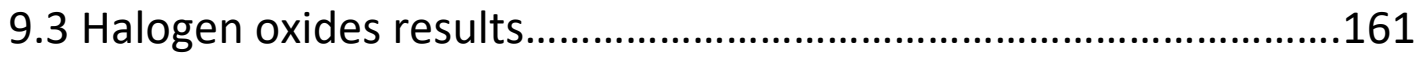

10 CONCLUSIONS AND FUTURE WORK...................................171

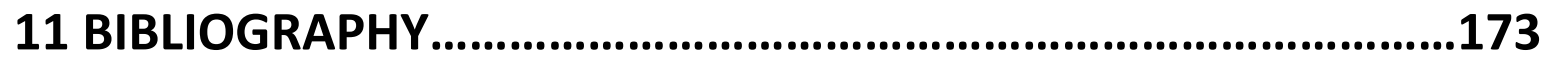




\section{List of figures}

Figure 2.1. Diagram of the layers in the atmosphere.

Figure 2.2. Chapman Cycle of ozone.

Figure 3.1. Simplified bromine explosion scheme.

Figure 3.2. Iodine direct emissions from the ocean (part 1), coastal algae (part 2) and sea ice (part 3).

Figure 3.3. Simplified scheme of iodine-driven ozone loss chemistry in the polar troposphere.

Figure 3.4. Arctic sea ice extent from the 80 s to 2020 . This figure is taken from the National Snow \& Ice Data Center.

Figure 4.1. Electromagnetic spectrum. Credit: NASA's Imagine the Universe.

Figure 4.2. Spectral irradiance of the Sun at the Earth's Top Of the Atmosphere (TOA).

Figure 4.3. Influence of clouds on daily irradiance (figure taken from Honsberg and Bowden, 2019).

Figure 4.4. Diagram of the observational geometries.

Figure 4.5. Different air mass factors representation.

Figure 5.1. Concept of the Lambert-Beer law.

Figure 5.2. Differential absorption cross section example for BrO.

Figure 5.3. Absorption cross sections of trace gases that can be analysed using the DOAS technique. This figure is taken from the book "Atmospheric Trace Gases" document version: 20.03.2014 (C.Kern).

Figure 5.4. MAX-DOAS measurement geometry.

Figure 5.5. Example of the "equivalent" of the absorption cross section of the Ring effect.

Figure 5.6. Electronic offset a) and dark current b) corrections in the visible spectral region for the MAX-DOAS instrument used in Chapter 9.

Figure 5.7. Example of the spectral irradiance of a solar atlas at high resolution a) in the IO fitting window and a zenith measured spectrum, b) in the Arctic using a MAX-DOAS at around noon on May 1, 2017. 
Figure 5.8. Comparison between the measured spectrum and the simulated spectrum from the calibration procedure.

Figure 6.1. Averaging Kernels in the UV region (centred at $360.8 \mathrm{~nm}$ ) for the different altitudes.

Figure 6.2. In-scattering and out-scattering diagram.

Figure 6.3. Rayleigh phase function.

Figure 6.4. Rayleigh scattering.

Figure 6.5. Rayleigh scattering coefficient at different wavelengths.

Figure 6.6. Mie phase functions.

Figure 6.7. Number density profile of a typical Arctic Atmosphere as a function of height.

Figure 6.8. Impact of atmospheric profiles and aerosol loading on the $\mathrm{O}_{4}$ DSCDs.

Figure 6.9. Influence of the aerosol loading on the box-AMF. Box-AMF for EVA $1^{\circ}$ in part a), and box-AMF for EVA $30^{\circ}$ in part b).

Figure 6.10. RTM geometry scheme.

Figure 6.11. Scattering weights for a MAX-DOAS cycle at noon on May 10, 2017 in the high Arctic.

Figure 6.12. Influence of multiple scattering on the scattering weights for an EVA $1^{\circ}$.

Figure 7.1. MAX-DOAS instrument without the insulation layer and the tracking box.

Figure 7.2. Cover layer of the External Unit and the outer layer of the External Unit.

Figure 7.3. Spectrometer Unit and Power Supply Unit.

Figure 7.4. Control Module.

Figure 7.5. Complete Internal Unit part.

Figure 7.6. MAX-DOAS software main screen.

Figure 7.7. Instrument parameters screen

Figure 7.8. Cloud index estimation for a cloudy sky.

Figure 7.9. Cloud index estimation when the Sun is present.

Figure 7.10. Polar proof temperature tests.

Figure 7.11. Station Nord location (taken from villumresearchstation.dk) and VRS (photo taken by Bjarne Jensen). 
Figure 7.12. MAX-DOAS installed in the Villum Research Station.

Figure 8.1. DSCDs comparison between the scan mode and the noon mode converted to its equivalent scan mode.

Figure 8.2. Estimated optical densities for $\mathrm{HCHO}(500 \mathrm{pptv})$ and $\mathrm{BrO}(25 \mathrm{pptv})$.

Figure 8.3. Spectral fit example on May 10, 2017. The red curve is the calculated optical density for $\mathrm{BrO}$ while the black curve represents the measured optical density and the residual of the analysis.

Figure 8.4. Complete database of BrO DSCDs measured by our MAX-DOAS instrument at VRS in 2017-2018.

Figure 8.5. Comparison between simulated and measured DSCDs for BrO on May 10, 2017 a) and the correlation between them $b$ ).

Figure 8.6. BrO profiles a) and VCDs b) (May 10, 2017).

Figure 8.7. Comparison between simulated and measured DSCDs for the two years: 2017 and 2018.

Figure 8.8. Monthly statistical analysis of $\mathrm{BrO}$ mixing ratios a) and VCDs b) during the years 2017-2018.

Figure 8.9. Spectral fitting example of IO, the spectra was taken on May 3, 2017. The red curve is the calculated 10 optical density while the black curve represents the measured optical density.

Figure 8.10. Complete database of IO DSCDs measured by our MAX-DOAS instrument at VRS in 2017-2018.

Figure 8.11. Correlation between simulated and measured IO DSCDs, on May 11, 2017.

Figure 8.12. 10 mixing ratio profiles a) and VCDs b) on May 11, 2017.

Figure 8.13. Comparison between simulated and measured IO DSCDs for both years 2017 and 2018.

Figure 8.14. Monthly statistical analysis of $I O$ mixing ratios a) and VCDs b) during the years 2017-2018.

Figure 8.15. Ozone loss rate in pptv s${ }^{-1}$. The magenta curve represents the ozone loss rate without halogens, black curve describes the ozone loss rate taking into account the bromine 
chemistry and red curve shows the combined impact of iodine and bromine chemistries on the loss rate of ozone.

Figure 9.1. Antarctic Circumnavigation Expedition map.

Figure 9.2. MAX-DOAS angular correction during ACE.

Figure 9.3. Ship-based MAX-DOAS instrument on board the vessel "Akademik Tryoshnikov". Figure 9.4. Sky images taken during the ACE campaign.

Figure 9.5. Spectral fitting examples for $\mathrm{O}_{4}$. The blue curves are the calculated optical densities for each trace gas while the red curves represent the measured optical density a) and the residual of the analysis b). This spectrum was taken on March 8, 2017 at a SZA of $55^{\circ}$ and an EVA of $6^{\circ}$, the RMS is $2.4 \times 10^{-4}$ in density units.

Figure 9.6. Spectral fitting examples for $\mathrm{O}_{4}$. The blue curves are the calculated optical densities for each trace gas while the red curves represent the measured optical density a) and the residual of the analysis b). This spectrum was taken on March 8 , the EVA is $4^{\circ}$ and the SZA is $78^{\circ}$, the RMS is $2.6 \times 10^{-4}$ in density units.

Figure 9.7. Spectral fitting examples for IO. The blue curves are the calculated optical densities for each trace gas while the red curves represent the measured optical density a) and the residual of the analysis b). This spectrum was taken on February 22, 2017. The spectrum was taken at a SZA of $83^{\circ}$ and an EVA of $3^{\circ}$.

Figure 9.8. Comparison between measured and simulated DSCDs for BrO a), b) and IO c), d).

Figure 9.9. Retrieved AOD for the ACE campaign.

Figure 9.10. Available BrO measurements during the ACE campaign along the ship track. Figure 9.11. Available IO measurements during the ACE campaign along the ship track. 


\section{List of tables}

Table 2.1. Main atmospheric compounds and their relative abundance.

Table 8.1. DOAS fitting parameters for BrO in the UV band.

Table 8.2. Previous ground-based measurements of $\mathrm{BrO}$ in the Arctic.

Table 8.3. DOAS fit setting for IO in the VIS band.

Table 8.4. THAMO model simulation design.

Table 9.1. DOAS fit setting for BrO in the UV band for the ACE campaign. 



\section{List of abbreviations}

\begin{tabular}{|c|c|}
\hline AERONET & AErosol RObotic NETwork \\
\hline ACE & Antarctic Circumnavigation Expedition \\
\hline AMF & Air Mass Factor \\
\hline AOD & Aerosol Optical Depth \\
\hline BOAS & Basic Optical Absorption Spectroscopy \\
\hline $\mathrm{CCN}$ & Cloud Condensation Nuclei \\
\hline CFC & ChloroFluoroCarbon \\
\hline DOAS & Differential Optical Absorption Spectroscopy \\
\hline DSCD & Differential Slant Column Density \\
\hline EVA & Elevation Viewing Angle \\
\hline $\mathrm{EF}$ & Enhancement Factor \\
\hline FWHM & Full Width at Half Maximum \\
\hline FYSI & First Year Sea Ice \\
\hline LP-DOAS & Long Path Differential Optical Absorption Spectroscopy \\
\hline MAX-DOAS & Multi AXis Differential Optical Absorption Spectroscopy \\
\hline ODE & Ozone Depletion Event \\
\hline OEM & Optimal Estimation Method \\
\hline RMS & Residual Mean Square \\
\hline RRS & Rotational Raman Scattering \\
\hline RTM & Radiative Transfer Model \\
\hline SAA & Solar Azimuth Angle \\
\hline SEA & Solar Elevation Angle \\
\hline SZA & Solar Zenith Angle \\
\hline TOA & Top Of the Atmosphere \\
\hline VAA & Viewing Azimuth Angle \\
\hline VCD & Vertical Column Density \\
\hline VRS & Villum Research Station \\
\hline
\end{tabular}





\section{Abstract}

The chemical composition of the polar troposphere is influenced by reactive halogens such as $\mathrm{Cl}, \mathrm{Br}$ and I atoms, and their oxides $\mathrm{ClO}, \mathrm{BrO}$ and $\mathrm{IO}$, which can also exert an influence on climate. $\mathrm{I}, \mathrm{Br}$ and $\mathrm{Cl}$ are involved in catalytic reactions which lead to the near complete destruction of surface ozone in polar regions.

In order to get a better knowledge of the levels and seasonal variability of these halogens, we have conducted two years of observations of two important halogens species (BrO and 10 ) in the Arctic. We built a Multi-AXis Differential Optical Absorption Spectroscopy (MAX-DOAS) instrument which has been adapted to the extreme Arctic environmental conditions and installed at Villum Research Station -Station Nord (Greenland), $81^{\circ} 36 \mathrm{~N}, 16^{\circ} 40 \mathrm{~W}$-, in April 2017. During the course of this thesis, we used the DOAS technique, based on the analysis of the narrowband features that trace gases have in their spectral absorptions, to retrieve concentration profiles of these reactive halogen species. Since the MAX-DOAS instrument collects scattered sunlight, it works continuously during sunlit periods, thereby allowing long-term analysis. This thesis reports the first longterm ground-based measurement series (years 2017 and 2018 are presented) of vertical concentration profiles of combined $\mathrm{BrO}$ and $\mathrm{IO}$ in the Arctic.

BrO monthly daytime averages are measured up to 25 pptv in early spring and autumn, while values of about 5 pptv are reached in summer. However, 10 , which is found to be ubiquitous during the sunlit period, shows a less pronounced seasonality with a background mixing ratio of about 1 pptv of $I O$ in the boundary layer. We have estimated the ozone loss rate caused by the measured levels of halogens and found that Arctic iodine increases the $\mathrm{O}_{3}$ loss rate by $\sim 30 \%$, as compared to a simulation taking only bromine into account. 
This thesis also reports halogen oxide results from the first Antarctic Circumnavigation Expedition (ACE) in which we installed a MAX-DOAS instrument on board the research vessel "Akademik Tryoshnikov". We measured scattered sunlight spectra in the marine boundary layer in the Antarctic and in the Atlantic Ocean. Although the measurements conditions were much more challenging for the ship-borne MAX-DOAS, we also report here the measurements of $\mathrm{IO}$ and $\mathrm{BrO}$ during this Antarctic circumnavigation.

Overall, this thesis document includes MAX-DOAS observations of $\mathrm{BrO}$ and $\mathrm{IO}$ over the Arctic and Antarctic, and contributes to the evolving understanding of halogen levels and their impact on atmospheric chemistry in the polar boundary layer. 


\section{Resumen}

La composición química de la troposfera polar está influenciada por halógenos reactivos tales como $\mathrm{Cl}, \mathrm{Br}$ y I, y por sus óxidos $\mathrm{ClO}, \mathrm{BrO}$ y $\mathrm{IO}$, los cuales pueden ejercer una influencia en el clima. I, $\mathrm{Br}, \mathrm{Cl}$ están involucrados en reacciones catalíticas las cuales conducen a la destrucción casi completa del ozono superficial en las regiones polares.

Con el objetivo de obtener un mejor conocimiento de los niveles de halógenos y de su variabilidad estacional, hemos realizado dos años de medidas de dos importantes especies halogenadas ( $\mathrm{BrO}$ y IO) en el Ártico. Para ello, se construyó un instrumento "MultiAXis Differential Optical Absorption Spectroscopy" (MAX-DOAS) el cual, ha sido adaptado a las extremas condiciones ambientales del Ártico, se instaló en la estación de investigación "Villum Research Station" en Station Nord, Groenlandia, a una latitud de $81^{\circ} 36^{\prime} \mathrm{N}$ y una longitud de $16^{\circ} 40^{\prime} \mathrm{W}$ en abril del 2017. Durante el transcurso de esta tesis, se ha utilizado la técnica DOAS, basada en el análisis de las características espectrales de banda estrecha que cada gas traza tiene en su espectro de absorción, para conseguir perfiles de concentración de esas especies de halógenos reactivos. Como el instrumento MAX-DOAS colecta luz del sol dispersada, y está continuamente recopilando datos durante los períodos de luz solar, nos permite realizar un análisis a largo plazo. En esta tesis se reporta la serie completa durante dos años (2017 y 2018) de perfiles de concentración vertical de BrO e IO, siendo el primer análisis a largo plazo de un instrumento MAX-DOAS en el Ártico.

Promedios diurnos de BrO han sido medidos hasta 25 pptv en la primavera temprana y en otoño, mientras que valores hasta 5 pptv han sido alcanzados en verano. Con respecto al IO, se ha demostrado que está presente durante todo el período de luz solar. Además, valores de 1 pptv de 10 están presente durante todos los meses en la capa límite mostrando una estacionalidad menos pronunciada que la del BrO. La presencia de 
yodo en las cantidades que hemos medido causa incrementa la tasa de pérdida de ozono en un $\sim 30 \%$, si la comparamos con la simulación con solo bromo.

Esta tesis también reporta resultados de óxidos de halógenos de la primera campaña de circunnavegación antártica (ACE), en la cual se instaló un instrumento MAX-DOAS a bordo del buque de investigación "Akademik Tryoshnikov". Se ha medido luz del sol dispersada en la capa límite marina en la Antártida y en el Océano Atlántico. Aunque las condiciones de estas medidas MAX-DOAS han sido más exigentes debido al movimiento del barco, hemos podido obtener medidas de IO y BrO durante esta circunnavegación antártica.

En conclusión, esta tesis incluye observaciones MAX-DOAS de $\mathrm{BrO}$ y de 10 en el Ártico y en la Antártida, contribuyendo a un mejor conocimiento de los niveles de halógenos y su impacto en la química atmosférica en la capa límite polar. 


\section{Resum}

La composició química de la troposfera polar està influenciada per halògens reactius com és el cas dels àtoms $\mathrm{Cl}, \mathrm{Br}$ i I, i dels seus òxids $\mathrm{ClO}, \mathrm{BrO}$ i IO, els quals tenen una certa influència en el clima. I, $\mathrm{Br}$ i $\mathrm{Cl}$ estan involucrats en reaccions catalítiques les quals condueixen a la destrucció gairebé completa de l'ozó superficial a les regions polars.

Per tal d'obtenir un millor coneixement dels nivells i de la variabilitat estacional d'aquests halògens, s'ha dut a terme dos anys d'observacions de dues importants espècies d'halògens (BrO i IO) a l'Àrtic. S'ha construït un instrument “Multi-AXis Differential Optical Absorption Spectroscopy" (MAX-DOAS) adaptat a les condicions ambientals extremes de l'Àrtic, aquest instrument s'ha instal·lat a l'estació d'investigació Villum - Station Nord, a Groenlàndia, aquest lloc té una latitud de $81^{\circ} 36 \mathrm{~N}$ y una longitud de $16^{\circ} 40 \mathrm{~W}$ - a l'Abril de 2017.

Durant el transcurs d'aquesta tesi, s'ha utilitzat la tècnica DOAS, basada en l'anàlisi de les característiques de banda estreta que tenen els gasos traça en les seves absorcions espectrals, per obtenir perfils de concentració d'aquestes espècies halògenes reactives. Atès que l'instrument MAX-DOAS recull la llum solar dispersa, funciona de forma contínua durant els períodes de llum solar, permetent així l'anàlisi a llarg termini. Aquesta tesi informa de les primeres sèries de mesurament terrestres a llarg termini (es presenten els anys 2017 i 2018) de perfils de concentració vertical de BrO i IO combinats a l'Àrtic.

Les mitjanes mensuals de BrO han sigut mesurades fins 25 pptv a principis de primavera i tardor, mentre que a l'estiu s'assoleixen valors d'uns 5 pptv. Tanmateix, l'IO, que es troba omnipresent durant el període il-luminat pel sol, mostra una estacionalitat menys pronunciada amb una relació de barreja de fons d'aproximadament 1 pptv d'IO a la capa límit. S'ha estimat la taxa de pèrdua d'ozó causada pels nivells mesurats d'halògens i 
$s^{\prime}$ ha vist que el iode àrtic augmenta la taxa de pèrdua d' $\mathrm{O}_{3}$ en un $30 \%$, en comparació amb una simulació només amb brom.

Aquesta tesi també informa dels resultats d'òxids d'halògens de la primera campanya de circumnavegació antàrtica $(A C E)$, en la què vam instal·lar un instrument MAXDOAS a bord del vaixell de recerca "Akademik Tryoshnikov". Hem mesurat els espectres de llum solar dispersada a la capa límit marina de l'Antàrtic i de l'Oceà Atlàntic. Tot i que les condicions de mesura van ser molt més difícils per al MAX-DOAS ja que estava instal-lat al vaixell, també informem aquí de les mesures de IO i BrO durant aquesta circumnavegació antàrtica.

En general, aquest document de tesi inclou observacions MAX-DOAS de BrO i IO sobre l'Àrtic i l'Antàrtida, i contribueix a la comprensió evolutiva dels nivells d'halògens i el seu impacte en la química atmosfèrica a la capa límit polar. 


\section{MOTIVATION AND OBJECTIVES}

In the past decades, atmospheric scientists have come to realize that halogen species (like chlorine $(\mathrm{Cl})$, bromine $(\mathrm{Br})$ or iodine $(\mathrm{I})$ and their oxides chlorine monoxide $(\mathrm{ClO})$, bromine monoxide $(\mathrm{BrO})$ and iodine monoxide $(\mathrm{IO})$ ) exert a powerful influence on the chemical composition of the troposphere and through that influence, they thrust a potentially significant impact on climate. These reactive halogen species are potent oxidizers for organic and inorganic compounds throughout the troposphere. In particular, halogen cycles can impact on several compounds (such as methane $\left(\mathrm{CH}_{4}\right)$, ozone $\left(\mathrm{O}_{3}\right)$, particles and so on), all of which are climate forcing agents through direct and indirect radiative effects.

In both the Arctic and Antarctic boundary layers, strong and sudden increases in reactive bromine were observed during their respective springtime. This bromine increase is known as "bromine explosion" and it is caused by autocatalytic processes on halide rich surfaces (e.g. sea salts, first year sea ice, frost flowers, saline snow). This phenomenon often leads to the near complete destruction of surface ozone in the polar boundary layer (Barrie, 1988). Chlorine has also been widely studied in connection with ozone depletion, mainly through crossed chemical cycles with bromine. However, the levels of reactive iodine, and their role in polar tropospheric chemistry, particularly in the Arctic, are much less known.

With the purpose of improving the knowledge of the levels and seasonality of these halogens, their evaluation in polar regions is important to understand the evolution of atmospheric chemistry in these pristine environments. In order to do this, we have conducted two years of observations of the important halogen species $\mathrm{BrO}$ and $\mathrm{IO}$ in the 
Arctic. During the course of this thesis, we have also conducted MAX-DOAS ship-borne observations of these two radicals in a circumnavigation around the Antarctic continent.

Overall, this thesis document includes MAX-DOAS observations of the reactive halogens $\mathrm{BrO}$ and $\mathrm{IO}$ over both the Arctic and Antarctic. It contributes to the evolving understanding of halogen levels and their impact on atmospheric chemistry in the polar boundary layer. The general goals of the thesis are:

- Further understand the seasonality of $\mathrm{BrO}$ in the Arctic, particularly during summer and autumn when fewer BrO ground-based observations are available.

- Explore the presence of IO in the Arctic atmosphere. While several observations have reported its widespread presence in the Antarctic, only sporadic measurements have been reported in the Arctic.

- Evaluate their combined effect on ozone loss in the Arctic boundary layer.

- Ship-borne observations of 10 and BrO during the Antarctic Circumnavigation Expedition. 


\section{INTRODUCTION TO THE}

\section{ATMOSPHERE OF THE EARTH}

This chapter describes the general composition and vertical structure of the atmosphere of the Earth.

\subsection{Brief introduction to atmospheric composition}

The atmosphere is a gaseous layer that envelops the Earth and contains a mixture of thousands of chemical compounds along with liquid droplets and solid aerosol particles. The atmosphere of the Earth is mainly composed by nitrogen $\left(\mathrm{N}_{2}\right)$, oxygen $\left(\mathrm{O}_{2}\right)$ and argon (Ar). Table 1.1 summarizes the main components of the atmosphere, along with their corresponding percentage contribution to total mass.

Water vapour, a significant atmospheric compound, has a highly variable concentration and is mainly located in the lower atmosphere as its abundance is controlled by evaporation and precipitation. The remaining gases (trace gases), not listed in Table 1.1, represent less than $1 \%$ of the total atmospheric mass, although they play an important role in the radiative balance of the Earth and in the chemical properties of the atmosphere (Seinfeld and Pandis, 2004). 
Table 2.1. Main atmospheric compounds and their relative abundance.

\begin{tabular}{|c|c|}
\hline Constituent & Percentage or volume mixing ratio in air \\
\hline Nitrogen & $78 \%$ \\
\hline Oxygen & $21 \%$ \\
\hline Argon (Ar) & $0.93 \%$ \\
\hline Carbon dioxide $\left(\mathrm{CO}_{2}\right)$ & $0.0035 \%$ \\
\hline Water vapour $\left(\mathrm{H}_{2} \mathrm{O}\right)$ & $0-4 \%$ \\
\hline Helium $(\mathrm{He})$ & $5.5 \mathrm{ppm}$ \\
\hline Neon $(\mathrm{Ne})$ & $18 \mathrm{ppm}$ \\
\hline $\mathrm{CH}$ & $1.7 \mathrm{ppm}$ \\
\hline
\end{tabular}

The study of atmospheric chemistry goes back to the eighteenth century when chemists like Joseph Pristley, Antoine-Laurent Lavoisier and Henry Cavendish made an effort to determine the components of the atmosphere. In the nineteenth century, chemists and physicists, with the helpful contribution of previous chemists, established the presence of several components in the atmosphere: $\mathrm{N}_{2}, \mathrm{O}_{2}, \mathrm{CO}_{2}, \mathrm{H}_{2} \mathrm{O}$, and the rare trace gases. Later on, in the twentieth century research was focused on the trace gas constituents which have mole fractions below $10^{-6}, 1 \mathrm{ppm}$ (part per million) by volume, and now, compound levels of $10^{-12}$, ppt (parts per trillion) by volume.

Nowadays, there is an increase in the amount of atmospheric trace gases in comparison with those of the past (Gonzalez-Abad et al., 2019). For example, human activities account for most of the rapid changes in trace gas levels (e.g. $\mathrm{CO}_{2}, \mathrm{CH}_{4}$ ) over the past 200 years, mainly due to the combustion of fossil fuels for energy and transportation, agricultural and industrial activities, biomass burning and deforestation. 
Records of atmospheric $\mathrm{CO}_{2}, \mathrm{CH}_{4}$ and nitrous oxide $\left(\mathrm{N}_{2} \mathrm{O}\right)$ show a steady increase since the end of the eighteenth century with the invention of the steam engine in 1784 . Additionally, more nitrogen is currently present in the atmosphere because of the use of synthetic fertilizers in agriculture (Seinfeld and Pandis, 2004).

The evolution of the Antarctic hole in the 1980s (Farman et al., 1984) gives a clear vision of the ability of trace species (e.g. halogens) to perturb the atmosphere. The increase in aerosols is also marked since the Industrial Revolution. This is relevant as aerosols have been shown to affect the climate and have been implicated in human mortality in urban areas.

All of the above is due to the fact that the atmosphere is a dynamic system, with its gaseous constituents being continuously exchanged with vegetation, oceans and biological organisms. On one hand, atmospheric compounds can be produced by chemical processes within the atmosphere, by biological activity, volcanic emissions and human industrial activities. On the other hand, these compounds can be removed from the atmosphere by chemical reactions, physical processes (such as particle formation), by biological activities and by deposition and uptake by the land and oceans (Seinfeld and Pandis, 2004). One important concept in atmospheric chemistry is the lifetime of species, which can be defined as the average time that a molecule remains in the atmosphere before it is removed by chemical reaction or deposition. It is a magnitude that varies from seconds to years.

Most of the species which are considered air pollutants - when their concentration exceeds the normal levels- have anthropogenic or natural sources. Therefore, in order to evaluate the effect of anthropogenic emissions, it is necessary to understand the atmospheric cycles of the trace gases, including anthropogenic and natural sources as well as their transformation and removal mechanisms. 
During transport in the atmosphere, all gases, except the most inert substances, participate in chemical reactions. A given compound can be transformed into a different species, it can change the original state (gas, liquid or solid) and the chemical form. The resulting product is different from its parent substance in terms of chemical properties or other characteristics (Pryor et al., 2015).

The atmosphere is generally an oxidizing environment, for this reason, chemical compounds are converted into substances characterized by higher chemical oxidation states than their parent substances. This oxidative transformation produces a decrease in volatility and an increase in polarity.

Finally, one can conclude that the atmosphere is an enormous chemical reactor in which there is a high amount of species which are continually being removed and introduced over a huge array of spatial and temporal scales.

\subsection{Layers of the atmosphere}

The layers of the atmosphere are based on the variation of the average temperature profile with altitude. The atmospheric layers, shown in Figure 2.1, are divided as follows:

- Troposphere: is the lowest part of the atmosphere; it is the part we live in. It contains about $80 \%$ of the total mass of the atmosphere, and almost all of the water vapour that exists in the atmosphere resides there. The temperature gets colder as the distance above the Earth surface increases, and this decrease is produced at a fairly constant rate (roughly $-6.5^{\circ} \mathrm{C} \mathrm{km}^{-1}$ The decrease in temperature with height is linear and there is a rapid vertical mixing in this layer. The lowest level of the troposphere is called the boundary layer and it is of great importance for atmospheric chemistry studies. This is where the air motion is defined by the surface properties of the Earth. The top of the troposphere is called the tropopause, it is lowest at the poles $(7-10 \mathrm{~km})$ and highest at the equator $(17-18 \mathrm{~km})$. 
- Stratosphere: extends from the tropopause to the stratopause (45 - $55 \mathrm{~km})$, here the temperature increases with altitude due to the absorption of ultraviolet (UV) solar radiation, the vertical mixing is slow in this layer. It contains the largest amount of ozone in the atmosphere which absorbs dangerous solar UV radiation.

- Mesosphere: it comprises the region that goes from the stratopause up to the mesopause $(80-90 \mathrm{~km})$. Temperature decreases with altitude, and the coldest point in the atmosphere is reached here. Vertical mixing is very efficient.

- lonosphere: is a region of the upper mesosphere and lower thermosphere, in which there are ions produced by photoionization. The ionosphere absorbs and reflects radio waves, allowing us to receive shortwave radio.

- Thermosphere: this region ranges from the mesopause up to about $700 \mathrm{~km}$ height. It is characterized by elevated temperatures due to absorption of short-wavelength radiation by $\mathrm{N}_{2}$ and $\mathrm{O}_{2}$ molecules, as well as rapid vertical mixing.

- Exosphere: it is the outermost region of the atmosphere. It starts at the end of the thermosphere and is considered to extend until roughly $10^{4} \mathrm{~km}$ height. It contains helium and hydrogen atoms, some of which, with an adequate energy, can escape from the gravitational pull of the Earth. 


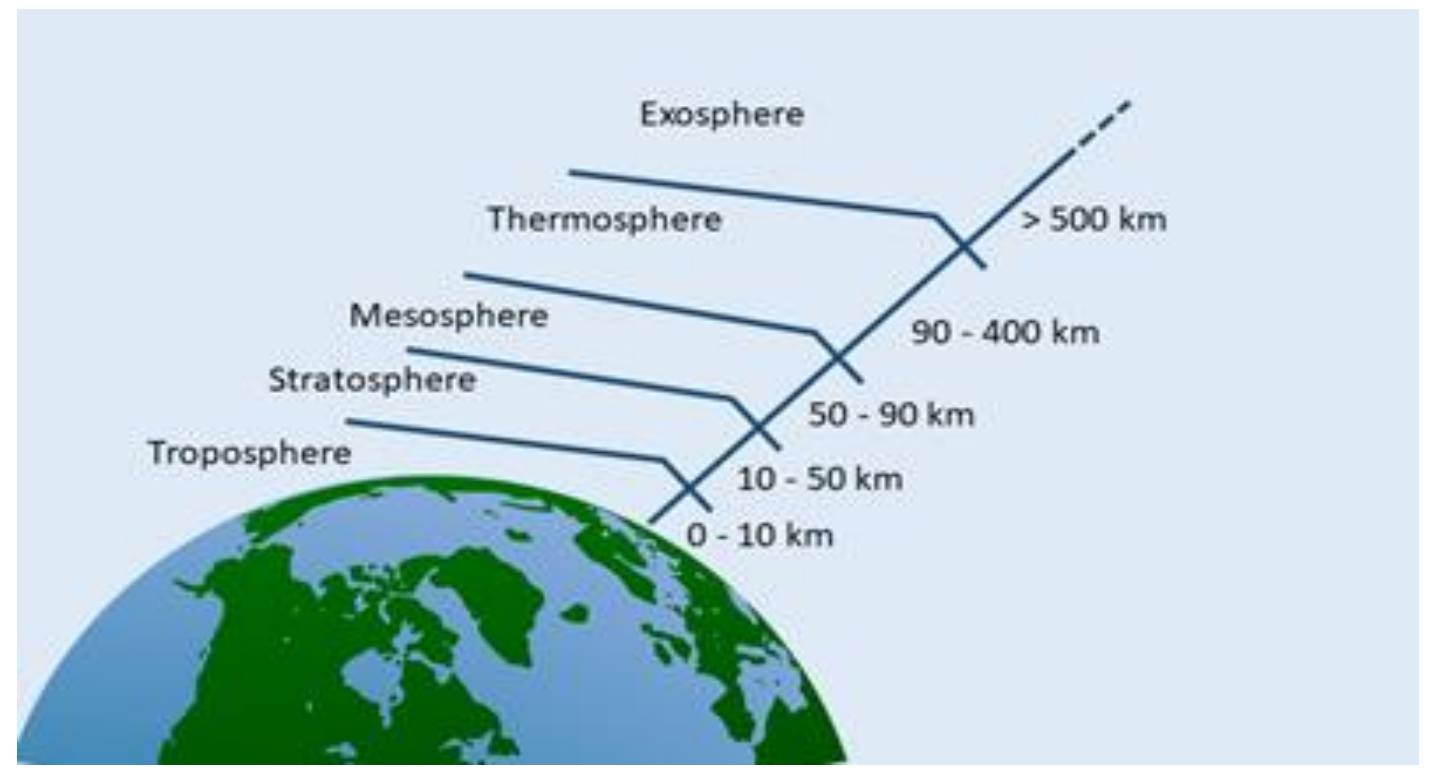

Figure 2.1. Diagram of the layers in the atmosphere.

\subsection{General atmospheric circulation system}

Almost all of the total energy that reaches the Earth comes from the Sun and it is balanced by the energy radiated from the Earth back to space. The total energy is different from one latitude to another, for example polar regions receive less energy than the equator.

Atmospheric circulation has a redistribution system, in which areas with an energy excess spread it to energy deficient areas. Here we briefly describe the general constitution of large-scale flow in the atmosphere. Cool, and denser, air drops while warm air rises due to its lower density relative to the surrounding air parcels. The sinking cold air provides a higher pressure at the surface while the warm air rises, leading to lower surface pressure. In order to conserve the mass, the warm air travels through the atmosphere to the cold areas, this means that there is a general circulation of air between the equator and the poles. The air rises in the equatorial regions, spreads poleward at the tropopause, converges and sinks in the polar regions and finally it moves backwards toward the equator at the surface of the Earth. This mechanism is called Hadley cell and it does not take into account the rotation of the planet (Brasseur et al., 1999). 
Due to the Earth's rotation, there is another force in the atmosphere which causes a flow of air masses: the Coriolis force. The air cannot directly flow in one direction from the poles to the equator and back. There is therefore an approximation of the three cell model which is based on:

- Hadley Cell: a model of atmospheric circulation in which warm air rises near the equator, cools while it travels poleward at high altitude, sinks as cold air, and warms as it travels back to the equator.

- Ferrel Cell: in this cell which occurs at mid-latitudes $\left(30^{\circ}\right.$ to $\left.60^{\circ}\right)$ the air flows polewards and eastwards near the surface and equatorwards and westwards at higher altitudes; this movement is the reverse of the airflow generated in the Hadley cell.

- Polar Cell: in this cell the air sinks over the highest latitudes $\left(60^{\circ}-70^{\circ}\right.$ north and south), when these polar regions are reached, the air becomes cold and descends as a dry and cold high pressure area, after it moves away from the poles. It is the smallest and weakest cell.

These provide a brief overview of vertical and horizontal transport of air in the atmosphere. Concerning timescales, the transport of air parcels in meridional direction is slower than in longitudinal direction due to the westerlies (strong winds from the west toward the east in the middle latitudes), air parcels need a few weeks to circumnavigate the Earth in longitudinal direction. Hence it is easier that a given air parcel reaches the polar regions from the tropics due to the temperature gradients. Nevertheless, since the mentioned latitudinal temperature gradient forces the air to generally flow from the tropics to the equator, it is difficult for a given air parcel to cross the equator and change from one hemisphere to the other (it may take over a year). 
Regarding vertical transport, the time scales of air transport from the surface to the tropopause depend on the turbulent atmospheric flow. The Arctic and Antarctic measurements that we present in this work were made in the polar boundary layer, and therefore subject to Polar cells transport.

\subsection{Brief introduction to general ozone chemistry}

Ozone, the most chemically-active greenhouse gas, is a molecule formed by three oxygen atoms: $\mathrm{O}_{3}$. Its presence in the atmosphere is very important due to different reasons. It is distributed along the atmosphere and the consequences of its presence in different atmospheric layers are different. High levels of $\mathrm{O}_{3}$ in the troposphere (near the ground) act like an air pollutant which causes health problems like respiratory issues, can damage lung tissues, can elevate the asthma attacks, produces eye irritation, nauseas, headaches. Tropospheric ozone is produced by the photolysis of nitrogen oxides or hydrocarbons, that are mainly emitted by anthropogenic activities. For example:

$$
\begin{aligned}
& \mathrm{NO}_{2}(\mathrm{~h} v) \rightarrow \mathrm{NO}+\mathrm{O} \\
& \mathrm{O}+\mathrm{O}_{2}(+\mathrm{M}) \rightarrow \mathrm{O}_{3}+\mathrm{M}
\end{aligned}
$$

The $\mathrm{NO}_{2}$ photolysis produces oxygen atoms which react quickly with oxygen molecules (R2.1). Note also that the photolysis of ozone is the most important source of hydroxyl radical $(\mathrm{OH})(\mathrm{R} 2.3-\mathrm{R} 2.4)$.

$$
\begin{aligned}
& \mathrm{O}_{3}+\mathrm{h} v(\lambda<350 \mathrm{~nm}) \rightarrow \mathrm{O}_{2}+\mathrm{O}^{1} D \\
& \mathrm{O}^{1} D+\mathrm{H}_{2} \mathrm{O} \rightarrow 2 \mathrm{OH}
\end{aligned}
$$


The hydroxyl radical is the most important oxidizer in atmosphere, and its increase can cause, for example, secondary reactions which can lead to higher levels of secondary pollutants in an urban area (Saiz-Lopez et al., 2017).

On the other hand, ozone molecules in the stratosphere form the ozone layer that absorbs harmful solar ultraviolet radiation before it reaches the ground. In the 80 's, the ozone hole, is a decrease in the levels of ozone in the stratosphere, was discovered in Antarctica (Farman et al., 1985). Note that more recently, significant ozone loss in the Arctic stratosphere have also been reported. There is extensive literature on stratospheric ozone photochemistry, however it is very briefly commented here since it is not the topic of this thesis.

Chapman was the first to explain the stratospheric ozone chemistry (Chapman, 1930). The ultraviolet radiation reaches the stratosphere and it can dissociate the oxygen molecules. Then, oxygen atoms react with molecular oxygen and the result is one ozone molecule. After that, this ozone molecule absorbs solar UV radiation photolysing to a molecule of oxygen and an oxygen atom. Ozone can also react with an oxygen atom, these reactions are known as Chapman Cycle, a scheme of the Chapman Cycle appears in Figure 2.2 .

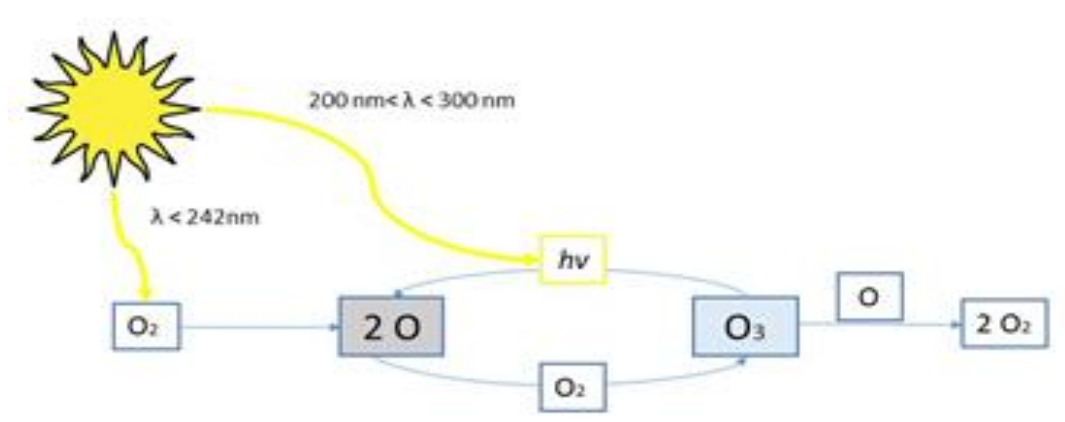

Figure 2.2. Chapman Cycle of ozone. 
The reaction in which the ozone is formed is faster than the reaction in which molecular oxygen is produced. Therefore, only a small fraction of oxygen is retransformed to molecular oxygen.

Early on, scientists working in stratospheric ozone research realised that by only taking into account the Chapman cycle, they were not able to describe the observed ozone profiles, and concluded that there had to exist some other mechanisms which can help to explain the observed ozone. Bates in 1950 proposed that there would be a set of ozone destroying reaction cycles, involving hydrogen oxides (Bates and Nicolet, 1950). Later, Crutzen and Johnston in the 70s (Crutzen, 1970 and Johnston, 1971) suggested that the nitrogen oxides are involved in the catalytic ozone destruction cycles. About the same time, Molina and Rowland (1974), suggested that man-made chlorine could also lead to the destruction of stratospheric ozone. More details on halogen chemistry in relation to tropospheric are discussed in Chapter 3. 


\section{HALOGEN CHEMISTRY IN THE}

\section{POLAR BOUNDARY LAYER}

This Chapter describes the importance of halogens (chlorine, bromine and iodine) for ozone depletion and its underlying chemistry.

\subsection{Background}

Arctic and Antarctic regions play a key role in the global atmosphere. They represent an important contribution to atmospheric and oceanic circulation and global atmospheric composition. Some characteristics of the polar regions include: atmospheric compound's lifetimes are longer than in other environments because of the lower temperatures and the reduced solar radiation conditions. Arctic atmosphere is influenced by seasonal atmospheric transport and it is affected by anthropogenic emissions due to its proximity to industrially developed countries. The Antarctic atmosphere is uncontaminated, dry, isolated from the rest of the Earth, it is encircled by the Southern Ocean and the polar vortex. The interest in Antarctic stratospheric chemistry was accentuated when Molina and Rowland in 1974 postulated that industry-emitted halocarbon compounds (Chlorofluorocarbons, CFCs) can cause depletion of stratospheric ozone (Molina and Rowland, 1974).

Disappearances of surface ozone were first observed in Canada in the high Arctic in 1985. In this investigation, ozone mixing ratios dropped from 30-40 parts per billion in volume (ppbv) to almost zero in just a few hours (Bottenheim et al., 1986). Barrie (1988) discovered that high levels of bromine were related to the observed low ozone levels. These 
ozone levels decay mainly occurred during the transition from winter (dark) to spring (sunlight) (Barrie et al., 1988). All of these investigations concluded with the discovery of the polar boundary layer Ozone Depletion Events (ODEs). Currently, ODEs are a demonstrated phenomenon that occurs in coastal areas in both southern and northern polar regions during spring (Simpson et al., 2007b). It is driven by the rapid ozone drop at ground levels and it has a duration from hours to days (Jones et al., 2009).

Scientists now recognize that the chemical composition of the troposphere is influenced by highly reactive halogens: atomic halogen radicals $(\mathrm{Cl}, \mathrm{Br}, \mathrm{I})$ and their respective monoxides $(\mathrm{ClO}, \mathrm{BrO}, \mathrm{IO})$, which are considered as catalysts for ODEs. Bromine is more efficient at destroying ozone than chlorine (Saiz-Lopez et al., 2012) since the photolysis rate of $\mathrm{BrO}$ is two or three orders of magnitude faster than that for $\mathrm{ClO}$. $\mathrm{BrO}$ observations in the Arctic by Hausmann and Platt, 1994 and Wagner et al., 1998 confirmed that bromine is involved in ODEs. Since then, many measurements of $\mathrm{BrO}$, as well as aerosols, have been carried out in the polar environment (e.g. Kreher et al., 1997, Wagner et al., 1998, Jacobi et al., 2006, Wagner et al., 2007; Saiz-Lopez et al., 2007 Pöhler et al., 2010; Merlaud et al., 2011; Zhao et al., 2016; Schönhart et al., 2012, Prados-Roman et al., 2018).

All of these halogen compounds may affect climate and the oxidation capacity of the atmosphere (Saiz-Lopez and von Glasgow, 2012; Simpson et al., 2015). This is because halogens are involved in ozone-destroying catalytic reactions that change the oxidizing capacity of the atmosphere. The photolysis of ozone produces $\mathrm{OH}$ radicals -the most important oxidant in the atmosphere. This highlights the importance of reactive halogens, which will be dealt with in more detail in the following sections.

Apart from ozone loss, Atmospheric Mercury Depletion Events (AMDEs) also occur in the polar regions. This mercury depletion represents a very fast removal of elemental mercury $(\mathrm{Hg})$ from the atmosphere. An important property of elementary mercury is the 
low chemical reactivity, the lifetime in the atmosphere goes from 6 to 12 months and it is considered a global contaminant (Saiz-Lopez et al., 2018). Elemental Hg can be transformed into chemical species (oxidized forms) which are bioavailable and can bioaccumulate to harmful or toxic levels in the aquatic food chain, extending to birds, mammals who consume fish (Lindqvist et al., 1991; Mintra et al., 1986). The first AMDE was observed in Alert (Canadian Arctic) in 1995 (Schroeder et al., 1998). The cycle starts with the oxidation of $\mathrm{Hg}(0)$ via $\mathrm{Br}$ atoms to form reactive mercury $\left(\mathrm{Hg}^{+2}\right)$, which can be deposited in the snow, and from there it can enter the aquatic food chain. The AMDEs are correlated with ODEs because both are driven by halogen reactions. Therefore, halogens play a key role in the oxidation chemistry of the polar troposphere.

\subsection{Atmospheric chemistry of bromine}

An important tropospheric inorganic bromine source is the polar sea ice region (Kaleschke et al., 2004 and references therein). The rapid and sudden appearance of $\mathrm{BrO}$ over the polar regions has been called the "bromine explosion" (Barrie and Platt, 1997). The first measurements of $\mathrm{BrO}$ (Hausmann and Platt 1994) verified the importance of bromine radicals in ODEs. BrO has been measured in the Arctic up to 30-40 pptv (Pöhler et al., 2010), Antarctic up to 20 pptv (Saiz-Lopez et al., 2007) and Atlantic marine boundary layer up to 4 pptv (Read et al., 2008).

For this reason, it is important to know the chemical coupling between bromine and ozone in the polar environment. A large amount of active bromine compounds is released by an autocatalytic heterogeneous mechanism and leads to substantial ozone depletion (Fan and Jacob, 1992; McConnell et al., 1992; Simpson et al., 2007a, b) and mercury depletion (Steffen et al., 2008) in the polar boundary layer in spring. In 2007, Grannas et al., demonstrated that ice and snow play a significant role in the photochemical production of important atmospheric species containing halogens. Halides (chloride, bromine and iodide

ions) are exposed to the Arctic and Antarctic atmosphere via heterogeneous reactions on first year sea ice (FYSI), saline snow, frost flowers, and marine aerosols and sea water. FYSI 
is important in this remote places due to its high content in bromide -and-chloride. Snowpack has also been suggested as a substrate where halogen heterogeneous reactions take place, leading also to the activation of bromine and chlorine (the reactions are specified in R3.7 and R3.8) (Peterson et al., 2019).

Large amounts of molecular bromine $\left(\mathrm{Br}_{2}\right)$ are released from the snowpack and aerosols following heterogeneous reactions on the abovementioned surfaces. This catalytic process continues until the surface is halide depleted or the boundary layer inversion, which inhibits atmospheric mixing, breaks down. Once in the atmosphere, the photolysis of $\mathrm{Br}_{2}$, bromine chloride $(\mathrm{BrCl})$ or (brominated organic compounds $(\mathrm{RBr})$ yields highly reactive bromine atoms during the sunlit hours (R3.1):

$$
\mathrm{Br}_{2}+\mathrm{h} v \rightarrow 2 \mathrm{Br}
$$

Once $\mathrm{Br}_{2}$ is photolyzed, the bromine atoms can destroy $\mathrm{O}_{3}$ through a catalytic cycle (R3.2-3.4):

$$
\begin{aligned}
& 2\left(\mathrm{Br}+\mathrm{O}_{3}\right) \rightarrow 2\left(\mathrm{BrO}+\mathrm{O}_{2}\right) \\
& \mathrm{BrO}+\mathrm{BrO} \rightarrow 2 \mathrm{Br}+\mathrm{O}_{2}
\end{aligned}
$$

Net reaction: $2 \mathrm{O}_{3} \rightarrow 3 \mathrm{O}_{2}$

Then, $\mathrm{BrO}$ can react with $\mathrm{HO}_{2}$ (hydroperoxyl) or with $\mathrm{NO}_{2}$. The kinetic database from the NASA/Jet Propulsion Laboratory compendium (Burkholder, et al. 2015) provides the rate coefficient $(k)$ for each reaction: reaction $\mathrm{R} 3.5, \mathrm{k}_{1}=2.1 \times 10^{-11} \mathrm{~cm}^{3}$ molecule ${ }^{-1} \mathrm{~s}^{-1}$ at 298 $\mathrm{K}$; and reaction $\mathrm{R} 3.6, \mathrm{k}_{2}=3.5 \times 10^{-12} \mathrm{~cm}^{3}$ molecule ${ }^{-1} \mathrm{~s}^{-1}$. Therefore, $\mathrm{BrO}$ will preferentially react with $\mathrm{HO}_{2}$. 
$\mathrm{BrO}+\mathrm{HO}_{2} \rightarrow \mathrm{HOBr}+\mathrm{O}_{2}$

$\mathrm{BrO}+\mathrm{NO}_{2} \rightarrow \mathrm{BrNO}_{3}$

$\mathrm{HOBr}$ can be taken up on the frozen surfaces, where it reacts to form $\mathrm{BrCl}$ and $\mathrm{Br}_{2}$, which are subsequently released into the gas-phase (R3.7 and R3.8) (e.g. Adams et al., 2002), thereby reinitiating the cycle again (R3.1).

$\mathrm{HOBr}+\mathrm{Br}^{-} \rightarrow \mathrm{Br}_{2}+\mathrm{OH}^{-}$

$\mathrm{HOBr}+\mathrm{Cl}^{-} \rightarrow \mathrm{BrCl}+\mathrm{OH}^{-}$

$\mathrm{BrNO}_{3}$ can also undergo similar redox reactions:

$\mathrm{BrNO}_{3}+\mathrm{Br}^{-} \rightarrow \mathrm{Br}_{2}+\mathrm{NO}_{3}^{-}$

$\mathrm{BrNO}_{3}+\mathrm{Cl}^{-} \rightarrow \mathrm{BrCl}+\mathrm{NO}_{3}^{-}$

Additionally, under low $\mathrm{NO}_{2}$ concentrations typical of the polar regions, the halogen cross-reaction cycles can also take place:

$$
\begin{aligned}
& \mathrm{BrO}+\mathrm{BrO} \rightarrow 2 \mathrm{Br} \\
& \mathrm{BrO}+\mathrm{ClO} \rightarrow \mathrm{BrCl} \\
& \mathrm{BrO}+\mathrm{OH} \rightarrow \mathrm{Br}+\mathrm{HO}_{2}
\end{aligned}
$$

Figure 3.1 shows a simplified bromine explosion scheme where green curves represent the emissions from the FYSI and orange arrows symbolize the deposition from 
the atmosphere to the FYSI. This bromine explosion occurs when the Sun is above the horizon, because this cycle is triggered by photolysis of $\mathrm{Br}_{2}$ and the cycle can continue. The major source of bromine is Arctic FYSI (Pratt et al., 2013), but in summer months the ice melts, for this reason the bromine source decreases, the consequence is that there is less bromine monoxide than in spring months.

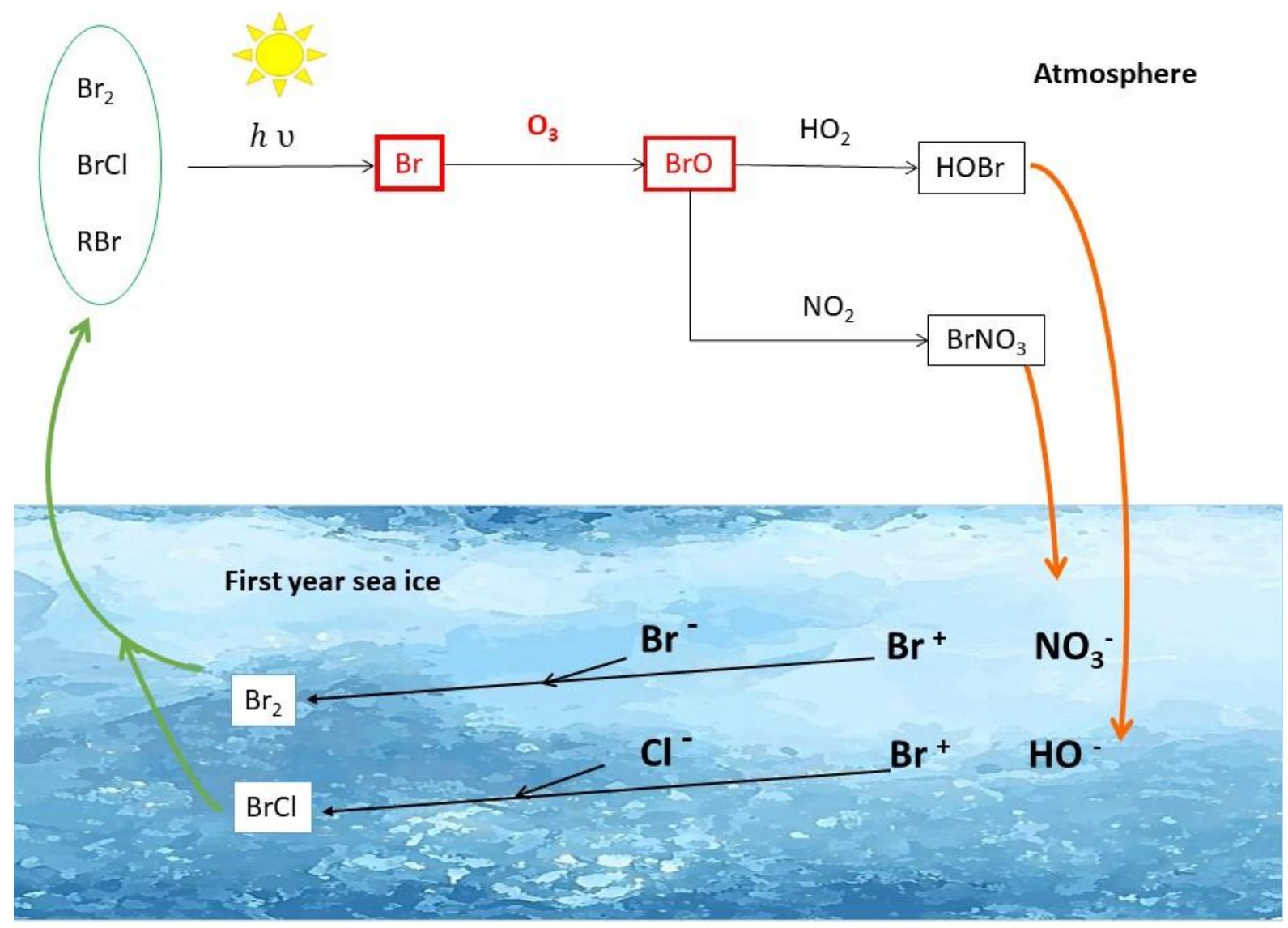

Figure 3.1. Simplified bromine explosion scheme. 
Regarding examples of previous measurements of the $\mathrm{BrO}$ radical in polar environments: BrO was measured in Barrow Alaska up to 22 pptv (Brooks et al., 2006) and at the same location, Vertical Column Densities (VCD) values of $3 \times 10^{14}$ molecule $\mathrm{cm}^{-2}$ (Frie $\beta$ et al., 2011); in Alert Canada up to 15 pptv (Pöhler et al., 2010); in Spitsbergen (Norway) up to 17 pptv (Hausmann and Platt, 1994) and 15 pptv (Prados-Roman et al., 2011); Arctic measurements values are $8 \times 10^{13}$ in molecule $\mathrm{cm}^{-2}$ in VCD (Sihler et al., 2012). In the Antarctica values of BrO up to $10^{15}$ (Wagner et al., 2001); VCD of $5 \times 10^{13}$ molecule $\mathrm{cm}^{-2}$ (Roscoe et al., 2014), 26 pptv at Marambio (Antarctica) (Prados-Roman et al., 2018).

\subsection{Atmospheric chemistry of iodine}

Chameides and David in 1980 were the first who studied the significance of atmospheric inorganic iodine (Chameides and David, 1980), they suggested the important role of iodine compounds in the budget of tropospheric ozone. With the goal of understanding iodine chemistry, several field campaigns have measured IO -a key atmospheric compound to understand the active iodine chemistry- in the marine environment (e.g. Mahajan et al., 2010 a, b; Mahajan et al., 2012; Puentedura et al., 2012; Gomez-Martin et al., 2013; Prados-Roman et al., 2015).

The atmospheric chemistry of iodine is significant in different ways (Saiz-Lopez et al., 2012). The first one, it is transported from the ocean sources to the continents (the socalled route for iodine). The second one, iodine chemistry influences the oxidizing capacity of the atmosphere, which refers to the capability of the atmosphere to oxidize and remove a large amount of different species (organic and inorganic). The path in which this oxidation occurs is by catalytic destruction of ozone, consequently the hydroxyl radical, the most important radical in the atmosphere, is altered. The third one is the participation of IO and OIO radicals in the formation of ultrafine aerosol particles (diameter between 3-10 nm). These particles can contribute to the formation of Cloud Condensation Nuclei (CCN), as recently demonstrated in the Arctic (Baccarini et al., 2020), and alter the radiative balance of the atmosphere and, consequently, exert an impact on climate. And the last one is the 
depletion of gaseous elemental $\mathrm{Hg}$ by oxidation to reactive gaseous mercury compounds. This oxidized mercury is deposited in the snowpack and could come back to the atmosphere, while the remaining mercury in the snowpack could enter the food channel, as explained in section 3.1.

The main source of global atmospheric iodine are the oceans through emissions of different precursors such as propyl iodide (1- and $\left.2-\mathrm{C}_{3} \mathrm{H}_{7} \mathrm{l}\right)$, ethyl iodide $\left(\mathrm{C}_{2} \mathrm{H}_{5} \mathrm{I}\right)$, chloroiodomethane $\left(\mathrm{CH}_{2} \mathrm{ICl}\right)$, bromo iodo methane $\left(\mathrm{CH}_{2} \mid \mathrm{Br}\right)$, methyl iodide $\left(\mathrm{CH}_{3} \mathrm{I}\right)$, diiodomethane $\left(\mathrm{CH}_{2} \mathrm{I}_{2}\right)$ and inorganic species: hypoiodous acid (HOI) and $\mathrm{I}_{2}$. Once in the atmosphere, these species can photolyze release the reactive iodine atom:

$$
\begin{aligned}
& \mathrm{CH}_{3} \mathrm{I}+\mathrm{h} v \rightarrow \mathrm{CH}_{2}+\mathrm{I} \\
& \mathrm{I}_{2}+\mathrm{h} v \rightarrow 2 \mathrm{I}
\end{aligned}
$$

From their respective atmospheric mixing ratios point of view, the organoiodines increase in the order of $\mathrm{CH}_{2} \mid \mathrm{Br}<\mathrm{CH}_{2} \mathrm{I}_{2}<\mathrm{CH}_{2} \mathrm{ICl}<\mathrm{CH}_{3} \mathrm{I}$ and their presence in the open ocean is lower than in the coastal regions because in coastal regions they are mainly emitted from macroalgae beds. When coastal macroalgae (e.g. Laminaria digitata) undergoes oxidative stress via exposure to high irradiance and high ozone levels, iodide $\left(I^{-}\right)$is oxidized to molecular iodine $\left(\mathrm{I}_{2}\right)$ (see Saiz-Lopez and Plane, 2004; McFiggans et al., 2004; Dixneuf et al., 2009). Over the open oceans, $\mathrm{HOI}$ and $\mathrm{I}_{2}$ formed in the seawater surface (R3.16 and R3.17) (Carpenter et al., 2013) are emitted to the atmosphere as $\mathrm{HOl} 90 \%$ and $\mathrm{I}_{2}$ 10\% (PradosRoman et al., 2015).

$$
\begin{aligned}
& \mathrm{I}^{-}+\mathrm{H}^{+}+\mathrm{O}_{3} \rightarrow \mathrm{HOI}+\mathrm{O}_{2} \\
& \mathrm{H}^{+}+\mathrm{HOI}+\mathrm{I}^{-} \rightarrow \mathrm{I}_{2}+\mathrm{H}_{2} \mathrm{O}
\end{aligned}
$$


In the polar environment, direct emission of iodine to the atmosphere is thought to occur mainly via sea ice emissions from underneath ice phytoplankton colonies (Saiz-Lopez et al., 2015) and to a lesser extent also via heterogeneous photochemistry of iodide (Kim et al., 2016) (R3.18) and $\mathrm{IO}_{3}{ }^{-}$contained in ice (Gálvez et al., 2016):

$$
\mathrm{I}^{-}+\mathrm{h} v \rightarrow \mathrm{I}_{3^{-}} \leftrightarrow \mathrm{I}_{2}
$$



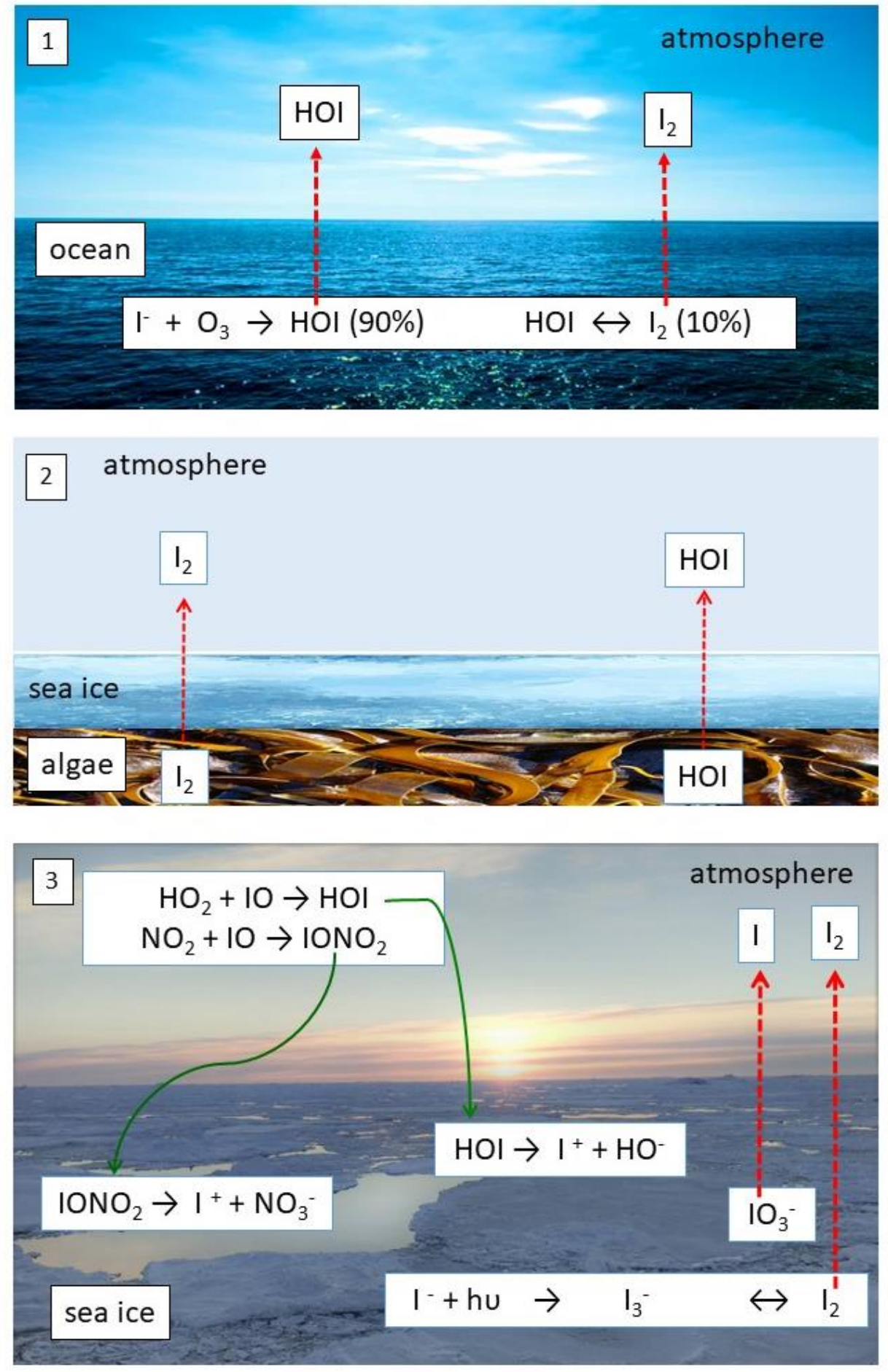

Figure 3.2. Iodine direct emissions from the ocean (part 1), coastal algae (part 2) and sea ice (part 3). 
In Figure 3.2 briefly summarizes the main sources of iodine emissions to the atmosphere from sea ice, ocean and algae to the atmosphere.

Once in the atmosphere, reactive iodine can have a major impact on the ozone levels. The most important iodine-mediated pathway for ozone destruction is the following (from R3.19 to R3.23).

$$
\begin{aligned}
& \mathrm{I}_{2}+\mathrm{h} v \rightarrow 2 \mathrm{I} \\
& \mathrm{I}+\mathrm{O}_{3} \rightarrow \mathrm{IO}+\mathrm{O}_{2} \\
& \mathrm{IO}+\mathrm{HO}_{2} \rightarrow \mathrm{HOI}+\mathrm{O}_{2} \\
& \mathrm{HOI}+\mathrm{h} v \rightarrow \mathrm{OH}+\mathrm{I} \\
& \mathrm{IO}+\mathrm{NO}_{2} \rightarrow \mathrm{IONO}_{2}
\end{aligned}
$$

The photolysis of HOI form the iodine atom which can start the cycle (R3.22). Two products $\left(\mathrm{HOI}\right.$ and $\left.\mathrm{IONO}_{2}\right)$ from $\mathrm{R} 3.21$ and 3.23 are deposited into the ice, and the cycle starts in reaction (R3.16). Figure 3.3 depicts a simplified scheme of ozone catalytic destruction mediated by iodine. 


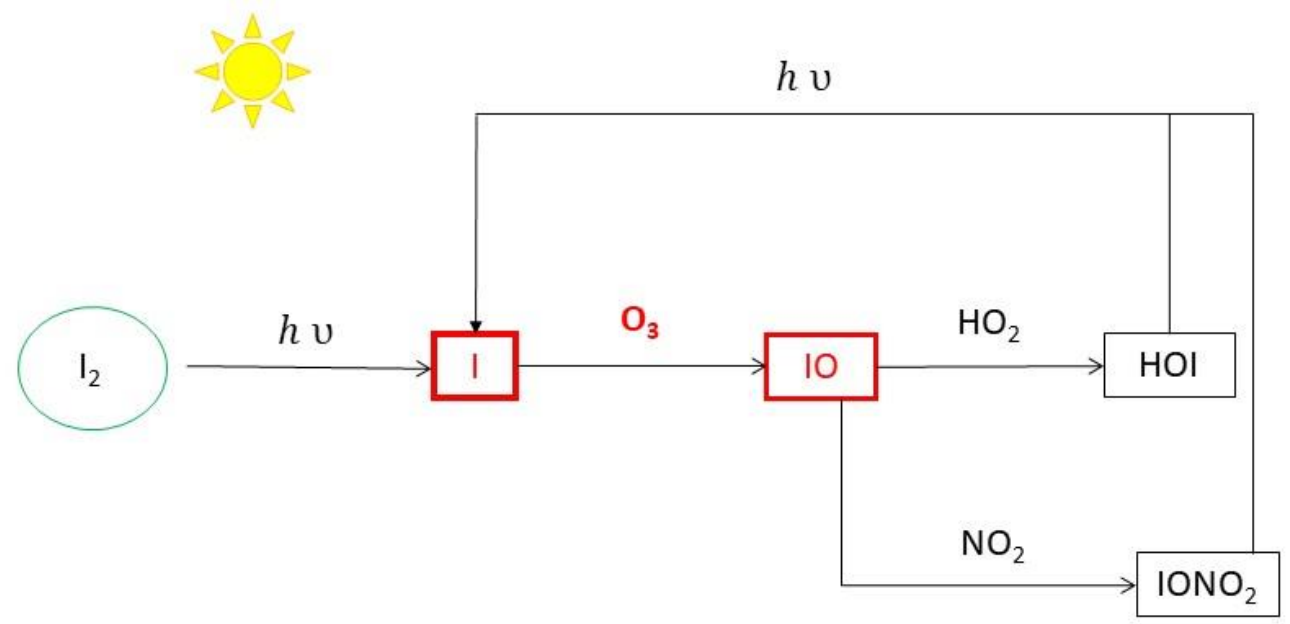

Figure 3.3. Simplified scheme of iodine-driven ozone loss chemistry in the polar troposphere.

Mahajan et al., 2010a reported the first 10 measurement in the Arctic boundary layer using a LP-DOAS and a MAX-DOAS instrument. IO was measured to appear sporadically in connection with ice open leads in a campaign carried out in February-March 2008. The maximum mixing ratio of 10 measured in that campaign was 3.4 pptv for the LPDOAS and Differential Slant Column Densities (DSCDs) about $4 \times 10^{13}$ molecules $\mathrm{cm}^{-2}$.

Very recently, Cuevas et al., 2018, discovered a rapid increase in the Arctic iodine levels, which could be explained by several reasons that are explained next. The iodine increase in the coastal polar regions could be related to biological production under sea ice (Saiz-Lopez et al., 2015) and with abiotic ice surface photochemistry (Kim et al., 2015; Gálvez et al., 2016). It is known that the sea ice in the Arctic has been reduced due to climate change, the Arctic sea ice is now thinner and younger than in previous decades. For this reason, there is now a more efficient diffusion and release of biologically produced iodine (Saiz-Lopez et al., 2015), so there are changes that modified the Arctic Ocean ecology in the past two decades. In Cuevas et al., 2018 it was found that the iodine concentrations are related to the sea ice thickness, moreover iodine has been influenced by sub-ice biological production since the 1990s. In contrast, before the 1990s there was not a clear relationship between sea ice and iodine. But nowadays, the decrease in sea ice thickness would ease the 
propagation of sunlight that controls the iodine production via algal oxidative stress, this would result in higher iodine emissions. Moreover, the abiotic photochemical recycling in the sea ice surface is another contributing factor to iodine emissions. Therefore, in light of the rapidly occurring changes in iodine levels, it is important to study the presence, seasonality and evolution of 10 mixing ratios in the Arctic. Figure 3.4 shows how the Arctic sea ice extent is reduced from the 80 s, with a decrease of about $10 \%$ per decade.

Average Monthly Arctic Sea Ice Extent

October 1979 - 2020

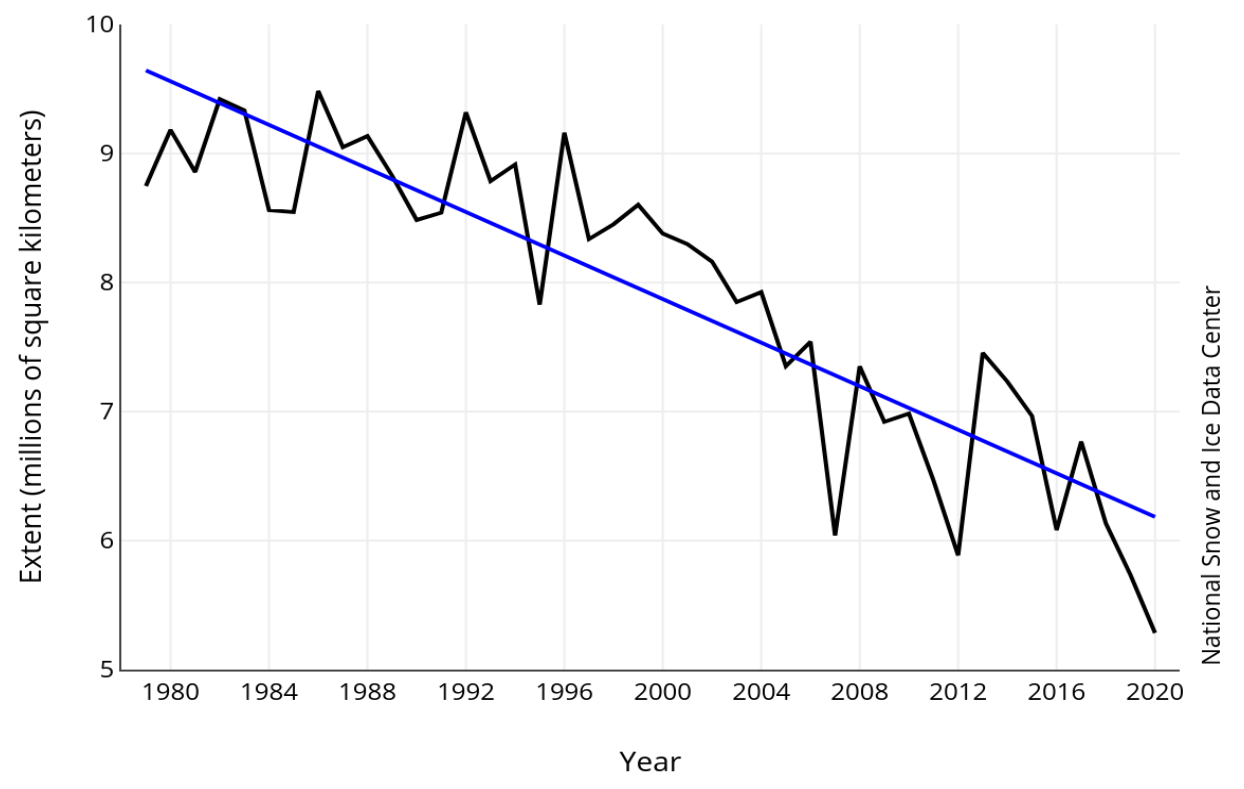

Figure 3.4. Arctic sea ice extent from the 80 s to 2020 . This figure is taken from the National Snow \& Ice Data Center. 


\section{SOLAR ELECTROMAGNETIC}

\section{RADIATION}

This chapter describes the interaction of solar radiation with the atmosphere. Starting with an introduction of the electromagnetic radiation, followed by the solar radiation and Fraunhofer lines, and the atmospheric interaction with the radiation. Finally, some definitions of observational geometries are given.

\subsection{Introduction}

The electromagnetic radiation is defined as the propagation of the electromagnetic fields, carrying electromagnetic radiant energy in the process. Regarding its nature of wave, the electromagnetic radiation is usually referred to in terms of its wavelength or frequency. Both magnitudes are related to the speed of propagation of the wave: the speed of light $c$ (with a tabulated value for the vacuum of $2.998 \times 10^{8} \mathrm{~ms}^{-1}$ ) (Platt and Stutz, 2008).

$$
c=\lambda * v
$$

Here $v$ is the frequency and $\lambda$ stands for the wavelength. When a certain electromagnetic radiation is decomposed based on its own wavelengths -and hence frequencies- we obtain a spectrum. Although the term spectrum can be widely used, in science it corresponds to the mentioned vectorial decomposition of the electromagnetic radiation. Figure 4.1 presents a diagram of the electromagnetic spectrum, along with some of its subgroups (in increasing order of wavelength: gamma rays, X-rays, ultraviolet (UV), 
visible (VIS), infrared (IR), microwave and radio). Note that, in accordance with Equation 4.1, shorter wavelengths equate to higher frequencies, and vice versa.

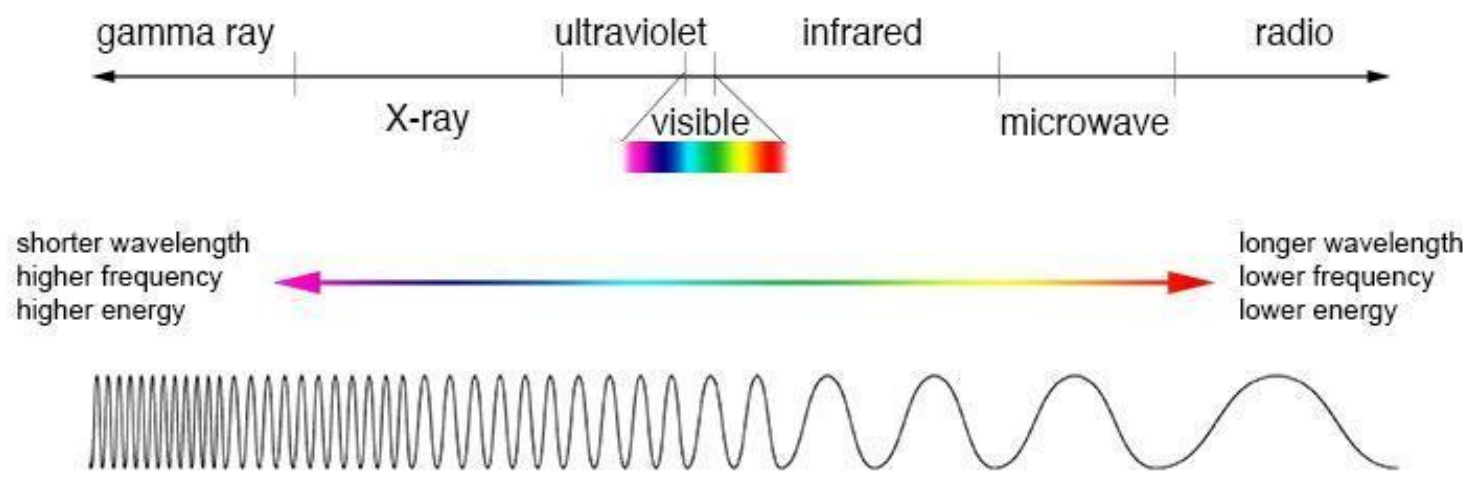

Figure 4.1. Electromagnetic spectrum. Credit: NASA's Imagine the Universe.

However, the wave-particle duality of the electromagnetic radiation is well known as of now, the main principles being derived from experiments performed as early as in the 19th century (the double-slit experiment by Young). The work done by Planck and Einstein established that the electromagnetic radiation can be regarded as composed of photons, which are elementary particles that act as carriers of the electromagnetic force. The relationship between the energy of a photon $(E)$ and the frequency $(v)$ of the electromagnetic radiation is as 4.2 .

$$
E=h * v=h * c / \lambda
$$

where $h$ is the Planck constant (which has a tabulated value of $6.623 \times 10^{-34} \mathrm{~J} \mathrm{~s}$ ). For atmospheric sciences, the corpuscular approach is more suitable, since we will be dealing with spectrometers that collect 'counts' as equivalent of photons. It can be observed in Eq. 4.2 that frequency and energy of the electromagnetic radiation are proportional, hence both are inversely related to wavelength (Platt and Stutz, 2008). 
Although the term "light" is commonly used as interchangeable for "electromagnetic radiation", strictly speaking light is defined as the portion of the electromagnetic spectrum perceived by the human eye. It approximately ranges from 400 $\mathrm{nm}$ to $700 \mathrm{~nm}$ (equivalent to a frequency interval of roughly $430-750 \times 10^{12} \mathrm{~Hz}$ ), between the ultraviolet and the infrared spectral regions. These different wavelengths can be experimentally obtained by different means, for instance, making the light pass through a prism. A complete physical description of the properties of light would require quantum mechanics, but within atmospheric sciences, and for the purpose of this work, it will be enough to keep in mind the concepts of light energy, wavelength, frequency and their relationships.

\subsection{Solar radiation and Fraunhofer structures}

The energy that reaches the Earth comes from the Sun and the sum of the incoming and outgoing energy radiation constitutes the energy balance of the Earth. Our atmosphere plays an important role in the energy budget of the Earth, because it exerts the control of the radiation that reaches the surface and the radiation which is sent back to space (Trenberth et al., 2019).

The light that we can see every day with our eyes is only a fraction of the total energy emitted by the Sun. This sunlight is a form of electromagnetic radiation, and the visible light represents a small subset of the overall electromagnetic spectrum. The Sun is a gaseous, hot sphere made up of $\mathrm{H}_{2}(75 \%)$ and $\mathrm{He}(25 \%)$. Its internal part reaches a temperature over 20 million $\mathrm{K}$ due to nuclear fusion reactions at its core. The main process is the conversion of hydrogen into helium. Nevertheless, the radiation generated in the inner core does not come out since it is strongly absorbed by a layer of hydrogen atoms that is located close to the surface. Hence the radiation emitted by the Sun is mainly generated at its surface. The surface of the Sun is called the photosphere, a temperature of roughly $6000 \mathrm{~K}$, and its emission spectrum can be approximated to that of a blackbody of about $5777 \mathrm{~K}$. The light 
emitted from the Sun does not come from a single wavelength, indeed it comprises many wavelengths which combine in such a way that sunlight appears white to the human eye.

Once this radiation leaves the Sun, it travels spectrally unaffected through the vacuum space, due to the absence of interaction phenomena there. However, as a given amount of energy flow has to be conserved as the wavefront travels, the power goes down as the distance travelled from the Sun increases, though the relative spectral content remains. The magnitude that best describes the transport of electromagnetic energy is the energy flux, which is defined as the amount of energy per unit time that crosses through a certain surface perpendicular to the direction of propagation. When dealing with the energy flux received at a certain surface, the magnitude is called irradiance and it has units of W $\mathrm{m}^{-2}$. However, as will be seen throughout this work, we are interested in the spectral decomposition of the irradiance: i.e. the so-called spectral irradiance (with dimensions of power received per unit area per wavelength interval, and units of $\left.\mathrm{W} \mathrm{m}^{-2} \mathrm{~nm}^{-1}\right)$. This magnitude will be key as we get into radiative transfer calculations in Chapter 6 .

Since we will be collecting photons with our spectrometers, we need to derive the spectral photon flux, because the electron flux is essential for the current produced in the detector. This conversion to photon flux can readily be done taking into account the amount of energy that a single photon has at a given frequency (see Equation 4.1).

When light arrives at the Earth's Top Of the Atmosphere (TOA), the spectral irradiance slightly varies since the distance between the Sun and the Earth changes over time, and also the emission of the Sun is not constant. However, these variations are rather small (with typical fluctuations lower than $3 \%$ ) so the spectral irradiance at TOA can be considered constant, with a spectrally integrated value of about $1366 \mathrm{Kw} \mathrm{m}^{-2}$ (Liu, 2002). The TOA spectra are measured with great accuracy by satellites, Figure 4.2 provides an example. 


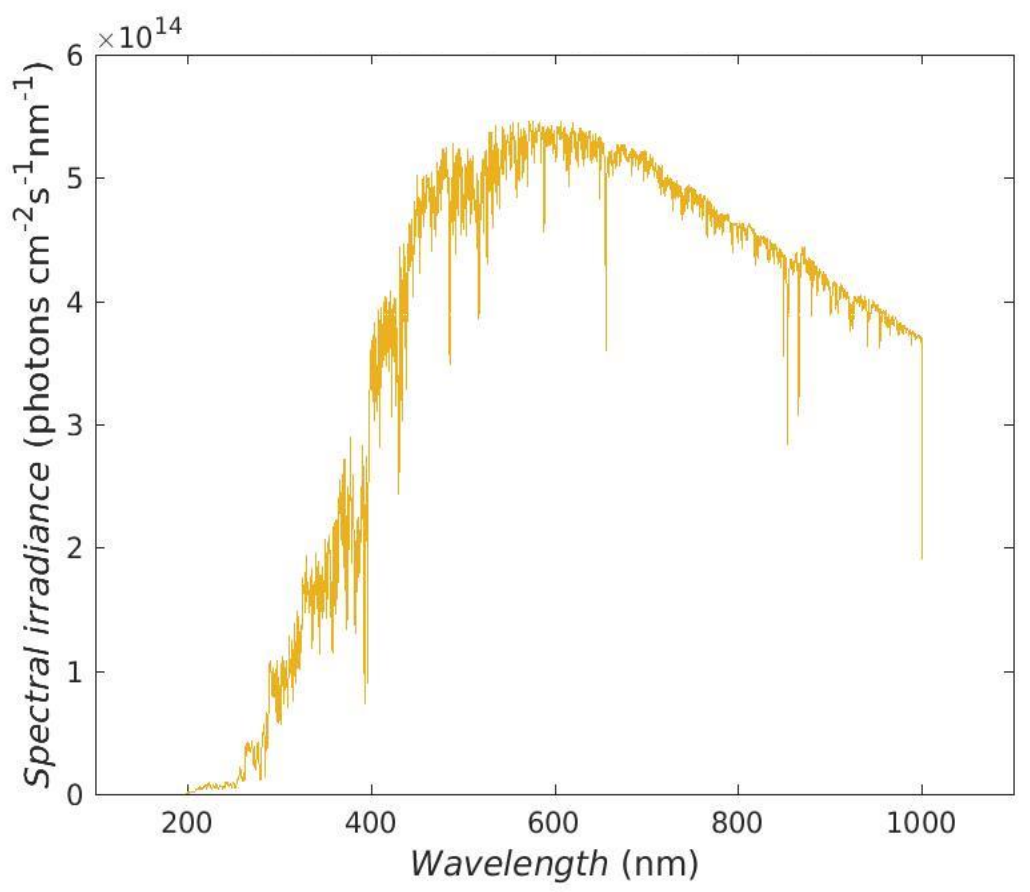

Figure 4.2. Spectral irradiance of the Sun at the Earth's Top Of the Atmosphere (TOA).

The intensity peaks in the visible part of the spectrum (at about $550 \mathrm{~nm}$ ). Although the curve in Figure 4.2 follows a broad, slow trend much like the blackbody emission spectrum, we can easily observe some structures and since we assumed that there are no interactions for the radiation when travelling in vacuum, where do these structures come from? Compounds in the atmosphere of the Sun emit and absorb light at specific wavelengths: they form the aforementioned structures, called the Fraunhofer lines. These lines are strong and come from selective absorption and emission of radiation by atoms in the solar atmosphere such as calcium, iron and so on (Liou, 2002). The Fraunhofer lines have to be taken into account in the spectral analysis procedures.

Before assessing the interactions that may occur within the atmosphere between the spectral irradiance that comes from the Sun and the atmosphere itself, there are several key characteristics of the solar spectral irradiance that arrives at the TOA which are critical in determining how the incident sunlight interacts with any given object: 
- the spectral content of the incident light.

- the total amount of received power from the Sun.

- the angle at which the solar spectral irradiance arrives at a certain point in the atmosphere.

- the day of the year slightly changes the radiation of the Sun.

\subsection{Atmospheric interaction with radiation}

While we have assumed the solar spectral irradiance at TOA as relatively constant, the spectral irradiance at the surface of the Earth indeed widely varies mainly due to:

- atmospheric processes: absorption or scattering by molecules or particulate matter.

- some atmospheric magnitudes might present local fluctuations, for instance the water vapour amount, the presence of clouds or the impact of pollution.

- geolocation.

- the season and the time within a day also have an influence.

The aforementioned atmospheric effects exert an impact on our measurements. For instance, the intensity and content of the collected spectra may be affected. We now take a closer look at the two most relevant of the atmospheric processes for absorption spectroscopy measurement: 
- Absorption: as solar radiation passes through the atmosphere, gases, dust and aerosols absorb the incident photons. These absorptions cause deep troughs in the spectral irradiance. Some of the absorptions have a very well-known impact, for example the absorption of ultraviolet light by stratospheric ozone protects us from this harmful radiation.

Despite having a minor impact on the overall intensity, absorption processes are key for our calculations due to the notable change in the spectral content, see Chapter 5. Regarding the atmospheric trace gases, the absorption spectra have characteristic band structures because of their different energy levels, e.g. one molecule can absorb radiant energy but only when the wavelength of the radiation corresponds exactly to the difference between two levels. These energy levels are different from one molecule to another and they depend on the different compositions and shapes of molecules.

- Scattering: it is the process where a particle diffuses incoming radiation at a given angle and with certain energy. The principal scattering mechanism in the atmosphere is known as Rayleigh scattering, and it is caused by molecules. Given its strong dependence with wavelength, Rayleigh scattering is particularly effective for short wavelength light. In addition to Rayleigh scattering, aerosols and dust particles contribute to the scattering of incident light known as Mie scattering.

Scattered light has no preferred direction, hence it appears to be coming from any region of the sky. The scattered light is also called diffuse light. Without atmospheric scattering, the sky would appear black and the Sun would be a radiant, bright disk in the sky. On a clear-sky day, about $10 \%$ of the total incident solar radiation is diffuse. Atmospheric scattering is the main factor reducing the intensity of sunlight. This reduction heavily depends on the photon path through the atmosphere. 
Note also that clouds are another important factor in remote sensing of atmospheric composition: the lack of clouds is key in order to accurately simulate the photon light paths, as will be discussed in Chapter 5. and Chapter 6. In addition, solar intensity at the surface will also decreased in the presence of clouds, as shown in Figure 4.3, thus worsening the signal-to-noise ratio in our measurements.

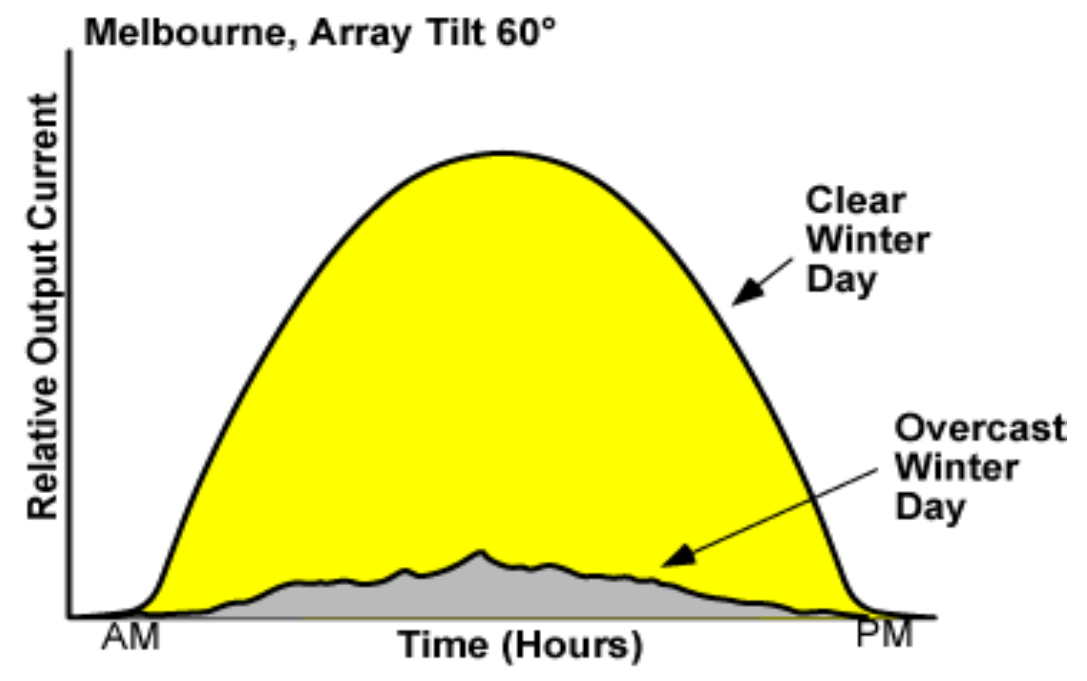

Figure 4.3. Influence of clouds on daily irradiance (figure taken from Honsberg and Bowden, 2019).

Summarizing, scattering and absorption have an impact on the received solar spectra by means of:

- the intensity of the radiation is reduced due to absorption and, mostly, scattering.

- there is a change in the spectral content of the solar irradiance. This change is relatively small in terms of absolute intensity, but is key to evaluate the atmospheric composition and will be the main column of our analysis. This effect is mainly caused by absorption by atmospheric compounds. 
- since there is a strong scattering component within the atmosphere, the concept of diffuse or scattered sunlight comes into play. In fact, our instruments mainly collect scattered light rather than direct sunlight.

- the local variations of some atmospheric parameters such as clouds or pollution have an additional effect on the intensity, the spectral features and the directionality of the light.

\subsection{Observational geometry}

\subsubsection{Solar Azimuth Angle}

The Solar Azimuth Angle (SAA) is the angle measured between the solar beam and the horizon plane. Sun position is always directly south in the northern hemisphere and directly north in the southern hemisphere. The SAA starts at 0 degrees and corresponds to the true north and it goes clockwise. SAA fluctuates throughout the day, shown as red in Figure 4.4.

\subsubsection{Solar Zenith Angle}

The Solar Zenith Angle (SZA) is a measure that helps to describe the path of the Sun across the sky. It is defined as the angle of the Sun relative to a line perpendicular to the surface of the Earth. This angle is linked with the Solar Elevation Angle (SEA) which is the complementary angle of the SZA (Equation 4.3). The SEA is the Sun elevation angle measured from the horizon. Figure 4.4 orange curve represents the SZA.

$$
S Z A=90-S E A
$$




\subsubsection{Viewing Azimuth Angle}

The Viewing Azimuth Angle (VAA) is the azimuthal angle at which the line of sight of an instrument is pointing. In Figure 4.4 the VAA is represented by the blue angle.

\subsubsection{Elevation Viewing Angle}

The Elevation Viewing Angle (EVA) is the angular height of the instrument line of sight measured from the horizontal. This angle is $90^{\circ}$ at solar noon (its maximum value) and $0^{\circ}$ at sunrise. VAA and EVA differ from the location, measurement campaign and they change during the day. The EVA is the green curve in Figure 4.4.

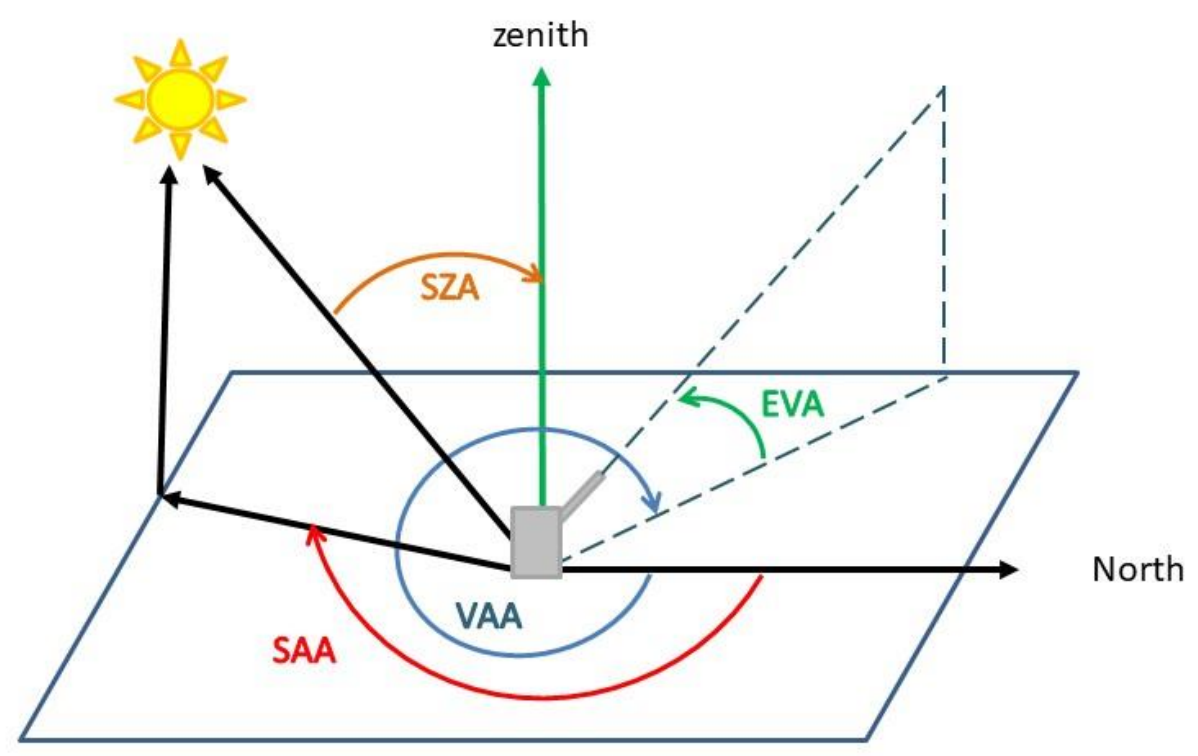

Figure 4.4. Diagram of the observational geometries.

\subsubsection{Air Mass Factor}

The Air Mass Factor (AMF) is the path length that light takes through the atmosphere normalized to the shortest path length (when the Sun is overhead). AMF quantifies the reduction in the power of light as it passes through the atmosphere and is absorbed by aerosols and air. Taking a geometrical approximation, it can be estimated by Equation 4.4, although this approximation assumes the atmosphere as a flat horizontal layer. 


$$
A M F=1 / \cos (S Z A)
$$

This concept will be useful when the light paths are calculated. The essential idea is that an AMF is the ratio between the actual photon path in a given atmospheric volume and the thickness of that volume (Figure 4.5).

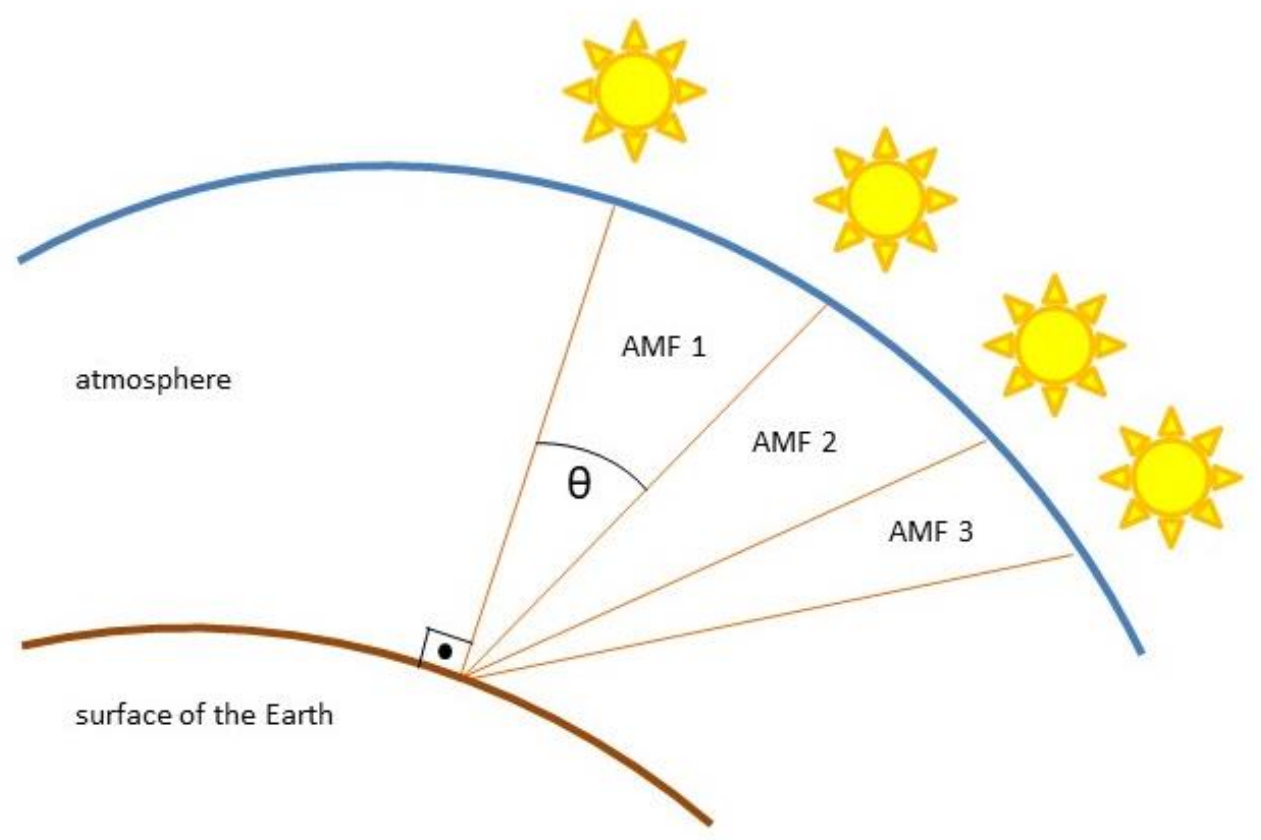

Figure 4.5. Different air mass factors representation. 


\section{DIFFERENTIAL OPTICAL}

\section{ABSORPTION SPECTROSCOPY}

This chapter describes the theoretical foundation and main concepts of the DOAS technique. After that, a complete description of the measurement geometries (with special emphasis for the MAX-DOAS method) and the absorption cross section of trace gases is provided. Later on, the DOAS calculations are detailed along with some important instrumental effects.

The field that studies the interaction between electromagnetic radiation and matter within a certain medium as a function of the radiation wavelength and frequency is called spectroscopy. As mentioned in Chapter 4, there are three main spectroscopic interactions relevant to atmospheric sciences: scattering, emission and absorption. The combination of the three affects the sunlight spectrum concerning its absolute intensity as well as altering its spectral features by means of emission lines or absorption gaps. This work is focused on the impact of spectral absorptions on the measured solar spectra. Absorption spectroscopy methods are well-established tools for the analysis of atmospheric gases. The assessment of spectral absorptions allows the evaluation of the physical and chemical properties and processes in the medium of study (in our case, the atmosphere of the Earth).

Among all the spectroscopic techniques, DOAS is one of the most robust and widely used for the detection and analysis of atmospheric trace gases. The foundation of the technique lies on the wavelength dependent absorption of light by atmospheric constituents (Platt and Stutz, 2008). Using the DOAS method, several trace gases can be identified simultaneously by their unique spectral signatures. The theoretical principle of 
DOAS consists of identifying and separating the spectral broadband background -originated mainly due to both atmospheric (Rayleigh and Mie scattering) and instrumental effects (Plane and Saiz-Lopez, 2006)- from the spectral narrowband features caused by absorption. This separation yields differential spectral structures that can be assigned to the unique spectral absorption features that most of the atmospheric trace gases have and they act like a "fingerprint", allowing not only their detection but also to distinguish between them. Absorption spectroscopy is therefore a well-established tool for the analysis of atmospheric composition. It has been used for this purpose for decades now within different research disciplines like remote sensing, astronomy or atomic and molecular physics.

The advantages of the DOAS method include i) the possibility of simultaneously measuring several compounds since their spectral signature is just the addition of all of their absorptions in a wavelength interval and $i i)$ the ability to detect extremely weak absorptions with optical depths of around $10^{-4}$, which means it is sensitive enough to detect trace gases at typical atmospheric mixing ratios from as low as 0.1 parts per trillion (pptv) to several parts per billion (ppbv).

The initial use of spectroscopy in the atmosphere comes from the identification of some atmospheric gases. Later on, this method was used to measure column densities of these gases. For instance, Dobson built the first instrument to measure atmospheric ozone in the 1920's. Noxon used the absorption spectroscopy of zenith scattered sunlight to measure $\mathrm{NO}_{2}$ in both the stratosphere and the troposphere in the 1970's (Noxon, 1975). After that, Platt et al., 1979 introduced the DOAS concept to measure atmospheric compounds using artificial light. DOAS has been used since then to measure compounds both in the stratosphere and in the troposphere (Solomon, 1987), as well as to measure in remote and urban environments. DOAS has been used to monitor atmospheric composition from different platforms including ground-, ship-, aircraft-, balloon-, and satellite-based instruments (Platt and Stutz, 2008; Plane and Saiz-Lopez, 2006). Some examples of the use of DOAS for atmospheric measurements in our group are detailed in Garcia-Nieto et al., 
2018 (acid nitrous (HONO) measurements), Benavent et al., 2019 (glyoxal (CHOCHO) and formaldehyde ( $\mathrm{HCHO}$ ) in an urban site), along with earlier halogen oxides such as $\mathrm{IO}$ and BrO in polar environments (e.g. Saiz-Lopez et al., 2007) and in the remote marine atmosphere (e.g. Prados-Roman et al., 2015).

The wavelength region of the analysis should be chosen with care, in such a way that assures that every trace gas included in the fit does not have spectral features within the mentioned window that may interfere or correlate with any other trace gas, hence the influence of the secondary trace gases (those which have to be included to optimise the analysis, but are not the principal goal) is negligible. Another important advantage of DOAS is the capability of measuring without any in situ calibration needed, because all the measured spectra will subsequently be calibrated before the spectral analysis (see Section 5.7). In addition, the measurement is performed without any chemical interaction involved, which is particularly useful when dealing with highly reactive species such as $\mathrm{BrO}$ or IO.

\subsection{Fundamentals}

The fundamental idea of the absorption spectroscopy techniques is embodied by the Lambert-Beer law, which describes the reduction in intensity that suffers the electromagnetic radiation when it crosses a certain medium due to processes of absorption and scattering.

In Figure 5.1 the main concept of the Lambert-Beer law is represented: the exponential attenuation of the radiation intensity when passing through a certain sample that contains a given amount of absorber species. The decay depends on the concentration of the absorbers and the path followed by the radiation:

$$
I(\lambda, L)=I_{0}(\lambda) \exp \left(-\sum_{i} \int_{0}^{L} \sigma_{i}(\lambda) \rho_{i}(s) d s\right)
$$


where $\sigma_{i}$ is the spectral absorption cross section of an absorber $i, \rho_{i}(s)$ represents its concentration along the light path, and $I_{0}(\lambda)$ and $I(\lambda)$ are -respectively- the intensities before and after the considered absorption processes. In our case, $I_{0}(\lambda)$ is the Fraunhofer reference solar spectrum (with no atmospheric absorption) while $I(\lambda)$ stands for the recorded, ground-based spectrum, with all the absorption and scattering events included. The integral is done including the actual photon path and the results are added for every absorber.

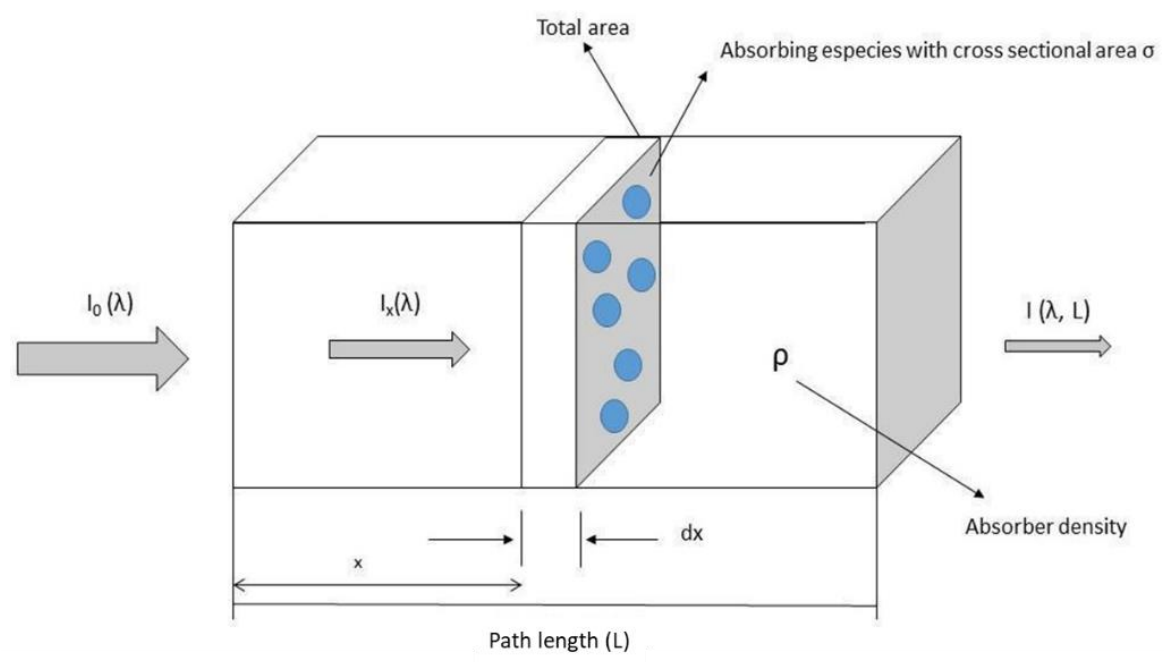

Figure 5.1. Concept of the Lambert-Beer law.

From Equation 5.1 requires to not only determine the actual photon paths, but also to quantify all the possible interactions and effects that may occur within the light path. Under laboratory conditions, this could be achieved, but while measuring sunlight in the atmosphere is not possible to numerically evaluate all the possible factors. The DOAS technique overcomes this problem to an extent, since many atmospheric processes exhibit broad, smooth wavelength functions, therefore it is possible to filter them out and focus on the narrowband spectral features that are produced by the specific atmospheric trace gases. Hence the goal is the numerical separation of spectral structures within the measured spectra into two groups: broadband components (which vary slowly with wavelength and are present in most of the atmospheric and instrumental effects) and 
narrowband features (mainly generated by trace gases). With the purpose of carrying out the DOAS fit, we have to define the differential optical density (Equation 5.2) (Hönninger et al., 2004).

$$
\tau(\lambda)=\ln \left(\frac{I_{0}(\lambda)}{I(\lambda)}\right)
$$

Equation 5.2 results in Equation 5.3 after taking natural logarithms at both sides.

$$
\tau(\lambda)=\sum_{i} \int_{0}^{L} \sigma_{i}(\lambda) \rho_{i}(s) d s
$$

In order to simplify Equation 5.3, we introduce the primary result from a DOAS analysis: the Slant Column Density (SCD), which is defined as the integrated concentration of an absorber throughout the light path:

$$
S C D=\int_{0}^{L} \rho_{i}(s) d s
$$

We then get the basic DOAS fit equation by introducing the DSCD into Equation 5.3, yielding Equation 5.5 .

$$
\tau(\lambda)=\sum_{i} S C D_{i} \times \sigma_{i}(\lambda)+\text { low order polynomial }
$$

In Equation 5.5, the first term on the right side corresponds to what is known as differential optical density, and contains the narrowband features that will allow the analysis. Therefore, applying Equation 5.5, optical density vectors are fitted using a nonlinear fit to get the optimal SCDs. Since each trace gases have their own spectral absorption features, they can be measured simultaneously since their absorption features are superimposed. 


\subsection{Absorption cross sections}

The absorption cross section (sometimes we will refer to it as just 'cross section') is a unique characteristic of every species. In general, molecules exhibit both vibrational and rotational structures in their absorption spectra. However, these rotational structures often consist of many narrowband lines with a spectral resolution that cannot be detected by typical DOAS instruments. Hence the resulting spectra have an approximately continuous function within each vibrational band, which envelopes the rotational structures inside. The absorption cross sections can be accurately measured in spectroscopy laboratories.

In principle, all gases that have narrow spectral features can be measured applying the DOAS technique to any spectral region (UV, VIS, or even near IR). Nevertheless, these spectral features should be narrow enough (typically much less than $10 \mathrm{~nm}$ in width) to be clearly distinguished from other trace gases. The actual concentration of a target trace gas -along with the detection limit of the DOAS instrument used-also limits the conditions of a positive spectral detection. However, there are still many detectable species (each with a unique spectral absorption structure), such as $\mathrm{O}_{3}, \mathrm{NO}_{2}, \mathrm{HONO}, \mathrm{HCHO}, \mathrm{CHOCHO}, \mathrm{BrO}$, IO, to give a few examples.

In a similar fashion as done with the measured spectral optical density in the previous section, the absorption cross sections of trace gases can also be decomposed in the sum of broadband and narrowband components. The latter can be obtained by two different ways: either subtracting a low order polynomial to the tabulated absorption cross section, or applying a high-pass filter. Anyway, the resulting differential spectral absorption cross sections remain as Equation 5.6.

$$
\sigma^{\prime}(\lambda)=\sigma(\lambda)-\sigma_{\text {broad }}(\lambda)
$$

where the absorption cross section has a broad trend that varies slowly with wavelength, describing a general slope, while the differential absorption cross section 
$\left(\sigma^{\prime}(\lambda)\right)$ obtained by subtracting the broadband part from the absorption cross section) shows rapid variations with wavelength. It is this differential absorption cross section that is used in the DOAS analysis, standing for each trace gas in the differential optical density fitting. Figure 5.2 shows an example of how to obtain a differential absorption cross section.
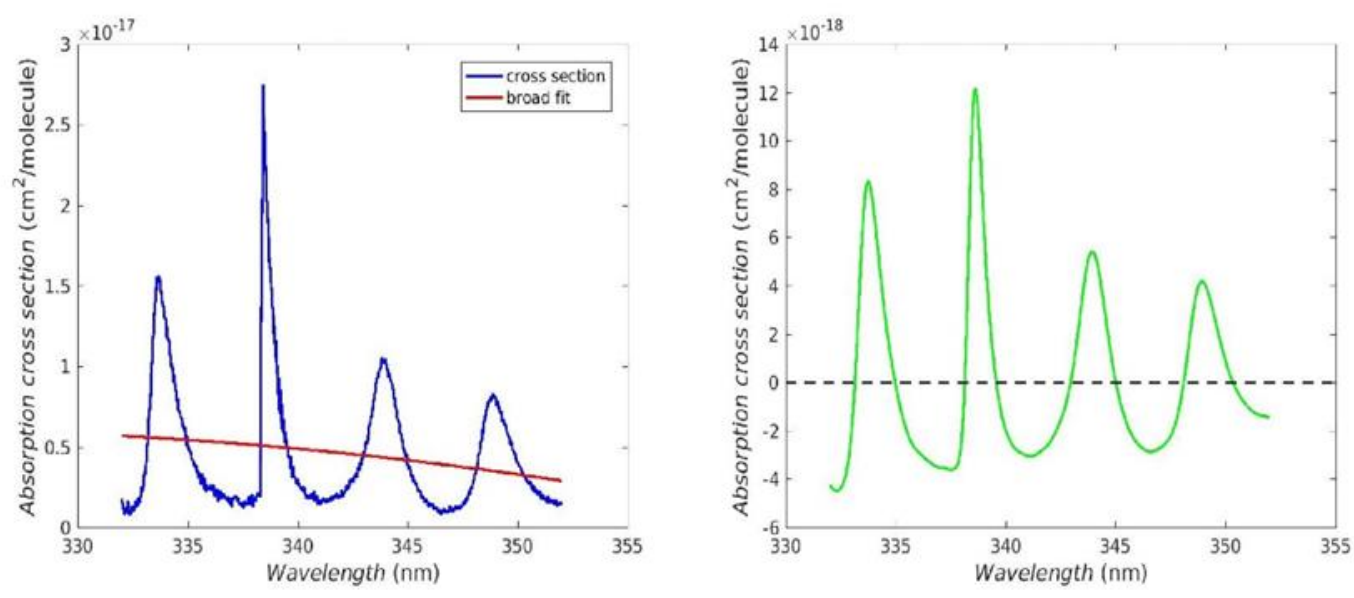

Figure 5.2. Differential absorption cross section example for BrO.

As shown in Equation 5.5, it is assumed that the absorption cross sections of trace gases are independent of the light path, i.e., that they do not depend on temperature and pressure. Nonetheless, for some DOAS applications, this assumption no longer holds, thus a more rigorous numerical approach is needed. There are, however, some procedures to deal with this inaccuracy: several absorption cross sections of the same trace gas (measured at different temperature and pressure conditions) can be included in the fit, as long as they are orthogonally independent and that their sum equals the amount derived for a single cross section. This approach is quite useful whenever a trace gas has significant amounts in different layers of the atmosphere: for instance, notable mixing ratios of $\mathrm{O}_{3}$ can be found both in the stratosphere and within the boundary layer, therefore two separate spectral absorption cross sections of $\mathrm{O}_{3}$ (measured at the typical stratospheric and tropospheric temperatures) are usually considered in the DOAS analysis (see Tables 8.1 and 8.3). 
Figure 5.3 includes the absorption cross section of several different trace gases that are regularly measured in DOAS applications. There are some properties that can be deduced from closely inspecting the figure:

- each trace gas has a unique spectral shape: their spectral "signature".

- a spectral region can contain many absorbers within. For instance, in the $300-350$ nm range the $\mathrm{O}_{3}, \mathrm{SO}_{2}, \mathrm{NO}_{2}, \mathrm{HONO}, \mathrm{HCHO}$ and $\mathrm{BrO}$ show absorption features.

- due to their unique spectral features, a separation of the absorbers is possible.

- from Equation 5.5 it is clear that, for a given trace gas, the spectral region where $\sigma^{\prime}$ is higher would in principle be the most suitable for the analysis. Each trace gas has an optimal wavelength region, however one has to often compromise this choice because expanding the wavelength window reduces the spectral resolution and the overall accuracy of the analysis.

One requirement has to be met in order to get an unequivocal spectral detection of a trace gas: we have to make sure that the target trace gas does not share spectral absorption features with any other trace gas, or at least that if they do, that the optical density of the interfering trace gas is significantly lower than the one produced by the target trace gas. 


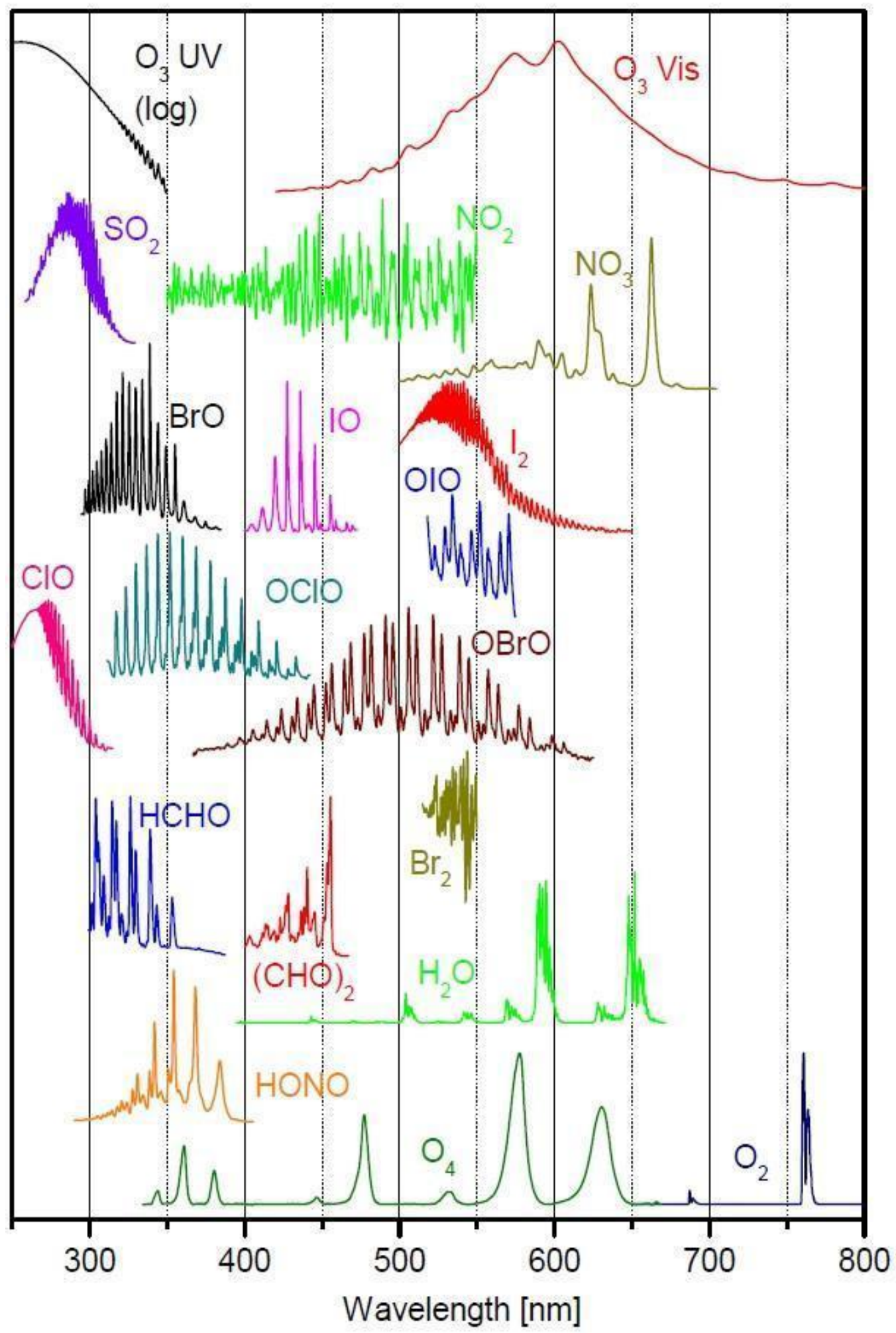

Figure 5.3. Absorption cross sections of trace gases that can be analysed using the DOAS technique. This figure is taken from the book "Atmospheric Trace Gases" document version: 20.03.2014 (C.Kern). 


\subsection{DOAS classification}

The DOAS principle can be applied to a wide variety of light path configuration and observation platforms: from ground, aircrafts, balloons and satellites, and by using either artificial light sources, scattered sunlight or direct sunlight (or moonlight) (Hönninger et al., 2004).

There are two types of DOAS systems depending on the light source used:

- Active DOAS techniques: use an artificial light source, often combined with retroreflectors (Platt, 1994), such as the Long Path DOAS (LP-DOAS). The principal advantage of the active DOAS technique is that the light path is precisely known, hence the calculations are simple and straightforward. Moreover, the use of long paths will facilitate the improvement in the detection limit, thus being able to measure trace gases at very low mixing ratios near the ground. Another advantage is the capability of measuring at night and within wavelength regions that are not accessible collecting sunlight. However, active DOAS instruments require a much more complicated optical setup, which also requires a much higher maintenance need. Active DOAS has been widely used in atmospheric sciences for both urban and remote environments (e.g. Plane and Saiz-Lopez et al., 2006).

- Passive DOAS techniques: their main characteristic is that they make use of natural radiation, for instance light coming from the Sun, the Moon or stars. The absence of the artificial light source implies a simpler, cheaper experimental setup. However, since light is collected from several parts of the atmosphere, the optical paths are not clearly determined, hence a direct calculation of the concentrations is not feasible. Therefore, after the evaluation of the absorptions, some radiative transfer knowledge must be applied in order to retrieve vertical concentration profiles of atmospheric compounds. There is a wide variety in terms of passive DOAS measurement instrumentation: ground-based, balloon-borne, airborne and even 
from satellites. Regarding the observational geometries, there can be direct sunlight DOAS, scattered sunlight DOAS (a variation of which is the Zenith Scattered Light DOAS, ZSL-DOAS, van Roozendael et al., 1994; Kreher et al., 1996), Imaging DOAS (iDOAS), even nadir and limb DOAS (see Platt and Stutz, 2008 for more details about the DOAS classification) or MAX-DOAS (Hönninger et al., 2004).

Within the passive DOAS applications, ground-based MAX-DOAS measurements are quite suitable for long term analysis of atmospheric constituents. Since only scattered sunlight is needed, relatively small and portable instruments can be used for the observations. In addition, as mentioned above, the ground-based instruments require almost no maintenance, and given their autonomy they are ideally qualified for remote environments with restrictions in the technical assistance, for instance volcanic plumes, steep terrain, or polar regions. In this work, ground-based MAX-DOAS measurements of scattered sunlight have been used.

\subsection{Multi AXis Differential Optical Absorption Spectroscopy}

The DOAS method has been extensively used in the measurement of atmospheric components since about 1970 . The first passive DOAS observations were made using zenith geometry: this means collecting scattered sunlight pointing at the zenith. However, this geometry is best suited for stratospheric amounts and yields the total column over a height layer rather than allowing the retrieval of tropospheric vertical profiles. As time went by, several additional off-axis -other than the zenithal direction- were added to the measurements. The first off-axis observations were made by Solomon et al., 1987 and in the early 1990s by Sanders et al., 1993. At the beginning, the addition of additional angular directions was done at high elevation angles of the light collector, with the purpose of improving the sensitivity within the stratosphere and gaining insight to get more robust results and to somehow retrieve a stratospheric profile: twilight off-axis observations were made by Arpag et al., 1994 to measure stratospheric $\mathrm{BrO}$ at mid-latitudes for the first time, while Miller et al., 1997 incorporated measurements at elevation angles of $87^{\circ}$ and $85^{\circ}$ to 
measure stratospheric $\mathrm{BrO}$ and $\mathrm{OClO}$ related to polar sunrise boundary layer ODEs in Greenland. Soon enough, it was concluded that the use of several angular axes would enhance the vertical sensitivity within the troposphere, especially using relatively low elevation angles.

The use of multiple off-axis observation angles to obtain increased information about the vertical distribution of trace gases in the proximity of the instrument, was then developed, and became known as Multi-Axis Differential Optical Absorption Spectroscopy (MAX-DOAS) (Hönninger et al., 2004). MAX-DOAS instruments are relatively simple, lowcost, portable and capable of real-time (can provide information on the actual chemical composition of a given air mass typically in a few minutes), unattended operation.

MAX-DOAS measurements are made with a light collector pointing at multiple elevation angles (most of them close to the surface) in order to collect scattered sunlight. The lower elevation angles typically contain larger absorptions caused by longer light paths and higher concentrations of the targeted trace gases close to the surface relative to higher elevation angles. Thus the SCDs measured at lower elevation angles are enhanced by trace gases located in the lower troposphere. In particular, this technique is highly sensitive only to trace gas abundance in the lowest $1-2 \mathrm{~km}$ of the atmosphere for ground-based instruments, which is the typical upper range of the marine boundary layer height (Leser et al., 2003) and the ideal range for pollution studies. Figure 5.4 depicts a basic diagram of the MAX-DOAS measurement geometry. 


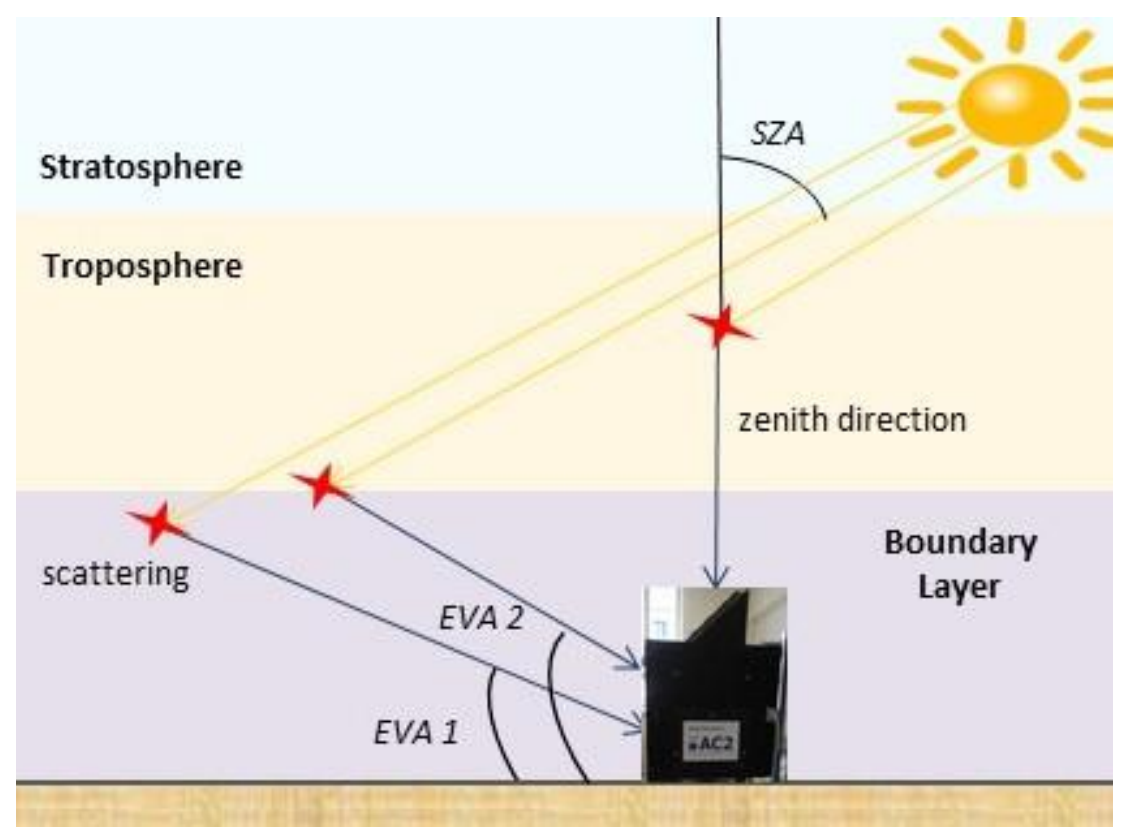

Figure 5.4. MAX-DOAS measurement geometry.

In MAX-DOAS applications $I_{0}$ (see Section 5.1) stands for the solar spectrum (measured above the atmosphere, with no atmospheric absorptions), while I represents the recorded ground-based spectrum, which includes all the absorption and scattering processes. However, and since the actual photon path is difficult to determine with accuracy (see Chapter 6), and determining the spectral instrumental effects with great accuracy is also very complex, the MAX-DOAS calculations are done using relative absorptions between two different optical paths: a zenith spectrum -that contains less absorptions and is assumed as a reference spectrum- and other spectrum pointing to a given elevation angle. Several absorbers can be measured simultaneously even if their absorption features are superimposed. By fitting their cross sections to the recorded differential spectra, the SCDs are retrieved. We also need to consider the contribution of the instrumentation as a whole (transmittance of the lenses, spectral sensitivity of the light collector, polarization effects...) to the recorded spectrum. Most instrumental effects, as well as most of the light paths especially in the stratosphere- tend to cancel each other out during the DOAS analysis. Therefore, the direct product of the method is the DSCD, which can be defined as the difference in the integrated concentration of a given absorber between the two selected 
pointing directions (more details about the numerical procedure that lies behind can be found in Hönninger et al., 2004, Plane and Saiz-Lopez, 2006 and Platt and Stutz, 2008). Finally, these DSCDs are used as the main input for the profile retrieval algorithms, which try to reconstruct the photon paths. This final step produces the vertical concentration profiles (see Chapter 6 for more details). Sometimes, it is useful to use a geometric approximation in order to get a sense the order of an estimated VCD (Hönninger et al., 2004), following Equation 5.7.

$$
V C D \cong \frac{D S C D}{\left[\frac{a}{\sin (\alpha)}+\frac{1-a}{\cos (\beta)}\right]}
$$

where $a$ is the fraction of the total vertical trace gas column that resides below the scattering altitude. An absorber below the scattering altitude (e.g. in the boundary layer) enhances the light path by a factor of approximately $(1 / \sin (\alpha))$, where $\alpha$ is the elevation angle of the MAX-DOAS instrument and $\beta$ represents the zenith angle of the Sun. We can observe that there is a strong effect of the instrumental elevation angles on the tropospheric light paths. Note that the higher the elevation angle of the instrument, the shorter the light path.

\subsection{DOAS retrieval}

The DOAS spectral analysis has two different approaches:

-Basic Optical Absorption Spectroscopy (BOAS): the fit is achieved directly over the spectra, a synthetic spectrum is generated, which simulates the measured one.

-DOAS: the fit is performed on the differential structures of the spectra. This approach is the one that is used in this study.

We used the QDOAS analysis software (developed at BIRA-IASB http://uvvis.aeronomie.be/software/QDOAS/). DOAS employs linear or non-linear least squares 
fitting to minimise the difference between the measured optical densities and the differential cross sections of the relevant absorbers. There are some parameters that have to be chosen, one of them is the wavelength window. It must be wide enough to contain distinctive narrowband absorption features of the target gases while minimizing the interference of spectral features of other absorbers. Moreover, the absolute absorption must be weak enough to avoid high optical depths such as the Huggins bans of ozone in the UV region, the Chappuis bands in the VIS region and water vapour bands.

The QDOAS analysis follows the subsequent steps. First, the reference spectrum is aligned with the Fraunhofer spectrum using nonlinear least squares fitting (Aliwell et al., 2002). After, the measured spectrum is aligned with respect to the reference spectrum: this reference can either be the zenith spectrum of the respective MAX-DOAS cycle or a noon, zenith spectrum. This choice determines the measurements mode: scan or noon. Later, the measured spectra are divided by a reference spectrum in order to eliminate the Fraunhofer structures. Some uncertainties might appear in the ratio, thus sometimes a shift in wavelength may be useful in order to improve the analysis.

Background spectral features, that vary slowly with wavelength -for instance Rayleigh and Mie scattering- are handled as "pseudo-absorptions" and are approximated by low order polynomials to separate them from the fine spectral structures. The measured differential optical densities are fitted by a non-linear least squares system to the differential spectral absorption cross sections of each absorber (included in the analysis). The uncertainties in the DSCDs retrieved are derived from one standard deviation of the residual uncertainties from the least squares fitting. The Root Mean Square (RMS) of the residual (in optical density units) is often used as a way to calibrate the goodness of the analysis 


\subsubsection{Instrumental Slit Function}

The instrumental slit function or resolution is defined as the Full Width at Half Maximum (FWHM) of the instrument function. The spectrum shape could change due to the entrance slit of the spectrometer grating and the focusing and dispersing optics when we use a spectrometer to measure the absorption spectrum. This parameter is calculated by QDOAS and it requires that the instrumental resolution function remains stable and constant during solar spectra measurements (Aliwell et al., 2002). It can be corrected by an accurate wavelength calibration of the measured spectra since a misalignment in wavelength can lead to significant uncertainties in the QDOAS retrieval.

When this function is obtained, the measured spectra are corrected for instrumental effects by a convolution with the instrument resolution function. Besides, the cross sections included in the retrieval are usually provided with a high spectral resolution. Therefore, they have to be convolved with the instrumental resolution functions in order to have comparable resolution to that of the measured optical density.

\subsubsection{Ring effect}

In 1961, J.Gringer and J.Ring discovered that the depth of the Fraunhofer lines was smaller in scattered sunlight than in direct sunlight. This was attributed to inelastic Rotational Raman Scattering (RRS, Vountas et al., 1988), which slightly changes the wavelength of the scattered photon when the scattering occurs. This causes a "filling in" of strong absorption lines, as wavelengths on either side of the line are shifted into it. This causes an intensity loss at the original incident wavelength and an intensity gain at the neighbouring wavelengths to which they are distributed. The atmospheric absorption lines are also broadened by RRS events occurring after absorption (molecular Ring effect). Although RRS accounts for only a few percent of the measured intensity, it significantly affects DOAS measurements of scattered radiation since typical trace gas absorptions are of the order of a few percent or less in the usual DOAS measurement regions. If not properly corrected, the Ring effect produces strongly structured residuals in the differential optical 
density, due to the fact that Fraunhofer lines do not cancel perfectly between $I$ and $I 0$. Especially in the UV spectral range, the remaining spectral structures can by far exceed the structures of weak atmospheric absorbers.

To first order, the correction for the Ring effect in atmospheric spectra is simply the convolution of the irradiance with the spectrum of Raman scattering by air molecules (mainly $\mathrm{N}_{2}$ and $\mathrm{O}_{2}$ ), where the cross sections for the dominant rotational Raman component are given by Chance and Spurr, 1997. The longer the path in the lower atmosphere where the air density is higher, the more likely a Raman scattering event becomes. Therefore, the Ring effect is dependent on the solar geometry, the cloud cover and the aerosol concentration in the atmosphere. To correct for the Ring effect, a so-called Ring spectrum $R(\lambda)$ is calculated. Usually the Ring effect is taken into account by including an additional "absorber" in the DOAS fit. The Ring effect can be approximated using the following development for an optically thin atmosphere: one can consider that in any scattered light observation, the light detected by the instrument ( $\left.I_{\text {meas }}\right)$ is the sum of elastic and inelastic scattering processes (Equation 5.8).

$$
I_{\text {meas }}=I_{\text {elas }}+I_{R R S}
$$

To analyse a measured spectrum, the logarithm of $I_{\text {meas }}$ is taken. Since $I_{R R S}$ is very small compared to Ielastic, the logarithm can be approximated by the first two terms of the Taylor expansion:

$$
\ln \left(I_{\text {meas }}\right)=\ln \left(I_{\text {elas }}\right)+I_{R R S} / I_{\text {elas }}
$$

The last term $I_{R R S} / I_{\text {elas }}$ is the Ring term which can be approximated by the product of a Ring coefficient $\alpha_{\text {Ring }}$ and a Ring cross section $S_{\text {Ring. }}$. Although a fictitious absorber, $\alpha_{\text {Ring }}$ can be fitted together with other absorbers in the DOAS procedure. A good approximation of the Ring cross section can be obtained from calculation of a source term Io Raman derived 
by simple convolution of the solar spectrum with Raman cross sections, i.e. with calculated $\mathrm{N}_{2}$ and $\mathrm{O}_{2}$ RRS cross sections. The term $I_{R R S} /$ Ielastic $_{\text {in }}$ Equation 5.9 is then substituted by the product $\alpha_{\text {Ring }} S_{\text {Ring }}$ (where $S_{\text {Ring }}=I 0$, Raman $/ I 0$ ), assuming that the molecular Ring effect can be neglected. The QDOAS Ring tool calculates a Ring cross section according to this approach. The normalization of the Raman spectrum is optional.

Figure 5.5 includes an example of the derivation of a Ring cross section: it starts with the convolution of the solar atlas (plot a)) using a certain spectral resolution (in this case 0.5 $\mathrm{nm})$; in panel b) the same solar atlas convolved with the Raman scattering cross sections of $\mathrm{N}_{2}$ and $\mathrm{O}_{2}$ molecules is shown. The ratio between $\mathrm{b}$ ) and a) gives the absolute ring cross section at panel c). Finally, after subtracting a broad polynomial, the differential cross section of the Ring effect can be observed in panel d), ready to include in the DOAS fit.
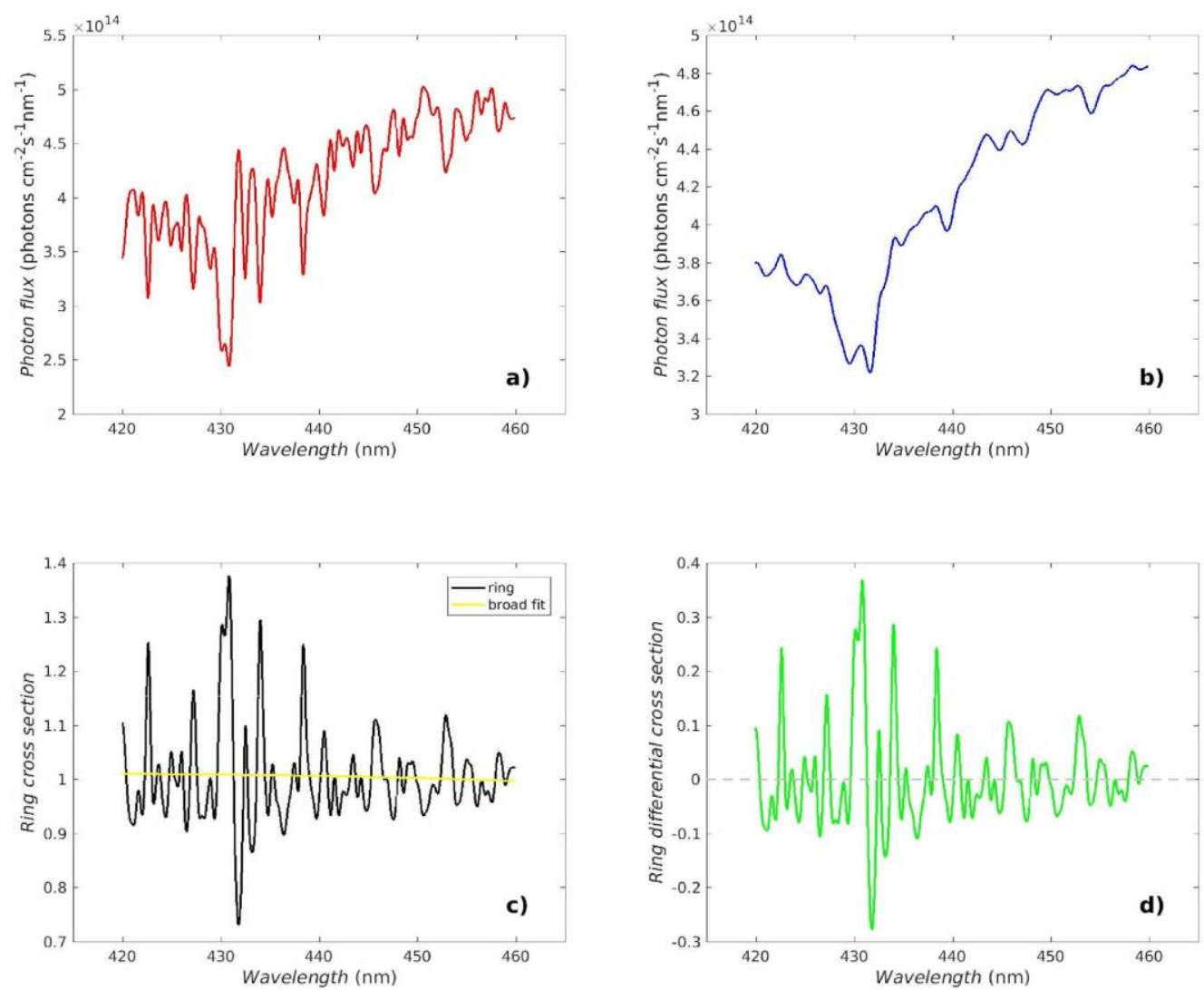

Figure 5.5. Example of the "equivalent" of the absorption cross section of the Ring effect. 


\subsection{Background measurements and instrumental effects}

Two important parameters in solar spectral measurements are the number of scans and the exposure time. The number of scans ( $\left.n_{\text {scans }}\right)$ represents how many spectra are collected within a given geometry and set of conditions. On the other hand, the exposure time (texp) stands for how much time spends the spectrometer receiving light for an individual spectrum. In DOAS measurements, usually several scans are taken within a given geometry, and afterwards all of the spectra are accumulated into one spectrum. There is another parameter, derived from the former two: the integration time. The integration time $\left(t_{\text {int }}\right)$ consists of the product of $n_{\text {scans }}{ }^{*} t_{\text {exp }}$ and takes care of how much time the instrument is measuring at a given observational geometry. In order to improve the signal-to-noise ratio and maximise the light input, an optimal combination of the mentioned parameters has to be found, quite often a compromise with time resolution in the measurements. In addition to these parameters, there are several other instrumental effects, which will be described in subsequent sections.

\subsubsection{Saturation}

The pixels of the spectrometer have a maximum capacity in their counts, i.e. once they reach that maximum, they will not be able to collect more photons, no matter how many more arrive at a given pixel. The detector could be saturated if the exposure times are long. On the other hand, if the exposure time is too short, the recorded signal will be composed mainly of background noise and the spectrum will likely not be useful for DOAS analysis. Therefore, it is important to use the full dynamic range of the detector and find a compromise in the light input so that the signal-to-noise ratio is maximised. We define the saturation level of a certain pixel $n$ as $s(n)$ (Equation 5.10).

$$
s(n)=\frac{c(n) * 100}{n_{\text {scans }} * c_{\max }}
$$


where $c(n)$ is the number of counts that the pixel $\mathrm{n}$ has received and $c_{\max }$ is the maximum capacity of that mentioned pixel. Although it might seem that a saturation level close to a $100 \%$ would be ideal, it is well documented in the literature that detectors usually reduce their performance when approaching their full capacity and introduce non-linear effects, hence saturation levels between $70-85 \%$ are typically used for atmospheric measurements.

\subsubsection{Electronic offset and dark current}

The electronic offset (which depends on the number of scans taken) and the dark current (that presents a strong dependency on the exposure time) can affect the recorded spectra. Both are indirectly related, and here we describe and explain how to characterise them numerically.

The detector of a spectrometer receives irradiance at each pixel in the form of photon flux. Once the photons arrive, they are converted into an electronic signal in order to register and subsequently treat the data. The AD-converters take care of this, generating a proportional voltage -i.e. current- for each pixel: the number of counts. However, in this process those converters always introduce a certain, discrete offset that is added to the light irradiance spectrum (which is photon induced). This spectral shift in the registered counts has to be accounted for in the DOAS analysis in order to avoid a non-atmospheric offset in the optical density. The electronic offset is added once for every measured scan, so it does not depend on the exposure time. Hence this effect can be experimentally characterised by recording a single scan at a very low exposure time with no light entering the spectrometer (for instance blocking the optical fibre). Since the dark current heavily depends on the exposure time, it is safe to assume that under these conditions, its impact can be regarded as negligible. This collected spectrum will basically consist of the electronic offset signal. For the purpose of improving the statistics and reducing the noise, several (generally in the order of hundreds or even a thousand) scans should be taken with the 
mentioned low exposure time. The electronic offset correction that should be applied to the measured spectrum at pixel $n$ would be:

$$
I_{o c}(n)=I_{\text {meas }}(n)-n_{\text {scans }} * e o(n) / n_{e o}
$$

where $I_{\text {meas }}(n)$ and $I_{o c}(n)$ represent -respectively- the measured and offsetcorrected spectra at pixel $n$, and $e o(n)$ stands for the total electronic offset signal (previously recorded in the laboratory under dark conditions) at pixel $n$, adding $n_{e o}$ measurements as explained above.

Dark current is unwanted signal or photons caused by thermally excited electrons when they travel across the semiconductor band. For this reason, it is important to pay attention to the temperature of the detector. Often, the spectrometers contain a cooling device to keep the temperature low $\left(-50^{\circ} \mathrm{C}\right.$ or lower), thus reducing the dark current effect. As mentioned, dark current mainly depends on temperature and exposure time. So for a given, constant temperature, the dark current signal will be proportional to the exposure time. To measure it, a single spectrum (under dark conditions, i.e. with no input of light, as done for the electronic offset) has to be recorded with a very high exposure time. Due to the absence of external light, the signal will consist of a merge of the electronic offset (added once since here just one scan was taken) and dark current. As the electronic offset signal has already been estimated, the total dark current signal can be obtained by subtracting the electronic offset to the background measurement by means of Equation 5.11. Then, the resulting signal should be scaled with respect to the exposure time used for the dark measurement, thus remaining a dark current flow. Finally, a measured atmospheric spectrum can be corrected for dark current applying the following equation:

$$
I_{b c}(n)=I_{o c}(n)-t_{\text {exp }} * n_{s c a n s} * d c(n) / t_{d c}
$$


here $I_{b c}(n)$ is the background corrected (both for electronic offset and dark current) spectrum at pixel $n, I_{o c}(n)$ is the just electronic offset corrected spectrum (following Eq. 5.12), $d c(n)$ is the estimated dark current signal at pixel $d c(n)$ and $t_{d c}$ is the total exposure time of the dark current measurement in the laboratory. Figure 5.6 shows an example of the electronic offset and dark current signals in the visible region of the MAX-DOAS instrument used in Chapter 9. These background measurements were taken with 100 scans at 0.064 seconds per scan for the electronic offset characterisation, and 1 scan of 60 seconds for the dark current.

a)

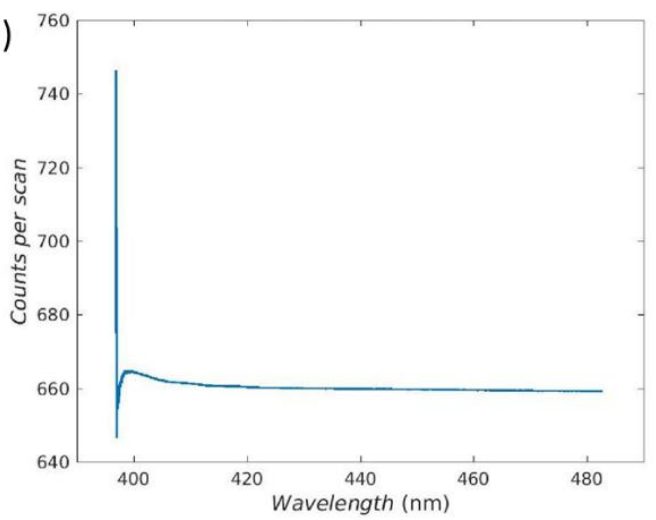

b)

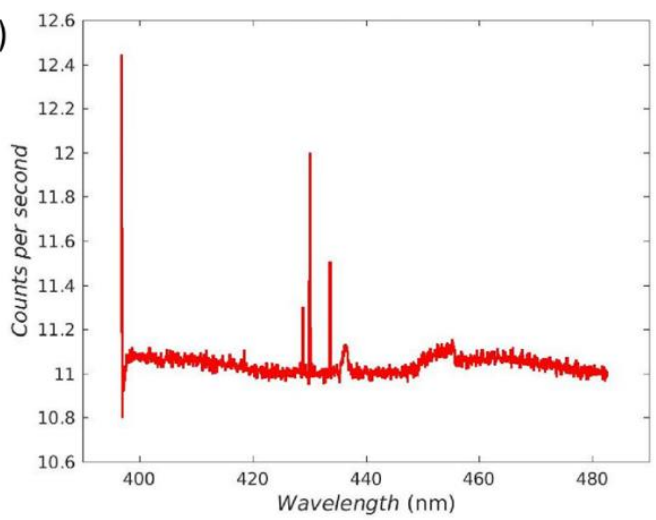

Figure 5.6. Electronic offset a) and dark current b) corrections in the visible spectral region for the MAX-DOAS instrument used in Chapter 9.

\subsection{Wavelength calibration}

For remote sensing measurements in general, and for DOAS analysis in particular, having a sound wavelength calibration of the instruments is crucial, not only for minimising the residuals in the calculations, but also for clearly distinguishing between trace gases spectral features. Spectrometers collect irradiance and once it arrives at the diffraction grating, it is dispersed in the form of a spectrum. Such spectrum is composed of photons that are converted into counts once they reach the detector. Therefore, what we have is an array of pixels, each of which has a certain number of counts associated. After that -and before the DOAS calculations- a precise wavelength vector has to be assigned to the array 
of pixels. This is key for the DOAS analysis, because not only each trace gas will have a tabulated spectral cross section with a certain wavelength grid (that may, in general will, differ from our wavelength grid) but there can also be slight changes in wavelength due to environmental and/or instrumental effects (for instance smooth temperature fluctuations). Therefore, in order to assure a good spectral analysis, a robust, solid wavelength vector has to be found.

There are two, complementary ways of calibrating a MAX-DOAS instrument: using the emission lines of a lamp, and studying the position of the absorption gaps in a collected solar spectrum. Usually, both methods are employed. In our case, we first perform a coarse calibration with a $\mathrm{Hg}-\mathrm{Ne}$ atomic emission lamp. Writing down the measured peaks of its emission lines, and comparing them to the expected values, we could get a wavelength vector using a polynomial correction. This calibration method should be enough for laboratory applications, given the steady environmental conditions, but this is not the case for a MAX-DOAS instrument, where the climate conditions are changing and a small wavelength shift could be critical in increasing the residual and thus complicating the evaluation of absorptions. As mentioned above, a relatively small drift in temperature could cause a dilatation of the grid to such an extent that our wavelength vector might not be accurate any more. Therefore, once the first, lab-calibration is performed, we make use of the second method: a live calibration using the measured spectra. The basic idea is to simulate a reference solar spectrum with the purpose of best matching the wavelength position of the measured absorptions.

Within this second method, there are several steps to follow. First, a highly resolved, accurate, extra-atmospheric solar spectrum is required. These solar spectra are commonly known as solar atlas, and since they have been registered at the TOA, there are no terrestrial absorptions that may interfere, thus they are measured in vacuum wavelengths. Usually this solar atlas is measured -with great accuracy- by satellites, and are considered as tabulated. For this work, the reference solar atlas detailed in Chance and Kurucz, 2010, has 
been used. Nonetheless, this solar atlas has a very high spectral resolution -much higher than the measured spectra, see Figure 5.7- so the solar atlas has to be degraded to the spectral resolution of our instrument. To do that, a certain convolution function -generally a Gaussian, although other fitting functions could be suitable too- is chosen. Subsequently, a measured spectrum can be calibrated using the solar atlas, both wavelength vectors -solar and spectrum- are compared and the correction in wavelength is extracted.

a)

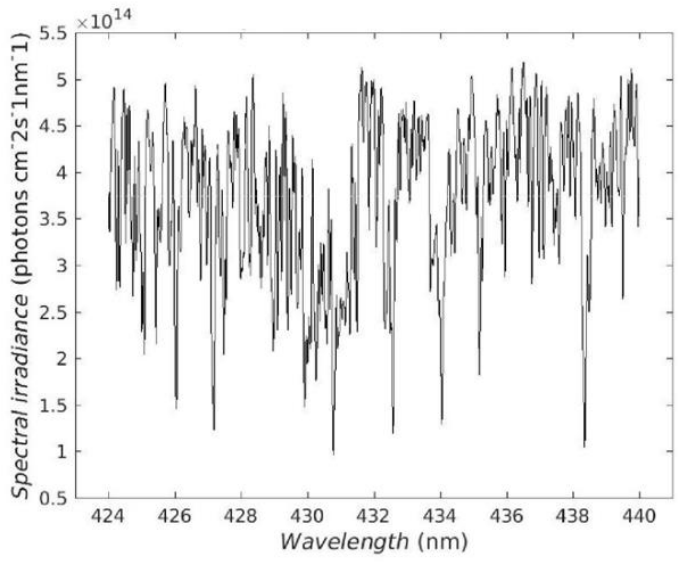

b)

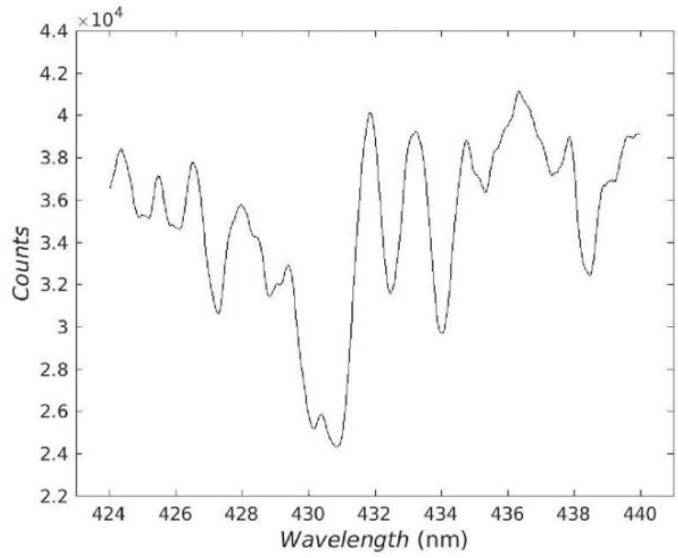

Figure 5.7. Example of the spectral irradiance of a solar atlas at high resolution a) in the IO fitting window and a zenith measured spectrum, b) in the Arctic using a MAX-DOAS at around noon on May 1, 2017.

Although there are several different numerical approaches here, the general procedure remains: the measured spectrum that has to be calibrated is compared to the convoluted solar atlas, thus both spectra are inputs of a non-linear, least-squares fitting that searches for the optimal solution applying the following parameters: the FWHM of the convolution function and a low order polynomial to correct the wavelength vector. Figure 5.8 shows an example of the wavelength calibration of the spectrum included in Figure 5.7. We can observe that there is a good agreement between the measured and the synthetic spectrum, although there are some variations in the intensity. Note that the fit is based on the wavelength position of the absorption lines, instead of the amplitudes (associated to the absorption in DOAS analysis). With the aim of cancelling out some spectral features, a 
Ring spectrum could be added in the calibration. After the calibration analysis, the spectrum is corrected and is considered well calibrated.

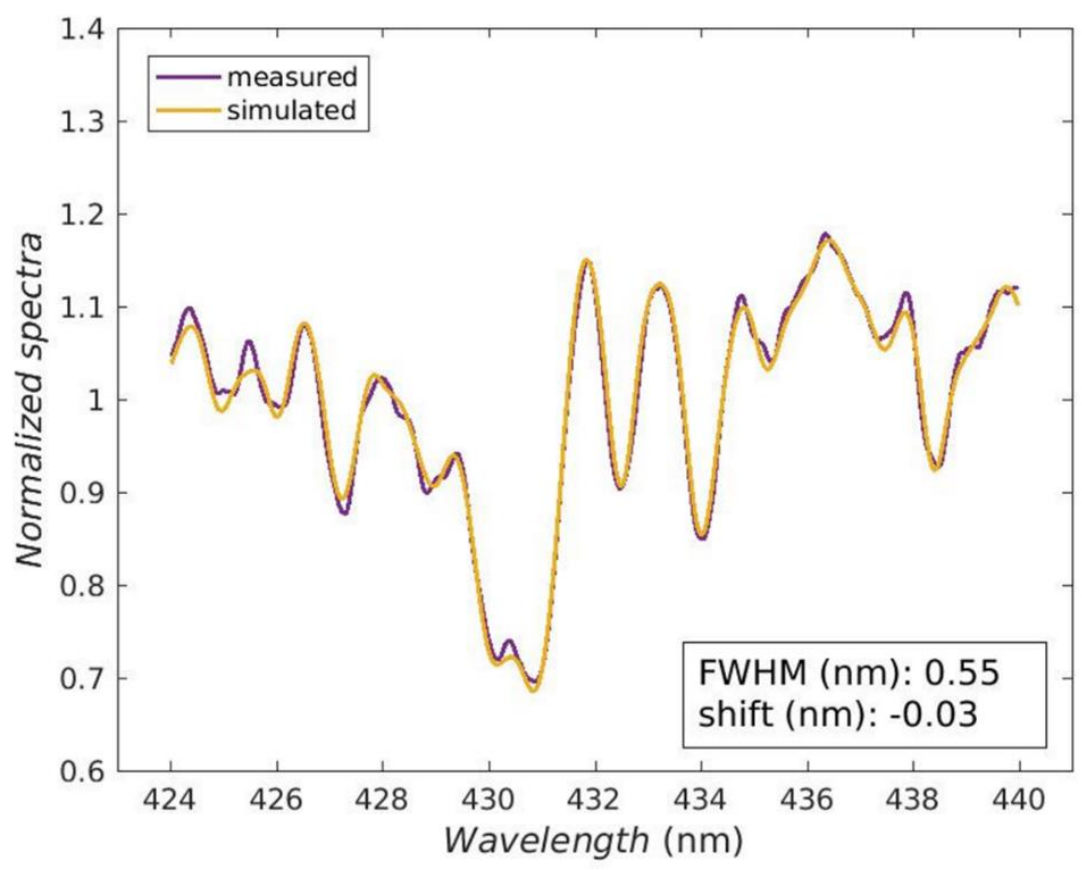

Figure 5.8. Comparison between the measured spectrum and the simulated spectrum from the calibration procedure. 


\section{RADIATIVE TRANSFER MODEL}

This chapter describes the foundation and main concepts of Radiative Transfer Models (RTM), and also describes the development of our own RTM.

\subsection{Introduction}

Radiative transfer is the field that studies the transfer of energy in the form of electromagnetic radiation through a medium, as well as the interactions that may occur inside it. Radiative transfer is prevalent in a wide variety of subjects, such as optics, astrophysics, atmospheric science and remote sensing. Within each subject, a RTM is a group of laws, principles and equations that simulates the electromagnetic radiation, the medium and the interactions between them.

Vertical concentration profiles of atmospheric trace gases like the halogen oxides, that we are studying here, can be derived using remote sensing measurements such as the MAX-DOAS technique. Since the calculations are based on indirect analysis, this type of ground-based measurements offer an effective way to assess atmospheric magnitudes, sometimes even at mesoscale. Nonetheless, the main disadvantage of the calculations is the following: quite often the variables subject of study involves some physical phenomena that are described by complicated mathematical expressions. For instance, the MAX-DOAS technique relies on the evaluation of relative spectral absorptions to obtain concentration profiles; for doing that, the paths followed by the photons as well as the spectroscopic processes have to be taken into account. Hence we need to fully describe the physics of the atmosphere in order to obtain quantitative results. Almost always there is no exact analytical solution, except for the simplest, geometrically symmetric cases (which 
unfortunately one does not find in nature quite often). Therefore, the profile inversion methods usually comprise optimal estimation techniques (see Rodger, 2000), even though there is usually no unique solution, which complicates the analysis even further.

The inversion algorithms take into account that each EVA has different scattering mean heights associated, and therefore different light paths (Solomon et al., 1987). In consequence, a set of measured DSCDs include information about the vertical distribution of a certain gas (in this study BrO and IO). Lower EVAs are generally related to lower scattering heights and vice versa, which means that different atmospheric layers can be sampled. In this study we use inversion algorithm methods and apply them to the DSCDs measured with the MAX-DOAS instrument- to first estimate the light paths and hence derive the trace gas vertical concentration profiles.

The analysis of the interaction between light and matter in the atmosphere is remarkably difficult. An important reason is the inhomogeneity of the atmosphere, because the density profiles and the entire composition always change with altitude. Moreover, there is not a simple way to simulate the entire atmosphere because some physical processes are difficult to describe mathematically.

The so-called Radiative Transfer Equation (RTE) explains mathematically the propagation of radiation through a small volume $(d V)$-which is considered homogenousthat may be altered by scattering, absorption and emission processes, see Equation 6.1.

$$
\frac{d I_{\lambda}}{d s} * d a * d \Omega=j_{\lambda} * d_{a} * d \Omega-\left(k_{\lambda}+\sigma_{\lambda}\right) I_{\lambda} * d a * d \Omega
$$

where $I_{\lambda}$ is the spectral radiance, $d_{s}$ and $d_{a}$ form the differential volume considered $\left(d V=d_{a}{ }^{*} d_{s}\right)$ and are the differentials of propagation and transversal area, respectively, while $d \Omega$ stands for the solid angle differential. On the other hand, $j \lambda$ represents the emission coefficient, $k_{\lambda}$ is the scattering coefficient and $\sigma_{k}$ stands for the absorption 
coefficient. The addition of the scattering and absorption coefficients $\left(k_{\lambda}+\sigma_{\lambda}\right)$ is frequently known as the extinction coefficient, and it has been experimentally demonstrated since long ago that this extinction coefficient is directly proportional to the spectral radiation $I_{\lambda}$ itself (as shown in Equation 6.1). That is the reason why the LambertBeer law exhibits an exponentially decreasing behaviour (see Chapter 5). Cancelling out the differential terms at both sides of Equation 6.1, we obtain the simplified version of the RTE:

$$
\frac{d I_{\lambda}}{d s}=j_{\lambda} *-\left(k_{\lambda}+\sigma_{\lambda}\right) I_{\lambda}
$$

As mentioned above, the RTE cannot be analytically solved apart from the most symmetrical, simplest, steady configurations. We have therefore to apply numerical methods to estimate the optimal solution. Within the atmospheric sciences field, there are several types of RTMs, but they can be classified into two main groups, regarding the approach they follow to solve -or optimise- the radiative transfer:

- Deterministic methods: briefly, these methods discretise the whole atmosphere and generate discrete radiation fields and physical phenomena until an optimal solution is obtained. One example is the Discrete Ordinates method (see Evans, 1988).

- Monte Carlo methods: in order to estimate the optimal solution, they use the Monte Carlo method, simulating the radiation fields and the atmospheric properties statistically (Deutschmann et al., 2011).

For the calculations carried out in this thesis, we have developed our own, homemade RTM using the radiative transfer theory and implementing it in our codes following the discrete description of radiation fields. But we have also made use of the bePRO profile algorithm, which is a discrete-type RTM developed by the BIRA-IASB institute (see more details in Clémer et al., 2010). 


\subsection{The forward model and its matrix notation}

Here is where the inversion problem arises: a known system of equations (the forward model) fully describes the atmosphere along with its physical phenomena, but we usually have indirect measurements -the column densities retrieved from the spectral absorptions-, hence we have to invert these measured absorptions in order to derive the atmospheric state that caused them. Although each atmospheric phenomena considered will be thoroughly detailed in subsequent Sections within this chapter, for simplicity we first take a general look at the matrix notation to better grasp the ideas behind the retrieval.

In order to get information about the vertical distribution of the measured species, the inversion of the DSCD measurements needs a precise description of the physics of the measurement process. The physics of the measurement is not completely understood or it is difficult enough that it must be approximated by the forward model $F(\vec{x}, b)$ and the experimental uncertainty:

$$
\vec{y}=F(\vec{x}, b)+\vec{\varepsilon}
$$

where $\vec{y}$ is the vector of measurements (in our case, the DSCDs) with uncertainty $\vec{\varepsilon}$, $\vec{x}$ is the state vector containing the vertical distribution of the trace gas or aerosols, and $b$ includes the forward model parameters that influence the modelled DSCDs, but are not retrieved. Since the measurements are discrete quantities, while the vertical distribution to be retrieved, $\vec{x}$, is a continuous function, the problem is formally ill-posed or underconstrained. Therefore, the state vector is discretized into a finite number of parameters depending on the resolution required and the information content of the measurement.

To start the radiative transfer model, the inputs -state profile $\vec{x}$ and the forward model parameters $b$ (such as temperature, pressure, ozone and aerosol profiles, to name a 
few) are needed. After that, the RTM calculates the simulated DSCDs vector $(\vec{y})$ using the forward model, as well as the weighting functions $(K)$, which are related as follows:

$$
K=\frac{d F(\vec{x})}{d b}
$$

The matrix $K$ is defined as the sensitivity of the forward model to the forward model parameters. In particular, $K$ gives the sensitivity of the modelled DSCD with respect to a change within each discrete layer of the state profile. It may also be named the Jacobian, since it is a matrix of derivatives, the kernel (hence $K$ ), or the adjoint. $K$ can be conceptually interpreted as the matrix that converts the vertical concentration profiles ( $\mathrm{BrO}$ and $\mathrm{IO})$ into column densities. Hence $K$ actually stands for the box-AMFs (i.e. the AMF of each atmospheric layer). As mentioned above, $K$ comprises all of the parameters, magnitudes and physical properties considered by the RTM (for instance the angular geometry, the aerosol extinction profile, the surface albedo coefficient or the atmospheric profiles of pressure and temperature) are included, so that all the possible interactions can be described.

The radiative transfer calculations are computationally expensive, but the most time-consuming part -by far- is the evaluation of the box-AMF. For a linear inversion, the sensitivity of the measurements to a certain atmospheric state vector must be independent of the state vector itself and the forward model can then be described in terms of the constant weighting function matrix, $K$ :

$$
\vec{y}=K \vec{x}+\vec{\varepsilon}
$$

Since the trace gases measured by MAX-DOAS are optically thin $(\tau<<1)$, this linear approach is safe, and the linear Maximum A Posteriori (MAP) retrieval method can be used. Optically thick absorbers and aerosols influence the radiance and hence the DSCDs in a nonlinear way with respect to optical density, so an iterative numerical solution such as a Gauss- 
Newtonian method must be used in that case (Wedderburn, 1974). But again, the halogen oxides analysed in this thesis are optically thin, thus the linear approach can be safely applied.

Given a vector of measurements $\vec{y}$, along with their associated uncertainty covariance matrix and any available a priori information, the possible atmospheric state vectors $(\vec{x})$ that are consistent with this information can be assigned by means of using a Probability Density Function (PDF). The MAP optimal estimation method chooses the state that maximises the posterior conditional PDF $P(x / y)$, meaning that $P(x / y) d x$ is the probability that $x$ is in the interval $[x, x+d x]$ for a given set of measurements $\vec{y}$. In contrast, the Maximum Likelihood $(\mathrm{ML})$ solution maximises the conditional PDF $P(x / y)$.

From all the possible solutions, the optimal estimation selects the best solution that minimises the difference between the modelled and measured state vectors, taking also into account the uncertainties and the prior constraints. It is important to know how the optimal solution is related to a "true", continuous state and to understand the various sources of uncertainties which influence the retrieval. The linear maximum a posterior solution can be vectorially written as in Equation 6.6.

$$
\hat{x}=\vec{x}_{a}+G\left(\vec{y}-K \vec{x}_{a}\right)
$$

where $G$ is the gain matrix, also known as the contribution function matrix, and $\vec{x}_{a}$ is an a priori state vector. The contribution function matrix is the matrix that quantifies the contribution of each DSCD measurement to the retrieved profile. Another important magnitude is described by the averaging kernel matrix, $A$, which renders the sensitivity of the retrieval to the "true" state and is the product of the gain and weighting function matrices, Equation 6.7.

$$
A=G K
$$


Figure 6.1 shows an example of the averaging kernels, where each curve (with an assigned altitude) represents the sensitivity of that mentioned height to the surrounding layers. In other words: the averaging kernel is an estimation of how a given amount of a certain trace gas inside a layer can influence the retrieved quantity of the same compound in a different layer. Ideally, the averaging kernel curves should have a peak form, much like a Dirac delta function. However, this is never the case, as it is not possible to perfectly separate the spectral signature generated in one layer from the remaining layers. Summarizing, the averaging kernels are used to evaluate the sensitivity of the overall retrieval at each layer. Moreover, the trace of the $A$ matrix is known as the degrees of freedom, and symbolizes the number of independent pieces of information for a certain retrieval. It is commonly used as a guide for the goodness of the analysis, as well as its independence of the a priori information.

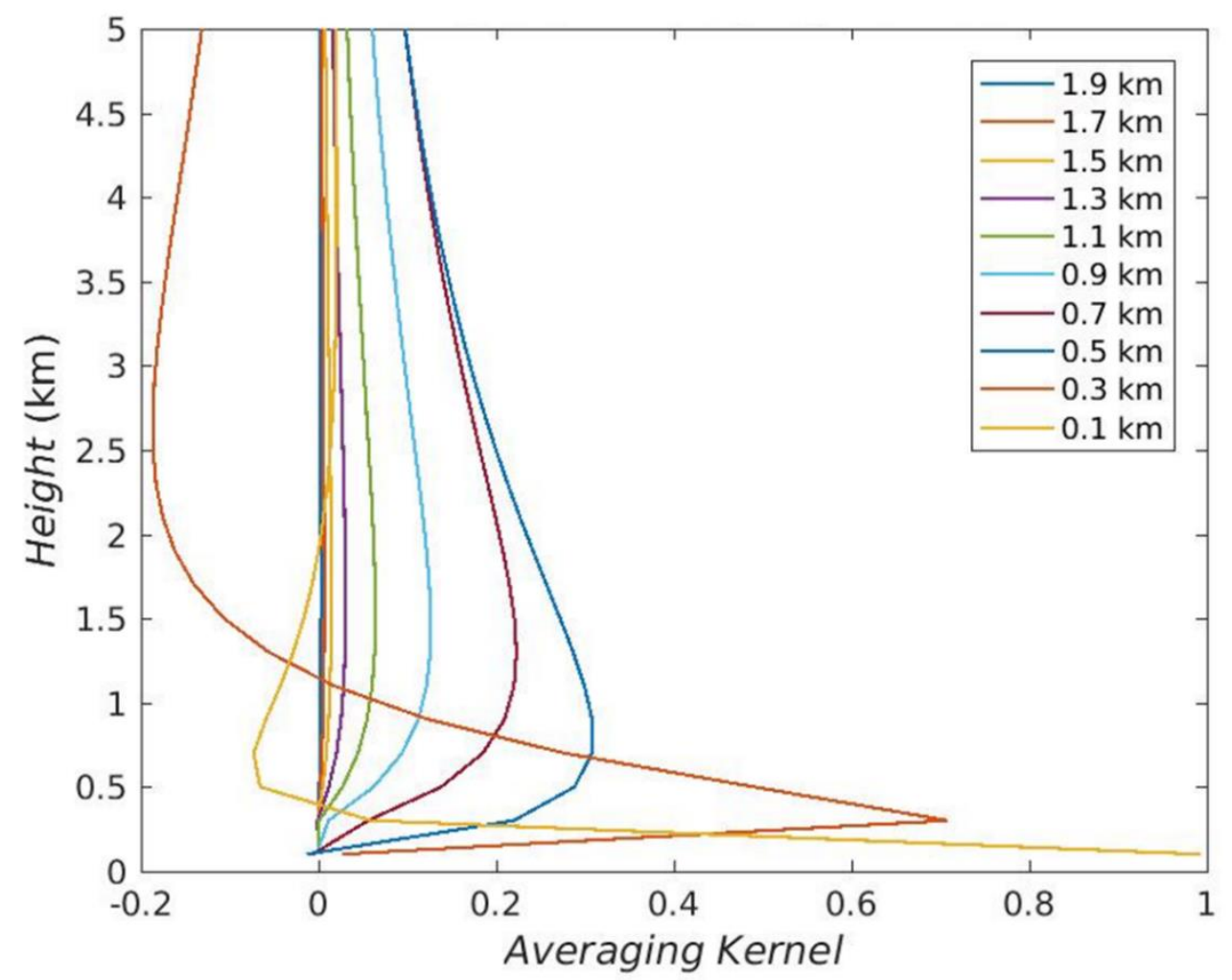

Figure 6.1. Averaging Kernels in the UV region (centred at $360.8 \mathrm{~nm}$ ) for the different altitudes. 


\subsection{Aerosol extinction and trace gas profile retrieval}

Once the matrix notation is clear, the next stride consists of giving more details about the profile retrieval. As stated above, the calculations are based on the Optimal Estimation Method (OEM; Rodgers, 2000) and it consists of two steps: first, the calculation of the light paths and the vertical profiles of irradiance extinction are carried out using the $\mathrm{O}_{4} \mathrm{DSCDs}\left(\mathrm{O}_{4}\right.$ is the dimer of the oxygen molecule). After that, the target trace gas vertical concentration profile is retrieved using the corresponding light paths and measured absorptions.

In order to estimate the light paths associated with each EVA, the measured $\mathrm{O}_{4}$ DSCDs are used, since they are proportional to the square of the atmospheric $\mathrm{O}_{2}$ vertical profiles, which are well known, fairly steady and do not heavily depend on chemical considerations. To simulate the atmosphere, the RTM includes the physical phenomena and parameters needed to model the atmospheric state vector (see Section 6.4). Once an atmospheric vector state is defined, its combination with a certain vertical concentration profile results in the simulated DSCDs of the considered species. This vertical profile is iterated until the generated set of simulated DSCDs is optimized with respect to the measured DSCDs so that the residual is minimised. As a result, an optimal vertical profile of aerosol extinction is obtained when the iteration is finished for each MAX-DOAS cycle. The basic equation that describes the light paths fit is as follows:

$$
X^{2}(x)=\sum_{m=0}^{M}\left(\frac{F_{m}(\vec{x})-y_{m}}{\sigma_{m}}\right)^{2}+\sum_{n=0}^{N}\left(\frac{x_{n}-x_{a, n}}{\sigma_{a, n}}\right)^{2}
$$

Equation 6.8 can be divided in two parts: one is based on the difference between the measured $(y m)$ and modelled $F_{m}(x)$ values; the second one describes the discrepancy between an a priori profile $\left(x_{a, n}\right)$ with its uncertainty $\sigma_{a, n}$ and one atmospheric state $\left(x_{n}\right)$ with uncertainty $\left(\sigma_{m}\right)$. This method finds by iterations one particular solution from an infinite range of possible solutions that is statistically optimal $\left(X^{2}(x) \min \right)$. 
Therefore, the measured $\mathrm{O}_{4}$ DSCDs can provide information on the irradiance extinction in the atmosphere. This extinction profile retrieved is associated with the aerosol extinction coefficients and thus, its vertical integration yields the Aerosol Optical Depth (AOD). These aerosol extinction profiles are required to subsequently evaluate trace gases since they strongly affect the relative light paths and hence the concentration profiles derived from them. When this step is finished, a similar process is done for the $\mathrm{IO}$ and $\mathrm{BrO}$ measured DSCDs, generating the optimal vertical concentration profile. The vertical integration of this profile is the VCD.

\subsubsection{A priori profiles}

One important parameter for the inversion method is the a priori profile, the first values for the iteration to obtain the accurate vertical profile for aerosols and trace gases. We develop this a priori profile for both aerosols and trace gases taking into account exponentially decreasing profiles, the Equation 6.9 is used.

$$
c_{a}(z)=\left(\frac{V C_{a}}{s h}\right) * \exp \left(\frac{-z}{s h}\right)
$$

where $c_{a}(z)$ is the light profile for the MAXDOAS cycle at given altitudes $z$, sh is the scaling height constant and $\mathrm{VC}_{\mathrm{a}}$ is the vertical column of the associated amount, the scaling height is $0.5 \mathrm{~km}$ for all the a priori profiles and a fixed total vertical amount: for the aerosol retrieval we took an $A O D$ value that could be either provided from a near source or was assumed to be 0.05 , while for trace gases we applied the geometrical approximation to the measured DSCDs at EVA $30^{\circ}$. This method is based on the idea that the trace gas of interest (e.g. BrO and IO) is assumed to be located below the scattering height when the EVA is higher than 10 (Hönninger et al., 2004). This approach approximates the possible diurnal variability of the a priori profiles with simple calculations. 


\subsection{Radiative Transfer Model of the Atmospheric Chemistry and Climate research group $\left(\mathrm{AC}_{2} \mathrm{RTM}\right)$}

\subsubsection{In-scattering and out-scattering}

The scattering term is the process in which a particle diffuses incoming radiation at a given angle and with certain energy. There are two types of scattering: elastic scattering if the energy is conserved and inelastic scattering if the energy changes.

Regarding the scattering in the atmosphere, light can be scattered more than once. The light which goes into the collector of the MAX-DOAS is single-scattered. The multiple scattering has a noticeable effect, and will be taken care of, but only is considered as a second-order contribution. For now, we can just assume that all of the irradiance that arrives at the MAX-DOAS instrument comes from a single scattering event, hence previous to that single scattering event the light must be direct sunlight. At the TOA all of the irradiance is maximum. From the TOA to the single scattering event, as light traverses the atmosphere, the irradiance decreases due to absorption and scattering processes.

Out-scattering is the fraction of light that is scattered out of the light beam (please see Figure 6.2) and the part of the light which is not in the way to the light collector. Consequently, the irradiance that reaches the instrument is lower than that at the TOA.

Atmospheric scattering processes depend on the probability of light reaching air molecules, for this reason, the denser the medium, the more probable scattering is. It is additionally related to light paths, e.g. the larger the light path, the higher the scattering probability. 


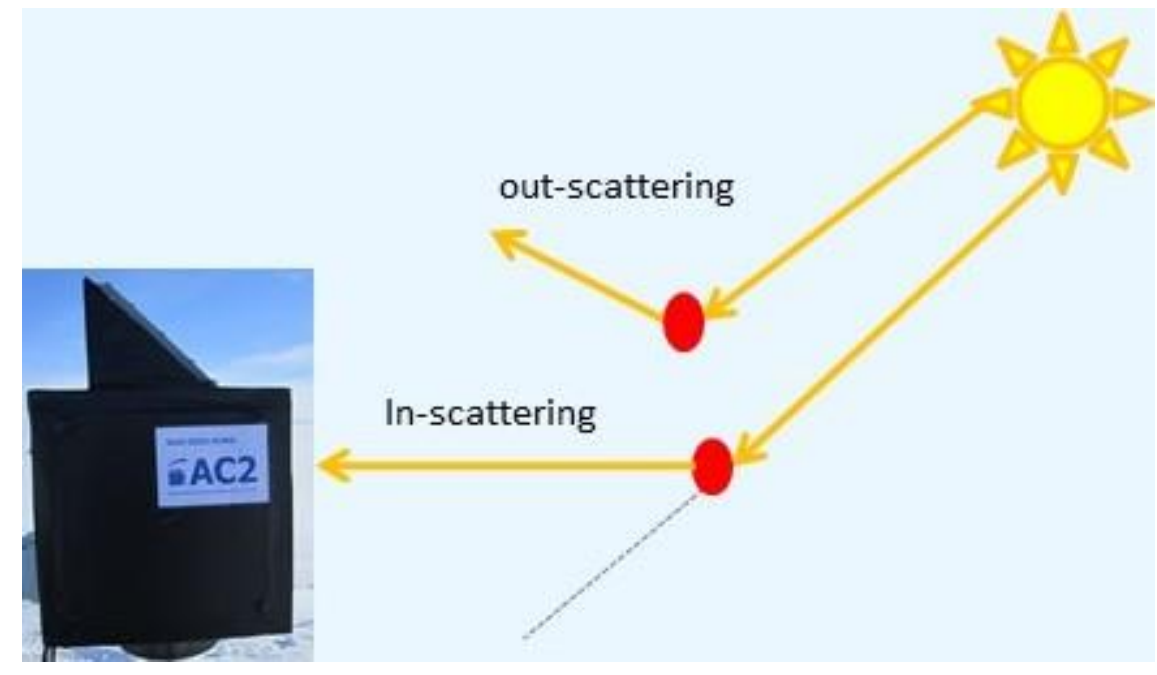

Figure 6.2. In-scattering and out-scattering diagram.

The aim of this in and out scattering is to know how much light is scattered in a certain direction (Equation 6.10, where $S(\lambda, \theta, z)$ is the scattering function).

$$
I_{f}(\lambda)=I_{0}(\lambda) * S(\lambda, \theta, z)
$$

\subsubsection{Rayleigh scattering}

Rayleigh scattering is based on the scattering of light by particles that are very small in relation to the wavelength of the light. When irradiance reaches a small particle, some of it will continue unaffected, but a portion of the incoming light will interact with the particle, being scattered in all directions. The intensity of the scattered light varies with $\lambda^{-4}$ with respect to the incoming wavelength. Nonetheless, the quantity of energy is not the same in all the possible angular directions, one example of these different energies is shown in Figure 6.3. 


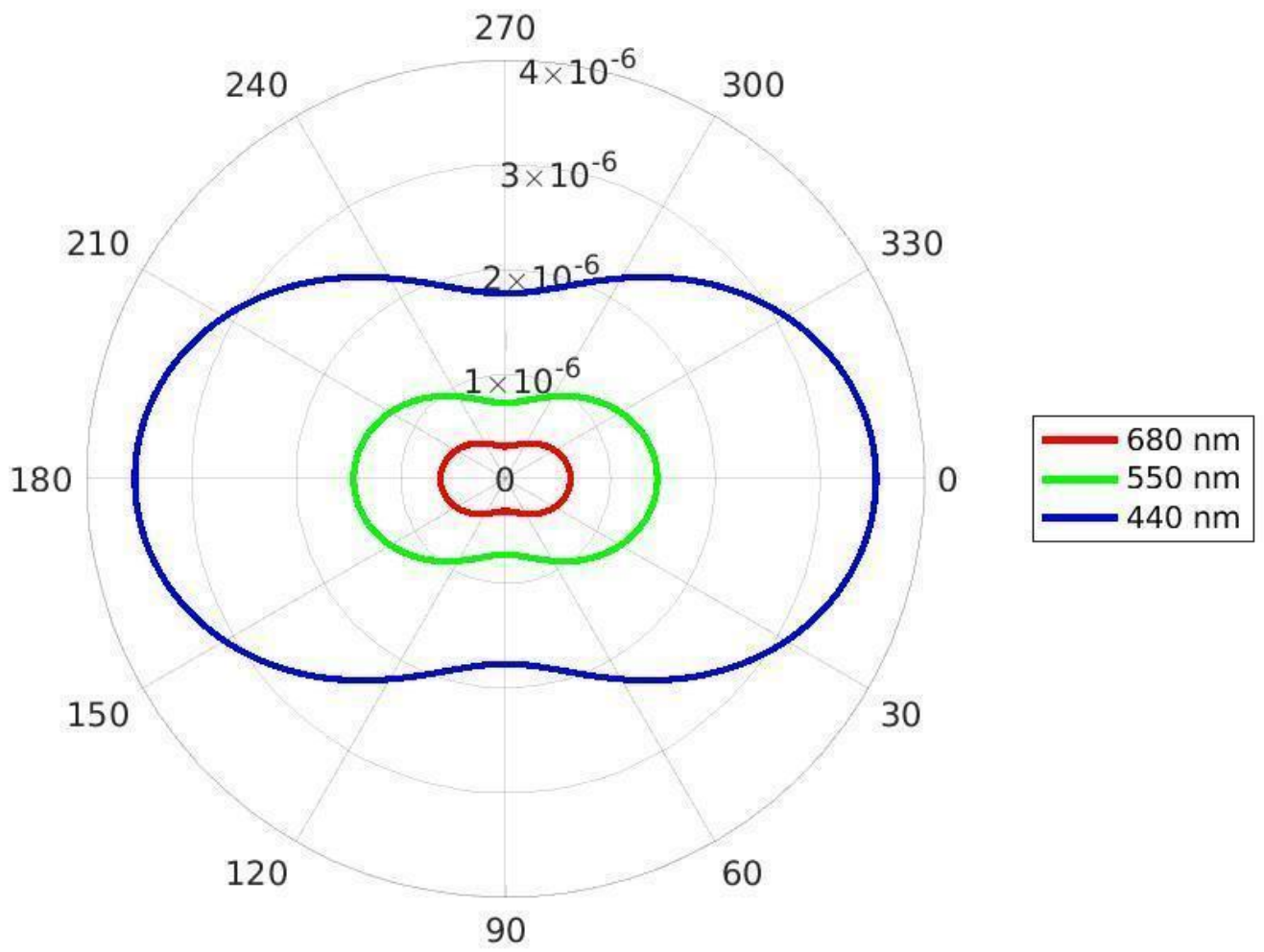

Figure 6.3. Rayleigh phase function.

Figure 6.3 shows the usual eight-shape of the Rayleigh function, as well as the strong relationship with wavelength. The two-lobed shape in the phase function shows that air molecules become electric dipoles, radiating exactly like microscopic antennas. The angular preferences of photons after a Rayleigh scattering are either continuing straight through unaffected, or going back at $180^{\circ}$, whereas the less probable outcome is being scattered at $90^{\circ}$.

Figure. 6.4 represents a simple diagram of a Rayleigh scattering event. The basic mathematical expression that describes the Rayleigh scattering function appears in Equation 6.11.

$$
S(\lambda, \theta, z)=\frac{\pi^{2}\left(n^{2}-1\right)^{2} \rho(z)\left(1+\cos ^{2} \theta\right)}{2 N \lambda^{4}}
$$


where $\lambda$ is the radiation wavelength, $\theta$ is the angular deviation from the scattered light with respect to the original direction of light and $z$ represents the altitude from the ground. Moreover, $n$ stands for the refractive index of air (we will take 1.00029 for the Earth's atmosphere), $\rho$ represents the density ratio and $N$ is the mean surface molecular number density of air (a value of $2.504 \times 10^{25}$ molecule $\mathrm{m}^{-3}$ was implemented).

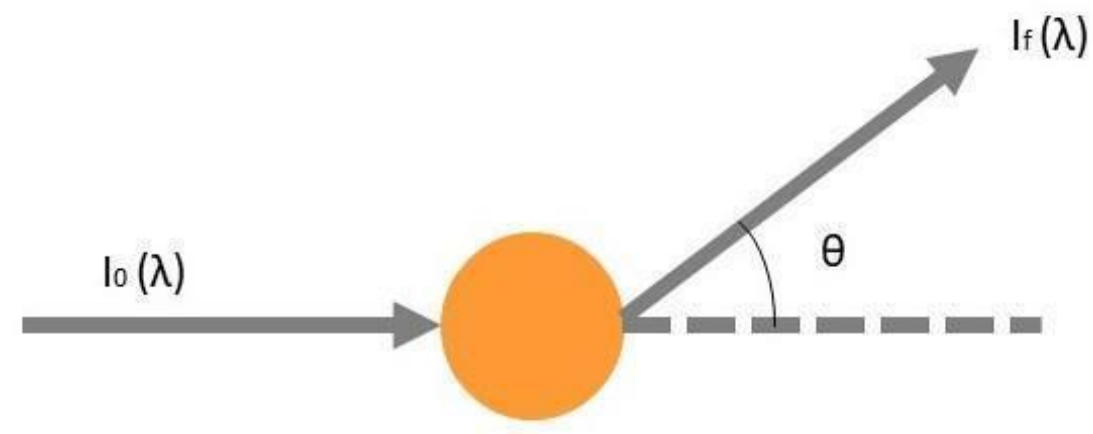

Figure 6.4. Rayleigh scattering.

Integrating the Equation 6.11 over the three-dimensional solid angle, and normalizing so that the integral over all possible angles sums 1, the Rayleigh scattering coefficient is obtained:

$$
\beta(\lambda, z)=\frac{8 \pi^{3}\left(n^{2}-1\right)^{2}}{3} \frac{\rho(z)}{N} \frac{1}{\lambda^{4}}
$$

where $\beta(\lambda, z)$ stands for the fraction of total energy which is lost after a single scattering event. Figure 6.5 displays the evolution of the Rayleigh scattering coefficient as a function of wavelength. 


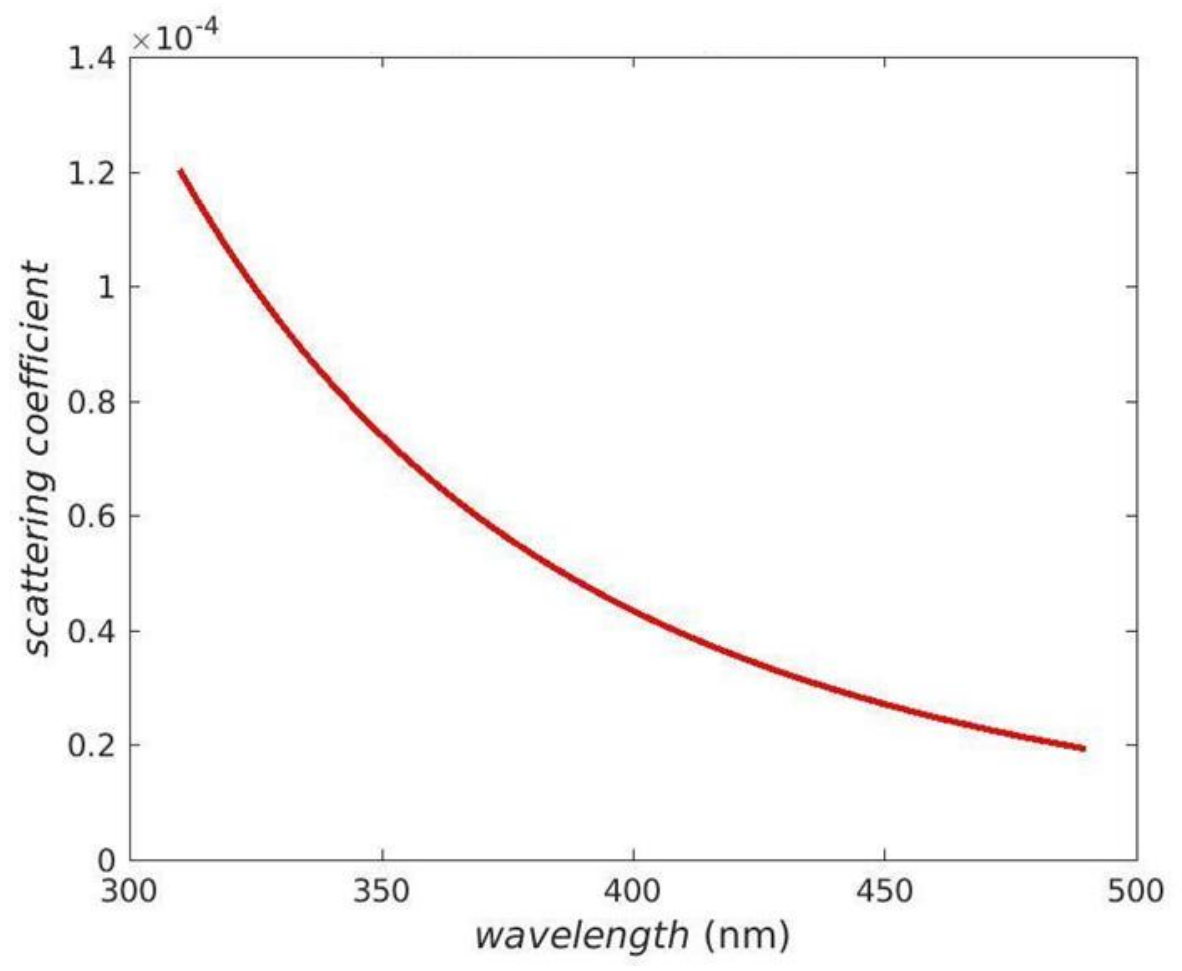

Figure 6.5. Rayleigh scattering coefficient at different wavelengths.

The strong relationship between Rayleigh scattering coefficient and wavelength is what makes the sky blue and the sunrises and sunsets red. As can be observed in Figure 6.5, bluish light (shorter wavelength) is heavily scattered in comparison with reddish light (larger wavelength).

Rayleigh scattering function can be decomposed in two parts: the Rayleigh scattering coefficient $\beta(\lambda, z)$ (models the intensity), and a component in charge of the angular direction. This last component can be derived by dividing Equation 6.11 and Equation 6.12.

$$
\gamma(\theta)=\frac{3}{16 \pi}\left(1+\cos ^{2} \theta\right)
$$


It is remarkable that $\gamma(\theta)$ does not depend on incoming light wavelength, as we could expect. This equation is responsible for the dipole shape in Figure 6.3.

\subsubsection{Mie scattering}

Mie scattering is typically used in situations where the size of the particle is comparable to the wavelength of the light. It was first reported by Gustav Mie (Mie, 1908). The most noticeable difference compared to Rayleigh scattering is the typically much weaker wavelength dependence (typically proportional to $\lambda^{-1.3}$ ) and a strong dominance of the forward direction in the scattered light (Hergert and Wriedt, 2012).

For Rayleigh scattering, simple approximations are sufficient to describe the physical behaviour. However, no simple approximation exists for Mie scattering, the calculation of the Mie scattering cross-section can be very complicated for both spherical and arbitrary shape particles. Consequently, Mie scattering contribution is approximated.

Mie scattering depends on the relative angular direction of the scattered light with respect to the incoming light. One of the most common approximations is the HenyeyGreenstein function, firstly derived in 1941.

$$
\gamma_{M}(\theta)=\frac{3}{8 \pi} \frac{1-g^{2}}{2+g^{2}} \frac{1+\cos ^{2} \theta}{\left(1+g^{2}-2 g \cos \theta\right)^{3 / 2}}
$$

Parameter $g$ ranges from -1 to 1 and is referred to as the preferred scattering direction, and controls the anisotropy of the Mie scattering, this parameter depends on some factors: environment and aerosol loading, in remote places the Mie scattering is weak due to the low aerosol loading. Figure 6.6 contains some examples of the Mie scattering phase function. 


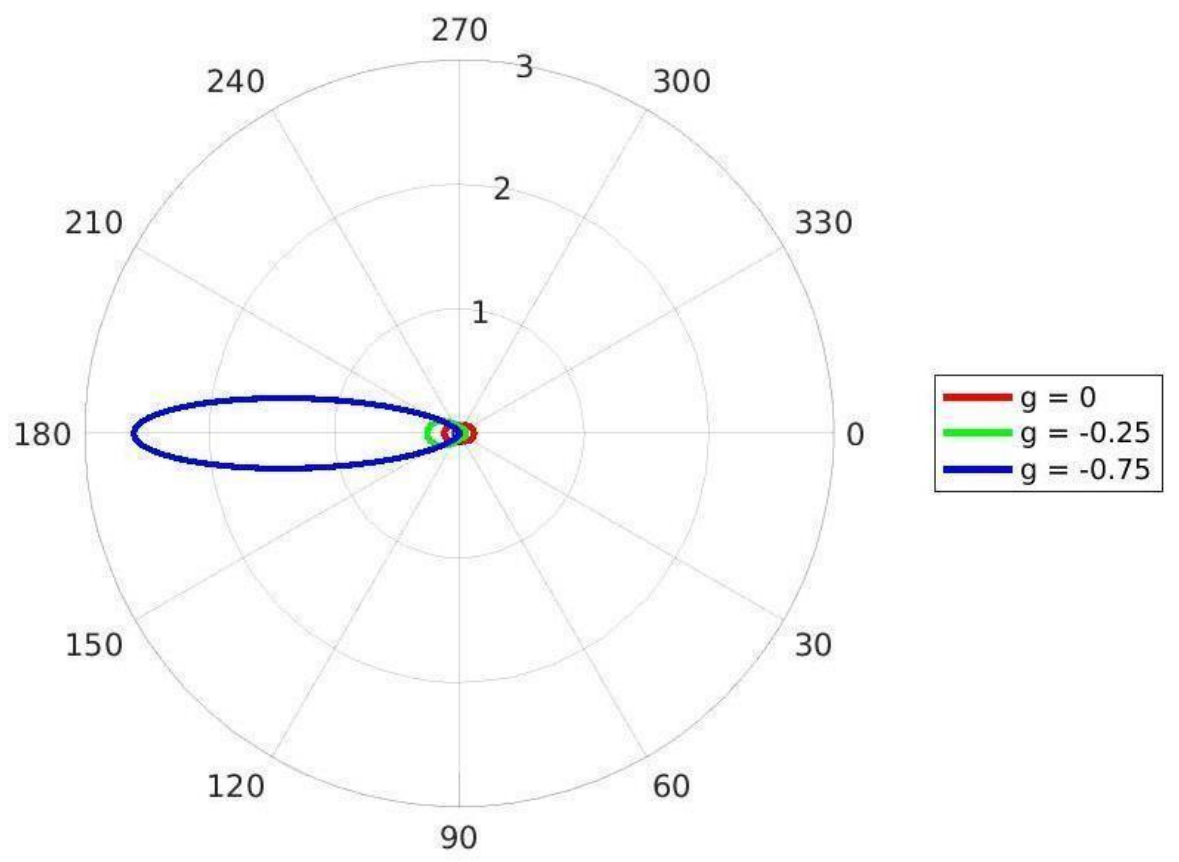

Figure 6.6. Mie phase functions.

\subsubsection{Atmospheric density}

Scattering is proportional to the atmospheric density, as low atmospheric density leads to less atmospheric scattering. The parameter $\rho(z)$ describes the normalized atmospheric density as a function of altitude (Equation 6.15).

$$
\rho(z)=\frac{n_{\text {air }}(z)}{n_{\text {air }}(0)}
$$

Here $n_{\text {air }}(z)$ stands for the atmospheric number density at a given altitude $z$. The atmospheric density vector can be calculated using the Ideal Gas Law along the temperature and pressure vertical profiles. Figure 6.7 shows the number density of a typical Arctic atmosphere used in this work (note the typical exponential decreasing trend). 


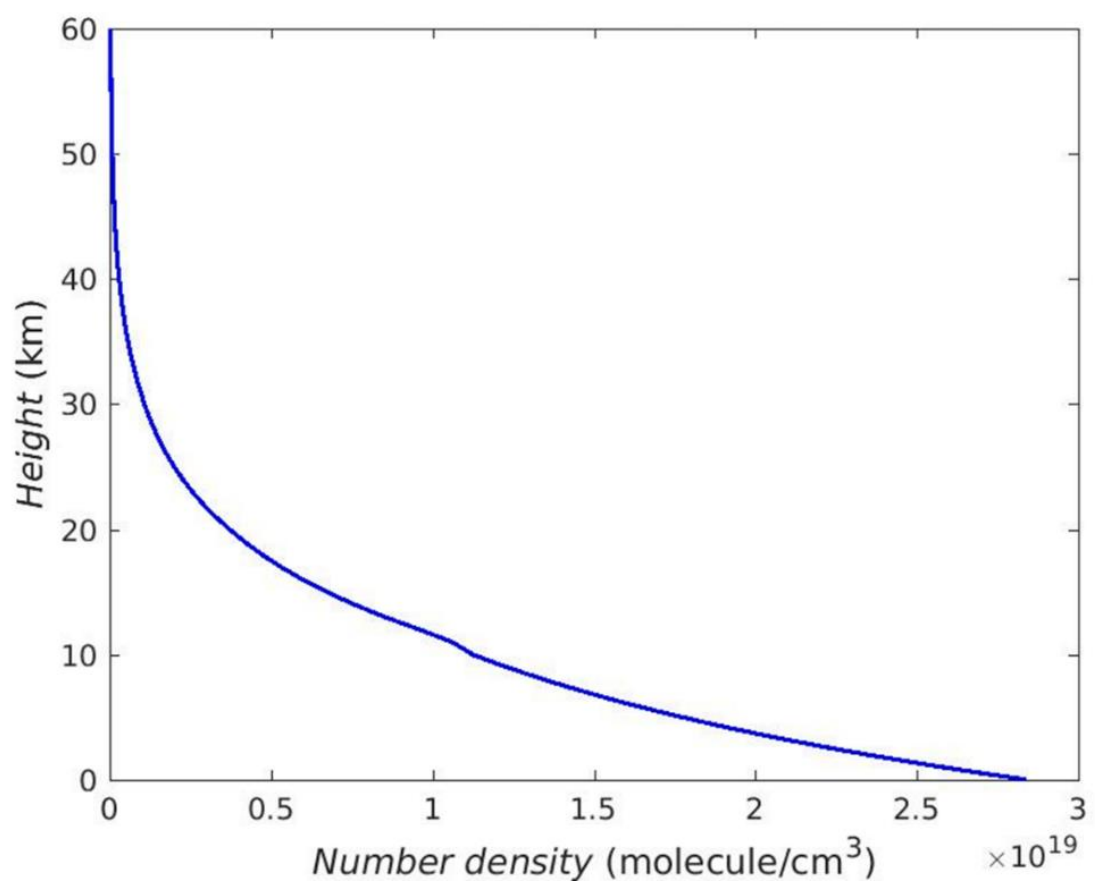

Figure 6.7. Number density profile of a typical Arctic Atmosphere as a function of height.

\subsubsection{Aerosol extinction}

The presence of aerosols in the atmosphere is one way of irradiance extinction. For this reason, it is important to know the aerosol vertical profile in DOAS measurements but these profiles are generally not available. There is no immediate way to assign the irradiance extinction of a certain layer to a load of aerosol within that layer, especially for altitudes higher than the planetary boundary layer. A small fluctuation of a few percent -or even less- in the atmospheric density profiles can produce an analogous effect to that of an aerosol loading. Nonetheless, an aerosol extinction vector has to be provided. The measured $\mathrm{O}_{4}$ DSCDs are used to estimate the light paths and the extinction coefficient of aerosol for each EVA.

The retrieved aerosol loading relies on the shape of the $\mathrm{O}_{4}$ DSCDs vector rather than the actual amount of $\mathrm{O}_{4}$ DSCDs, since as explained above, slight fluctuations in several parameters of the RTM can generate diverse irradiance extinction profiles (for instance, see Figure 6.8, where $\mathrm{O}_{4}$ DSCDs vectors were simulated using two different sets of atmospheric 
profiles -U.S. Standard and an Arctic atmosphere- coupled with two aerosol loadings), hence affecting the light paths. However, none of those can be unequivocally attributed to particulate matter. This issue gets even more complicated in polar regions, since there is no easy way to characterize the snow storms events.

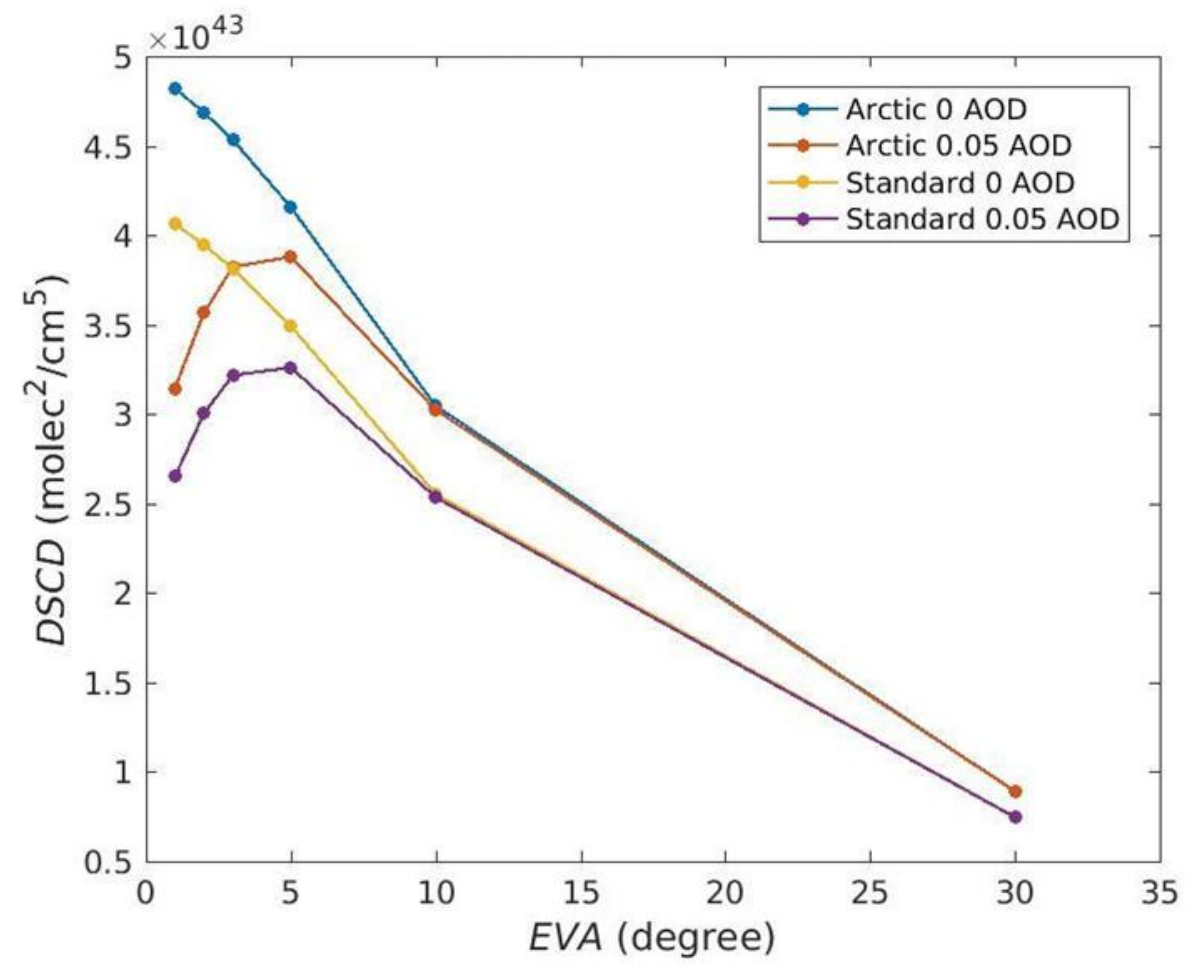

Figure 6.8. Impact of atmospheric profiles and aerosol loading on the $\mathrm{O}_{4}$ DSCDs.

The aerosol loading can have a notable impact in the overall retrieval of a given trace gas. Specially for low EVAs (and therefore for lower height levels), as shown in Figure 6.9. Here, the box-AMFs for EVA $1^{\circ}$ and EVA $30^{\circ}$ are depicted for the Arctic atmosphere. We can observe that a relatively small increase in the aerosol loading (up to 0.05 AOD) can significantly affect the box-AMFs -and hence the vertical concentration profile- at lower layers, but the effect is almost negligible at higher EVAs (i.e. at higher layers). 
a)

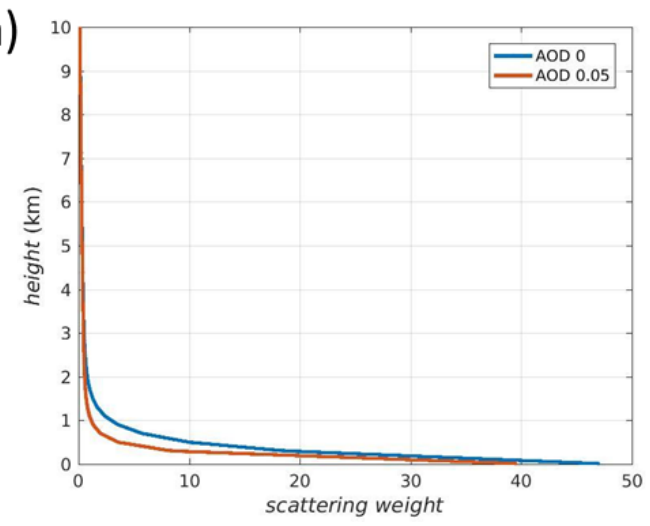

b)

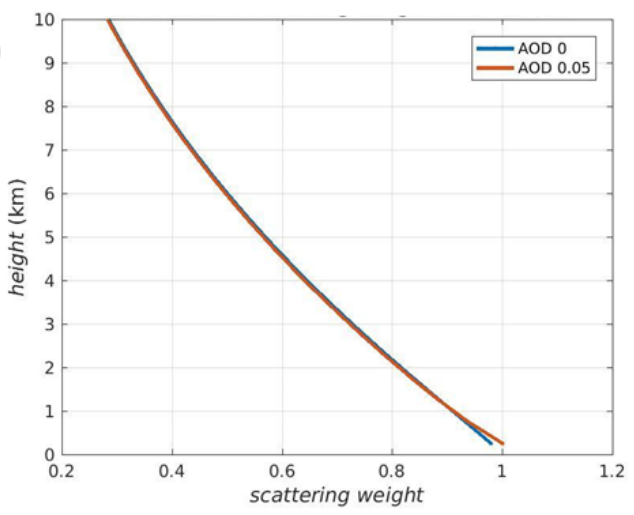

Figure 6.9. Influence of the aerosol loading on the box-AMF. Box-AMF for EVA $1^{\circ}$ in part a), and box-AMF for EVA $30^{\circ}$ in part b).

Due to the inherent complications of the inverse retrieval that have been already detailed in this chapter, the optimal fit is quite expensive in terms of both time and accuracy, because it is not easy to distinguish between irradiance extinction caused by the RTM itself and aerosol loading. Therefore, in order to estimate the light paths in a more rapid, easier way, we tabulated the relative shape of simulated $\mathrm{O}_{4}$ for a number of usual cases, trying to cover the typical aerosol values with enough resolution. For that purpose, we chose an exponentially decreasing aerosol profile with an altitude constant of $0.5 \mathrm{~km}$. Hence specifying the total AOD (which is the vertical integration of the aerosol profile) we can derive the aerosol vertical profile. We selected AOD values ranging from 0 (no aerosol loading) to 0.25 (significant amount of aerosol loading) in intervals of 0.01 (in optical density units). Subsequently, we simulated sets of $\mathrm{O}_{4} \mathrm{DSCD}$ for each case and all of them were registered. Finally, every measured $\mathrm{O}_{4}$ DSCD cycle using the MAX-DOAS installed in the Arctic was compared (in shape, using vectors normalized with respect to their mean value) to those tabulated vectors derived before. The closest tabulated vector was chosen as the most accurate solution for the aerosol loading, thus using a look-up table approach. Then, we did that for every MAX-DOAS cycle in the VRS measurements (MAX-DOAS installed in the Arctic, see section 7 for more details) in the years 2017 and 2018. Since there can be some fluctuations in the resulting values, and given the inherent uncertainties related to the look-up table approach, we took hourly averages to cancel out non-realistic high 
frequency variations. After that, the hourly light paths were calculated using the optimal, hourly-averaged, simulated AOD and its associated aerosol extinction vertical profile.

\subsubsection{Integrating over light paths}

The scattering coefficients describe the fraction of irradiance that is lost in a single scattering interaction, therefore the light that continues unaffected would be:

$$
I_{f}(\lambda)=I_{0}(\lambda)-I_{0}(\lambda) ß(\lambda)
$$

where $I_{0}(\lambda)$ and $I_{f}(\lambda)$ are the initial and final spectral irradiance, respectively.

In this process it is important to understand how much energy is scattered over a certain distance. In other words, at each point, the remaining light is subject to this process repeatedly. When light travels through a differential volume $d V$-considered a uniform medium- with a given scattering coefficient, the final irradiance that gets out of $d V$ is:

$$
I_{f}(\lambda)=I_{0}(\lambda) * \exp (-\beta * s)
$$

where $ß$ represents all of the scattering coefficients and $s$ the distance travelled by light within $d V$. Therefore, here we can already simulate the irradiance that would arrive at a MAX-DOAS instrument considering all of the possible scattering events. For this purpose, it is defined as a discrete three-dimensional grid generating cells of $d V$ where light propagates through, cubic cells of $1 \mathrm{~km}$ have been chosen.

The contribution to the scattered radiation by an infinitesimally thin layer at altitude $z$ is given by:

$$
I_{z, s}=I_{z} S_{R} * n_{\text {air }}(z) * E F * \Delta z
$$


where $I_{Z}$ is the radiation reaching the layer located at altitude $Z, S_{r}$ is the overall scattering cross section and $L, \Delta z$ are the sides of $d V$. Furthermore, $I_{Z}$ can be described by Equation 6.18. And $E F$ stands for the Enhancement Factor, i.e. how much longer is the actual photon path traversing the volume $d V$ in relation to its thickness $\Delta z$. In Figure 6.10, a geometry scheme divided by layers is depicted.

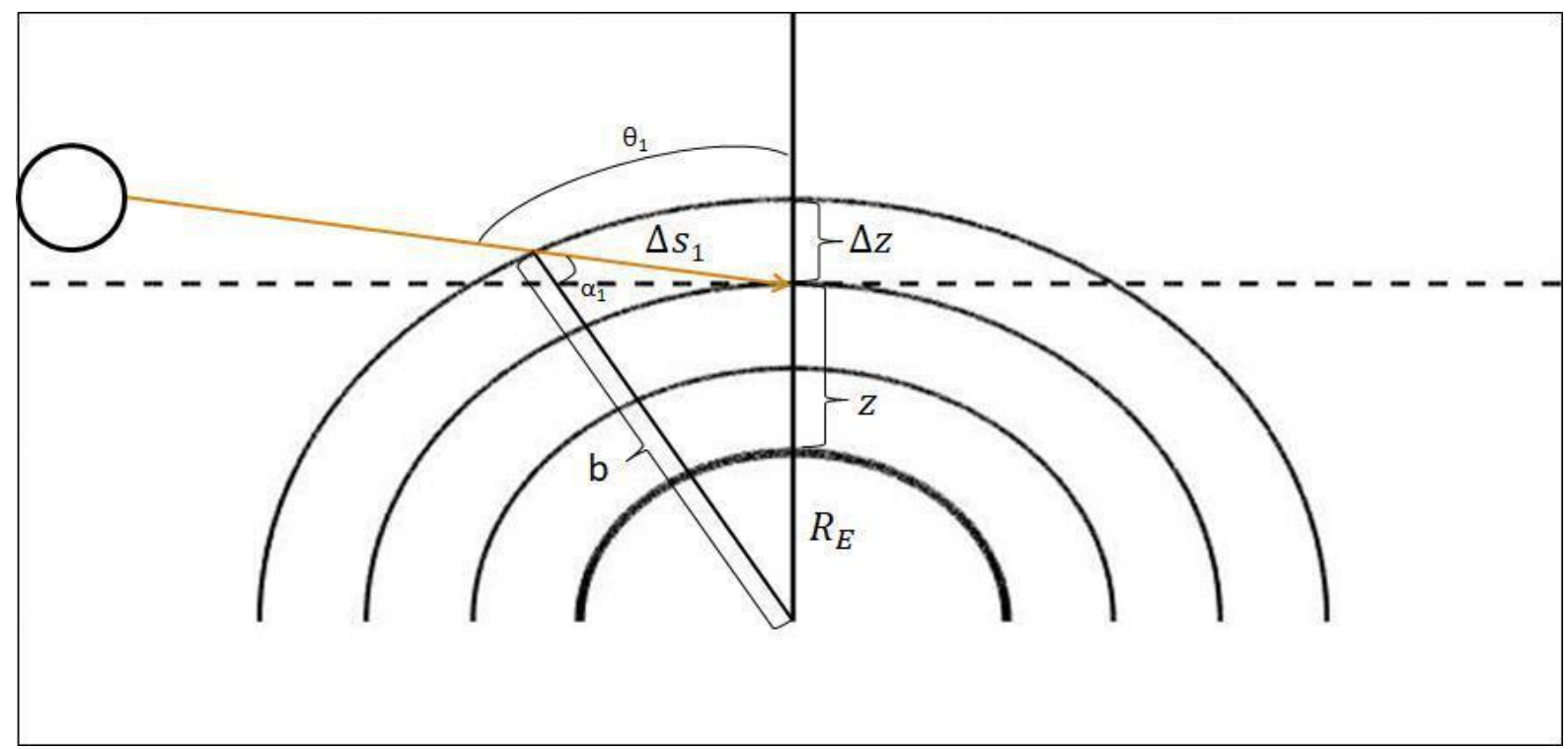

Figure 6.10. RTM geometry scheme.

By implementing these equations and summing over all of the cells, a vector of contributing intensities is estimated: each layer contributes with a relative irradiance to the total amount received at the light collector. Since we are dealing with relative intensities, a probability vector can be calculated normalizing the contribution intensities vector to one. This probability vector can be interpreted as the relative probability of a given collected photon coming from a certain layer.

\subsubsection{Scattering weights}

The box-AMFs describe the same as the AMF but for each layer. The collected photons do not follow a unique path, the registered spectrum consists of an ensemble of photons, each coming from different light paths. Since the scattering events can occur at 
any layer, different light paths need to be accounted for. The box-AMF for a layer $i$ is defined as:

$$
\text { box }-A M F_{i}=\frac{\Delta s_{i}}{\Delta z_{i}}
$$

here $\Delta s_{i}$ is the actual photon path inside layer $i$, whilst $\Delta z_{i}$ is the $i$-layer thickness. The scattering weights are calculated multiplying the probability vector times the box-AMF vector. They symbolize the contribution of a layer $i$ to the absorptions of a given species:

$$
\text { scd }=S W * \text { profile }
$$

Figure 6.11 shows an example of the scattering weights calculated for a MAX-DOAS vertical cycle in the Arctic. Note that the scattering weight vector of each EVA strongly responds to its surrounding layers: lower EVA scattering weights result in maximum values at lower altitude layers, and vice versa.

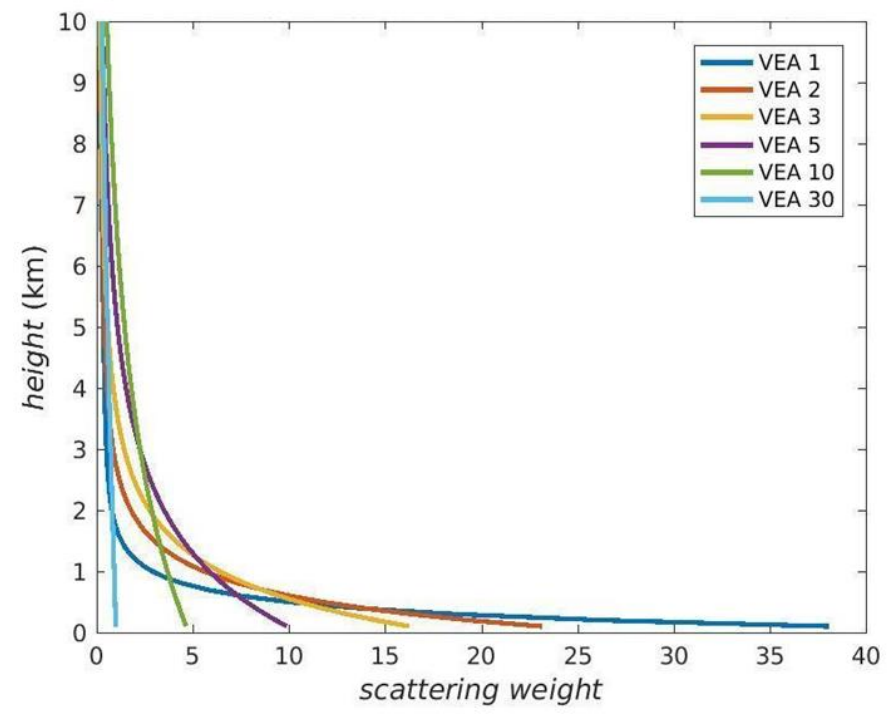

Figure 6.11. Scattering weights for a MAX-DOAS cycle at noon on May 10, 2017 in the high Arctic. 


\subsubsection{Multiple scattering and albedo}

The multiple scattering contribution can be estimated by letting single, outscattered photons to be in-scattered again into the light collector. In multiple scattering, the probability of a scattering event is relatively low, and a multiple scattering event includes several scatterings, in this case the scattering probability follows an exponential function, thus largely decreasing the contribution of high-order scatterings. Our RTM code only takes into account multiple scattering of second order. There are some studies which propose that the high-order multiple scattering contribution is negligible (Rozanov et al., 2010). In Figure 6.12, the effect of the multiple scattering is shown: although it may look small, a careful look at the lower altitudes shows an increase of the scattering weight values in the order of $10 \%$, which is in line with previous multiple scattering impact studies.

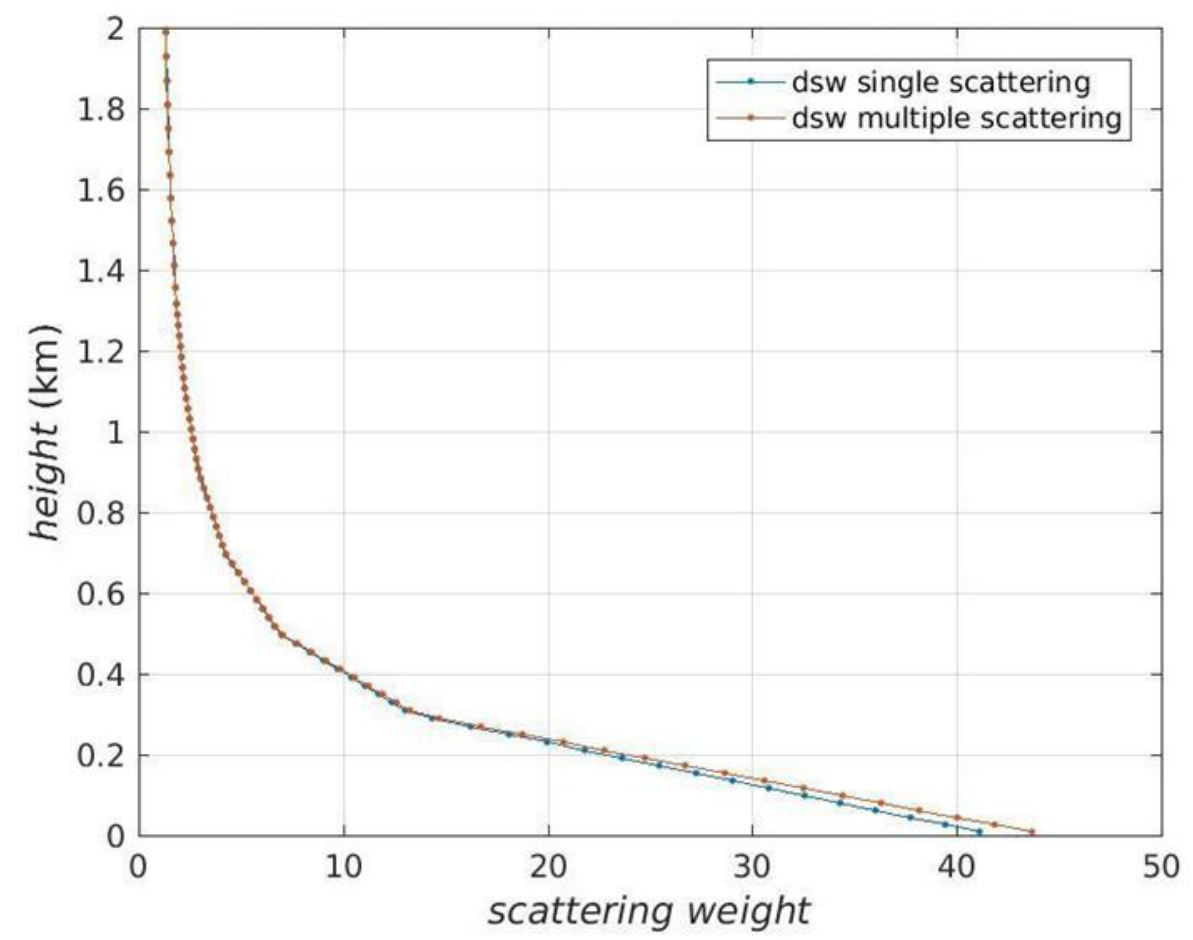

Figure 6.12. Influence of multiple scattering on the scattering weights for an EVA $1^{\circ}$. 
Surface albedo can be considered as a multiple scattering event, but the remaining ideas endure. Finally, both multiple scattering and albedo were included in our codes, allowing a better description of these atmospheric processes.

\subsection{Uncertainties}

The precision of the MAX-DOAS calculations mainly involves two main contributions:

- The uncertainties from the DOAS spectral analysis.

- The uncertainties of the profile retrieval.

Assuming they are independent, the overall uncertainty of the analysis is estimated propagating these two main uncertainty sources. It is worth noting that, although the absorption cross sections of the trace gases are considered as tabulated, they indeed have uncertainties, sometimes quite noticeable. Nonetheless, for the MAX-DOAS analysis, the cross sections are assumed as tabulated constants although their uncertainties are taken into account in the overall propagation of uncertainties. 


\section{DEVELOPMENT OF A NEW MAX- DOAS FOR POLAR OBSERVATIONS}

In this chapter the construction of a new MAX-DOAS instrument in our laboratory is described. It was installed in the Arctic (Station Nord) and therefore its design was adapted to cope with the extreme Arctic conditions.

\subsection{Instrument description}

Briefly, this instrument consists of a light collector that scans the atmosphere at different altitudes driven by a stepper motor attached to it. That means that light collected in every measurement at a given EVA of the instrument comes from different altitudes (layers) of the atmosphere. Subsequently, the light travels through the optical fibre up to the spectrometer. When the light is inside the spectrometer, it is scattered by the diffraction grating and recorded by the detector (a Charge-Coupled Device, CCD sensor). The spectrum is collected in the near UV region and in the Visible region.

The collector and the rest of the instrument are separated by an individual optical fibre. This allows us to put the collector outside (on top of the laboratory roof) and the rest of the instrument in the laboratory, with the benefit that the sunlight is not lost throughout this process.

Sometimes, it is necessary to use two or more subsystems (e.g. two diffraction grids) to work in different wavelength regions with good spectral resolution and a good dynamic range. Alternatively, one can use two spectrometers. Specifically, this MAX-DOAS 
instrument has two spectrometers, one for the UV range (roughly 300-400 nm) and the other for the VIS bound (400-500 nm approximately).

\subsubsection{External Unit}

The External Unit is made of a temperate, airproof steel box with a door on one side. The top window has an inclination of $45^{\circ}$ in order to avoid snow accumulation. The windows are made of methacrylate material and are hermetically closed. The mean spectral transmittance of these windows is 0.96 in the measurement range (300-500 nm). Before the set-up, we studied the sensitivity of the windows with respect to both the spectral transmittance and the light polarization. The conclusion is that these variations are negligible and are therefore not important in the spectral analysis. Moreover, since we will be dealing with DSCDs, which compare spectra taken at different EVAs, most of the instrumental spectral effects (including the transmittance of the windows) should be cancelled out.

Inside the box, we installed a mobile arm operated by a stepper motor, which ensures the position with an accuracy less than $0.1^{\circ}$. The collector is attached to it and includes a lens to receive the light $(25.4 \mathrm{~mm}$ diameter and $100 \mathrm{~mm}$ focal). The collector field of view is $0.4^{\circ}$ for each optical fibre. The light, received by the collector, is directed to the Spectrometer Module by two optical fibres with a diameter of 600 microns and a length of $10 \mathrm{~m}$ with no interruption. These fibres are inside the cable and they are separated before the Spectrometer Module and then, they go into each spectrometer.

The External Unit contains a shutter (device that blocks the light input) that allows us to measure the dark current ("zero instrumental" estimation) periodically. This shutter acts as support for discharging the Hg-Ne lamp (pencil lamp) used to auto calibrate the spectrometers in wavelength (Figure 7.1). This unit is covered by thermal and waterproof materials. They are intended for insulating the steel box from the external conditions, and the material they are made from is polystyrene X-FOAM (40 mm) (Figure 7.2). In addition, 
we installed one insulating layer that reflects the IR radiation and one elastic waterproof lining Sikafill. This lining avoids water accumulation inside the external part. We also installed an external vinyl cover to resist polar extreme weather conditions (Figure 7.2).

This External Unit is heated by four thermo-resistors. A fan was installed, and it is in charge of keeping a homogenous temperature inside the External Unit. Furthermore, a Nano Arduino reads the internal temperature and it works independently to keep the temperature constant. The temperature is kept at $5^{\circ} \mathrm{C}$ with some temperature variations but never lower than $\pm 0.25^{\circ} \mathrm{C}$. Some Silica gel bags are added to avoid the humidity inside the box (Figure 7.1). The goal to keep the temperature at $5{ }^{\circ} \mathrm{C}$ and as dry as possible is to avoid water condensation and ice or frost from forming on the windows. We can continuously supervise the window conditions because there is a camera installed on the collector, and it takes and saves images of the window periodically.

In addition, this unit has another camera to take some sky images. The orientation of this camera is the same as the VAA of the instrument and it is fixed at $20^{\circ}$ above the horizon. The camera has a field of view of roughly $120^{\circ}$ width and $80^{\circ}$ high. Images are saved and a specific cloud cover code (which will be described later) estimates the cloud index from each photo. 


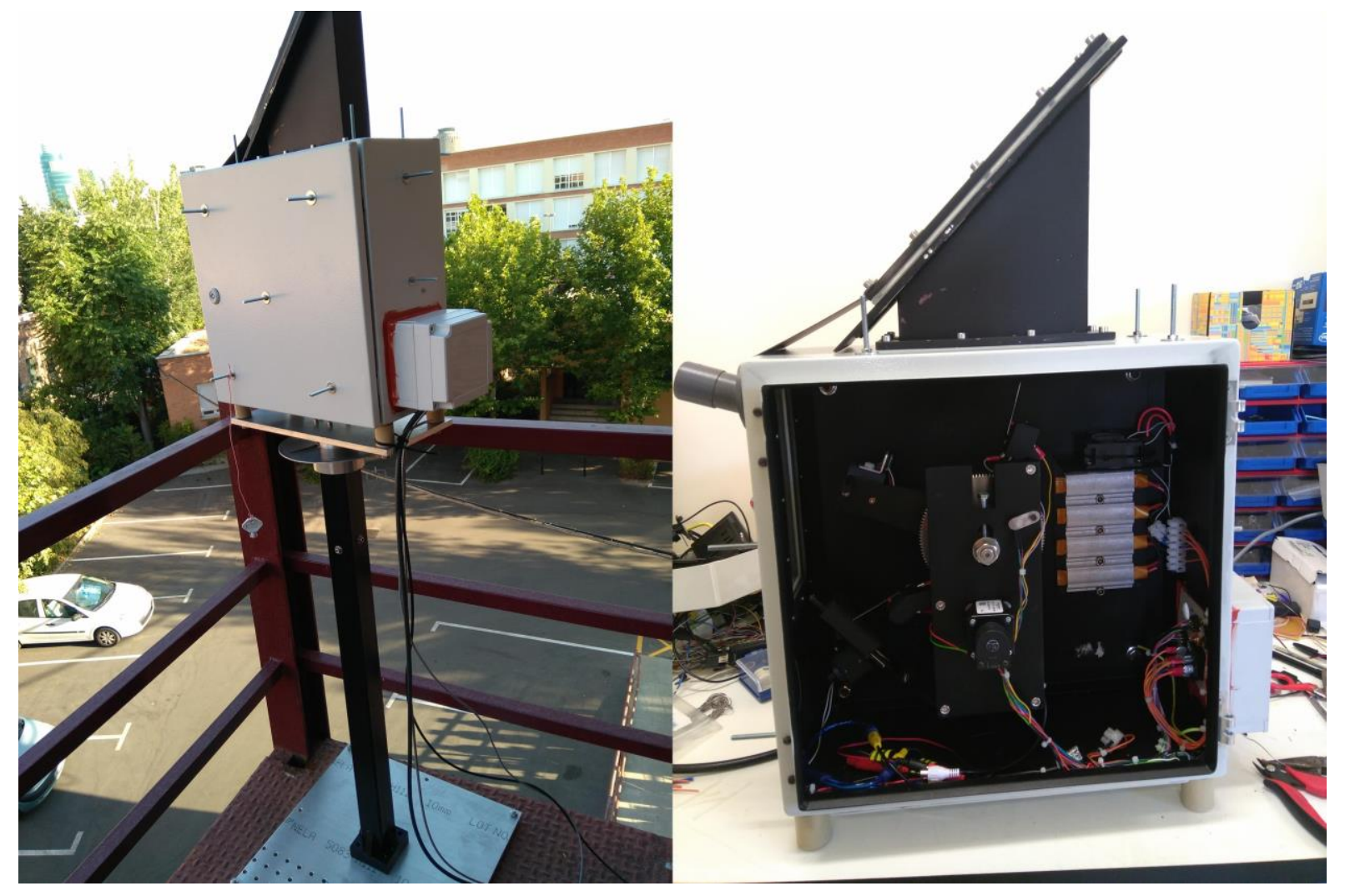

Figure 7.1. MAX-DOAS instrument without the insulation layer and the tracking box.

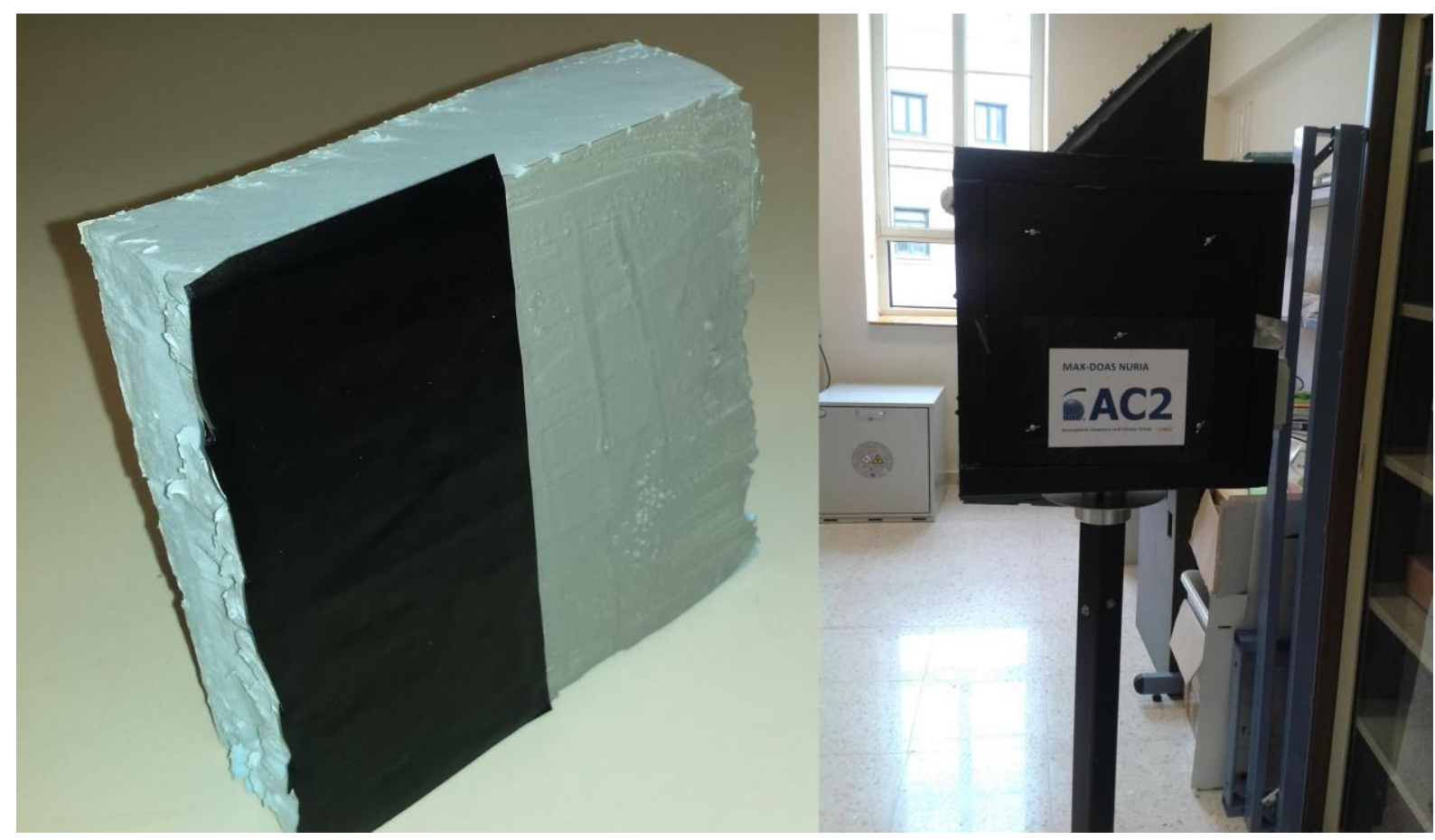

Figure 7.2. Cover layer of the External Unit and the outer layer of the External Unit. 


\subsubsection{Internal Unit}

The Internal Unit is located inside the laboratory. It consists of three modules: Power Supply Module, Control Module and Spectrometer Module.

-Power Supply Module: contains all the power supplies that the MAX-DOAS needs. The MAX-DOAS is connected to an Uninterruptible Power Supply (UPS) in order to keep the instrument running if there is a power cut and also to absorb any possible power peaks. The Power Supply Module is shown in Figure 7.3.

-Control Module: it has a NUC PC to control the entire instrument along with an Arduino that automatically keeps track of the temperature in the External Unit (Figure 7.4). Additionally, within this module, there is an external hard drive disk with a capacity of 1 TB to save the data. This external disk can be easily accessed and changed when needed; the exchange can occur without switching off the computer or stopping the measurements. Figure 7.4 shows the Control Module, in which the red lines represent the power supply and the dark blue lines represent the electrical signal.

-Spectrometer Module: comprises an independent unit and the power supply. This includes two Ocean Optics spectrometers type Flame $T$, each of them measuring in the UV and VIS spectral regions, respectively. These two spectrometers have an automatic thermal stabilization made by a Nano Arduino to keep the temperature in the spectrometers as constant as possible (Figure 7.3).

The spectrometers have the following technical specifications:

- $\quad$ Spectrometer Flame T-UV: region (298-447 nm), 50 $4 \mathrm{~m}$ slit, detector Toshiba TCD 1304AP with 3648 pixels, holographic grating with 2400 lines $/ \mathrm{mm}$. 
- $\quad$ Spectrometer Flame T-VIS: region (392 - $522 \mathrm{~nm}$ ), $25 \mu \mathrm{m}$ slit, detector Toshiba TCD 1304AP with 3648 pixels, holographic grating de 2400 lines/mm.

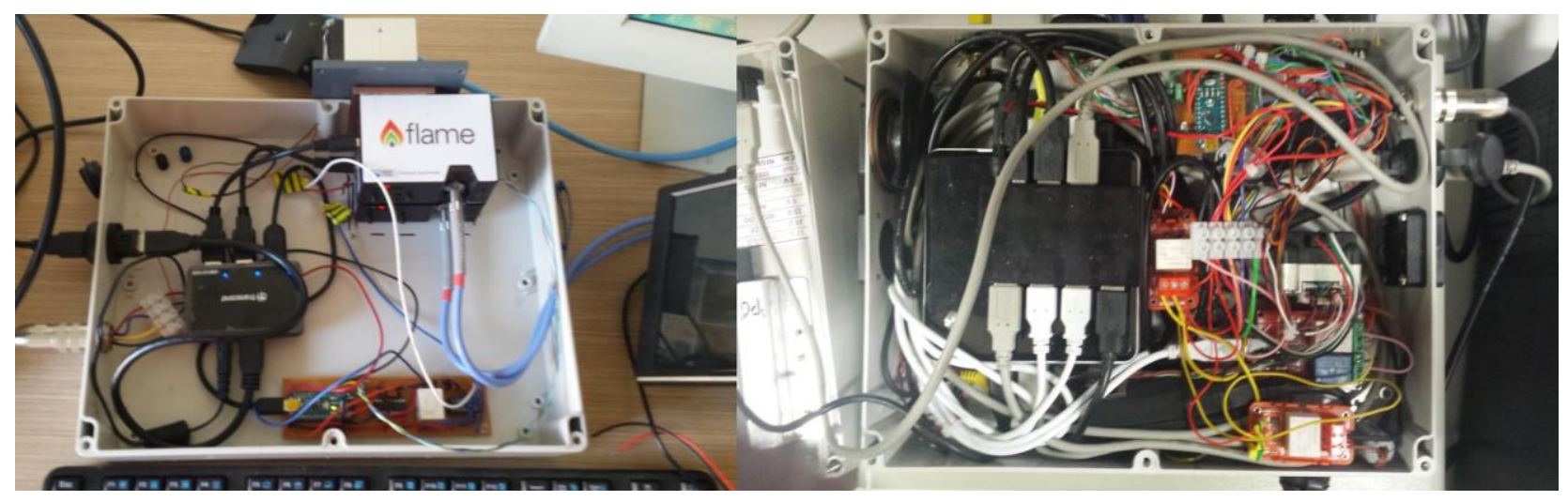

Figure 7.3. Spectrometer Unit and Power Supply Unit.

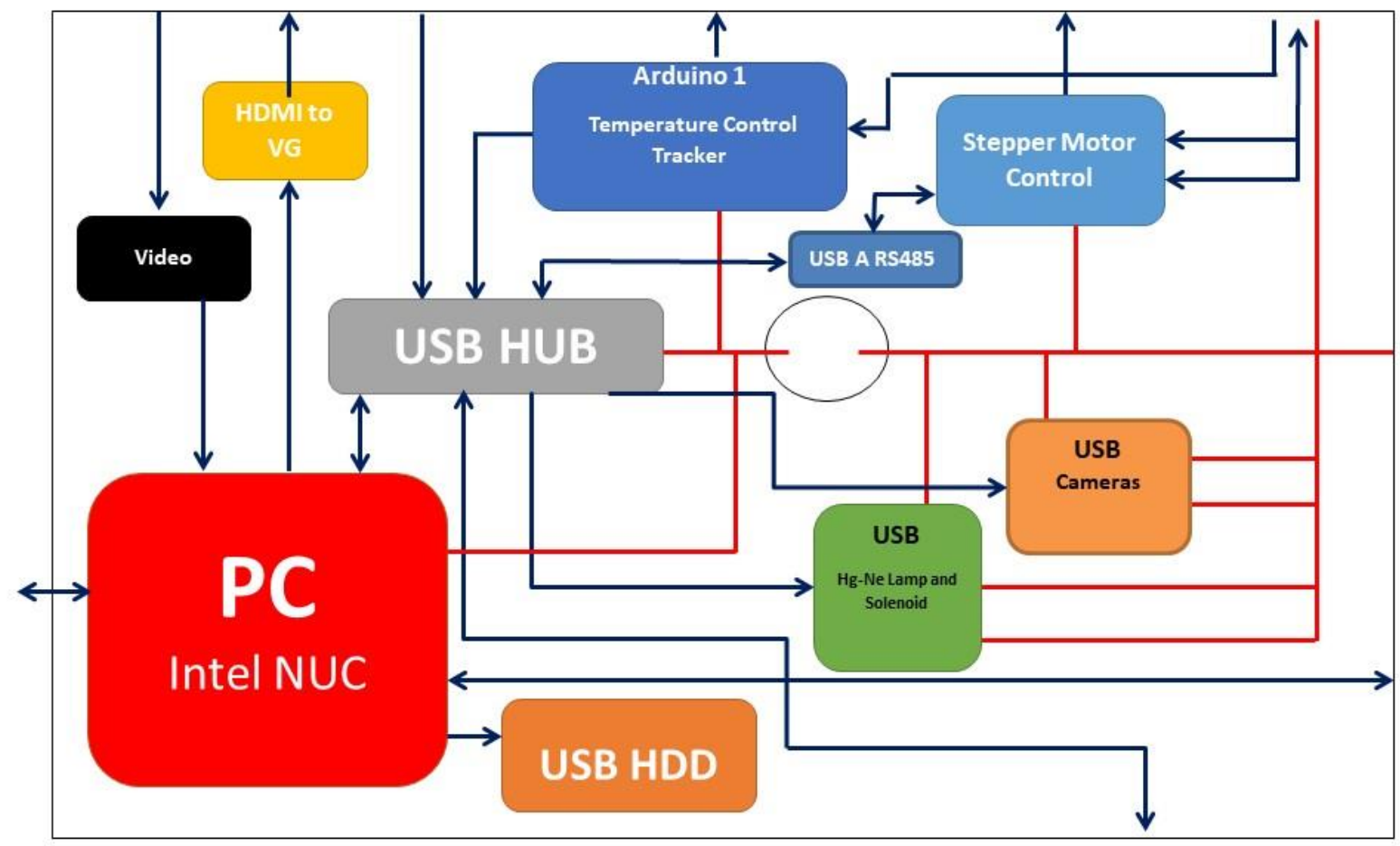

Figure 7.4. Control Module. 


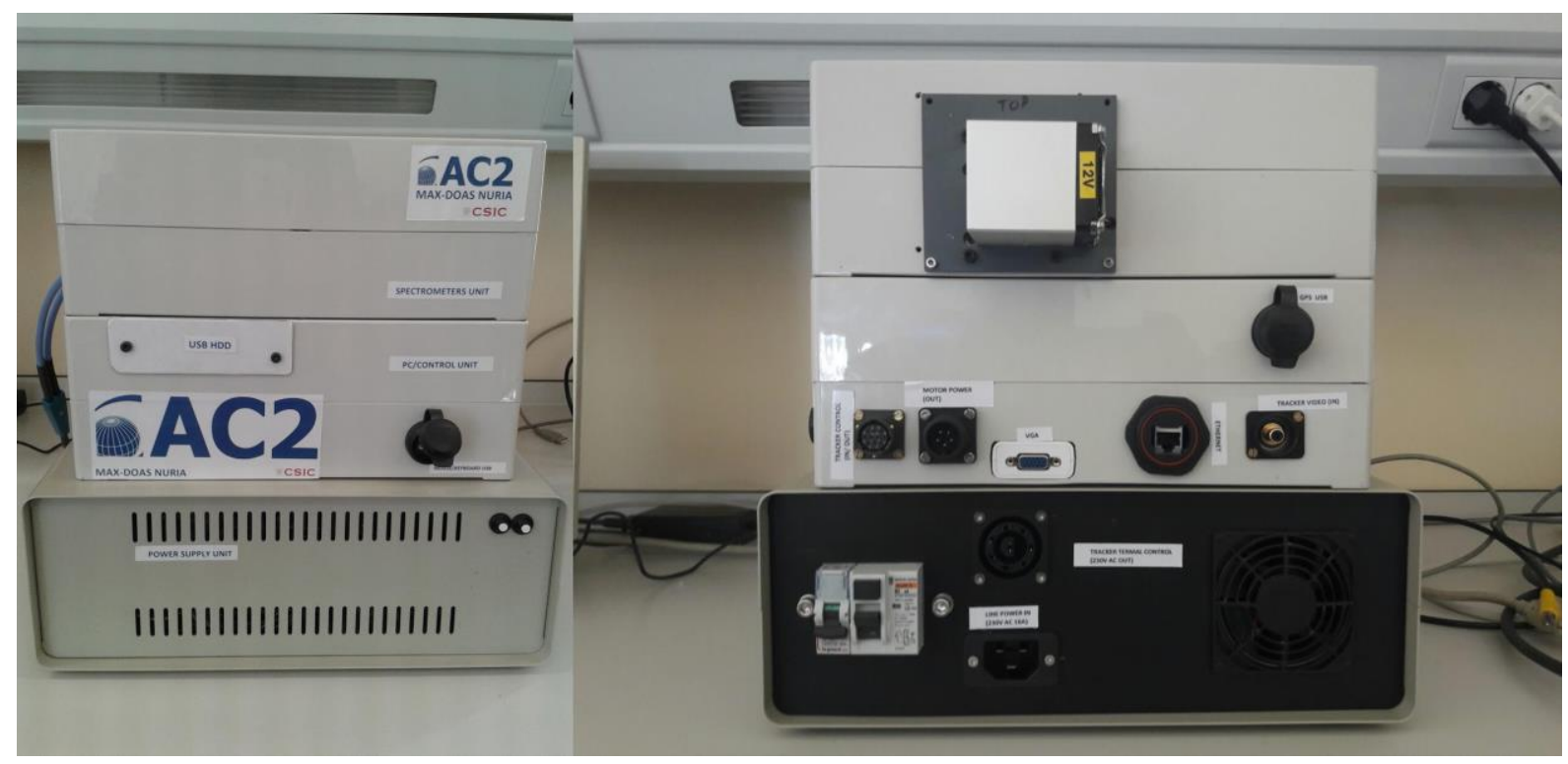

Figure 7.5. Complete Internal Unit part.

\subsection{MAX-DOAS software}

As soon as the Intel NUC PC receives power and starts up, the measurement software will automatically begin. Figure 7.6 depicts the MAX-DOAS software interface. 


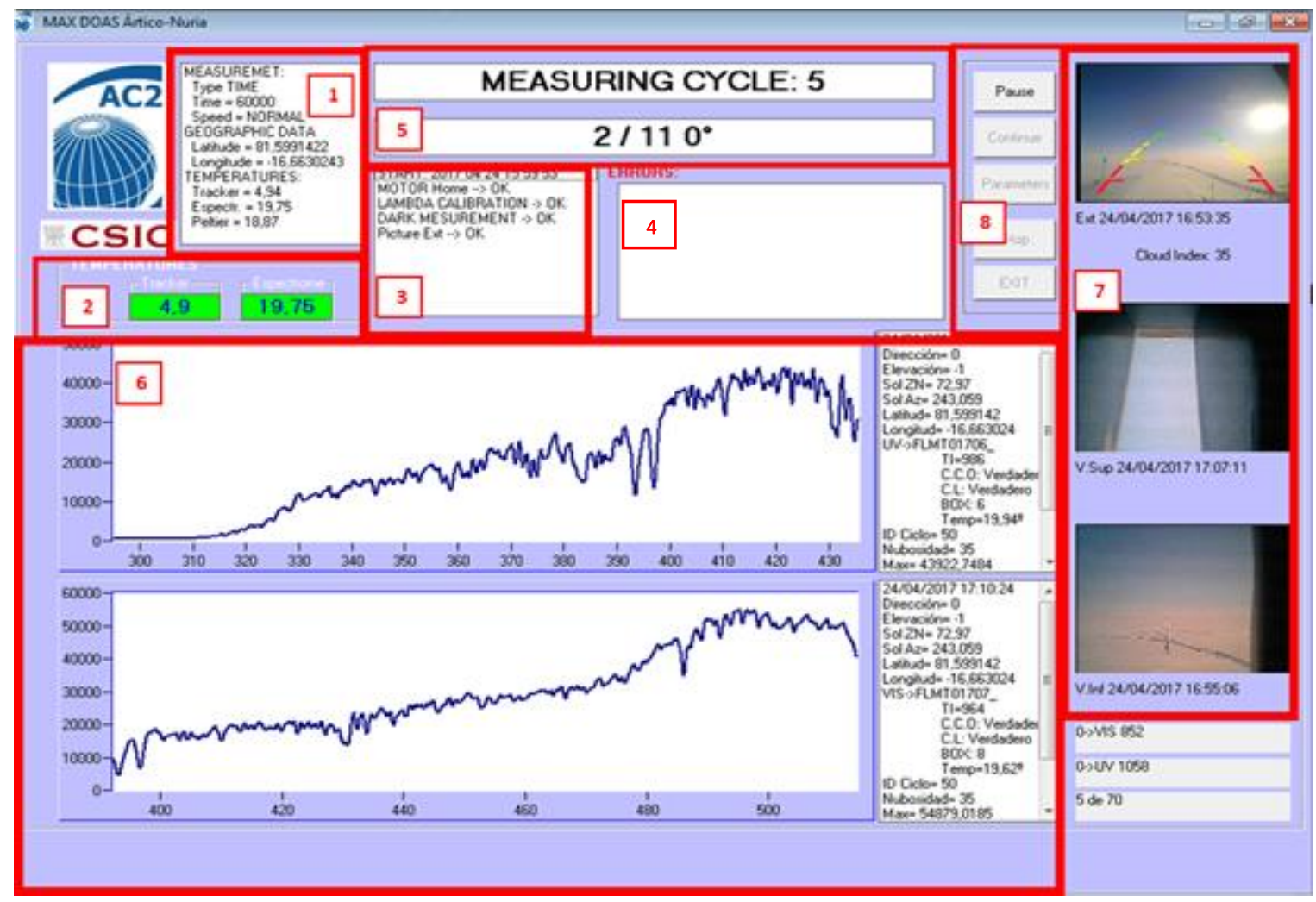

Figure 7.6. MAX-DOAS software main screen.

The interface of the MAX-DOAS software shown in Figure 7.6 includes the eight main parts in which the interface is divided:

- 1: measurement parameters, actual localization (latitude and longitude) and temperatures: tracker, spectrometers and Peltier cell.

- 2: again the temperatures of the tracker and spectrometers are included. But here a colour code is added: green indicates an OK temperature, an orange square means that the temperatures are not in the optimal range, while an ERROR message in red signals that something might be turned off or broken.

- 3: here we can observe the last instrument reset time. It also checks if the wavelength calibration, the zero measurement and the sky picture all work correctly.

- 4: any error that may happen is shown in this square.

- 5: general status of the measurement. 
- 6: plot of the last acquired spectra, along with their acquisition parameters.

- 7: in this column the last outdoor pictures as well as the time they were recorded and an estimation of the cloud index are shown.

- 8: action buttons to pause (the instrument stalls for 15 minutes and will automatically resume the measurements after 15 minutes), stop and continue the measurements. There is also a direct access to the parameters window, which will be addressed below.

Parameters window: we can modify at any time the parameters with which the MAX-DOAS instrument operates. Figure 7.7 shows the parameters window, which includes the EVA, the optimal temperature of the spectrometers, the latitude and longitude and some other magnitudes, all of which can be adjusted.

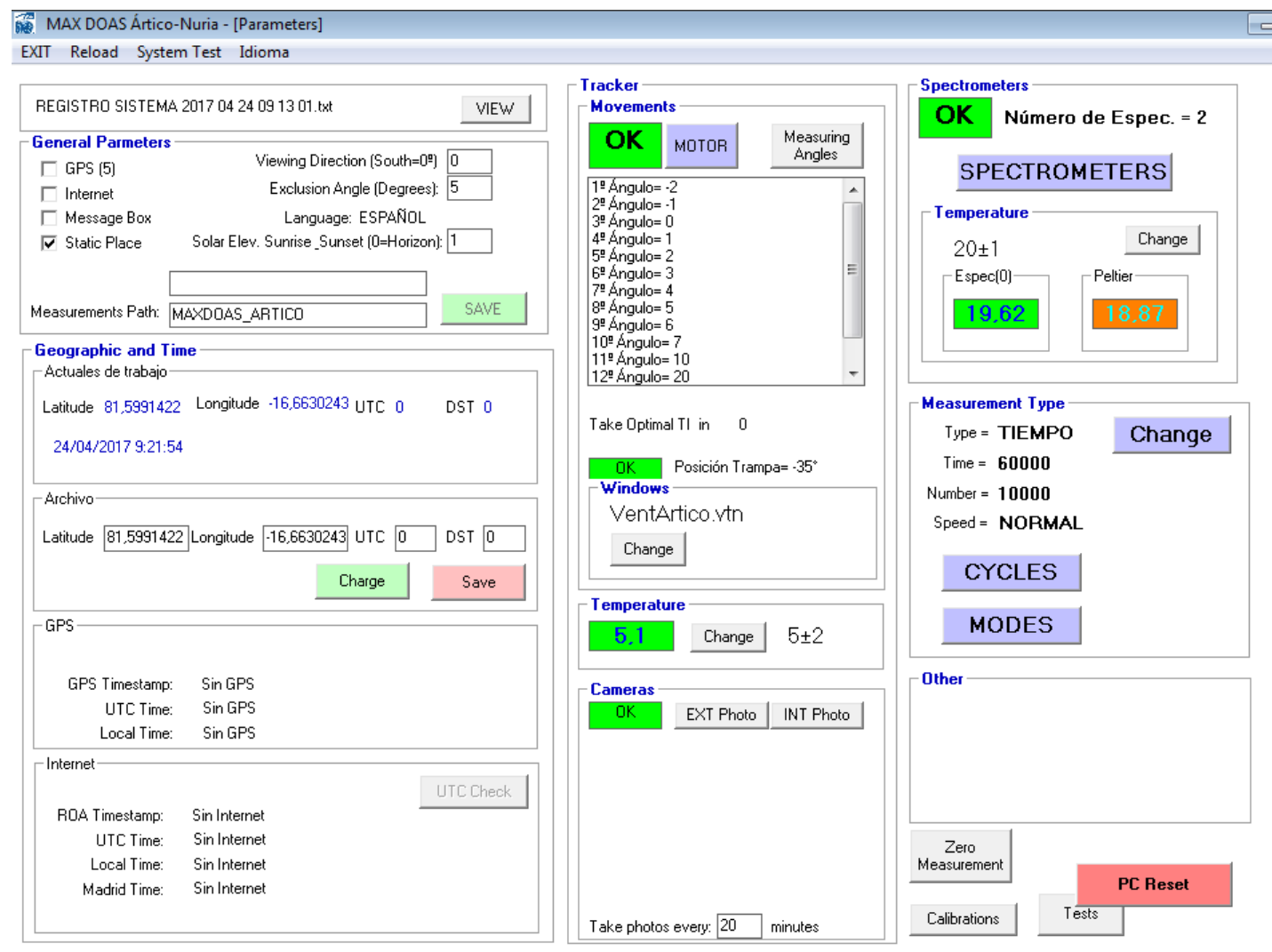

Figure 7.7. Instrument parameters screen 


\subsection{Instrument characterization}

\subsubsection{Cloud Index calculation}

MAX-DOAS measurements are affected by clouds, due to multiple scattering effects that lead to larger uncertainties in the retrieval or bad quality data in the results. For this reason, the could-contaminated database has to be marked and excluded. Aerosols and trace gas profile retrievals typically assume clear-sky conditions in the RTM. It is therefore needed to estimate the Cloud Index $(\mathrm{Cl})$, which is defined as the percentage of clouds in the atmospheric cover through the instrumental field of view.

The MAX-DOAS instrument is installed in the extreme Arctic conditions without any person continuously looking after it, and for this reason it is important to know when the $\mathrm{Cl}$ is high. The cloud index calculation code was made and installed in the software to automatically estimate the $\mathrm{Cl}$, and this parameter is assigned to every spectrum taken from the MAX-DOAS. This $\mathrm{Cl}$ code runs in the following way:

1. It takes the photo from the webcam.

2. It cuts the photo in order to get the portion that contains the sky.

3. The code gets the RGB coordinates -the three chromatists of the red, green and blue- and it transforms them into LCh coordinates - L indicates lightness, $C$ represents chroma (distance from the lightness axis $(L)$ ) and $h$ is the hue angle (it is expressed in degrees and it starts at the $+a$ axis).

4. The luminosity, colour and saturation are adapted.

5. Criteria are established to distinguish three variables: cloud, Sun and blue sky.

6. Once the criteria are met, the code estimates the cloud index following this equation:

CI $(\%)=($ clear sky pixels/total pixels $) * 100$ 


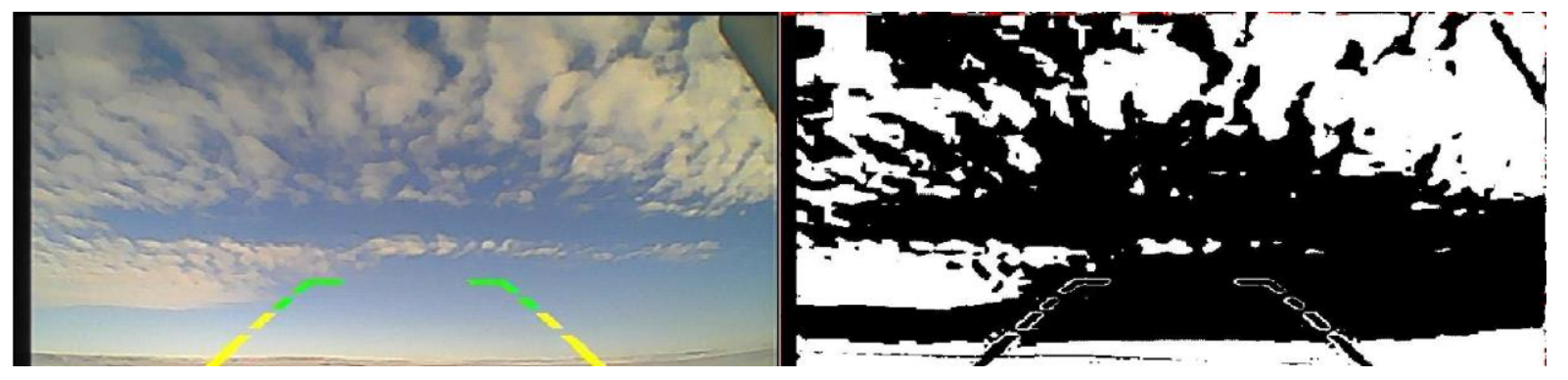

Figure 7.8. Cloud index estimation for a cloudy sky.

Figure 7.8 shows the original photo on the left and the corresponding simulation by our homemade cloud index estimation code on the right, including black pixels as clear sky and white pixels as no-clear sky. The code is able to detect the cloud cover, in this particular example, the code estimates a $\mathrm{Cl}$ of $41 \%$.

The code can also fit the Sun separately and remove it from the $\mathrm{Cl}$ estimation. Figure 7.9 shows in the left part an original photo with the Sun over the horizon and in the right part the associated simulation by the code, in which the Sun is depicted by yellow pixels. The $\mathrm{Cl}$ of this photo is $100 \%$, corresponding to clear sky.

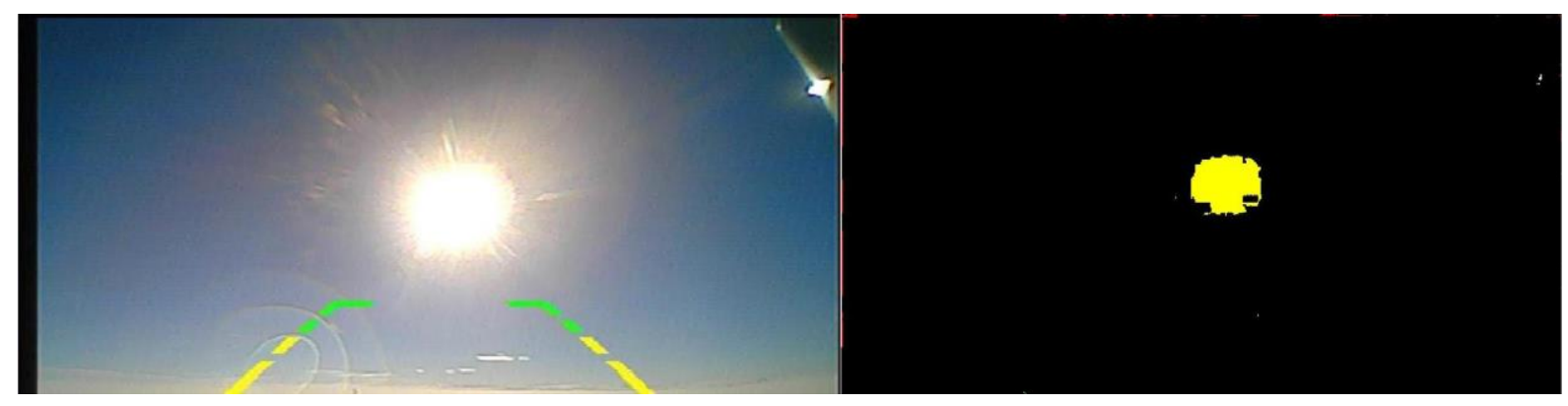

Figure 7.9. Cloud index estimation when the Sun is present.

\subsubsection{Weather proof tests}

In order to assess the low temperatures tolerance of the instrument, the following verification was carried out in our laboratory before the installation in the Arctic. The External Unit, the cables and the optical fibre were introduced in a freezer. After some hours inside, the instrument was checked in order to observe if it was working well. There are 4 
thermo-resistors in the instrument to keep the temperature constant inside the External Unit, for this reason and within the purpose of studying the instrument behaviour under polar temperatures we inserted dry ice -solid form of carbon dioxide- in the freezer, providing lower temperature than water ice and without leaving any residue. The lower temperature reached in the freezer was $-44^{\circ} \mathrm{C}$ and it was recorded every 20 seconds during some hours.

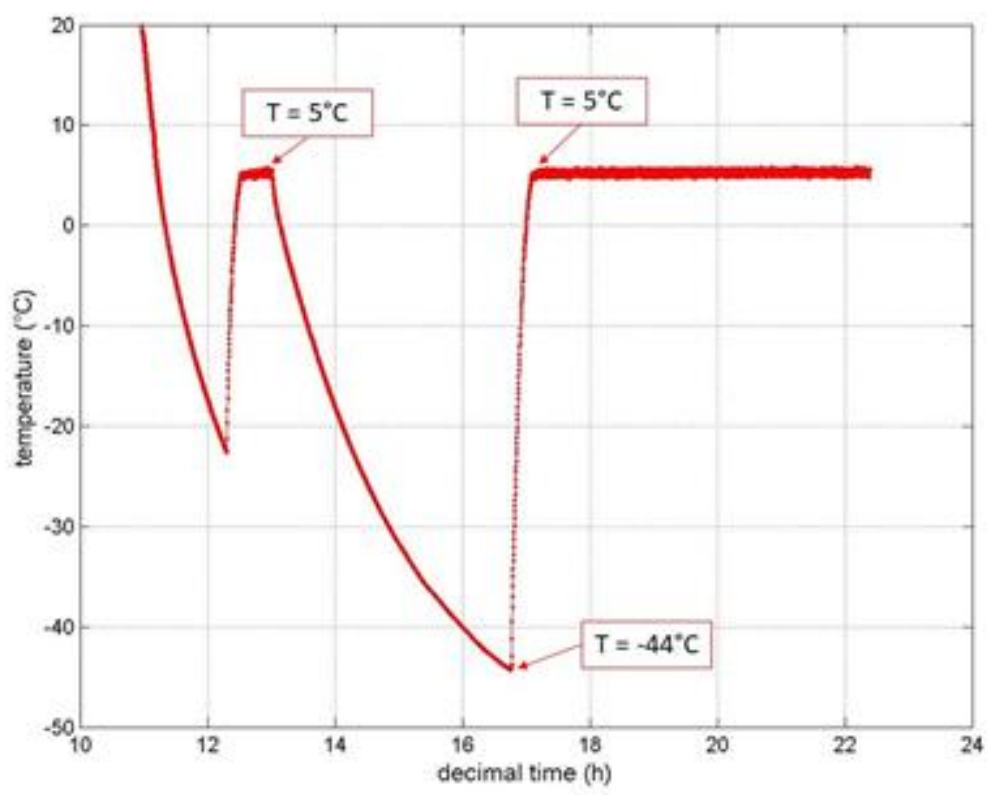

Figure 7.10. Polar proof temperature tests.

We can see in Figure 7.10 that heating in the External Unit works correctly, the temperature quickly increases up to $5{ }^{\circ} \mathrm{C}$-which was the goal temperature- when the resistors are activated. The thermo-resistors were switched on two times at $12.2 \mathrm{~h}$ and at $16.5 \mathrm{~h}$, and at those times the temperatures were -21 and $-44^{\circ} \mathrm{C}$, respectively. Once the thermos-resistors started to heat up the instrument, the temperature quickly increased until $5{ }^{\circ} \mathrm{C}$ were reached. 


\subsection{Arctic installation and measurement site}

Once the instrument was ready, it was transported and installed at Villum Research Station (VRS) in April 2017. VRS is owned by the Greenland Government and is being operated by the Aarhus University (Denmark) in cooperation with the Danish Defence (the Arctic Command). It was opened in 2015 at the military outpost Station Nord, in the high Arctic North Greenland. VRS is located at a latitude of $81^{\circ} 36^{\prime} \mathrm{N}$ and a longitude of $16^{\circ} 40^{\prime} \mathrm{W}$, in the Princess Ingeborn Peninsula, in northern Kronprins Christian Land as shown in Figure 7.11. The station is funded by a Danish private fund, the Villum Foundation.

The weather in Station Nord is typically Arctic, its characteristics are very cold polar tundra climate, the temperatures could reach $-33^{\circ} \mathrm{C}$ in winter and $14{ }^{\circ} \mathrm{C}$ in summer. Sunlight hours change throughout the seasons. During summer the Sun is over the horizon 24 hours per day, but in winter there is no Sun over the horizon, it means that the MAX-DOAS cannot work during winter time. The climate in Station Nord is cold and dry, with an annual mean precipitation of $188 \mathrm{~mm}$. Moreover, the average wind speed is $4 \mathrm{~m} \mathrm{~s}^{-1}$, but storms with wind speeds at $20-30 \mathrm{~m} \mathrm{~s}^{-1}$ occur regularly. VRS consists of three main blocks: an accommodation building, an atmospheric observatory and a garage. The station is open for access throughout the year, and it can host up to 14 scientists at a time (Figure 7.11).

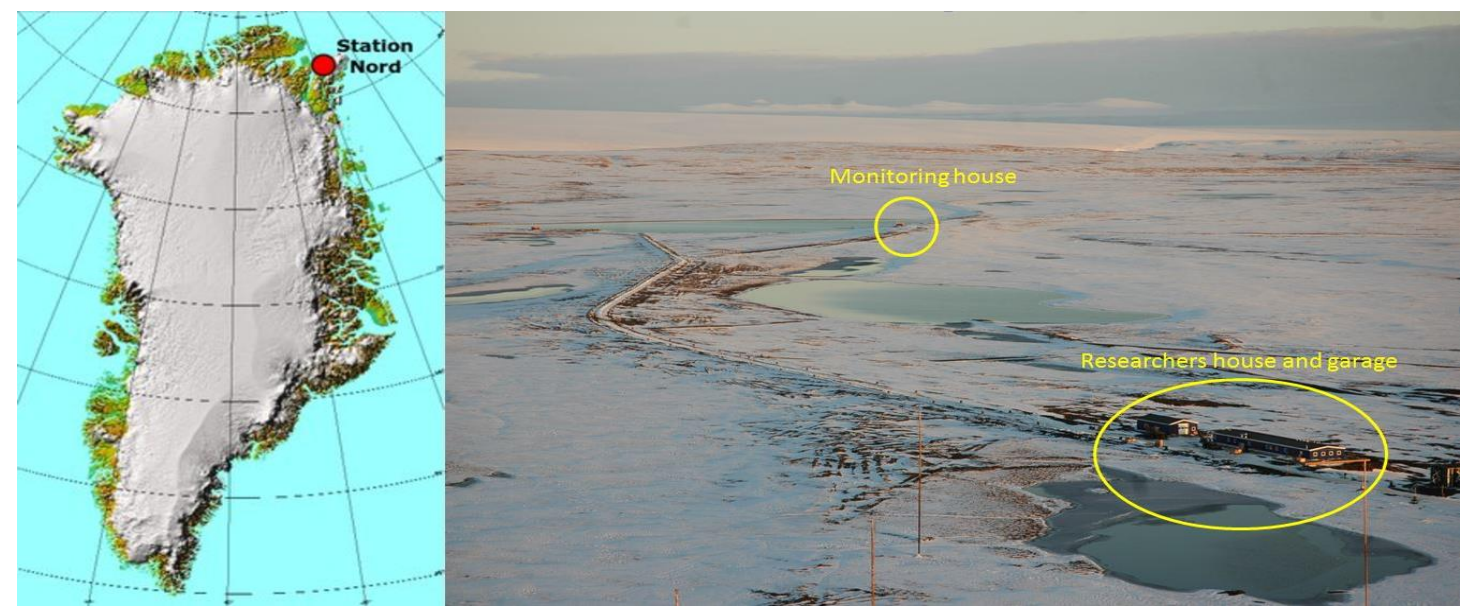

Figure 7.11. Station Nord location (taken from villumresearchstation.dk) and VRS (photo taken by Bjarne Jensen). 
The instrument was installed in the atmospheric observatory or monitoring house. Regarding other equipment operating at VRS, the accommodation house includes four laboratories: dirty laboratory, chemical laboratory, microbiological laboratory and cleaner laboratory (only access with permission). The atmospheric observatory comprises two laboratories: continuous monitoring (limited access) and field campaign laboratory.

The External Unit was placed on the roof of this laboratory (Figure 7.12), and the Internal Part was set up inside this place with a constant temperature of $15^{\circ} \mathrm{C}$. Therefore, the software was prepared so that the instrument was measuring continuously during the sunlit hours, and when the Sun reaches at SZA higher than $90^{\circ}$, the MAX-DOAS automatically shuts down until the SZA is again at $90^{\circ}$ or lower. The MAX-DOAS instrument was setup to measure in the following EVAs: $0,1,2,3,5,7,10,30,90^{\circ}$. The viewing azimuth angle is $183^{\circ}$ (measured eastwards with respect to the North). One MAX-DOAS cycle takes roughly 10 minutes (from an EVA of 0 to $90^{\circ}$ ). This MAX-DOAS instrument is the most northerly situated of all the MAX-DOAS in the Arctic. It is the first instrument with these characteristics permanently installed in the Arctic. This thesis included the collection and analysis of data from April 2017 to October 2018. Note that the instrument and the measurements are still ongoing since its installation in April 2017. 

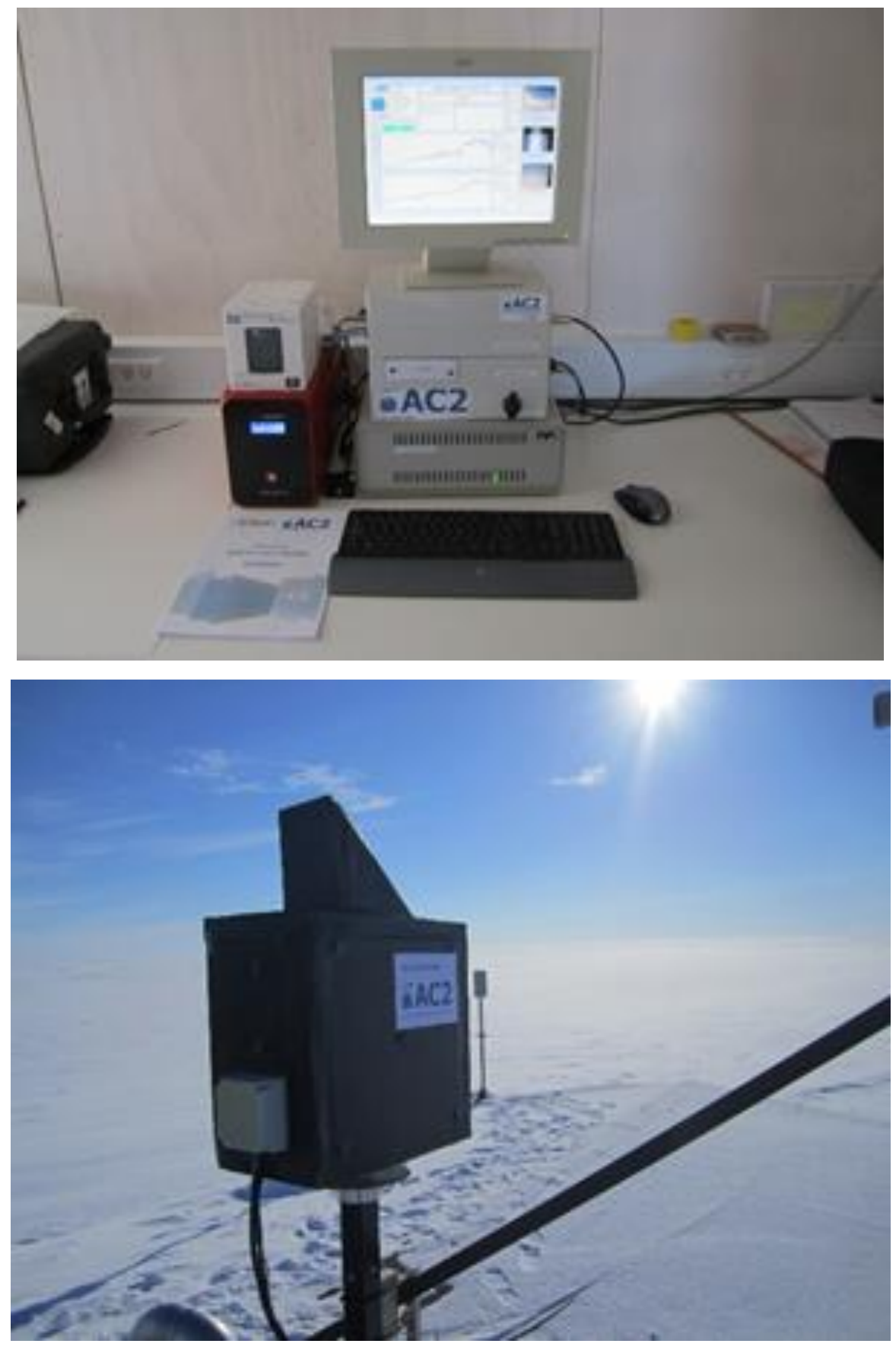

Figure 7.12. MAX-DOAS installed in the Villum Research Station. 


\section{MAX-DOAS HALOGENS}

\section{MEASUREMENTS IN THE ARCTIC}

A new MAX-DOAS instrument was developed for this thesis, and subsequently installed in the Arctic as mentioned in the previous chapter. The DOAS technique was used to retrieve the column densities of $\mathrm{BrO}$ and $\mathrm{IO}$. Note that only spectra below a $\mathrm{Cl}$ of $40 \%$ were further taken into account. The $\mathrm{BrO}$ and $\mathrm{IO}$ spectral absorptions were measured for two entire years: 2017 and 2018. BrO was analysed in the UV region and IO using the VIS region. The measured optical density was adjusted to the selected differential absorption cross sections using the QDOAS software and then the handmade RTM described in Chapter 6 was applied to retrieve vertical concentration profiles of these halogen oxides. Finally, a long-term assessment, as well as a study of its implications for ozone within the Arctic boundary layer has been carried out.

\subsection{Bromine monoxide results}

As briefly outlined in Section 3.2, bromine chemistry is important in the polar atmosphere as it drives catalytic ozone destruction cycles. For this reason, in this section we explore the values of $\mathrm{BrO}$ in the Arctic atmosphere during the years 2017 and 2018.

For the BrO retrieval, and considering the difficulties of the spectral analysis, several sensitivity tests have been performed in order to quantify any systematic uncertainties. First, we compared the results from two different choices of reference spectrum for the MAX-DOAS analysis: scan mode (i.e. selecting the zenith spectrum of each MAX-DOAS vertical cycle of measurements) and noon mode (-the one with the smallest SZA of the day- 
is chosen as reference). Theoretically, both choices should smoothly couple together and we can convert from one another using the following set of equations that defines each mode:

$$
\begin{aligned}
& \text { SCAN: } D S C D_{i}=S C D_{i}-S C D_{90} \\
& { }_{D S C}{ }_{90}=0
\end{aligned}
$$

NOON: $D S C D_{i}=S C D_{i}-S C D_{\text {noon }}$

$$
D S C D_{90}=S C D_{90}-S C D_{\text {noon }}
$$

If we wanted to transform the noon DSCDs into their scan mode equivalent DSCDs, we should apply the following conversion:

$$
\begin{aligned}
& D S C D_{\text {i noon }}-D S C D_{90 \text { noon }}=S C D_{i}-S C D_{\text {noon }}-\left(S C D_{90}-S C D_{\text {noon }}\right)= \\
& S C D_{i}-S C D_{\text {noon }}-S C D_{90}+S C D_{\text {noon }}=S C D_{i}-S C D_{90}
\end{aligned}
$$

We compared the measured DSCDs using scan to the scan-equivalent DSCDs measured using the noon mode but converting them to scan applying Equation 8.5. Figure 8.1 shows such comparison for a clear sky day: an excellent correlation is found (with a correlation coefficient of 0.99 and a slope very close to 1 , also providing a relatively very small intercept). 


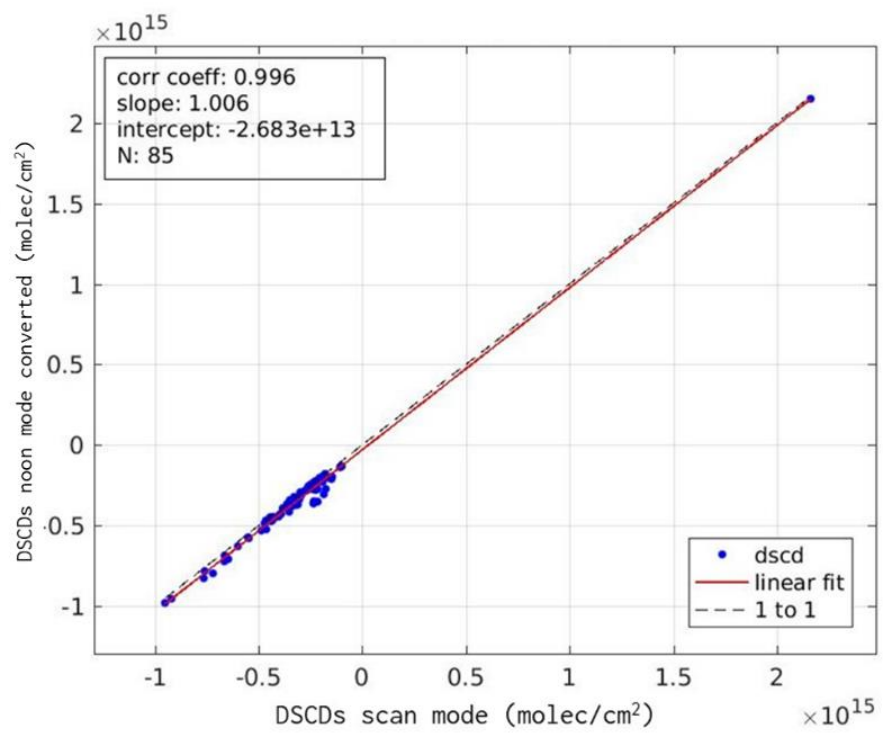

Figure 8.1. DSCDs comparison between the scan mode and the noon mode converted to its equivalent scan mode.

Therefore, we conclude that both reference modes yield essentially the same results when transforming one into another. We therefore decided to use the noon mode because when dealing with the low levels of BrO in the Arctic, oftentimes the DSCDs are very close to the noise spectra and hence on the edge of being discarded due to quality filters. However, the noon mode offers -in general- longer expected light paths, since the noon spectrum has the shortest mean light path in the entire day, so the absolute values of the DSCDs will be higher. This in turn allows that a higher number of DSCDs survives the quality filters.

In our next test, we compared two typical BrO spectral absorption cross sections:

- $\quad$ BrO measured by Wilmouth (1999).

- $\quad$ BrO measured by Fleischmann (2004). 
We concluded that the more recent, Fleischmann BrO cross section results in lower residuals and a better fit with respect to the measured optical density.

Another important test that we carried out was the assessment of the possible interference of $\mathrm{HCHO}$ in the $\mathrm{BrO}$ analysis. Since they absorb in the same spectral region (see Figure 5.3) and their absorption cross sections are somewhat similar, it was important to assess their possible overlap. For doing that, we estimated the optical densities of both $\mathrm{BrO}$ and $\mathrm{HCHO}$ that would be produced given a certain quantity of both trace gases. In order to do that, we applied the horizontally geometrical approach, which assumes that -at a EVA of $0^{\circ}$ and for an absorber mainly located within the boundary layer- the DSCDs are approximately equal to the SCDs that we would obtain measuring absorptions for a horizontal line of sight of the instrument. Assuming a mixing ratio of 25 pptv (and a typical horizontal light path of about $15 \mathrm{~km}$ ), we got roughly $1 \times 10^{15}$ molecule $\mathrm{cm}^{-2}$ for $\mathrm{BrO}$, while inserting 500 pptv and the same horizontal light path, we obtained $2 \times 10^{16}$ for $\mathrm{HCHO}$. For these two DSCDs, the generated optical density by each of them is obtained multiplying the DSCD by the cross sections of $\mathrm{BrO}$ and $\mathrm{HCHO}$. The resulting estimated optical densities are shown in Figure 8.2.

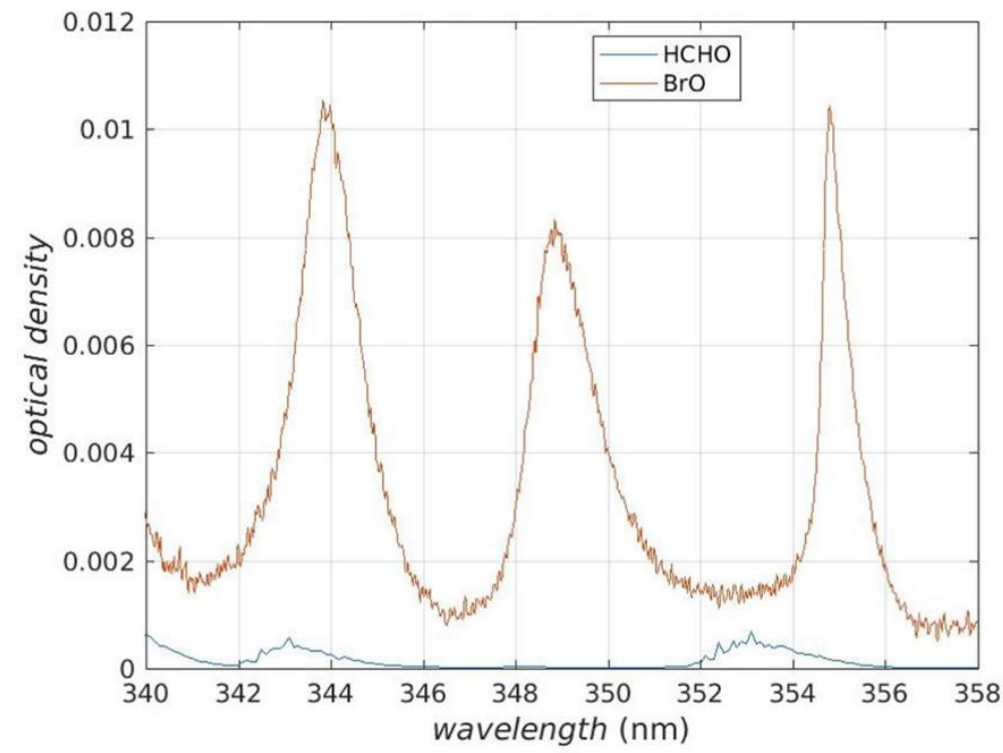

Figure 8.2. Estimated optical densities for $\mathrm{HCHO}(500 \mathrm{pptv})$ and $\mathrm{BrO}(25 \mathrm{pptv})$. 
We can observe in Figure 8.2 that the influence of $\mathrm{HCHO}$ is negligible when compared to that of $\mathrm{BrO}$, even using the very high (for the Arctic region) amount of 500 pptv of $\mathrm{HCHO}$. Thus, we do not further include $\mathrm{HCHO}$ in the $\mathrm{BrO}$ spectral analysis.

Furthermore, we compared different configurations of wavelength analysis regions based on previous works: a spectral range of 346-360 nm was used in Kreher et al., 1997; 346-358.5 nm in Frie $\beta$ et al. 2005; 346-359.5 nm in Frie $\beta$ et al., 2011; and 335-358 nm in Prados-Roman et al., 2018. The best BrO wavelength region that we found for this study goes from 341 to $357 \mathrm{~nm}$ (it provides a lower residual RMS). Regarding the cross sections included, we checked several combinations:

- $\quad \mathrm{O}_{4}$ cross section: Greenblat and Volkamer, no differences regarding the BrO DSCDs.

- $\mathrm{O}_{3}$ cross section: we decided to include two ozone absorption cross sections, measured at different temperatures ( $223 \mathrm{~K}$ and $273 \mathrm{~K}$ ), with the purpose of taking care of the ozone amount located at, respectively, the stratosphere and the troposphere. Moreover, two different sets of $\mathrm{O}_{3}$ absorption cross sections were tried (Bogumil and Serdyuchenko), with the latter being chosen due to a better, cleaner fit, with lower uncertainties.

- $\mathrm{NO}_{2}$ cross section: we compared the analysis using just one $\mathrm{NO}_{2}$ cross section at a temperature of $294 \mathrm{~K}$, and with two different $\mathrm{NO}_{2}$ cross sections to take care of the stratospheric amounts (much like for the $\mathrm{O}_{3}$ ). We obtained better residuals using two different $\mathrm{NO}_{2}$ absorption cross sections.

- If we add a long term average of the spectral residual of the DOAS fit like an artificial absorber (Benavent et al., 2019), the residual RMS is considerably reduced and at the same time the retrieved DSCDs are not affected but the uncertainties are lower. The correlation coefficient between DSCDs with the residual like an absorber and 
DSCDs without the residual is 0.949 , while the different DSCDs uncertainties, the correlation coefficient is 0.228 and the RMS is lower in DSCDs with the residual like an absorber. This approach provides a more robust fit safely using this artificial absorber that takes care of any spectral, systematic artefacts caused by the instrumentation.

Finally, the DOAS configuration that yielded the best spectral fit along with the lower residual RMS is summarized in Table 8.1. 
Table 8.1. DOAS fitting parameters for BrO in the UV band.

\begin{tabular}{|c|c|}
\hline Parameter & Value \\
\hline Fitting Window & $341-357 \mathrm{~nm}$ \\
\hline Wavelength Calibration & $\begin{array}{l}\text { Calibration based on reference solar atlas } \\
\text { (Chance and Kurucz, 210) }\end{array}$ \\
\hline Cross section & \\
\hline $\mathrm{BrO}$ & 223 K, Fleischmann (2004) \\
\hline $\mathrm{NO}_{2}$ & 220 K \& 294 K, Vandaele (1998) \\
\hline $\mathrm{O}_{3}$ & 223 K \& 273 K, Serdyuchenko (2014) \\
\hline $\mathbf{O}_{4}$ & Thalman and Volkamer (2013) \\
\hline OClO & 293 K, Bogumil (2003) \\
\hline Ring & Calculated by QDOAS \\
\hline Polynomial order & 2 \\
\hline Intensity Offset & Order 1 \\
\hline Shift & $\begin{array}{l}\text { The measured spectra and the Ring were } \\
\text { allowed to shift in wavelength (order } 1 \text { ) }\end{array}$ \\
\hline
\end{tabular}

An example of a $\mathrm{BrO}$ spectral detection is included in Figure 8.3: the spectrum was measured on May 10, 2017, pointing at an EVA of $3^{\circ}$ (with a SZA of $64^{\circ}$ ), the estimated DSCD was $7.9 \times 10^{14}$ molecules $\mathrm{cm}^{-2}$ while the residual (RMS) for this spectra is $8.2 \times 10^{-4}$ (in optical density units). 


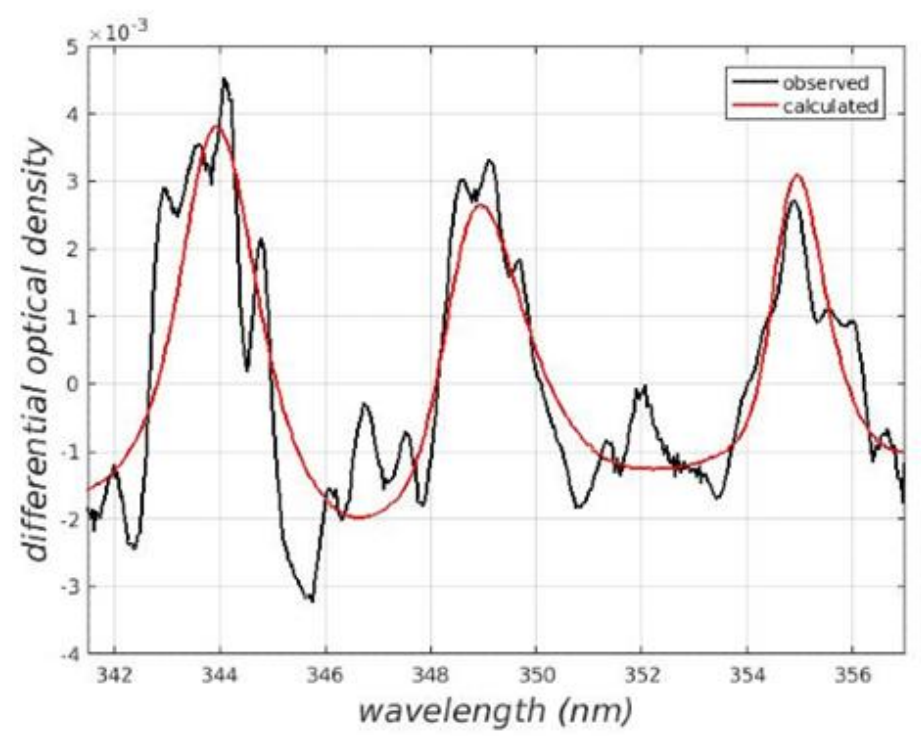

Figure 8.3. Spectral fit example on May 10, 2017. The red curve is the calculated optical density for BrO while the black curve represents the measured optical density and the residual of the analysis.

Once the DSCDs for the entire campaign are ready, we applied quality filters in order to obtain DSCDs reliable enough for the subsequent profile retrieval steps. We discarded DSCDs that yielded either a relative uncertainty larger than 1 or a residual RMS higher than 0.01 in optical density units. We calculated the detection limit as the ratio of the residual RMS associated to each DSCDs and the maximum value of the differential cross section of $\mathrm{BrO}$ (in the wavelength region that we used, this value is $7.7 \times 10^{-18} \mathrm{~cm}^{2}$ molecule-1). After that, we rejected the DSCDs that had an absolute value lower than twice the derived detection limit (Peters et al., 2012). The DSCDs that survived the quality filters and that were used as input for the RTM are shown in Figure 8.4. We can observe that there are enough values for the profile retrieval, and that the maximum DSCD values are reached during spring and early autumn. The observed seasonality generates a u-shape curve during each year, with lower values observed in summer. This is due to the seasonality of first year sea ice, one of the main sources of BrO precursors, that has a minimum extent in the summer months. Note also the clear distinction between the EVAs. 


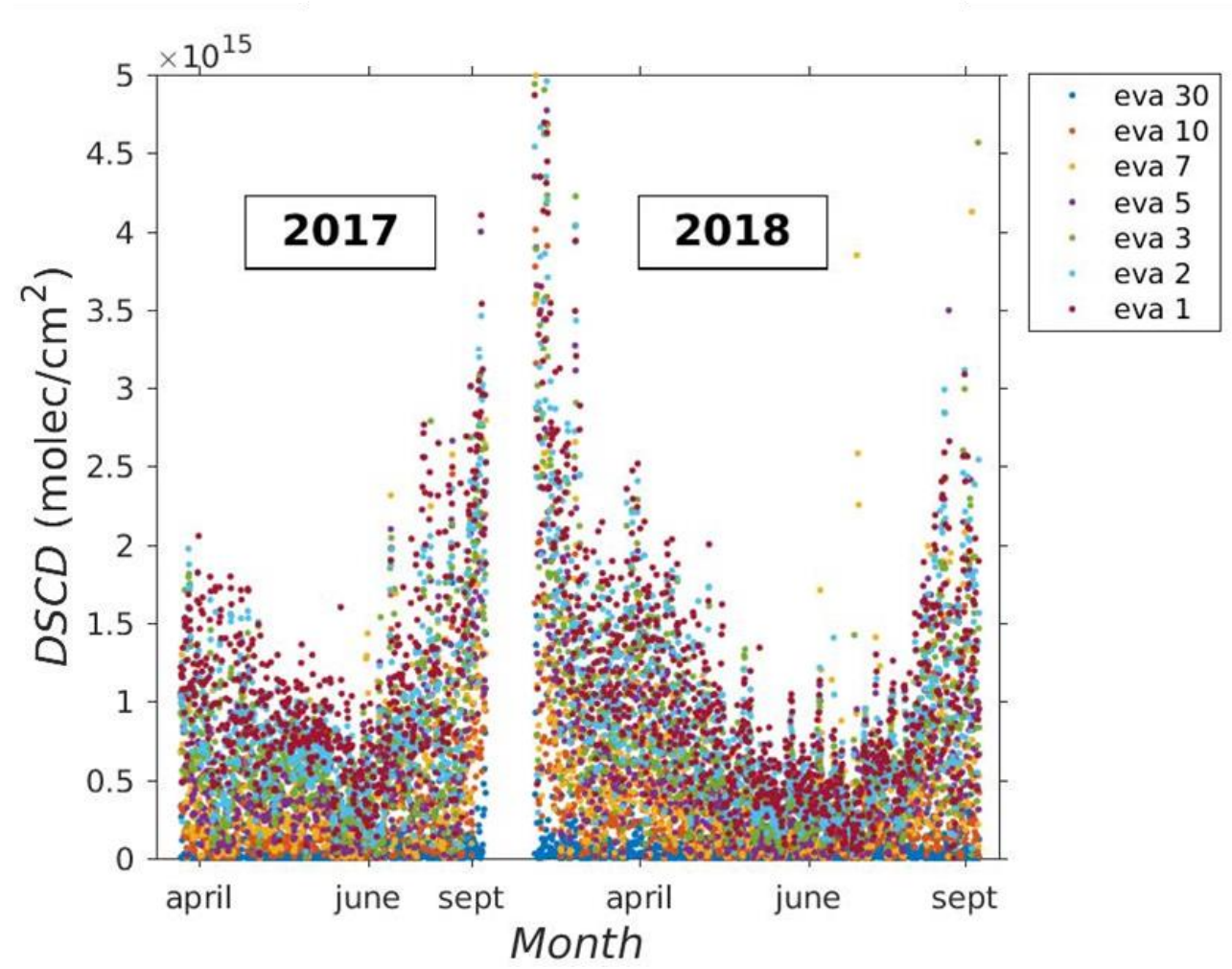

Figure 8.4. Complete database of BrO DSCDs measured by our MAX-DOAS instrument at VRS in 2017-2018.

With the purpose of knowing if our RTM worked accurately, we compared the DSCDs coming from our QDOAS configuration and the ones that the RTM simulates in order to provide an optimal solution. Given the importance of atmospheric vertical profiles of temperature and pressure in RTM calculations, we added a typical Arctic atmosphere temperatures and pressures for each month of observations. For that, we took the surface temperature and pressure measurements provided by the Station Nord Database (https://villumresearchstation.dk/data/). We then monthly average those surface values and subsequently we interpolated them to our altitude vector, assuming typical behaviours with respect to height for both magnitudes. The altitude vector used in the Arctic measurements has 67 layers: 20 layers of $200 \mathrm{~m}$ from $0 \mathrm{~km}$ to $4 \mathrm{~km}, 12$ layers of $500 \mathrm{~m}$ from $4 \mathrm{~km}$ to $10 \mathrm{~km}, 20$ layers of $1 \mathrm{~km}$ from $10 \mathrm{~km}$ to $30 \mathrm{~km}$ and the remaining layers up to $60 \mathrm{~km}$ height have a thickness of $2 \mathrm{~km}$. 
It has to be noted that throughout the year, we had some measurement gaps because at noon time the SAA was similar to the VAA, therefore although the spectra were usually not saturated (due to the internal calculation that optimizes the signal-to-noise ratio) the presence of direct sunlight -which is quite difficult to simulate by the RTM- is noticeable. For this reason, we removed the MAX-DOAS cycles that took place within an azimuthal interval of noon time $\pm 5^{\circ}$ in azimuth. The remaining data after the quality filters are: 59 days for 2017 and 92 days for 2018.

Figure 8.5 represents the correlation between DSCDs simulated and measured for one specific day of BrO. They are in a good agreement for this day (May 10, 2017), with a correlation coefficient $r^{2}$ of about 0.99 and a slope of 0.92 . These values reflect a reliable and consistent fit quality.

a)

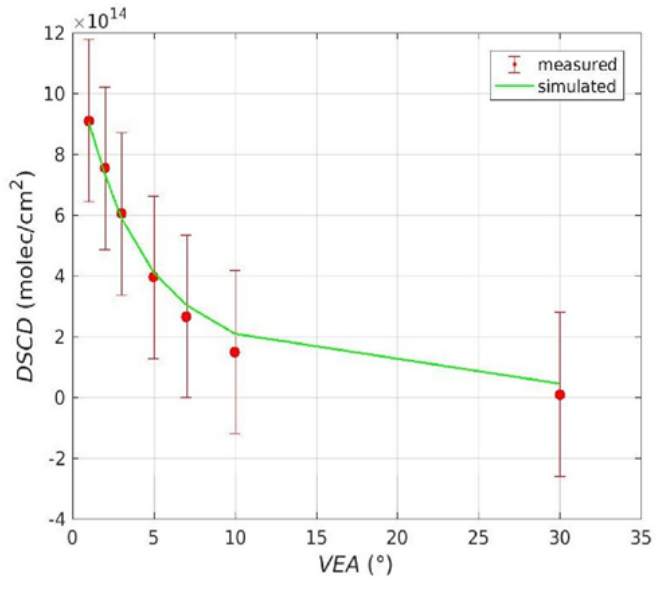

b)

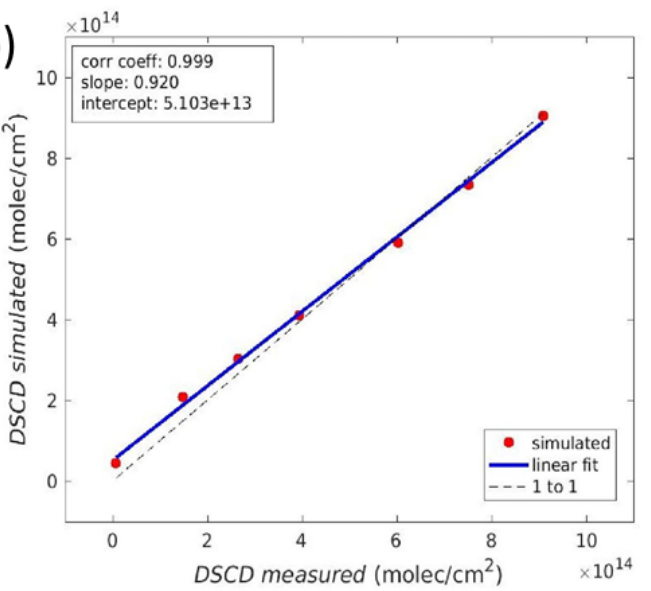

Figure 8.5. Comparison between simulated and measured DSCDs for BrO on May 10, 2017 a) and the correlation between them $b$ ). 

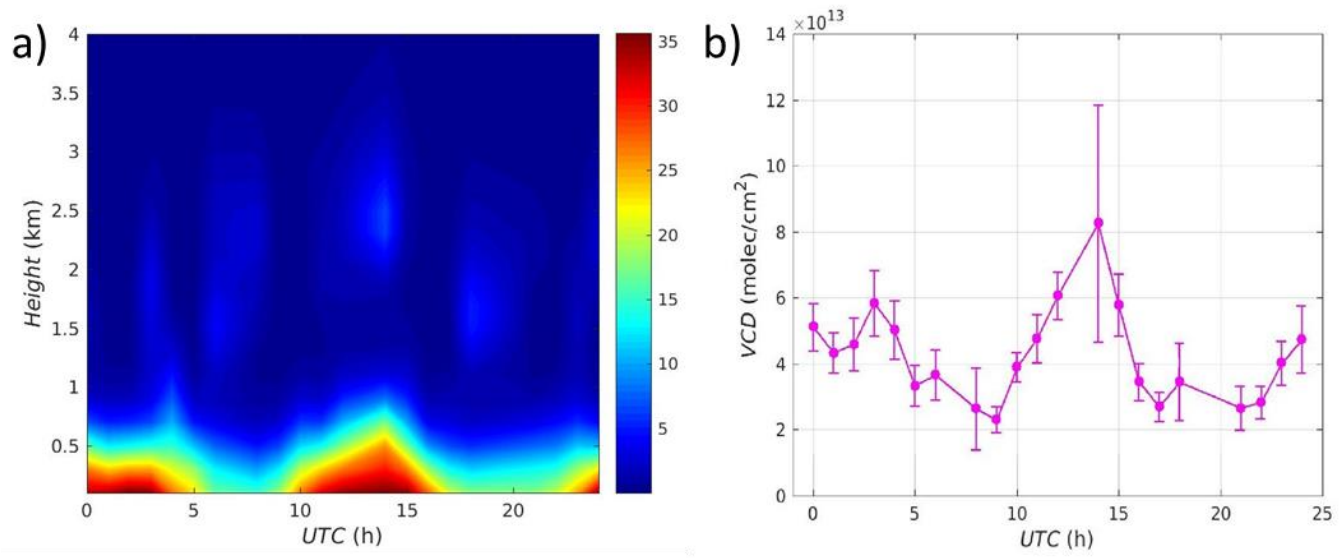

Figure 8.6. BrO profiles a) and VCDs b) (May 10, 2017).

The associated BrO profile -along with its corresponding VCD- is shown in Figure 8.6. On this day (May 10, 2017), values up to 40 pptv are found in the early morning (from 0 to 5 UTC), around noon (from 10 to 15 UTC) and at 22 UTC. We can estimate, based on the vertical profiles, that around $85-90 \%$ of the $\mathrm{BrO}$ total column is located within the first kilometre. Regarding the VCDs, they range from $2.2 \times 10^{13}$ molecules $\mathrm{cm}^{-2}$ at 9 UTC to $8 \times 10^{13}$ molecules $\mathrm{cm}^{-2}$ at 14 UTC, and they follow a similar temporal pattern as the BrO mixing ratios. This could be expected given that $\mathrm{BrO}$ is mainly located within the boundary layers, which means that most of its vertical column is below $1 \mathrm{~km}$ height.

Since two entire years of measurements are available, it is possible to assess the seasonal variation in the levels of BrO. Following the approach discussed for Figure 8.6, in Figure 8.7 we compare all the DSCDs simulated and measured for the years 2017 and 2018 after the RTM calculations. The comparison is solid, and shows very good correlations for the measured and simulated BrO DSCDs, with an $r^{2}$ coefficient close to 1 . We can conclude that our RTM is good enough to obtain reliable values of BrO. 

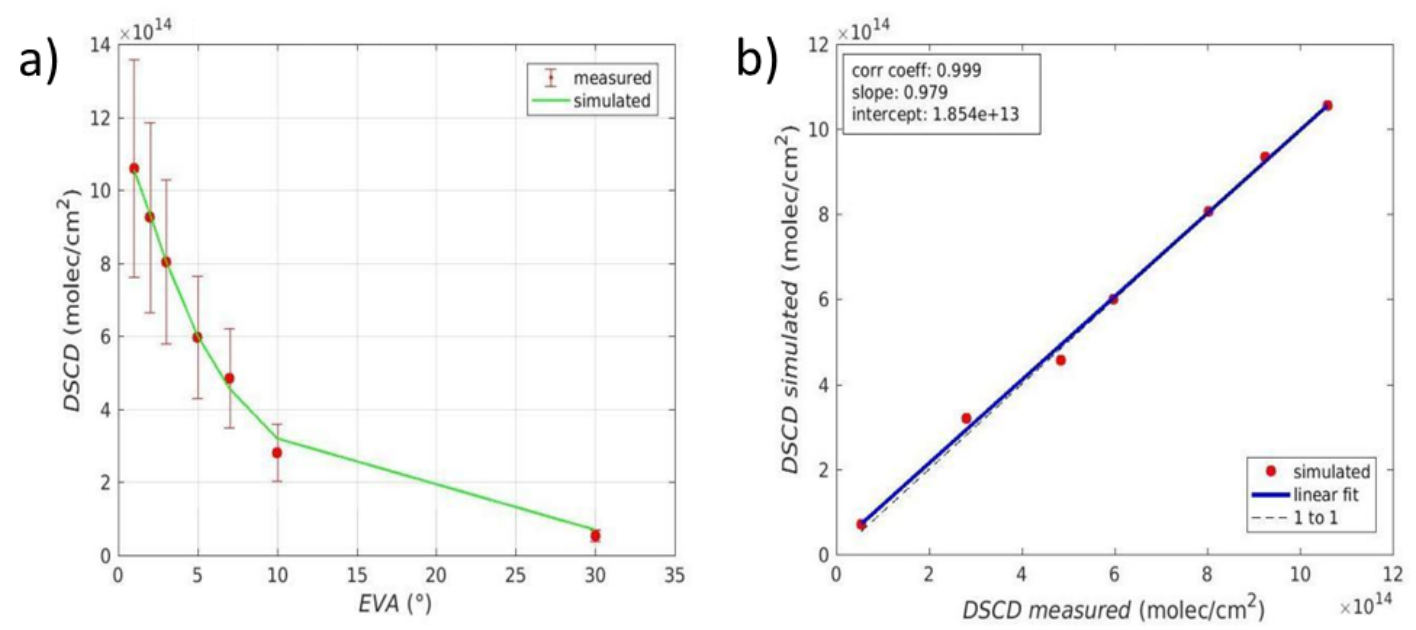

Figure 8.7. Comparison between simulated and measured DSCDs for the two years: 2017 and 2018.

Given the relatively low concentration of halogen oxides in the troposphere, there are usually large uncertainties, hence there is a relevant portion of the total, clear-sky MAXDOAS cycles that either fall under the estimated detection limit or do not pass the quality filters. The surviving cycles are the ones to which we applied the profile inversion algorithm. However, since we are mainly interested in analysing the long-term behaviour of both $\mathrm{BrO}$ and IO, a challenge arises: we would like to show monthly averages, but within every month there is a non-negligible amount of cycles that did not meet the quality criteria, although there was spectral detection and a clear sky. This would mean that these monthly averages would not be representative, due to a bias towards higher mixing ratios. With the purpose of dealing with that, we applied the following criteria: those filtered-out (though with clear sky) MAX-DOAS cycles are statistically somewhere between zero and the detection limit. With no further information about them, we have decided to assign half the detection limit values to those non-qualifying cycles (only for the long-term, monthly averages to account for the mentioned bias). Then, the same procedure involving the estimation of the light paths and the vertical profiles were carried out. 
Figure 8.8 shows the evolution of the BrO surface mixing ratio and VCDs during the sunlit periods of 2017 and 2018. The box plot is structured as follows: the edge of the box marks the first and third quartile of the respective data, while the dashed line signals the interval that covers the monthly median \pm 2 standard deviations. Data points with a plus symbol are regarded as outliers which are 1.5 times bigger than the interquartile range. The data series shows a U-shape curve within each year, with median monthly values up to 25

pptv in early spring and autumn, while values of about 5 pptv are reached in summer. A similar trend for the BrO VCDs can be found in Figure $8.8 \mathrm{~b}$ ), with VCDs ranging from $2 \times 10^{13}$ molecule $\mathrm{cm}^{-2}$ in June, 2018 to $7 \times 10^{13}$ molecule $\mathrm{cm}^{-2}$ in March, 2018, though there is more dispersion here (a larger number of outliers are found in the VCD figure), which indicates a higher uncertainty for the VCD. This is due to the inherent uncertainties when dealing with these halogens profiles: given their low concentration, and considering the sensitivity limitations of the RTM algorithm, especially for higher altitudes, there is no easy way to estimate BrO mixing ratios above the boundary layer. 

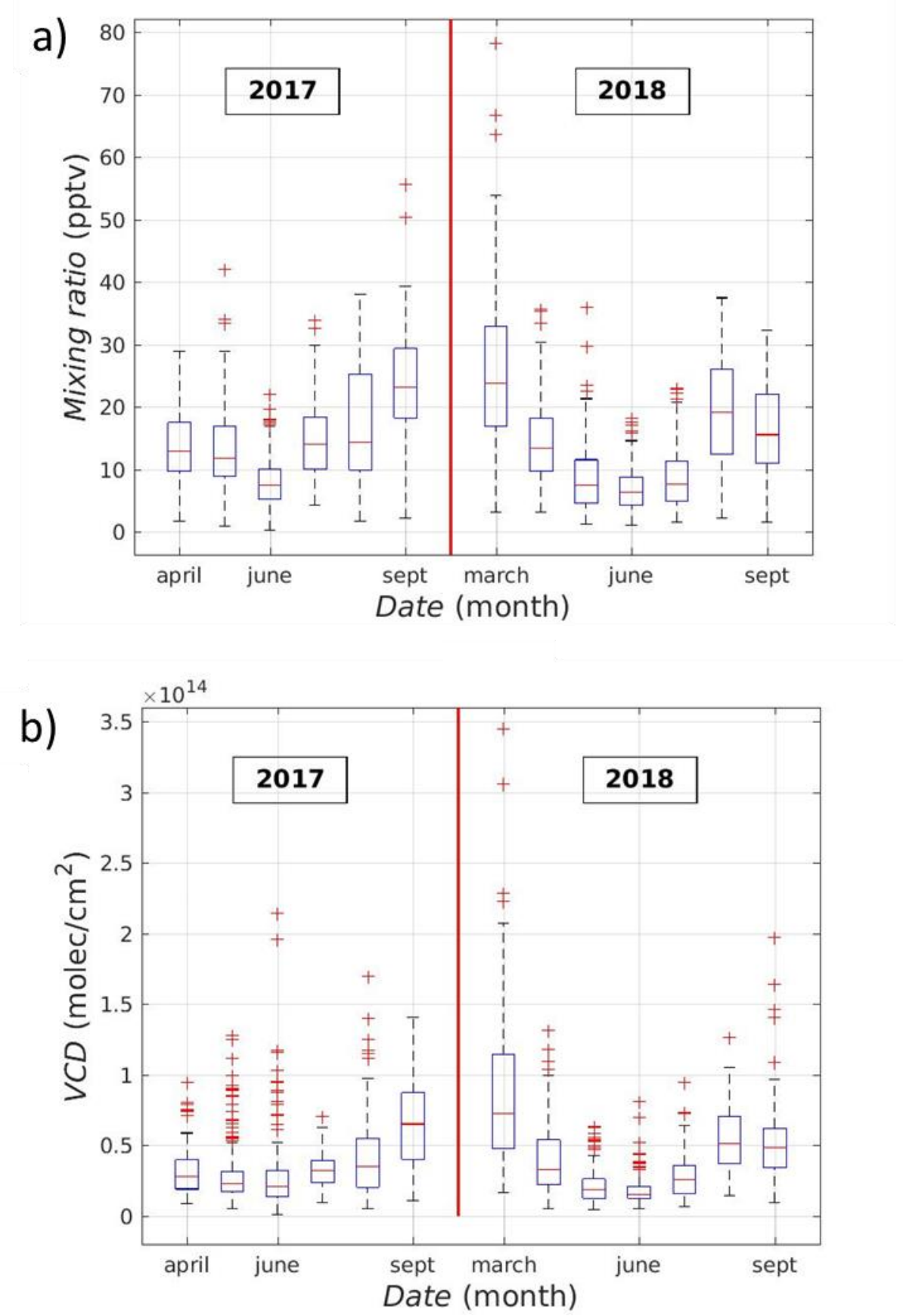

Figure 8.8. Monthly statistical analysis of $\mathrm{BrO}$ mixing ratios a) and VCDs b) during the years 2017-2018.

By reviewing the previous literature, similar Arctic $\mathrm{BrO}$ values are found. Table 8.2 presents previous $\mathrm{BrO}$ measurements performed in the Arctic. Note that all the reported data is in spring, but no measurements are reported during summer. Therefore, our 
measurements provide very valuable summertime data as we report the first ground-based long-term (two years so far) BrO mixing ratios and VCDs in the Arctic. Our database is important because we demonstrate that $\mathrm{BrO}$ is present in mixing ratios above the detection limit of the instrument for the entire summer. As it is explained in Section 3.1, during summer months the sources of BrO decrease due to the absence of sea ice in VRS. Data from VRS (villumresearchstation.dk) show mean values of snow depth up to $1 \mathrm{~m}$, while in summer months the thickness is $0 \mathrm{~m}$, meaning that there is no snow around the VRS. We do not have direct measurements of the FYSI amounts, but taking into account the reduction of snow in VRS, we could safely assume that there will also be a decrease in the FYSI, which is considered as one of the main precursors of $\mathrm{BrO}$, as detailed in Chapter 3.

Table 8.2. Previous ground-based measurements of $\mathrm{BrO}$ in the Arctic.

\begin{tabular}{|c|c|c|c|c|}
\hline Location & Periods & BrO mixing ratio & Instrument & Reference \\
\hline Alert, Canada & April 1992 & 17 pptv & LP-DOAS & Hausmann and Platt, 1994 \\
\hline Ny-Ålesund, Svalbard & April 1996 & 30 pptv & LP-DOAS & Tuckermann et al., 1997 \\
\hline Alert, Nunavut & April - May 2000 & 30 pptv & MAX-DOAS & Hönninger and Platt, 2002 \\
\hline Ny-Ålesund, Svalbard & April - May 2000 & 22 pptv & LP-DOAS & Avallone et al., 2003 \\
\hline Hudson Bay & April- May 2001 & 25 pptv & MAX-DOAS & Hönninger, 2004 \\
\hline Barrow, Alaska & March - April 2003 & 22 pptv & MAX-DOAS & Brooks et al., 2006 \\
\hline Greenland ice sheet & May-June 2007 & 3-5 pptv & LP-DOAS & Stutz et al., 2011 \\
\hline Amundsen Gulf & March - April 2008 & 41 pptv & LP-DOAS & Pöhler et al., 2010 \\
\hline Barrow, Alaska & February-April 2009 & 30 pptv & MAX-DOAS and LP-DOAS & Frieß et al., 2011 \\
\hline Barrow, Alaska & April 2012 & 40 pptv & MAX-DOAS & Simpson et al., 2017 \\
\hline Ny-Ålesund, Svalbard & April, 2015 & 2.6e14 (DSCD) & MAX-DOAS & Luo et al., 2018 \\
\hline
\end{tabular}

\section{2 lodine monoxide results}

As we described in section 3.2 , atmospheric iodine is involved in catalytic ozone destruction. The main direct emissions in polar regions are done by the algae which are below the ice in the FYSI. Cuevas et al., 2018, reported a rapid increase in the Arctic iodine levels since 1950s. The Arctic sea ice has been reduced because of climate change and now, Arctic sea ice is younger and thinner than in previous decades. 
This is the first time in which the 10 is continuously measured in the Arctic. Given the low levels of the radical, the MAX-DOAS analysis is challenging. We did some configuration tests in which we changed some parameters (wavelength range, different cross sections, mean instrumental residual acting as an artificial absorber), in order to get a good detection of 10 and a minimal residual RMS, the residual like an absorber has been included in the analysis. The settings used in the DOAS retrieval are summarized in Table 8.3.

Table 8.3. DOAS fit setting for IO in the VIS band.

\begin{tabular}{|c|c|}
\hline Parameter & Value \\
\hline Fitting Window & $425-439 \mathrm{~nm}$ \\
\hline Wavelength Calibration & $\begin{array}{l}\text { Calibration based on reference solar atlas } \\
\qquad \text { (Chance and Kurucz, 2010) }\end{array}$ \\
\hline Cross sections & \\
\hline 10 & 298 K, Spietz (2005) \\
\hline $\mathrm{NO}_{2}$ & 294 K, Vandaele (1998) \\
\hline $\mathrm{NO}_{2 a}$ & 220 K, Vandaele (1998) \\
\hline $\mathrm{O}_{3}$ & 223 K, Serdyuchenko (2014) \\
\hline $\mathbf{O}_{3 a}$ & 273 K, Serdyuchenko (2017) \\
\hline $\mathbf{O}_{4}$ & Thalman and Volkamer (2013) \\
\hline Ring & Calculated by QDOAS \\
\hline
\end{tabular}




\begin{tabular}{|c|c|}
\hline Polynomial order & 2 \\
\hline Shift & $\begin{array}{c}\text { The measured spectra and the Ring were } \\
\text { allowed to shift in wavelength (order 1) }\end{array}$ \\
\hline Intensity Offset & None \\
\hline
\end{tabular}

Figure 8.9 includes one example of the 10 spectral detection: the spectrum was measured on May 10, 2017 pointing at an EVA of $5^{\circ}$ (with a SZA of $67^{\circ}$ ), the DSCD has a value of $4.12 \times 10^{12}$ molecule $\mathrm{cm}^{-2}$, while the residual RMS is $4.2 \times 10^{-4}$ (in optical density units).

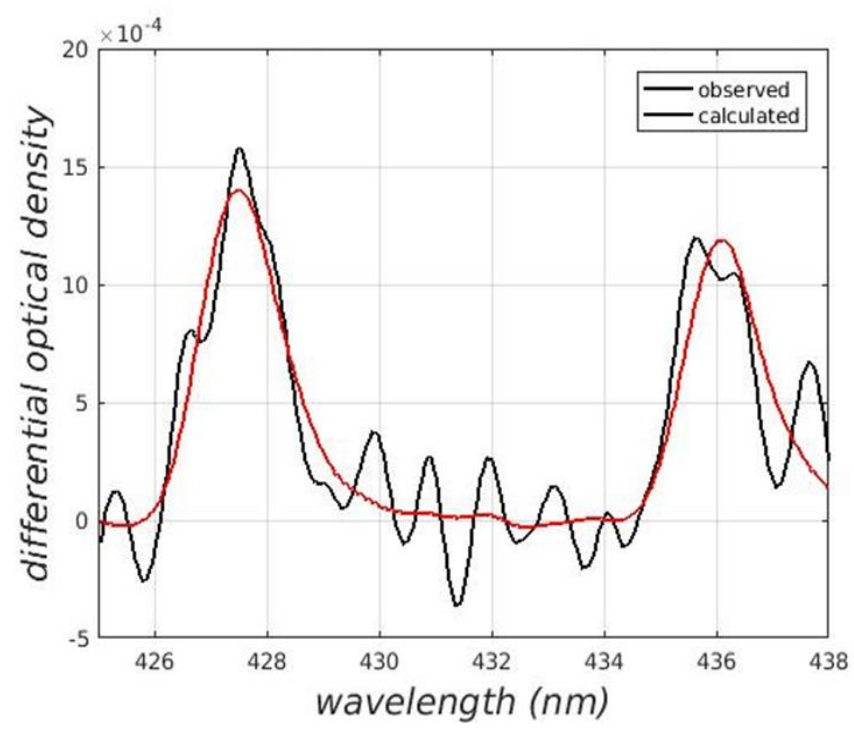

Figure 8.9. Spectral fitting example of IO, the spectra was taken on May 3, 2017. The red curve is the calculated IO optical density while the black curve represents the measured optical density.

Once we get the DSCDs from the 2017-2018 time period, the same quality filters as for $\mathrm{BrO}$ (section 8.1) were applied. For the estimation of the detection limit, the maximum value of the differential absorption cross section of 10 is $1.99 \times 10^{-17} \mathrm{~cm}^{2}$ molecule ${ }^{-1}$. The DSCDs that we used for the RTM appear in Figure 8.10, and, as for BrO, we can observe that there are enough values for the profile retrieval. In the IO retrieval, the separation between 
EVAs is not as clear as BrO. The remaining data after the quality filters are: 104 days for 2017 and 132 days for 2018, and again there is a small time gap in the data due to the noon time $\pm 5^{\circ}$ azimuthal filter caused by the impact of direct sunlight.

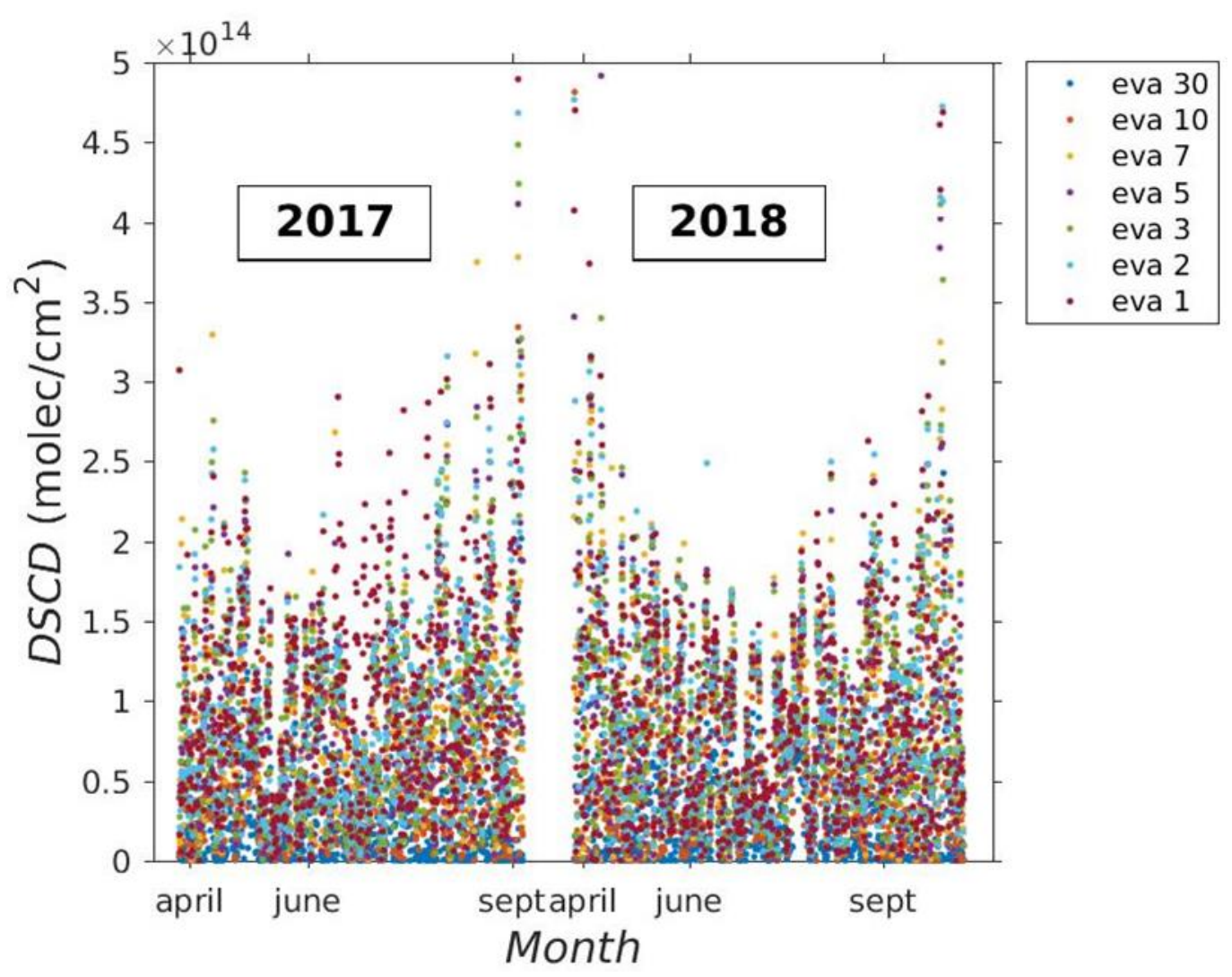

Figure 8.10. Complete database of IO DSCDs measured by our MAX-DOAS instrument at VRS in 2017-2018.

The comparison between the measured and simulated DSCDs is shown in Figure 8.11. The correlation between them is not as good as for $\mathrm{BrO}$, but we can conclude that they are in a good agreement for this day (May 11, 2017), the correlation coefficient $r^{2}$ is about 0.97 , with a slope of 1.11 . 

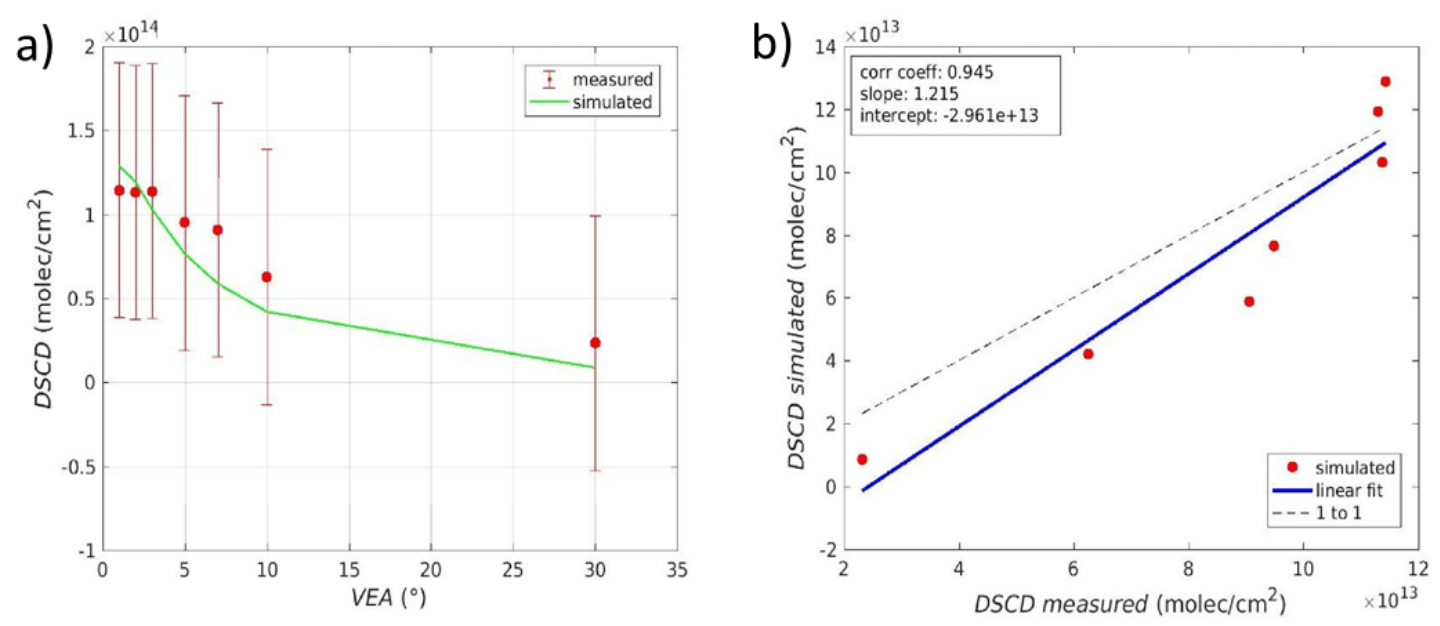

Figure 8.11. Correlation between simulated and measured IO DSCDs, on May 11, 2017.

The corresponding vertical profiles are shown in Figure 8.12. The mixing ratio is about 3 pptv at 3 UTC. We can observe that most of the 10 is located in the first 500 meters. For the IO VCD (Figure 8.12), the upper limit value is also at 3 UTC $\left(8.7 \times 10^{-12}\right.$ molecule $\mathrm{cm}^{-2}$ ), whereas a minimum detectable value of $1.8 \times 10^{-12}$ molecule $\mathrm{cm}^{-2}$ is found at 14 UTC. The entire DSCDs measured and simulated for the two years are summarized in Figure 8.13. We can observe here that the temporal mixing ratios and VCDs follow a similar shape, it could be because most of the 10 is located within the boundary layer. 

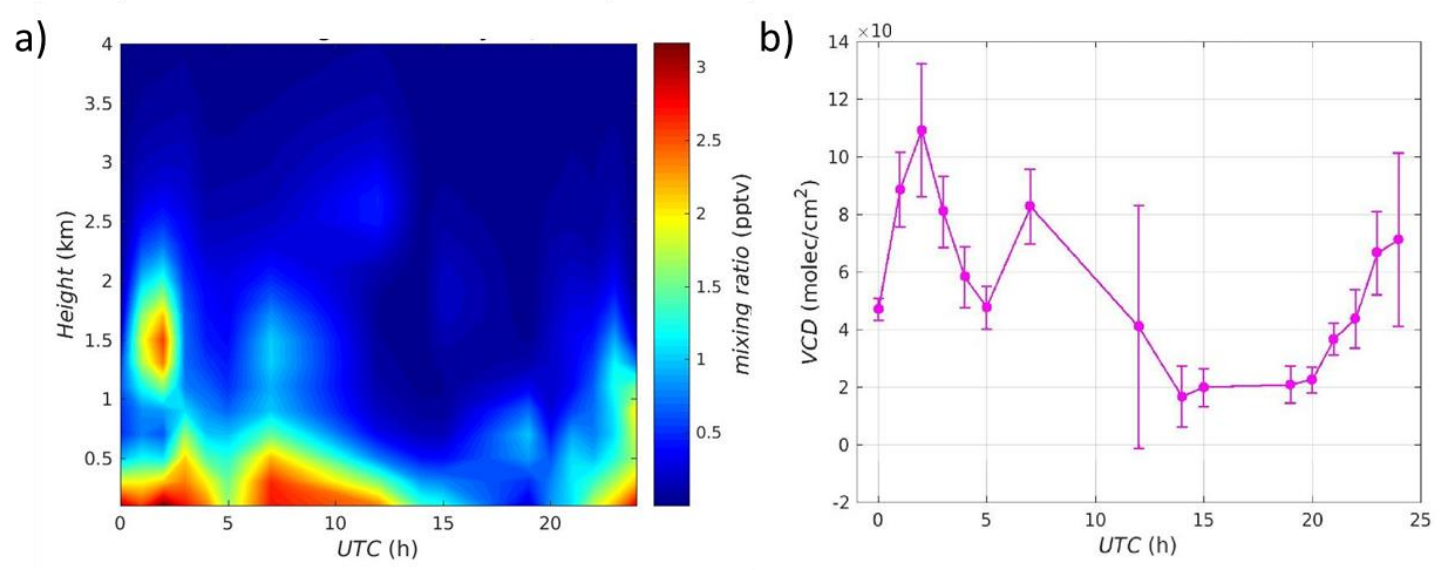

Figure 8.12. 10 mixing ratio profiles a) and VCDs b) on May 11, 2017.
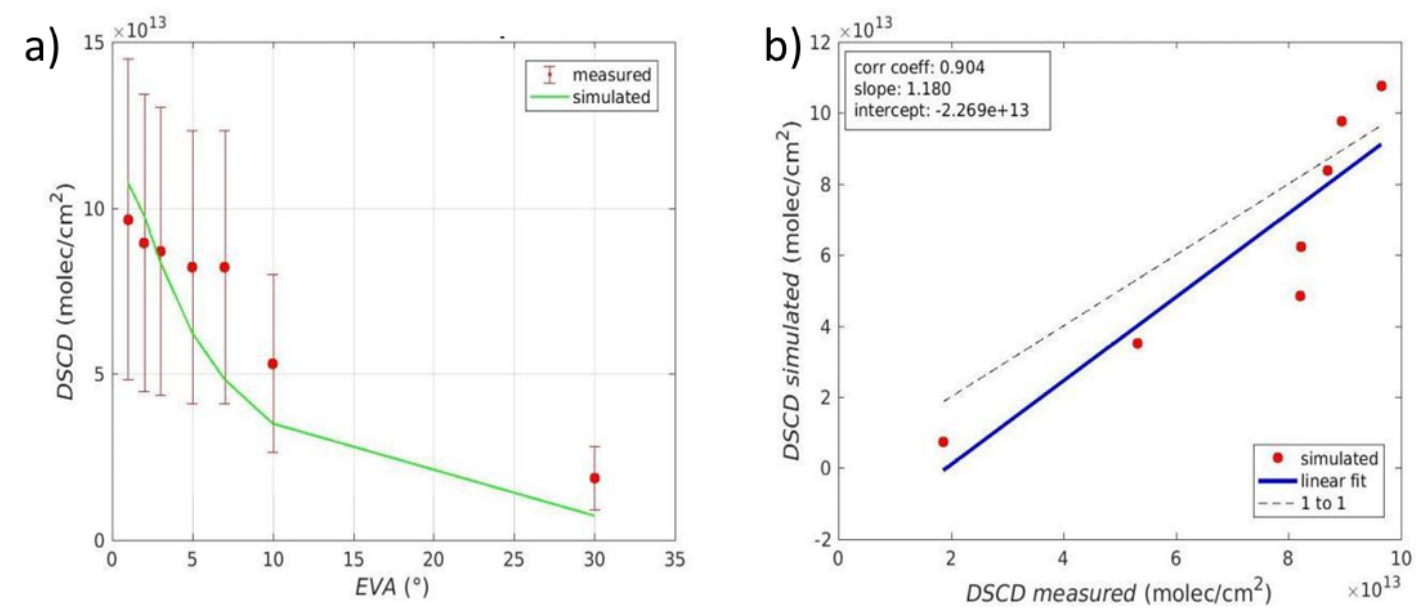

Figure 8.13. Comparison between simulated and measured IO DSCDs for both years 2017 and 2018.

The IO analysis yields some dispersion, mainly when trying to capture the relationship of the DSCDs with respect to the EVAs (Figure 8.13). This can be explained by the relatively large uncertainties in the 10 spectral analysis, along with their low mixing ratios, which make the $I O$ vertical profile complicated to invert. 
Figure 8.14 includes the evolution of the retrieved 10 surface mixing ratio and VCD during 2017 and 2018. Note that no clear seasonal pattern can be inferred here, since there is no apparent trend neither for the surface mixing ratio nor the VCDs. That could be related to some sort of background presence of $\mathrm{IO}$-at least within the boundary layer- in the region, regardless of the time of the year. We also observe higher uncertainties and larger dispersions -with respect to the box mean- for the $\mathrm{IO}$ in comparison with the $\mathrm{BrO}$. It seems that a background amount of about 1 pptv of $I O$ is present in the Arctic boundary layer. This investigation demonstrates for the first time the ubiquitous 10 presence in the Arctic boundary layer. 
a)

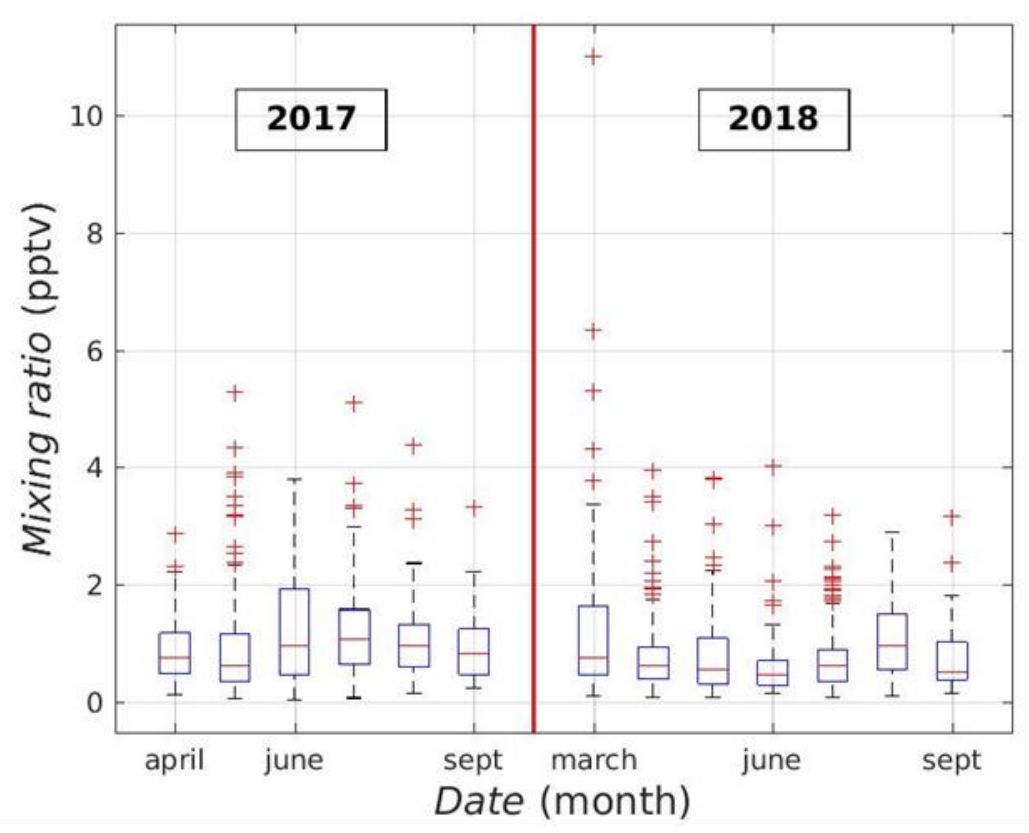

b)

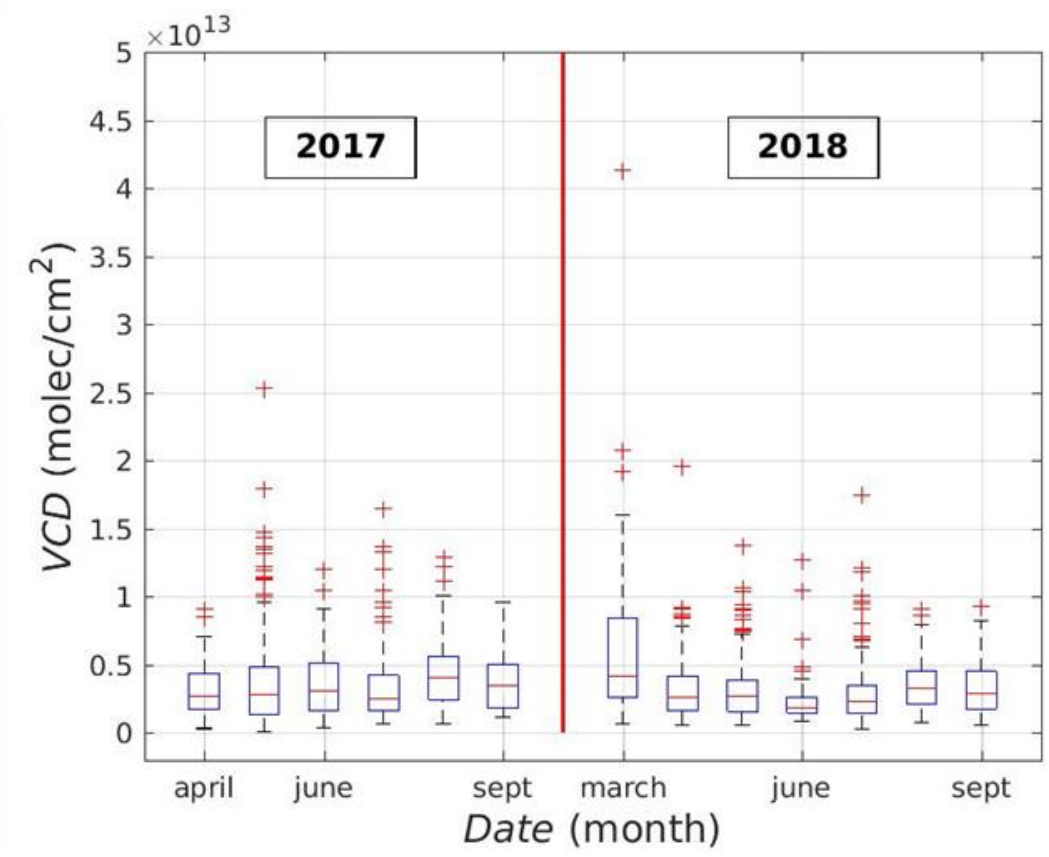

Figure 8.14. Monthly statistical analysis of $I O$ mixing ratios a) and VCDs b) during the years 2017-2018.

In recent years, it is known that sea ice extent in the Arctic is receding as a result of global warming. As we explained in section 3.3 a shorter sea ice thickness boosts the 
propagation of sunlight which regulates the iodine production via algal oxidative stress, and result in more efficient iodine emissions to the atmosphere.

\subsection{Impact of bromine and iodine on Arctic ozone loss}

We evaluate here the combined impact of the measured levels of $\mathrm{BrO}$ and $\mathrm{IO}$ on ozone at VRS using the chemical transport THAMO model (Saiz-Lopez et al., 2008). The ozone measurements were taken from the $\mathrm{O}_{3}$ monitor installed in the VRS laboratory. Three simulations (full, onlyBr, and nohal), were conducted as shown in Table 8.4, to isolate the effects of iodine and bromine.

Table 8.4. THAMO model simulation design.

\begin{tabular}{cccc}
\hline & full & onlyBr & nohal \\
& & & \\
\hline lodine emission & Yes & - & - \\
& & & \\
Bromine emission & Yes & Yes & - \\
\hline
\end{tabular}

We first ran the 'full' scenario with an assumed flux of iodine and bromine emissions to match the observed $\mathrm{IO}$ and BrO. Then, we disabled the emission of iodine for the 'only $\mathrm{Br}^{\prime}$ case and both iodine and bromine for the 'nohal' case. The average simulated IO (1.39 pptv) and $\mathrm{BrO}(16.5 \mathrm{pptv})$ are in line with the corresponding observations (1.29 pptv for IO and 15.7 pptv for BrO). Note that between 6 and 10 UTC, simulated and observed IO are almost the same as each other (coincidentally).

The loss rates of $\mathrm{O}_{3}$ derived from the three cases are shown in Figure 8.15. The average loss rate of $\mathrm{O}_{3}$ in the 'full' case is $4.7 \mathrm{pptv} \mathrm{s}^{-1}$, and in 'onlyBr' is $3.7 \mathrm{pptv} \mathrm{s}^{-1}$, and that in 'nohal' is only 0.60 pptv s' ${ }^{-1}$. Figure 8.15 shows that iodine chemistry is able to increase the $\mathrm{O}_{3}$ loss rate by $\sim 30 \%$, on top of the bromine effect, which is a significant fraction that requires inclusion in polar atmospheric models. 


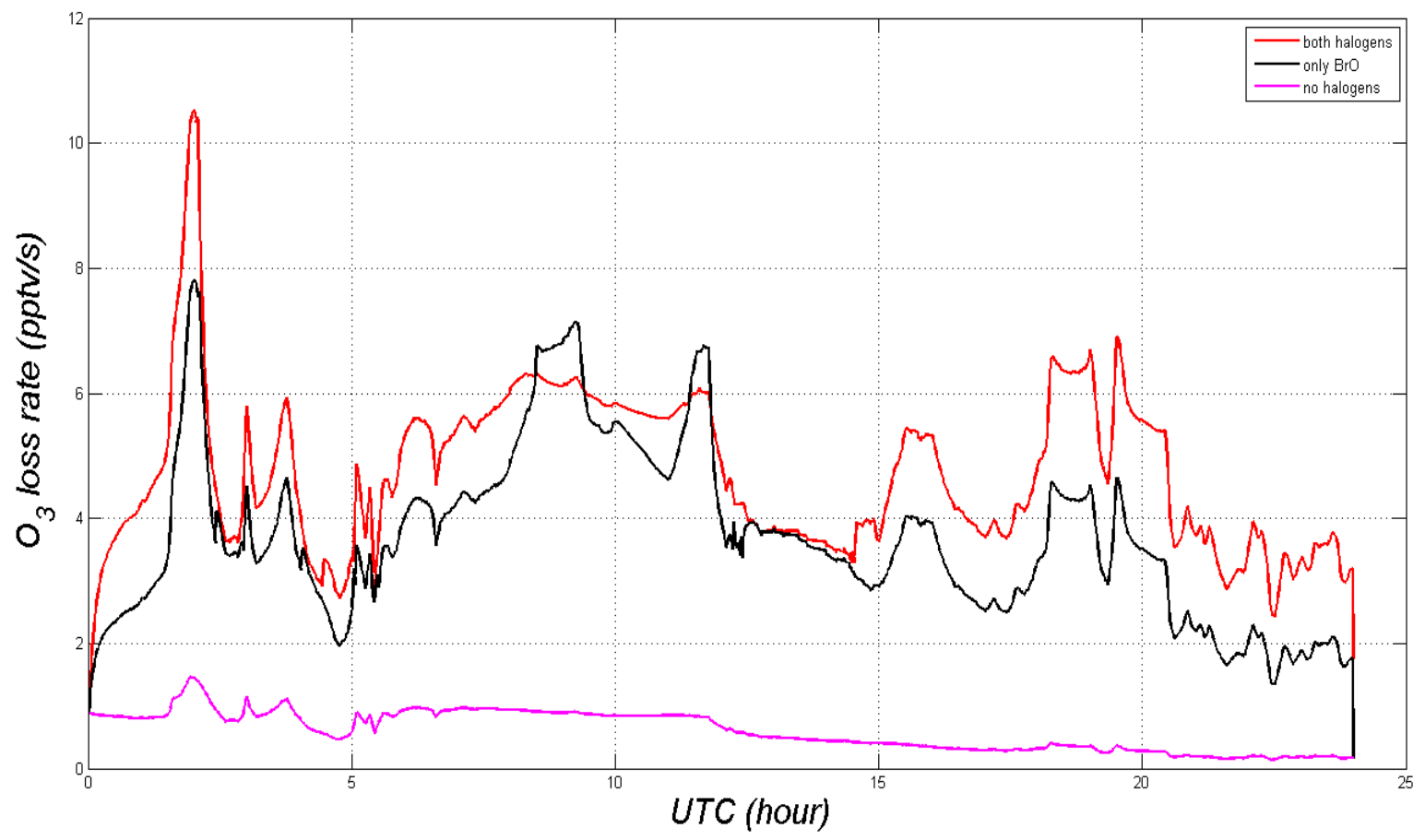

Figure 8.15. Ozone loss rate in pptv s${ }^{-1}$. The magenta curve represents the ozone loss rate without halogens, black curve describes the ozone loss rate taking into account the bromine chemistry and red curve shows the combined impact of iodine and bromine chemistries on the loss rate of ozone. 


\section{MAX-DOAS HALOGENS}

\section{MEASUREMENTS IN ANTARCTICA}

This chapter describes the halogen oxides measurements made in the Antarctic, performed using our ship-based MAX-DOAS instrument on board the Antarctic Circumnavigation Expedition (ACE).

\subsection{Antarctic Circumnavigation Expedition (ACE)}

The ACE campaign was carried out by the Swiss Polar Institute (SPI), the circumnavigation took place between December 2016 and March 2017, but there were also two extra legs: one at the beginning from November to December 2016 in which the vessel travelled from Bremerhaven (Germany) all the way down to Cape Town (South Africa), the second extra leg went the other way around (from Cape Town to Bremerhaven) in March April 2017 to close out the campaign. All of these legs are depicted in Figure 9.1. The expedition took place on board of the Russian icebreaker vessel "Akademik Tryoshnikov", which was built in 2012. Inside the vessel there was space for instrumentation and portable laboratories, in which 22 projects from 21 different countries developed their work. 


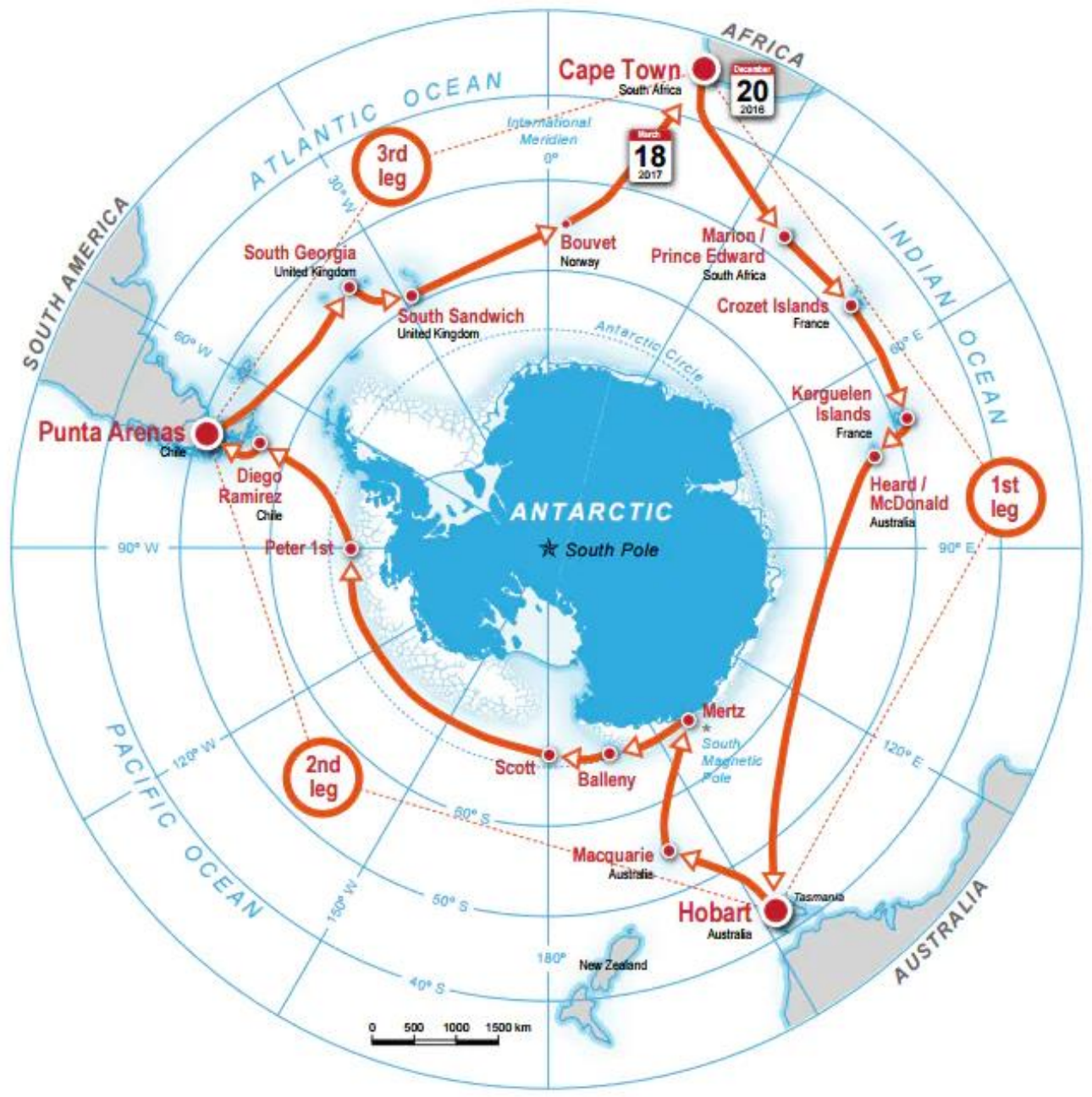

Figure 9.1. Antarctic Circumnavigation Expedition map.

The project in which we participated was named SORPASSO (Surveying Organic Reactive gases and Particles Across the Surface Southern Ocean), with the aim of conducting the first observations of the circumpolar distribution of surface ocean trace gases and particles which are important for the Antarctic atmospheric chemistry and climate. We installed a MAX-DOAS instrument in order to study trace gases which are important for a better knowledge of the interaction between the atmosphere and the ocean. 


\subsection{MAX-DOAS instrument in ACE}

The MAX-DOAS instrument used in the ACE campaign was made up of two parts. The first one is the scanning telescope system, which was placed outside on the second deck of the ship, with a clear view of the horizon. It consists of a weatherproof metal chamber that is located on top of a stabilization system (gimbal table) in order to counteract the ship movements. An inclinometer was also attached to the gimbal table to record the actual pitch and roll of the instrument with the purpose of correcting the EVAs afterwards. Figure 9.2 shows the angular correction of the inclinometer during the ACE campaign.

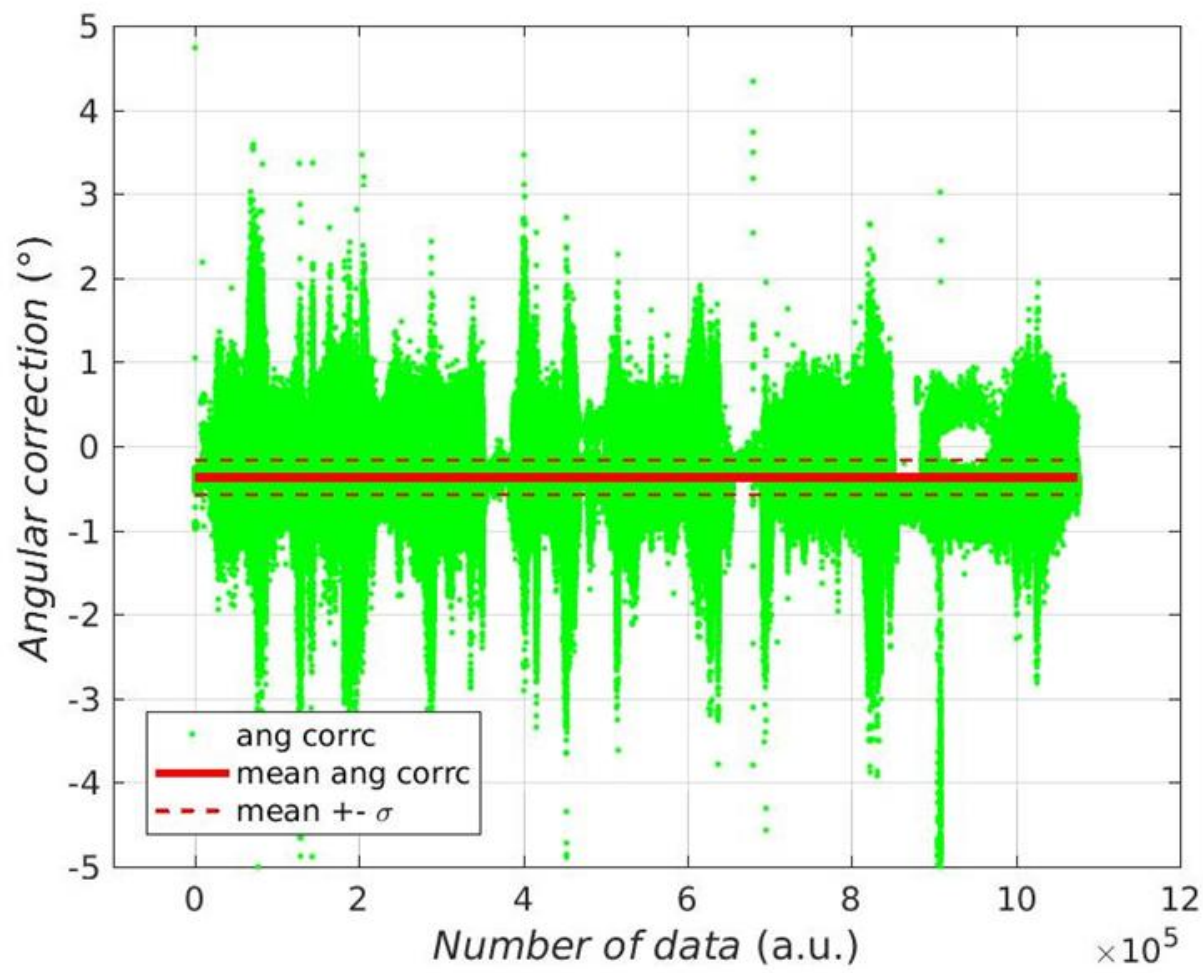

Figure 9.2. MAX-DOAS angular correction during ACE.

The metal chamber has a light collector that receives scattered sunlight. The incoming light is focused by a lens (focal of $200 \mathrm{~mm}$, diameter of $50.8 \mathrm{~mm}$ ) onto an optical fibre which has 19 individual quartz fibres. The optical fibre is then connected to the second part (indoors), which comprises a spectrometer (Princeton Instruments SP500i), a Charge- 
Coupled Device detector (camera CCD Princeton Instruments Pixis 400B) and a computer. Once in the spectrometer, the light is diffracted and dispersed by a 600 groove $/ \mathrm{mm}$ grating resulting in a spectral window of about $90 \mathrm{~nm}$ width, the UV region comprises between 300 $400 \mathrm{~nm}$ and the VIS region $400-500 \mathrm{~nm}$. This indoor part is located in a temperaturecontrolled laboratory. The instrument electronic offset and dark current are subtracted from each measured spectrum following the equations detailed in Section 5.6.2. The exposure time is adjusted automatically depending on the sunlight intensity (Garcia-Nieto, et al., 2018). A couple of pictures that depict both the inner (on the left) and outer (on the right) part of the ship-based MAX-DOAS instrument installed in the ACE campaign is shown in Figure 9.3.
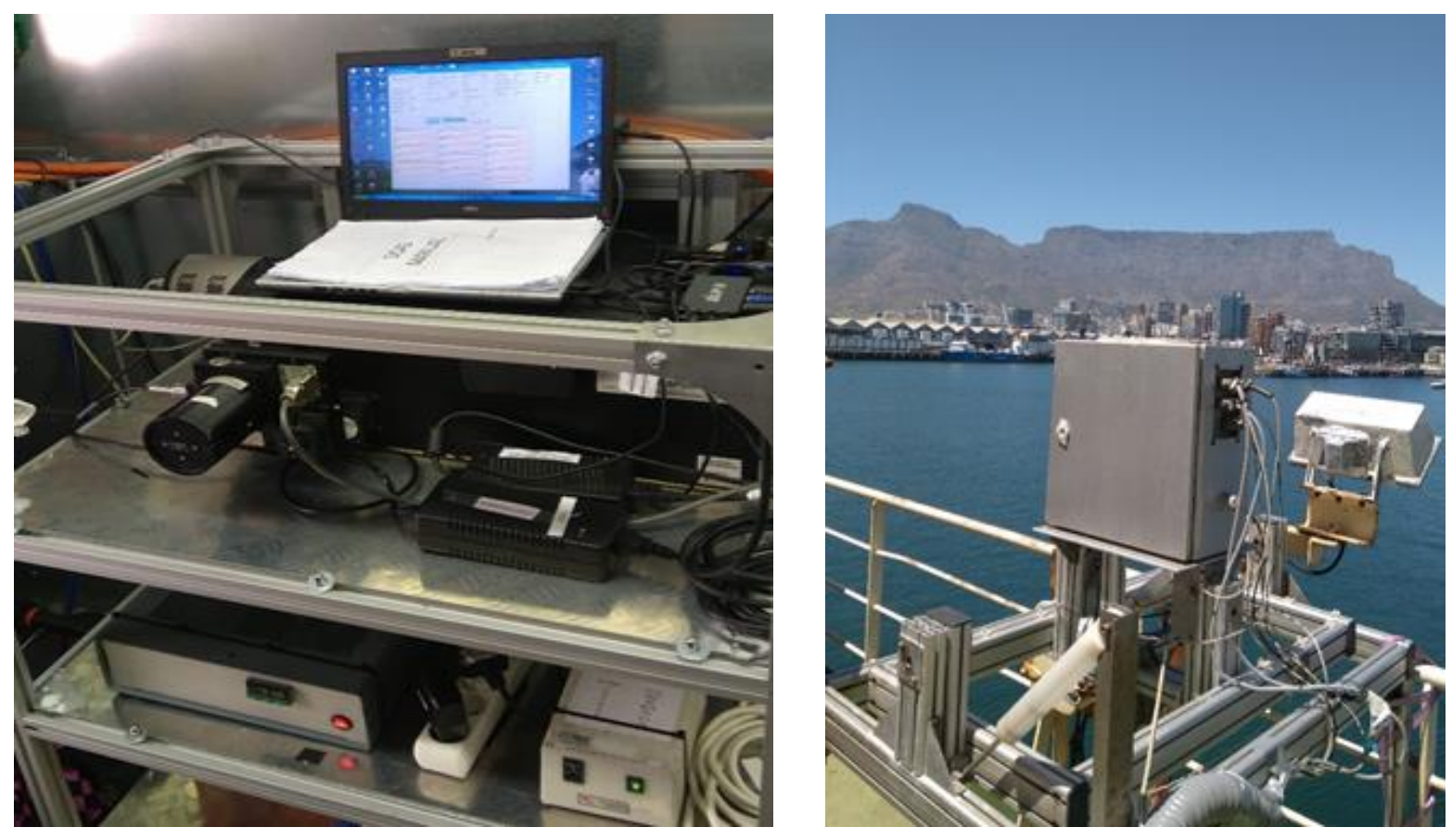

Figure 9.3. Ship-based MAX-DOAS instrument on board the vessel "Akademik Tryoshnikov".

The GPS is necessary for the instrument to know where it is, calculate the SZA, and start measuring whenever the SZA is equal or lower than $90^{\circ}$. However, our GPS broke during the campaign. For this reason, we do not have the complete days during Leg 2 (Figure 9.1), so we cannot analyse the complete results of the leg from Hobart to Punta Arenas. The 
GPS was changed on board (close to the Antarctic peninsula) and all the necessary tests were made in order to keep the instrument running again.

As previously noted, scattered sunlight measurements can be strongly affected by clouds, mainly due to multiple scattering effects that give rise to large uncertainties in the light path retrieval. We installed a camera alongside the MAX-DOAS in order to take pictures of the sky every 5 minutes to evaluate a cloud index (Figure 9.4) which goes from $0 \%$ (clear sky) to $100 \%$ (completely overcast). Only spectra with a cloud index below $40 \%$ are taken into account for further analysis. Note the ACE traversed a particularly cloudy part of the world. All the pictures collected in the campaign are available in the zenodo data set:

\section{https://doi.org/10.5281/zenodo.3827445}
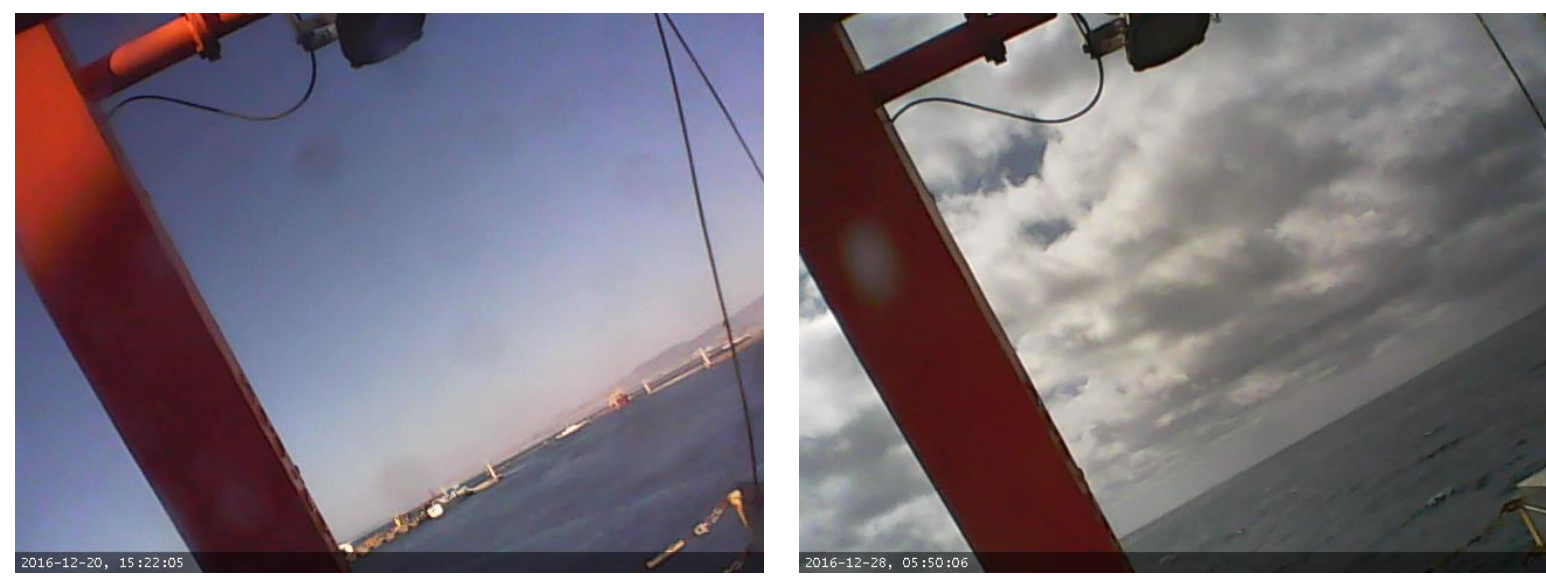

Figure 9.4. Sky images taken during the ACE campaign.

\subsection{Halogen oxides results}

For the $\mathrm{O}_{4}$ analysis, we used the range of 338-370 nm (analysis window used in $\mathrm{O}_{4}$ Garcia-Nieto et al., 2018) with the following cross sections: $\mathrm{O}_{4}$ (Thalman and Volkamer, 2013), $\mathrm{NO}_{2}$ (298 K \& 220 K, Vandaele et al., 1998), O 3 (223 K \& 243 K, Serdyuchenko et al., 2014), HCHO (297 K, Meller and Moortgat, 2000), BrO (223 K, Fleischmann et al., 2004) and a synthetic ring spectrum (calculated by QDOAS). An example of the $\mathrm{O}_{4}$ spectral capture appears in Figure 9.5. 

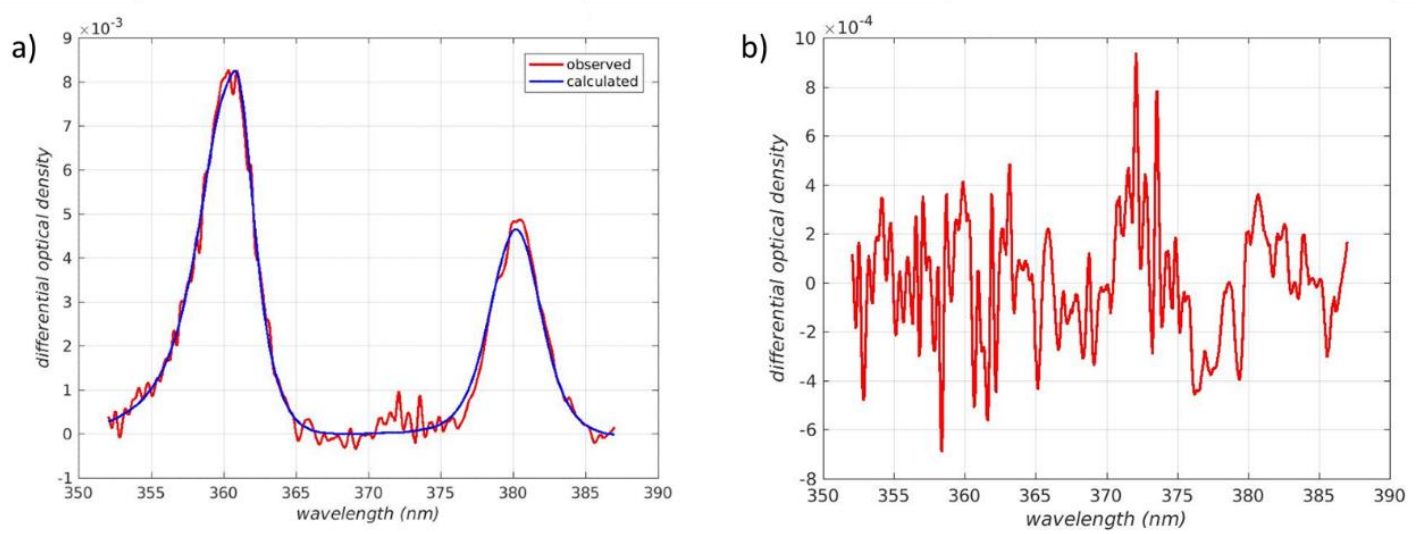

Figure 9.5. Spectral fitting examples for $\mathrm{O}_{4}$. The blue curves are the calculated optical densities for each trace gas while the red curves represent the measured optical density a) and the residual of the analysis b). This spectrum was taken on March 8, 2017 at a SZA of $55^{\circ}$ and an EVA of $6^{\circ}$, the RMS is $2.4 \times 10^{-4}$ in density units.

The following step is to estimate the AOD and the extinction coefficient. To do this, we used the bePRO inversion algorithm (Clémer et al., 2010). For a complete description of that inversion algorithm see Hendrick et al., 2014. The first step in bePRO is to estimate the aerosol extinction profiles. Making use of the extinction coefficient profiles derived from the UV region (at $360 \mathrm{~nm}$ ) and the Ångström exponent $(\alpha)$ (available on the AERONET website) we calculated the extinction coefficient in the visible region following this equation:

$$
\tau_{427}=\tau_{360}\left(\frac{\lambda_{427}}{\lambda_{360}}\right)^{-\alpha}
$$

where $\tau$ is the extinction coefficient, $\lambda$ is the wavelength and $\alpha$ is the Ångström exponent between $380 \mathrm{~nm}$ and $500 \mathrm{~nm}$.

For BrO, the DOAS analysis setup is summarized in Table 9.1. Note that the configuration is similar to the one used in the Arctic (see Table 8.1) but we included the water vapour absorption cross section because the spectra were collected over the ocean 
at much higher relative humidity. This fitting window is based on Prados-Roman et al., 2018. In order to minimize the root mean square of the residuals, we included the averaged residual for the entire campaign as a cross section with the advantage of taking care of possible systematic structures in our spectra that might be caused by instrumental effects.

Table 9.1. DOAS fit setting for BrO in the UV band for the ACE campaign.

\begin{tabular}{|c|c|}
\hline Parameter & Value \\
\hline Fitting Window & $338-356 n m$ \\
\hline Wavelength Calibration & $\begin{array}{l}\text { Calibration based on reference solar atlas } \\
\text { (Chance and Kurucz, 210) }\end{array}$ \\
\hline Cross section & \\
\hline $\mathrm{BrO}$ & 223 K, Fleischmann (2004) \\
\hline $\mathrm{NO}_{2}$ & 220 K \& 294 K, Vandaele (1998) \\
\hline $\mathrm{O}_{3}$ & 223 K \& 273 K, Serdyuchenko (2014) \\
\hline $\mathbf{O}_{4}$ & Thalman and Volkamer (2013) \\
\hline $\mathrm{H}_{2} \mathrm{O}$ liquid & Pope and Fry (1997) \\
\hline Ring & Calculated by QDOAS \\
\hline Polynomial order & 2 \\
\hline Shift & $\begin{array}{l}\text { The measured spectra and the Ring were } \\
\text { allowed to shift in wavelength (order } 1 \text { ) }\end{array}$ \\
\hline Intensity Offset & Order 2 \\
\hline
\end{tabular}


Figure 9.6 shows the spectral detection of BrO -on February 23, 2017-is presented at SZA of $78^{\circ}$ and EVA of $4^{\circ}$, the RMS is $2.6 \times 10^{-4}$ in density units.

a)

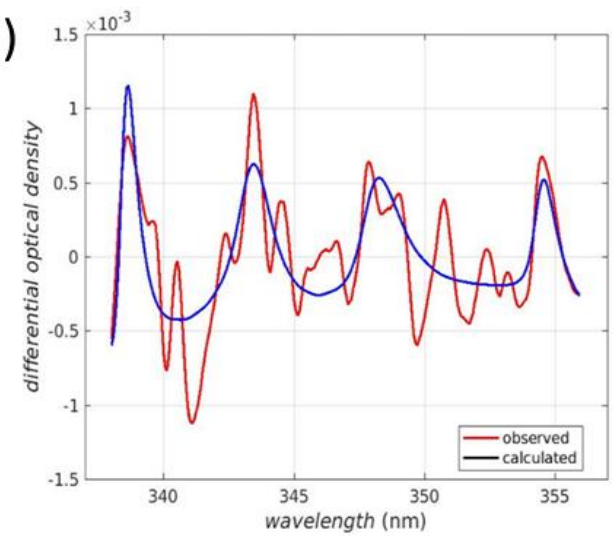

b)

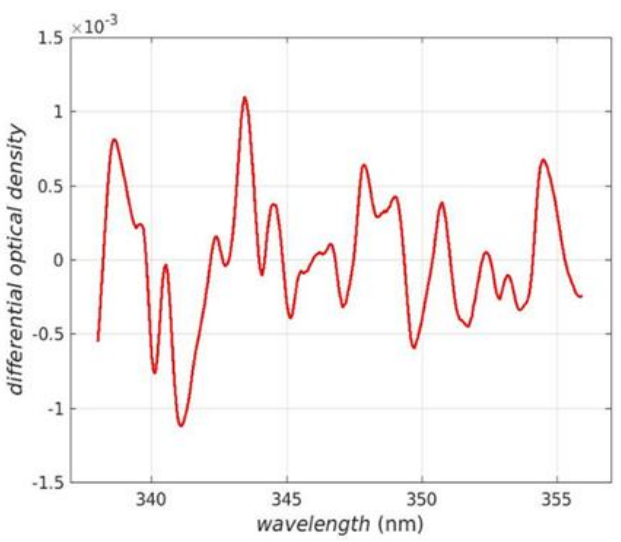

Figure 9.6. Spectral fitting examples for $\mathrm{BrO}$ The blue curves are the calculated optical densities for each trace gas while the red curves represent the measured optical density a) and the residual of the analysis b). This spectrum was taken on March 8 , the EVA is $4^{\circ}$ and the SZA is $78^{\circ}$, the RMS is $2.6 \times 10^{-4}$ in density units.

Moving to the 10 analysis, 10 has strong absorption structures in the spectral range between 415 and $440 \mathrm{~nm}$. The exact configuration and the cross sections used for this analysis are the same as those used for the VRS measurements, section 8.2. (Table 8.3). A daily noon spectrum (also at $90^{\circ}$ of VEA) was used as a reference for the calculations. A spectral detection of 10 at EVA $=3^{\circ}$ and the SZA is $83^{\circ}$ and the RMS associated to this spectrum is $4.12 \times 10^{-4}$ in density units are shown in Figure 9.7. 

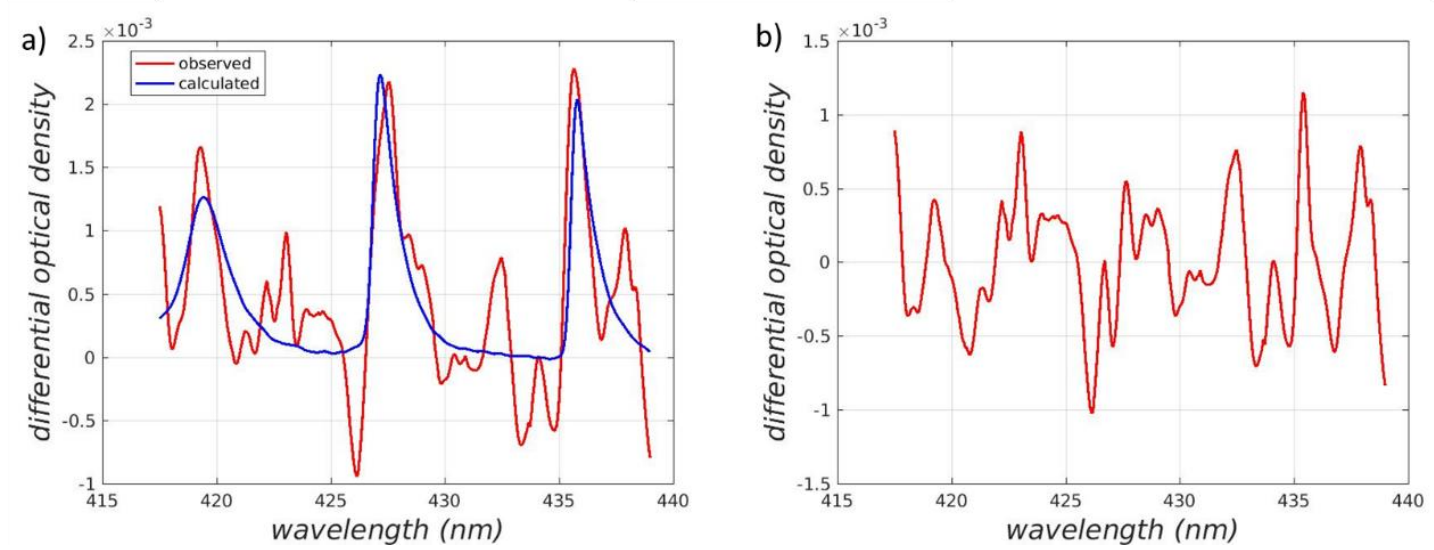

Figure 9.7. Spectral fitting examples for IO. The blue curves are the calculated optical densities for each trace gas while the red curves represent the measured optical density a) and the residual of the analysis b). This spectrum was taken on February 22, 2017. The spectrum was taken at a SZA of $83^{\circ}$ and an EVA of $3^{\circ}$.

Once the aerosol extinction coefficient is subtracted, the following step is to retrieve the trace gas profile. There are important parameters in the OEM model like the a priori profiles. This study uses an exponentially-decreasing curve as a priori profile, with an exponential constant of $0.5 \mathrm{~km}$ and an assumed VCD coming from the geometrical approximations which is that the trace gas is placed below the scattering altitude (Hendrick et al., 2014). The a priori profiles are used in bePRO to start the iteration in the inversion algorithm and to prevent solutions to be not realistic enough. The covariance matrices associated to the a priori profile have considerable effect in the results. To prevent nonphysical oscillations an equilibrium has to be found to optimize the degrees of freedoms. The relative weight of the a priori profiles in the analysis comes from the covariance matrix. A scaling factor of 0.5 times the a priori profile squared, with a correlation length between layers of $0.2 \mathrm{~km}$ has been chosen (see Clémer et al., 2010).

The height grid used in this work had 68 layers, the first one ranging from $0 \mathrm{~m}$ (ground surface) to $200 \mathrm{~m}$; then nine layers of $200 \mathrm{~m}$ thickness each, between $0.2 \mathrm{~km}$ and $4 \mathrm{~km}$; after that, we included another twelve layers ranging from $4 \mathrm{~km}$ to $10 \mathrm{~km}$ of $500 \mathrm{~m}$ thickness each; from $10 \mathrm{~km}$ to $30 \mathrm{~km}$ the layers have $1 \mathrm{~km}$ and finally the remaining layers 
have $2 \mathrm{~km}$ thickness (up to $60 \mathrm{~km}$ height). For the bePRO retrievals, the temperature and pressure profiles were taken from the average temperature provided by the ship database during ACE circumnavigation and interpolated to the height grid described above.

bePRO provides the optimal simulated DSCDs. One day of this comparison between simulated and measured DSCDs is shown in Figure 9.8 for both $\mathrm{BrO}$ and $\mathrm{IO}$, with a correlation coefficient of 0.99 and the slope is 1.13 for $\mathrm{BrO}$, and a correlation coefficient of 0.99 and a slope of 0.93 for 10 . Both comparisons are indicative of a good analysis. The uncertainties are large, and one reason could be that the measurements are made on board of a vessel and it is in continuous movement, in a particularly rough ocean. We corrected for the EVA but it might not be enough.

a)
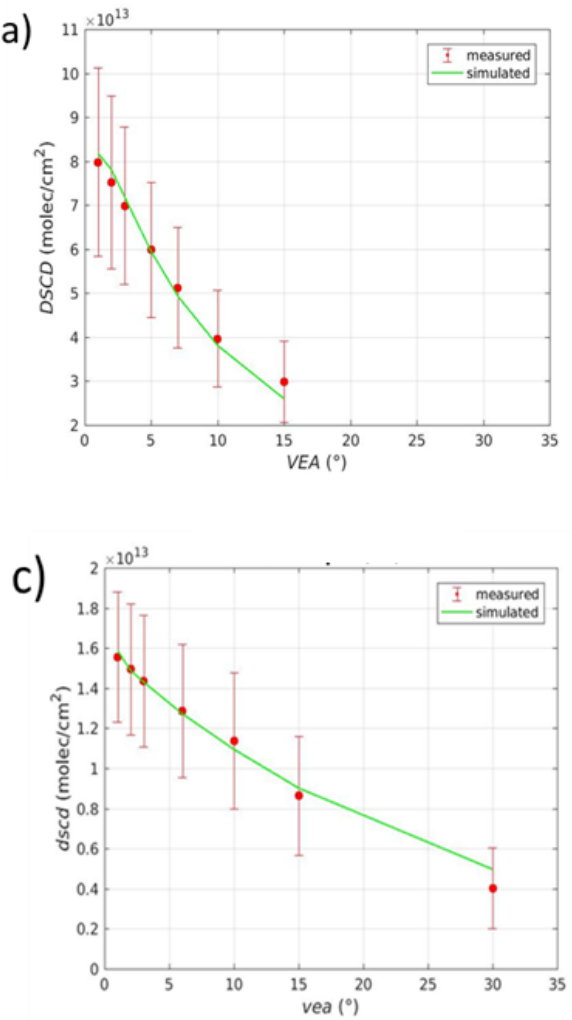

b)
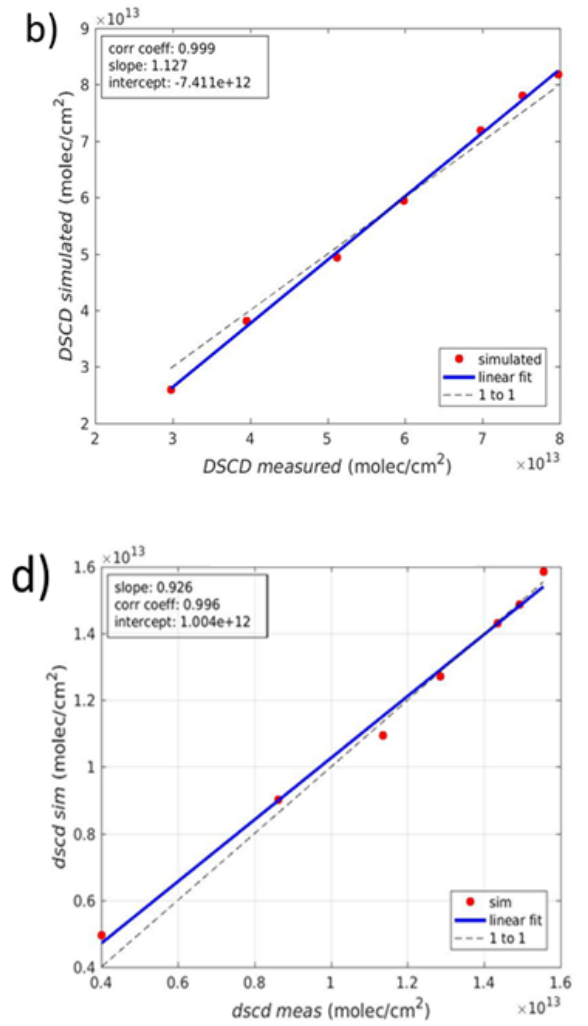

Figure 9.8. Comparison between measured and simulated DSCDs for $\mathrm{BrO}$ a), b) and IO c), d). 
Figure 9.9 represents the AOD values. Using AERONET data for AOD in the Antarctic bases, AOD of about 0.4 were measured in 2018 in Marambio Station $\left(64.24^{\circ} \mathrm{S}, 56.26^{\circ} \mathrm{W}\right.$ ) and in Crozet Island $\left(46.43^{\circ} \mathrm{S}, 51.85^{\circ} \mathrm{E}\right)$; mean values of about $0.55 \mathrm{AOD}$ were measured in Vechernaya Hill $\left(67.66^{\circ} \mathrm{S}, 46.16^{\circ} \mathrm{E}\right)$. Average values in the Atlantic Ocean are on average 0.57 in St. Helena $\left(15.94^{\circ} \mathrm{S}, 5.67^{\circ} \mathrm{W}\right)$ in 2017 . Comparing these values with the ones that MAXDOAS measured in the UV region, we observe similar results, this circumnavigation offers therefore a complete database of AOD along the Atlantic and Antarctic Oceans.

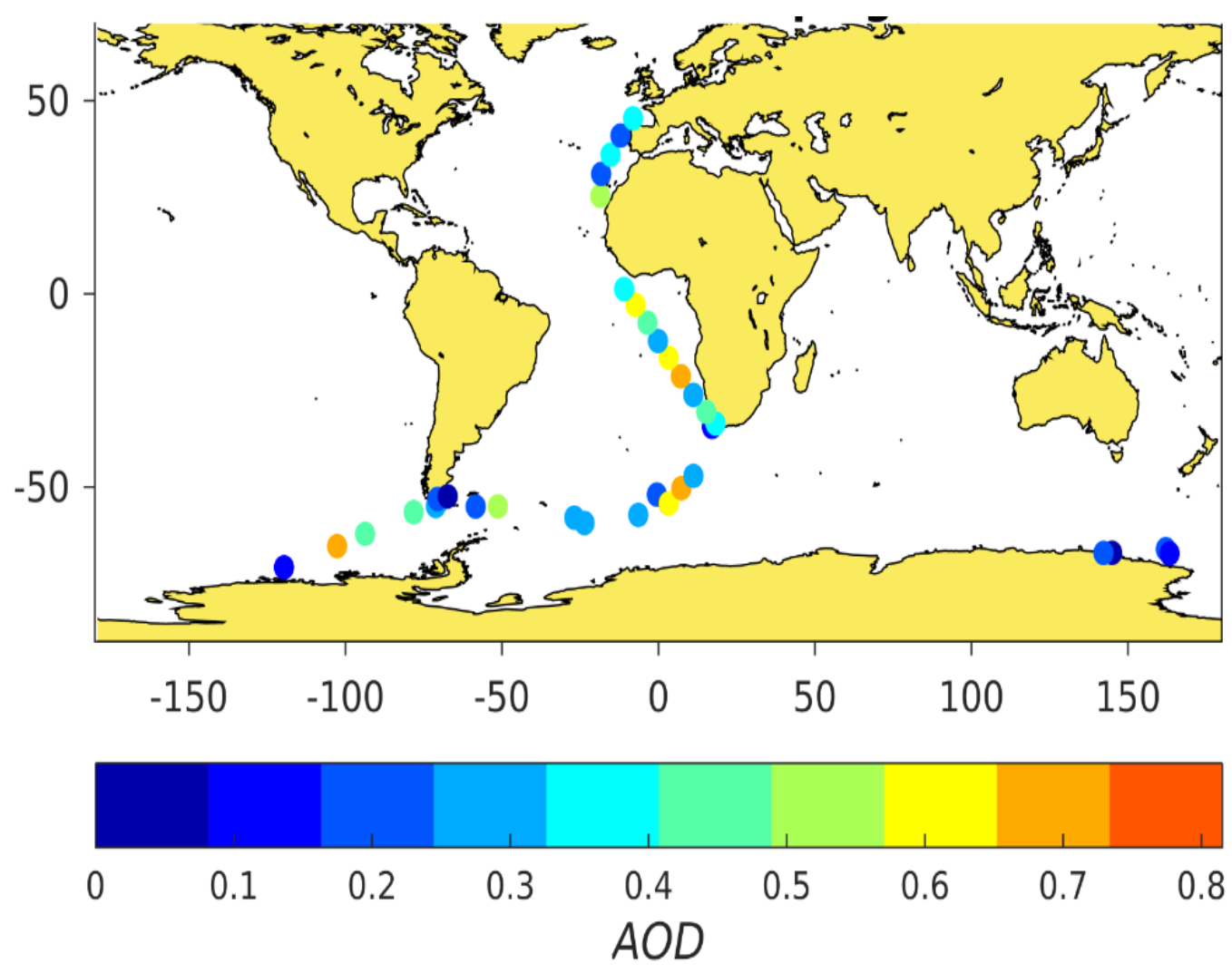

Figure 9.9. Retrieved AOD for the ACE campaign.

We now turn to the retrieved $\mathrm{BrO}$ values. The surface mixing ratios are shown in Figure 9.10. Previous BrO measurements in the Antarctic reported values of tens of pptv (Wagner et al., 2007). Values up to 20 pptv at Halley Station, Antarctica (Saiz-Lopez et al., 2007); 13 pptv were measured at Halley Station (Buys et al., 2012). These measurements are made during spring time while our results are for summer months. BrO results in the 
Antarctic Ocean show lower values than in the Antarctic Stations. We report BrO measurements ranging from 0.5 pptv to values up to 14.3 pptv. Surfaces mixing ratios up to 10 pptv are measured near the Equator. Note that in a previous campaign, Martin et al., 2009 reported mixing rations of BrO next to the equator of about 10 pptv in February 2007. Our results present summer values of around 1 pptv in the Antarctic Ocean at a latitude of $66^{\circ}$ and a longitude of $162^{\circ}$. This database was published in Zenodo (Benavent et al., 2020). Regarding the BrO VCD, satellite observations reported by Schönhardt et al., 2012, show VCD values of $4-7 \times 10^{13}$ molecule $\mathrm{cm}^{-2}$ while values of $7.5 \times 10^{13}$ molecule $\mathrm{cm}^{-2}$ were retrieved in Antarctica (Hollwedel et al., 2004). The BrO VCD in this circumnavigation ranges from values up to $3.38 \times 10^{11}$ molecules $\mathrm{cm}^{-2}$ at this location: $-55.01^{\circ}$ (latitude), $100.16^{\circ}$ (longitude), to $1.7 \times 10^{13}$ molecules $\mathrm{cm}^{-2}$ at a latitude of $58.73^{\circ}$ and a longitude of $-55.04^{\circ}$.

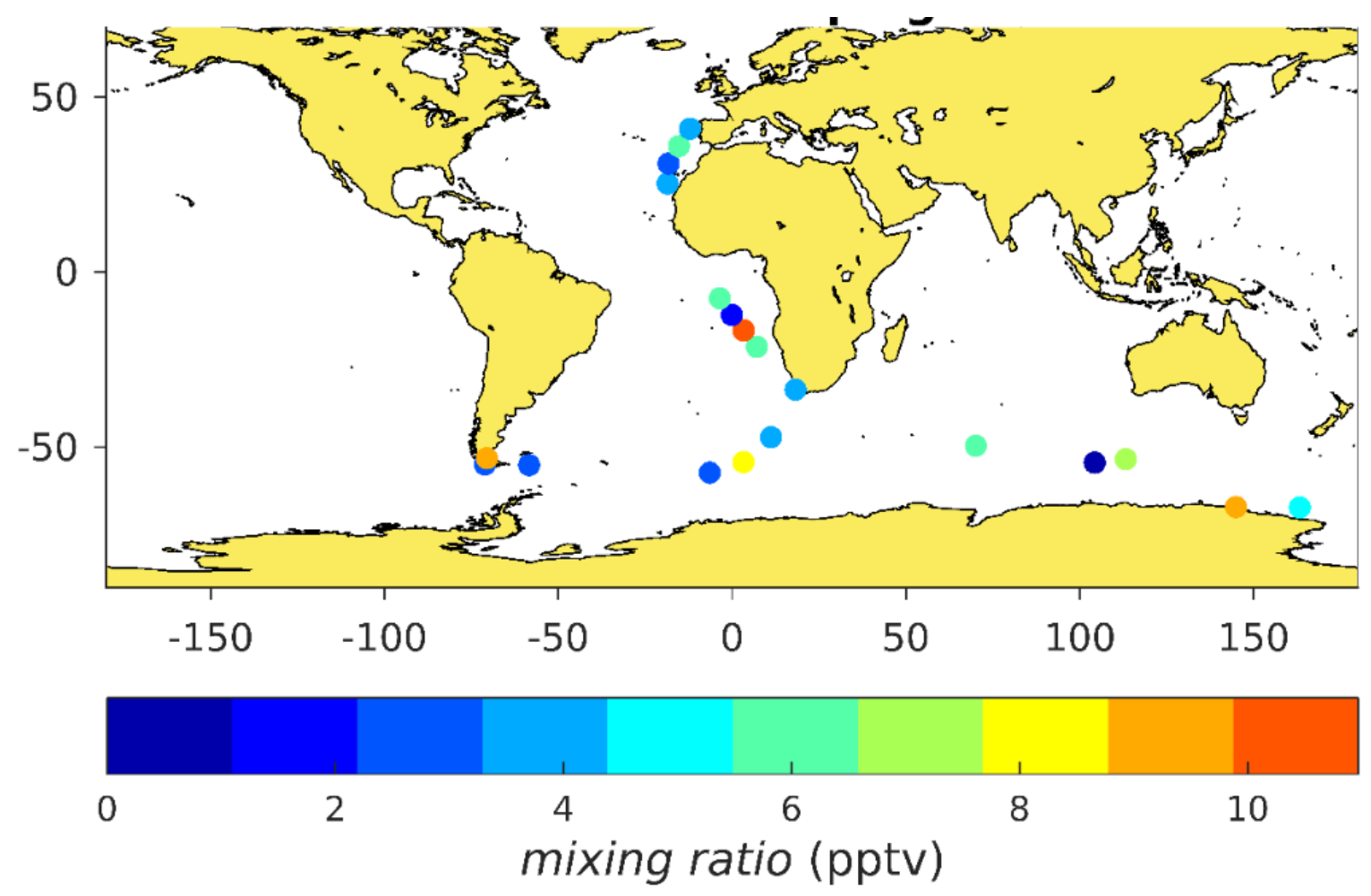

Figure 9.10. Available BrO measurements during the ACE campaign along the ship track. 
IO mixing ratios during the circumnavigation are shown in Figure 9.11. Mixing ratios range from 0.2 pptv to 3 pptv, with the maximum values found near the Equator and close to coastal Europe, whereas close to the Antarctic continent, the summer mixing ratios in the boundary layer are usually below 1 pptv. Previous studies reported 10 values of about 1.6 pptv at Neumayer Station in austral summer 2002/2003 (Frieß et al., 2009); similar values reported in Prados-Roman et al., 2015 show values of 0.5-0.6 pptv in the South Atlantic Ocean (December 2010-July 2011) and up to 5 pptv at Cape Verde (Mahajan et al., 2010) (February-March 2008). As for the IO VCDs, the values are in the lower $10^{12}$ molecule $\mathrm{cm}^{-2}$, while higher values of about $1 \times 10^{13}$ molecule $\mathrm{cm}^{-2}$ were found close to the coast (near Punta Arenas and in the West Africa coast).

Finally, note that our ACE observations need further research to assess the sources of the measured levels, along with differences with other reports, and their impact on atmospheric ozone. However, despite the difficulties during the campaign, the few available data shed some light on the halogen levels on previously non-sampled parts of the ocean.

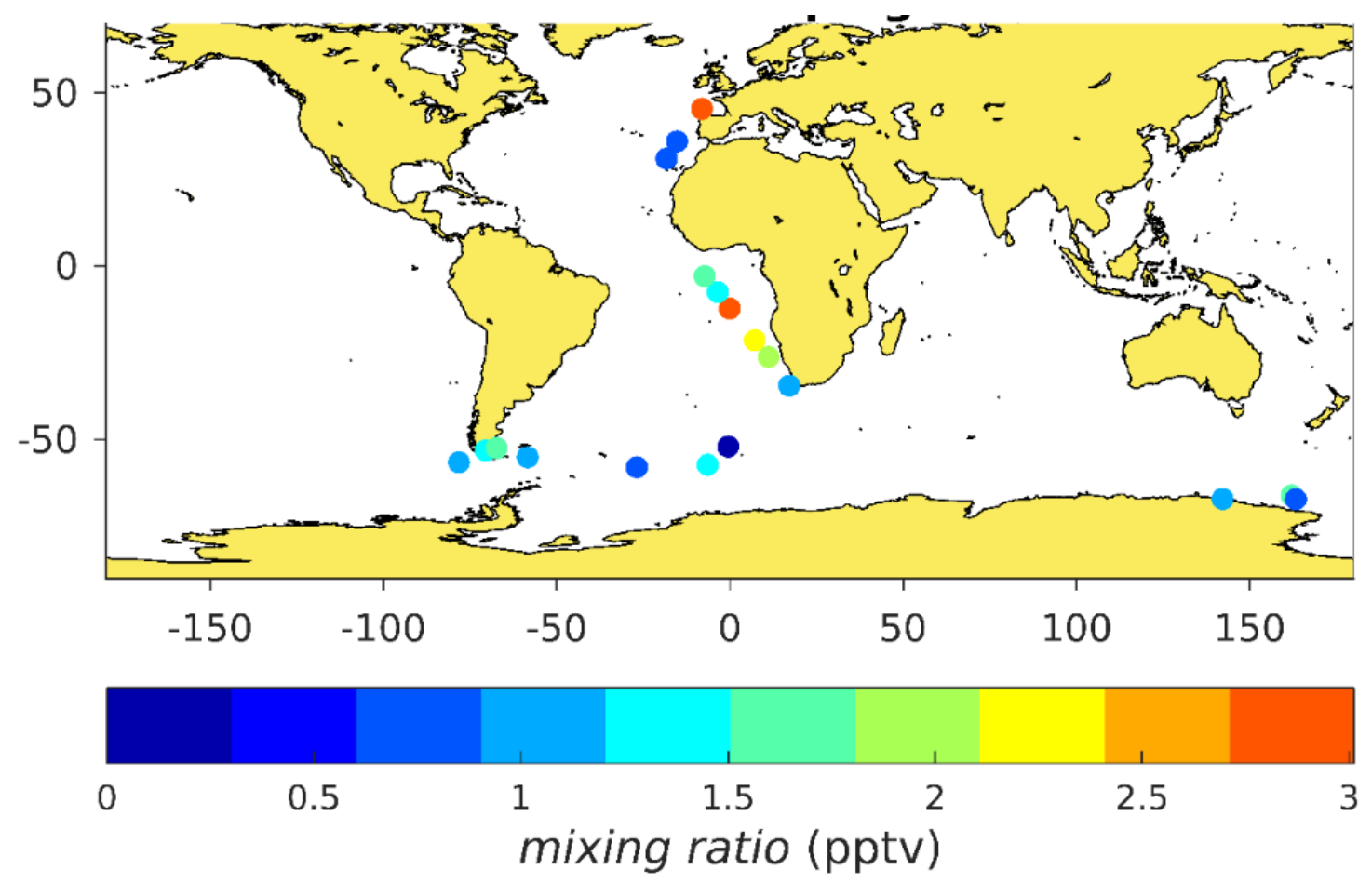

Figure 9.11. Available IO measurements during the ACE campaign along the ship track. 


\section{CONCLUSIONS AND FUTURE}

\section{WORK}

Ground-based Multi-Axis Differential Optical Absorption Spectroscopy (MAX-DOAS) measurements of bromine oxide $(\mathrm{BrO})$ and iodine oxide $(\mathrm{IO})$ were made in the Arctic (Station Nord, Greenland) during 2017-2018 and the Antarctic Ocean (ACE campaign) during 2016-2017.

The first aim of this thesis was to build a MAX-DOAS instrument adapted to the polar conditions (strong winds, temperatures below zero...). Once the instrument was built and thoroughly tested, it was installed at Station Nord (Villum Research Station, Greenland) in April 2017. Since then, the instrument has been operating during the Arctic sunlit periods. The collected spectra have been filtered and analysed following the DOAS technique, together with a radiative transfer code developed during this thesis, to retrieve the concentrations of $\mathrm{BrO}$ and $\mathrm{IO}$.

The seasonal pattern of $\mathrm{BrO}$ follows that of an U-shape with peak values in spring and autumn, and minima in the summer months. Monthly daytime average values up to 25 pptv in early spring and autumn are measured, while in summer values up to 5 pptv are retrieved. The $\mathrm{IO}$ analysis is more challenging than that of $\mathrm{BrO}$ typically due to much lower IO levels. We measured background levels of 10 of 1 pptv in the Arctic boundary layer, with peaks of $3.5 \mathrm{pptv}$. These measurements are the first continuous observations of 10 , demonstrating the ubiquitous of active iodine chemistry in the sunlit Arctic atmosphere. The instrument continues its operation at Station Nord and the goal is to extend the 
measurements several more years to assess long term changes in the loading of halogens in the Arctic atmosphere.

Based on the observed levels of $\mathrm{BrO}$ and $\mathrm{IO}$, we calculated the resulting ozone loss using the one-dimensional chemistry transport THAMO model. We calculate that including the inclusion of iodine chemistry in the model leads to an enhancement of the $\mathrm{O}_{3}$ loss rate of $30 \%$. We note that the ubiquitous presence of active iodine in the Arctic should be taken into account in the polar atmospheric models.

Finally, we also participated in the first Antarctic Circumnavigation Campaign (ACE) in which we installed a MAX-DOAS instrument on board the research vessel "Akademik Tryoshnikov". We measured scattered sunlight spectra in the marine boundary layer in the Antarctic Ocean and in the Atlantic Ocean. The austral summer measurements show less BrO mixing ratios in the Antarctic Ocean than in Atlantic. IO values range from 0.2 pptv to 3 pptv. Future work will use a global chemistry climate model to address the source precursors and atmospheric implications of the observed halogen oxides variability during the Antarctic circumnavigation 


\section{BIBLIOGRAPHY}

Aliwell, S. R., Van Roozendael, M., Johnston, P. V., Richter, A., Wagner, T., Arlander, D. W., Burrows, J. P., Fish, D. J., Jones, R. L., Tørnkvist, K. K., Lambert, J. C., Pfeilsticker, K., \& Pundt, I. (2002). Analysis for BrO in zenith-sky spectra: An intercomparison exercise for analysis improvement. Journal of Geophysical Research Atmospheres. https://doi.org/10.1029/2001JD000329.

Arpag, K. H., Johnston, P. V., Miller, H. L., Sanders, R. W., \& Solomon, S. (1994). Observations of the stratospheric BrO column over Colorado, $40^{\circ} \mathrm{N}$. Journal of Geophysical Research. https://doi.org/10.1029/94JD00144.

Baccarini, A., Karlsson, L., Dommen, J., Duplessis, P., Vüllers, J., Brooks, I. M., Saiz-Lopez, A., Salter, M., Tjernström, M., Baltensperger, U., Zieger, P., \& Schmale, J. (2020). Frequent new particle formation over the high Arctic pack ice by enhanced iodine emissions. Nature Communications. https://doi.org/10.1038/s41467-020-18551-0

Barrie, L. A., Bottenheim, J. W., Schnell, R. C., Crutzen, P. J., \& Rasmussen, R. A. (1988). Ozone destruction and photochemical reactions at polar sunrise in the lower Arctic atmosphere. Nature. https://doi.org/10.1038/334138a0.

Barrie, L., \& Platt, U. (1997). Arctic tropospheric chemistry: An overview. In Tellus, Series B: Chemical and Physical Meteorology. https://doi.org/10.3402/tellusb.v49i5.15984

Bates, D. R., and Nicolet M. (1950). The photochemistry of atmospheric water vapor, J. Geophys. Res., 55, 301. 
Benavent, N., Garcia-Nieto, D., Cuevas, C.A., \& Saiz-Lopez, A. (2020). Bromine monoxide (BrO) measurements made using a MAX-DOAS (Multi-AXis Differential Optical Absorption Spectroscopy) instrument in the austral summer of 2016/17 during the Antarctic Circumnavigation Expedition (ACE). (Version 1.0) [Data set]. Zenodo. http://doi.org/10.5281/zenodo.3843263.

Benavent, N., Garcia-Nieto, D., Cuevas, C.A., \& Saiz-Lopez, A. (2020). Sky images recorded during the austral summer of $2016 / 17$ as part of the Antarctic Circumnavigation Expedition (ACE). (Version 1.0) [Data set]. Zenodo.

http://doi.org/10.5281/zenodo.3827445.

Benavent, N., Garcia-Nieto, D., Wang, S., \& Saiz-Lopez, A. (2019). MAX-DOAS measurements and vertical profiles of glyoxal and formaldehyde in Madrid, Spain. Atmospheric Environment. https://doi.org/10.1016/i.atmosenv.2018.11.047.

Bogumil, K., Orphal, J., Homann, T., Voigt, S., Spietz, P., Fleischmann, O. C., Vogel, A., Hartmann, M., Kromminga, H., Bovensmann, H., Frerick, J., \& Burrows, J. P. (2003). Measurements of molecular absorption spectra with the SCIAMACHY pre-flight model: Instrument characterization and reference data for atmospheric remote-sensing in the 230$2380 \mathrm{~nm}$ region. Journal of Photochemistry and Photobiology A: Chemistry. https://doi.org/10.1016/S1010-6030(03)00062-5.

Bottenheim, J. W., Barrie, L. A., Atlas, E., Heidt, L. E., Niki, H., Rasmussen, R. A., Shepson, P. B. (1990). Depletion of Lower Tropospheric Ozone During Arctic Spring - the Polar Sunrise Experiment 1988. Journal of Geophysical Research-Atmospheres 95 (D11), 18555-18568.

Brasseur, G. P., Orlando, J. J., and Tyndall, G. S. (1999). Atmospheric Chemistry and Global Change, Oxford University Press, New York. 
Brooks, S. B., Saiz-Lopez, A., Skov, H., Lindberg, S. E., Plane, J. M. C., and Goodsite, M. E. (2006). The mass balance of mercury in the springtime arctic environment, Geophys. Res. Lett., 33, L13812, doi:10.1029/2005GL025525.

Burkholder, J. B., Sander, S. P., Abbatt, J. , Barker, J. R., Huie, R. E., Kolb, C. E., Kurylo, M. J., Orkin, V. L., Wilmouth, D. M., and Wine, P. H. (2015). Chemical Kinetics and Photochemical Data for Use in Atmospheric Studies, Evaluation No. 18, JPL Publication 1510, Jet Propulsion Laboratory, Pasadena, http://jpldataeval.jpl.nasa.gov.

Buys, Z., Brough, N., Huey, G., Tanner, D., Glasow, R., \& Jones, A.E. (2012). Br2 , BrCl, BrO and surface ozone in coastal Antarctica: a meteorological and chemical analysis. Atmospheric Chemistry and Physics, 12, 11035-11077.

Chameides, W. L. and Davis, D. D. (1980). lodine: Its possible role in tropospheric photochemistry, J. Geophys. Res., 85, 7383-7398.

Chance, K. V., \& Spurr, R. J. D. (1997). Ring effect studies: Rayleigh scattering, including molecular parameters for rotational Raman scattering, and the Fraunhofer spectrum. Applied Optics. https://doi.org/10.1364/ao.36.005224.

Chapman S.A (1930). Theory of Upper-Atmospheric Ozone, Memoirs of the Royal Meteorological Society, Vol. III (No. 26).

Clémer, K., Van Roozendael, M., Fayt, C., Hendrick, F., Hermans, C., Pinardi, G., Spurr, R., Wang, P., De Mazière, M., 2010. Multiple wavelength retrieval of tropospheric aerosol optical properties from MAX-DOAS measurements in Beijing. Atmos. Meas. Tech. 3 (4), 863.

Cuevas, C. A., Maffezzoli, N., Corella, J. P., Spolaor, A., Vallelonga, P., Kjær, H. A., Simonsen, M., Winstrup, M., Vinther, B., Horvat, C., Fernandez, R. P., Kinnison, D., Lamarque, J. F., 
Barbante, C., \& Saiz-Lopez, A. (2018). Rapid increase in atmospheric iodine levels in the North Atlantic since the mid-20th century. Nature Communications. https://doi.org/10.1038/s41467-018-03756-1.

Crutzen, P. J. (1970). The influence of nitrogen oxides on the atmospheric ozone content, Quart. J. R. Met. Soc.,96, 320-325.

Deutschmann, T., Beirle, S., Frieß, U., Grzegorski, M., Kern, C., Kritten, L., Platt, U., PradosRomán, C., Pukite, J., Wagner, T., Werner, B., \& Pfeilsticker, K. (2011). The Monte Carlo atmospheric radiative transfer model McArtim: Introduction and validation of Jacobians and 3D features. Journal of Quantitative Spectroscopy and Radiative Transfer. https://doi.org/10.1016/j.jqsrt.2010.12.009.

Dixneuf, S., Ruth, A. A., Vaughan, S., Varma, R. M., and Orphal, J. (2009). The time dependence of molecular iodine emission from Laminaria digitata, Atmos. Chem. Phys., 9, 823-829, https://doi.org/10.5194/acp-9-823-2009.

Fan, S. M., \& Jacob, D. J. (1992). Surface ozone depletion in Arctic spring sustained by bromine reactions on aerosols. Nature. https://doi.org/10.1038/359522a0.

Farman, J.C., Gardiner, B.G. \& Shanklin, J.D. (1985). Losses of total ozone in Antarctica reveal seasonal $\mathrm{ClO}_{x} / \mathrm{NO}_{x}$ interaction. Nature 315, 207-210. https://doi.org/10.1038/315207a0.

Fleischmann, O.C., Hartmann, M., Burrows, J.P., Orphal, J. (2004). New ultraviolet absorption cross-sections of $\mathrm{BrO}$ at atmospheric temperatures measured by time windowing Fourier transform spectroscopy. J. Photochem. Photobiol. A Chem. 168, 117-132. 
Fleischmann, O.C., Hartmann, M., Burrows, J.P., Orphal, J. (2004). New ultraviolet absorption cross-sections of $\mathrm{BrO}$ at atmospheric temperatures measured by timewindowing Fourier transform spectroscopy. J. Photochem. Photobiol. Chem. 168 (1-2), 117132.

Frieß, U., Sihler, H., Sander, R., Pöhler, D., Yilmaz, S., and Platt, U. (2011). The vertical distribution of $\mathrm{BrO}$ and aerosols in the Arctic: Measurements by active and passive differential optical absorption spectroscopy, J. Geophys. Res., 116, D00R04, doi:10.1029/2011JD015938.

Frieß, U., Deutschmann, T., Gilfedder, B., Weller, R. and Platt, U. (2009). lodine monoxide in the Antarctic snowpack, Atmospheric Chemistry and Physics, 102456, 2439, doi: 10.5194/acp-10-2439-2010

Frieß, U., K. Kreher, P. V. Johnston, and U. Platt, (2005). Ground-Based DOAS Measurements of Stratospheric Trace Gases at Two Antarctic Stations during the 2002 Ozone Hole Period. J. Atmos. Sci., 62, 765-777, https://doi.org/10.1175/JAS-3319.1.

Gálvez, O., Gómez Martín, J. C., Gómez, P. C., Saiz-Lopez, A., \& Pacios, L. F. (2013). A theoretical study on the formation of iodine oxide aggregates and monohydrates. Physical Chemistry Chemical Physics. https://doi.org/10.1039/c3cp51219c

Garcia-Nieto, D., Benavent, N., \& Saiz-Lopez, A. (2018). Measurements of atmospheric HONO vertical distribution and temporal evolution in Madrid (Spain) using the MAX-DOAS technique. Science of the Total Environment, 643. https://doi.org/10.1016/j.scitotenv.2018.06.180. 
Gómez Martín, J. C., Gálvez, O., Baeza-Romero, M. T., Ingham, T., Plane, J. M. C., \& Blitz, M. A. (2013). On the mechanism of iodine oxide particle formation. Physical Chemistry Chemical Physics. https://doi.org/10.1039/c3cp51217g.

Gonzalez Abad, G., Souri, A.H., Bak, J., Chance, K., Flynn, L., Krotkov, N., Lamsal, L., Li, C., Liu, X., Miller, C., Nowlan, C., Suleiman, R., \& Wang, H. (2019). Five decades observing Earth's atmospheric trace gases using ultraviolet and visible backscatter solar radiation from space. Journal of Quantitative Spectroscopy \& Radiative Transfer, 238, 106478.

Grainger, J. F., and Ring, J., (1962). The Physics and Astronomy of the Moon, edit. by Z. Kopal, 383, Academic Press.

Grannas, A. M., Jones, A. E., Dibb, J., Ammann, M., Anastasio, C., Beine, H. J., Bergin, M., Bottenheim, J., Boxe, C. S., Carver, G., Chen, G., Crawford, J. H., Dominé, F., Frey, M. M., Guzmán, M. I., Heard, D. E., Helmig, D., Hoffmann, M. R., Honrath, R. E., ... Zhu, T. (2007). An overview of snow photochemistry: Evidence, mechanisms and impacts. Atmospheric Chemistry and Physics. https://doi.org/10.5194/acp-7-4329-2007

Hausmann, M., \& Platt, U. (1994). Spectroscopic measurement of bromine oxide and ozone in the high Arctic during polar sunrise experiment 1992. Journal of Geophysical Research. https://doi.org/10.1029/94jd01314

Hendrick, F., Müller, J.-., Clémer, K., Wang, P., De Mazière, M., Fayt, C., Gielen, C., Hermans, C., Ma, J., Pinardi, G., Stavrakou, T., Vlemmix, T., Van Roozendael, M. (2014). Four years of ground-based MAX-DOAS observations of HONO and NO2 in the Beijing area. Atmos. Chem. Phys. 14 (2), 765.

Henyey L. G., and Greenstein J L. (1941). Diffuse radiation in the galaxy Astrophys. J., 93, 7083. 
Hergert, W., \& Wriedt, T. (2012). The Mie Theory. The Mie Theory: Basics and Applications. https://doi.org/10.1007/978-3-642-28738-1

Hollwedel, J., Wenig, M., Beirle, S., Kraus, S., Kühl, S., Wilms-Grabe, W., Platt, U., \& Wagner, T. (2004). Year-to-year variations of spring time polar tropospheric $\mathrm{BrO}$ as seen by GOME. Advances in Space Research, 34, 804-808.

Hönninger, G., Von Friedeburg, C., Platt, U. (2004). Multi axis differential optical absorption spectroscopy (MAX-DOAS). Atmos. Chem. Phys. 4, 231-254.7

Honsberg, C.B., and Bowden, S.G. (2019). "Absorption Coefficient," page on www.pveducation.org.

Jacobi, H. W., Kaleschke, L., Richter, A., Rozanov, A., \& Burrows, J. P. (2006). Observation of a fast ozone loss in the marginal ice zone of the Arctic Ocean. Journal of Geophysical Research Atmospheres. https://doi.org/10.1029/2005JD006715

Jones, A. E., Anderson, P. S., Begoin, M., Brough, N., Hutterli, M. A., Marshall, G. J., Richter, A., Roscoe, H. K., \& Wolff, E. W. (2009). BrO, blizzards, and drivers of polar tropospheric ozone depletion events. Atmospheric Chemistry and Physics. https://doi.org/10.5194/acp9-4639-2009

Johnston, H. (1971). Reduction of Stratospheric Ozone by Nitrogen Oxide Catalysts from Supersonic Transport. Exhaust, Science, 173, 517-522.

Kaleschke, L., Richter, A., Burrows, J., Afe, O., Heygster, G., Notholt, J., Rankin, A. M., Roscoe, H. K., Hollwedel, J., Wagner, T., \& Jacobi, H. W. (2004). Frost flowers on sea ice as a source of sea salt and their influence on tropospheric halogen chemistry. Geophysical Research Letters. https://doi.org/10.1029/2004GL020655 
Kim, K., Yabushita, A., Okumura, M., Saiz-Lopez, A., Cuevas, C. A., Blaszczak-Boxe, C. S., Min, D. W., Yoon, H. II, \& Choi, W. (2016). Production of Molecular lodine and Tri-iodide in the Frozen Solution of Iodide: Implication for Polar Atmosphere. Environmental Science and Technology. https://doi.org/10.1021/acs.est.5b05148

Kreher, K., Johnston, P. V., Wood, S. W., Nardi, B., \& Platt, U. (1997). Ground-based measurements of tropospheric and stratospheric BrO at Arrival Heights, Antarctica. Geophysical Research Letters. https://doi.org/10.1029/97GL02997

Kreher, K., Keys, J.G., Johnston, P.V., Platt, U., Liu, X. (1996). Ground-based measurements of OClO and $\mathrm{HCl}$ in austral spring 1993 at arrival heights, Antarctica.

Geophys. Res. Lett. 23, 1545-1548.

Leser, H., Hönninger, G., \& Platt, U. (2003). MAX-DOAS measurements of BrO and NO 2 in the marine boundary layer. Geophysical Research Letters. https://doi.org/10.1029/2002gl015811.

Lindqvist, O., Johansson, K., Aastrup, M., Andersson, A., Bringmark, L., Hovsenius, G., Hakanson, L., Iverfeldt, A., Meili, M., Tim, B. (1991). Mercury in the Swedish environment - Recent research on causes, consequences and corrective methods. Water Air Soil Pollut 55, xi-261.

Liou, K. N. (2002). An Introduction to Atmospheric Radiation (Google eBook). In International Geophysics.

Luo, Y., Si, F., Zhou, H., Dou, K., Liu, Y., and Liu, W. (2018). Observations and source investigations of the boundary layer bromine monoxide ( $\mathrm{BrO})$ in the Ny-Ålesund Arctic, Atmos. Chem. Phys., 18, 9789-9801, https://doi.org/10.5194/acp-18-9789-2018. 
Mahajan, A. S., Gómez Martín, J. C., Hay, T. D., Royer, S. J., Yvon-Lewis, S., Liu, Y., Hu, L., Prados-Roman, C., Ordóñez, C., Plane, J. M. C., and Saiz-Lopez, A. (2012). Latitudinal distribution of reactive iodine in the Eastern Pacific and its link to open ocean sources, Atmos. Chem. Phys., 12, 11609-11617, doi:10.5194/acp-12-11609-2012.

Mahajan, A. S., Shaw, M., Oetjen, H., Hornsby, K. E., Carpenter, L. J., Kaleschke, L., TianKunze, X., Lee, J. D., Moller, S. J., Edwards, P., Commane, R., Ingham, T., Heard, D. E., \& Plane, J. M. C. (2010a). Evidence of reactive iodine chemistry in the Arctic boundary layer. Journal of Geophysical Research Atmospheres. https://doi.org/10.1029/2009JD013665.

Mahajan, A. S., Plane, J. M. C., Oetjen, H., Mendes, L., Saunders, R. W., Saiz-Lopez, A., Jones, C. E., Carpenter, L. J., and McFiggans, G. B. (2010 b). Measurement and modelling of tropospheric reactive halogen species over the tropical Atlantic Ocean, Atmos. Chem. Phys., 10, 4611-4624, doi:10.5194/acp-10-4611-2010.

Martin, M., Pöhler, D., Seitz, K., Sinreich, R., \& Platt, U. (2009). BrO measurements over the Eastern North-Atlantic. Atmospheric Chemistry and Physics. https://doi.org/10.5194/acp9-9545-2009.

McFiggans, G., Coe, H., Burgess, R., Allan, J., Cubison, M., Alfarra, M. R., Saunders, R., SaizLopez, A., Plane, J. M. C., Wevill, D., Carpenter, L., Rickard, a. R., and Monks, P. S. (2004). Direct evidence for coastal iodine particles from Laminaria macroalgae - linkage to emissions of molecular iodine, Atmos. Chem. Phys., 4, 701-713, doi:10.5194/acp-4-7012004.

McElroy, C. T., McLinden, C. A., \& McConnell, J. C. (1999). Evidence for bromine monoxide in the free troposphere during the Arctic polar sunrise. Nature. https://doi.org/10.1038/16904 
McConnell, J. C., Henderson, G. S., Barrie, L., Bottenheim, J., Niki, H., Langford, C. H., \& Templeton, E. M. J. (1992). Photochemical bromine production implicated in Arctic boundary-layer ozone depletion. Nature. https://doi.org/10.1038/355150a0

Mie, G. (1908). On the optics of turbid media, especially colloidal metal solutions. Ann. Phys. Berlin.

Meller, R., Moortgat, G.K. (2000). Temperature dependence of the absorption cross sections of formaldehyde between 223 and $323 \mathrm{~K}$ in the wavelength range 225-375 nm. J. Geophys. Res.: Atmosphere 105, 7089-7101.

Merlaud, A., Van Roozendael, M., Theys, N., Fayt, C., Hermans, C., Quennehen, B., Schwarzenboeck, A., Ancellet, G., Pommier, M., Pelon, J., Burkhart, J., Stohl, A.; De Maziere, M. (2011). Airborne DOAS measurements in Arctic: Vertical distributions of aerosol extinction coefficient and $\mathrm{NO}_{2}$ concentration. Atmospheric Chemistry and Physics, Vol. 11, Issue 17, 9219-9236, DOI: 10.5194/acp-11-9219-2011.

Miller, H. L., Weaver, A., Sanders, R. W., Arpag, K., \& Solomon, S. (1997). Measurements of arctic sunrise surface ozone depletion events at Kangerlussuaq, Greenland $\left(67^{\circ} \mathrm{N}, 51^{\circ} \mathrm{W}\right)$. Tellus, Series B: Chemical and Physical Meteorology. https://doi.org/10.3402/tellusb.v49i5.15988

Mitra, S. (1986). Mercury in the Ecosystem, 327 pp., Trans Tech, Clausthal-Zellerfeld, Germany.

Molina, M. J., \& Rowland, F. S. (1974). Stratospheric sink for chlorofluoromethanes: Chlorine atomc-atalysed destruction of ozone. Nature. https://doi.org/10.1038/249810a0 
Noxon, J. F. (1975). Nitrogen Dioxide in the Stratosphere and Troposphere Measured by Ground-Based Absorption Spectroscopy. Science. https://doi.org/10.1126/science.189.4202.547.

Peters, E., Wittrock, F., GroBmann, K., FrieB, U., Richter, A., Burrows, J. (2012). Formaldehyde and nitrogen dioxide over the remote western Pacific Ocean: SCIAMACHY and GOME-2 validation using ship- based MAX-DOAS observations. Atmos. Chem. Phys. 12 (22), 11179.

Peterson, P.K., Hartwig, M., May, N.W., Schwartz, E., Rigor, I., Ermold, W., Steele, M., Morison, J.H., Nghiem, S.V. and Pratt, K.A., (2019). Snowpack measurements suggest role for multi-year sea ice regions in Arctic atmospheric bromine and chlorine chemistry. Elem Sci Anth, 7(1), p.14. DOI: http://doi.org/10.1525/elementa.352

Pöhler, D., Vogel, L., Frieß, U., \& Platt, U. (2010). Observation of halogen species in the Amundsen Gulf, Arctic, by active long-path differential optical absorption spectroscopy. Proceedings of the National Academy of Sciences of the United States of America. https://doi.org/10.1073/pnas.0912231107

Plane, J.M.C., Saiz-Lopez, A., (2006). UV-visible differential optical absorption spectroscopy (DOAS). In: Heard, D.E. (Ed.), Analytical Techniques for Atmospheric Measurement. Blackwell Publishing, Oxford.

Platt, U., Stutz, J., (2008). Differential Optical Absorption Spectroscopy: Principles and Applications. Springer Berlin Heidelberg, Berlin, Heidelberg, Berlin, Heidelberg.

Platt, U., \& Hausmann, M. (1994). Spectroscopic measurement of the free radicals NO3, BRO, IO, and $\mathrm{OH}$ in the troposphere. Research on Chemical Intermediates. https://doi.org/10.1163/156856794X00450. 
Platt, U.: 1994, Air Monitoring by Spectroscopic Techniques, Chemical Analysis Series, Vol. 127, Wiley, New York pp. 27-84.

Platt, U., Perner, D., \& Paetz, H. W. (1979). Simultaneous measurement of atmospheric $\mathrm{CH}_{2} \mathrm{O}, \mathrm{O}_{3}$ and $\mathrm{NO}_{2}$ by differential optical absorption. Journal of Geophysical Research. https://doi.org/10.1029/JC084iC10p06329

Prados-Roman, C., Gómez-Martín, L., Puentedura, O., Navarro-Comas, M., Iglesias, J., de Mingo, J. R., Pérez, M., Ochoa, H., Barlasina, M. E., Carbajal, G., and Yela, M. (2018). Reactive bromine in the low troposphere of Antarctica: estimations at two research sites, Atmos. Chem. Phys., 18, 8549-8570, https://doi.org/10.5194/acp-18-8549-2018.

Prados-Roman, C., Cuevas, C. A., Hay, T., Fernandez, R. P., Mahajan, A. S., Royer, S.-J., Galí, M., Simó, R., Dachs, J., Großmann, K., Kinnison, D. E., Lamarque, J.-F., and Saiz-Lopez, A. (2015). lodine oxide in the global marine boundary layer, Atmos. Chem. Phys., 15, 583-593, https://doi.org/10.5194/acp-15-583-2015.

Prados-Roman, C., Butz, A., Deutschmann, T., Dorf, M., Kritten, L., Minikin, A., Platt, U., Schlager, H., Sihler, H., Theys, N., Van Roozendael, M., Wagner, T., \& Pfeilsticker, K. (2011). Airborne DOAS limb measurements of tropospheric trace gas profiles: Case studies on the profile retrieval of $\mathrm{O} 4$ and $\mathrm{BrO}$. Atmospheric Measurement Techniques. https://doi.org/10.5194/amt-4-1241-2011

Pöhler, D., Vogel, L., Frieß, U., \& Platt, U. (2010). Observation of halogen species in the Amundsen Gulf, Arctic, by active long-path differential optical absorption spectroscopy. Proceedings of the National Academy of Sciences of the United States of America. https://doi.org/10.1073/pnas.0912231107 
Pope, R. M. and Fry, E. S. (1997). Absorption spectrum (380-700 nm) of pure water, II. Integrating cavity measurements, Appl. Optics,36, 8710-8723.

Pratt, K., Custard, K., Shepson, P., Douglas, T., Pöhler, D., General, S., Zielcke, J., Simpson, W., Platt, U., Tanner, D.J., Huey, L.G., Carlsen, M.S., \& Stirm, B. (2013). Photochemical production of molecular bromine in Arctic surface snowpacks. Nature Geoscience, 6, 351356.

Pryor, S. C. , Crippa, P., Sullivan, R. C. (2015). Atmospheric CHemistry. Reference Module in Earth Systems and Environmental Sciences doi:10.1016/B978-0-12-409548-9.09177-6.

Puentedura, O., Gil, M., Saiz-Lopez, A., Hay, T., Navarro-Comas, M., Gómez-Pelaez, A., Cuevas, E., Iglesias, J., and Gomez, L. (2012). lodine monoxide in the north subtropical free troposphere, Atmos. Chem. Phys., 12, 4909-4921, https://doi.org/10.5194/acp-12-49092012.

Rodgers, Clive D. (2000). Inverse methods for atmospheric sounding. Theory and Practice. In World Scientific Publishing Co.Pte.Ltd.

Roscoe, H. K., Brough, N., Jones, A. E., Wittrock, F., Richter, A., Van Roozendael, M., \& Hendrick, F. (2014). Characterisation of vertical BrO distribution during events of enhanced tropospheric BrO in Antarctica, from combined remote and in-situ measurements. Journal of Quantitative Spectroscopy and Radiative Transfer. https://doi.org/10.1016/i.jqsrt.2014.01.026.

Rozanov, V. V. and Rozanov, A. V. (2010). Differential optical absorption spectroscopy (DOAS) and air mass factor concept for a multiply scattering vertically inhomogeneous medium: theoretical consideration, Atmos. Meas. Tech., 3, 751-780, https://doi.org/10.5194/amt-3-751-2010. 
Sanders, R. W. (1993). Visible and near-ultraviolet spectroscopy at McMurdo Station, Antarctica 9. Observations of OClO from April to October 1991. Journal of Geophysical Research. https://doi.org/10.1029/93JD00042

Saiz-Lopez, A., Sitkiewicz, S. P., Roca-Sanjuán, D., Oliva-Enrich, J. M., Dávalos, J. Z., Notario, R., Jiskra, M., Xu, Y., Wang, F., Thackray, C. P., Sunderland, E. M., Jacob, D. J., Travnikov, O., Cuevas, C. A., Acuña, A. U., Rivero, D., Plane, J. M. C., Kinnison, D. E., \& Sonke, J. E. (2018). Photoreduction of gaseous oxidized mercury changes global atmospheric mercury speciation, transport and deposition. Nature Communications. https://doi.org/10.1038/s41467-018-07075-3

Saiz-Lopez, A., Borge, R., Notario, A., Adame, J.A., de la Paz, D., Querol, X., Artiñano, B., Gómez-Moreno, F.J., Cuevas, C.A. (2017). Unexpected Increase in the Oxidation Capacity of the Urban Atmosphere of Madrid, Spain. Scientific Reports 7 (45956).

Saiz-Lopez, A., Blaszczak-Boxe, C. S., \& Carpenter, L. J. (2015). A mechanism for biologically induced iodine emissions from sea ice. Atmospheric Chemistry and Physics. https://doi.org/10.5194/acp-15-9731-2015.

Saiz-Lopez, A., Plane, J. M. C., Baker, A. R., Carpenter, L. J., Von Glasow, R., Gómez Martín, J. C., McFiggans, G., \& Saunders, R. W. (2012). Atmospheric chemistry of iodine. In Chemical Reviews. https://doi.org/10.1021/cr200029u.

Saiz-Lopez, A. \& vonGlasow, R. (2012). Reactive halogen chemistry in the troposphere. Chemical Society Reviews. https://doi.org/10.1039/c2cs35208g. 
Saiz-Lopez, A., Plane, J. M. C., Mahajan, A. S., Anderson, P. S.,Bauguitte, S. J.-B., Jones, A. E., Roscoe, H. K., Salmon, R. A.,Bloss, W. J., Lee, J. D., and Heard, D. E. (2008). On the vertical distri-bution of boundary layer halogens over coastal Antarctica: implications for $\mathrm{O}_{3}, \mathrm{HO}_{\mathrm{x}}$, $\mathrm{NO}_{\mathrm{x}}$ and the Hg lifetime, Atmos. Chem.Phys., 8, 887-900, doi:10.5194/acp-8-887-2008.

Saiz-Lopez, A., Mahajan, A. S., Salmon, R. A., Bauguitte, S. J. B., Jones, A. E., Roscoe, H. K., \& Plane, J. M. C. (2007). Boundary layer halogens in coastal Antarctica. Science. https://doi.org/10.1126/science.1141408.

Saiz-Lopez, A., and Plane, J. M. C. (2004), Novel iodine chemistry in the marine boundary layer, Geophys. Res. Lett., 31, L04112, doi:10.1029/2003GL019215.

Seinfeld, J. H., \& Pandis, S. N. (2006). Atmospheric Chemistry and Physics. Atmospheric Chemistry and Physics. https://doi.org/10.5194/acp-5-139-2005.

Serdyuchenko, A., Gorshelev, V., Weber, M., Chehade, W., Burrows, J.P. (2014). High spectral resolution ozone absorption cross-sections - part 2: temperature dependence. Atmos. Meas. Tech. 7 (2), 625-636.

Schönhardt, A., Begoin, M., Richter, A., Wittrock, F., Kaleschke, L., Gómez Martín, J. C., \& Burrows, J. P. (2012). Simultaneous satellite observations of 10 and BrO over Antarctica. Atmospheric Chemistry and Physics. https://doi.org/10.5194/acp-12-6565-2012.

Schroeder, W. H., Anlauf, K. G., Barrie, L. A., Lu, J. Y., Steffen, A., Schneeberger, D. R. and Berg T. (1998). Arctic springtime depletion of mercury, Nature, 394(6691), 331-332. 
Sihler, H., Platt, U., Beirle, S., Marbach, T., Kühl, S., Dörner, S., Verschaeve, J., Frieß, U., Pöhler, D., Vogel, L., Sander, R., and Wagner, T. (2012). Tropospheric BrO column densities in the Arctic derived from satellite: retrieval and comparison to ground-based measurements, Atmos. Meas. Tech., 5, 2779-2807, https://doi.org/10.5194/amt-5-27792012.

Simpson, W. R., Brown, S. S., Saiz-Lopez, A., Thornton, J. A., \& Von Glasow, R. (2015). Tropospheric Halogen Chemistry: Sources, Cycling, and Impacts. In Chemical Reviews. https://doi.org/10.1021/cr5006638.

Simpson, W. R., Carlson, D., Hönninger, G., Douglas, T. A., Sturm, M., Perovich, D., \& Platt, U. (2007a). First-year sea-ice contact predicts bromine monoxide (BrO) levels at Barrow, Alaska better than potential frost flower contact. Atmospheric Chemistry and Physics. https://doi.org/10.5194/acp-7-621-2007.

Simpson, W. R., Von Glasow, R., Riedel, K., Anderson, P., Ariya, P., Bottenheim, J., Burrows, J., Carpenter, L. J., Frieß, U., Goodsite, M. E., Heard, D., Hutterli, M., Jacobi, H. W., Kaleschke, L., Neff, B., Plane, J., Platt, U., Richter, A., Roscoe, H., Wolff, E. (2007b). Halogens and their role in polar boundary-layer ozone depletion. Atmospheric Chemistry and Physics. https://doi.org/10.5194/acp-7-4375-2007.

Simpson, W. R., Peterson, P. K., Frieß, U., Sihler, H., Lampel, J., Platt, U., Moore, C., Pratt, K., Shepson, P., Halfacre, J., and Nghiem, S. V. (2017). Horizontal and vertical structure of reactive bromine events probed by bromine monoxide MAX-DOAS, Atmos. Chem. Phys., 17, 9291-9309, https://doi.org/10.5194/acp-17-9291-2017.

Solomon, S., Schmeltekopf, A. L., \& Sanders, R. W. (1987). On the interpretation of zenith sky absorption measurements. Journal of Geophysical Research. https://doi.org/10.1029/JD092iD07p08311. 
Spietz, P., Gomez Martin, J.C. and Burrows, J.P. (2005). Spectroscopic studies of the $\mathrm{I}_{2} / \mathrm{O}_{3}$ photochemistry. Part 2. Improved spectra of iodine oxides and analysis of the IO absorption spectrum. J. Photochem. Photobiol. A: Chem. 176, 50-67; DOI: 10.1016/j.jphotochem.2005.08.023

Steffen, A., Douglas, T., Amyot, M., Ariya, P., Aspmo, K., Berg, T., Bottenheim, J., Brooks, S., Cobbett, F., Dastoor, A., Dommergue, A., Ebinghaus, R., Ferrari, C., Gardfeldt, K., Goodsite, Lean, D., Poulain, A. J., Scherz, C., Skov, H., ... Temme, C. (2008). A synthesis of atmospheric mercury depletion event chemistry in the atmosphere and snow. Atmospheric Chemistry and Physics. https://doi.org/10.5194/acp-8-1445-2008.

Thalman, R., Volkamer, R., (2013). Temperature dependent absorption cross-sections of $\mathrm{O}_{2}$ $\mathrm{O}_{2}$ collision pairs between 340 and $630 \mathrm{~nm}$ and at atmospherically relevant pressure. Phys. Chem. Chem. Phys. 15 (37), 15371-15381.

Trenberth, K. E., Fasullo, J. T., \& Kiehl, J. (2009). Earth's global energy budget. Bulletin of the American Meteorological Society. https://doi.org/10.1175/2008BAMS2634.1.

Vandaele, A.C., Hermans, C., Simon, P.C., Carleer, M., Colin, R., Fally, S., Mérienne, M.F., Jenouvrier, A., Coquart, B., (1998). Measurements of the $\mathrm{NO}_{2}$ absorption cross-section from $42000 \mathrm{~cm}^{-1}$ to $10000 \mathrm{~cm}^{-1}(238-1000 \mathrm{~nm})$ at $220 \mathrm{~K}$ and $294 \mathrm{~K}$. J. Quant. Spectrosc. Radiat. Transf.; Atmospheric Spectroscopy Applications 9659 (3), 171-184.

Van Roozendael, M., Hermans, C., DeMaziere, M., Simon, P.C. (1994). Stratospheric $\mathrm{NO}_{2}$ observations at the Jungfraujoch Station between June 1990 and May 1992.

Geophys. Res. Lett. 21, 1383-1386. 
Vountas, M., Rozanov, V. V., \& Burrows, J. P. (1998). Ring effect: Impact of rotational Raman scattering on radiative transfer in earth's atmosphere. Journal of Quantitative Spectroscopy and Radiative Transfer. https://doi.org/10.1016/S0022-4073(97)00186-6

Wagner, T., Ibrahim, O., Sinreich, R., Frieß, U., Von Glasow, R., \& Platt, U. (2007). Enhanced tropospheric BrO over Antarctic sea ice in mid winter observed by MAX-DOAS on board the research vessel Polarstern. Atmospheric Chemistry and Physics. https://doi.org/10.5194/acp-7-3129-2007

Wagner, T., Leue, C., Wenig, M., Pfeilsticker, K., \& Platt, U. (2001). Spatial and temporal distribution of enhanced boundary layer BrO concentrations measured by the GOME instrument aboard ERS-2. Journal of Geophysical Research Atmospheres. https://doi.org/10.1029/2000JD000201

Wagner, T., \& Platt, U. (1998). Satellite mapping of enhanced BrO concentrations in the troposphere. Nature. https://doi.org/10.1038/26723

Wedderburn, R. W. M. (1974). Quasi likelihood functions, generalized linear models, and the Gauss Newton method. Biometrika. https://doi.org/10.2307/2334725.

Wilmouth, D.M., Hanisco, T.F., Donahue, N.M., and Anderson, J.G. (1999). Fourier transform ultraviolet spectroscopy of the $\mathrm{A}^{2} \Pi_{3 / 2} \leftarrow \mathrm{X}^{2} \Pi_{3 / 2}$ transition of BrO. J. Phys. Chem. A 103, 8935-8945; DOI: 10.1021/jp9916510.

Zhao, X., Strong, K., Adams, C., Schofield, R., Yang, X., Richter, A., Frie $\beta$, U., Blechschmidt, A.-M., and Koo, J.-H. (2016). A case study of a transported bromine explosion event in the Canadian high arctic, J. Geophys. Res. Atmos., 121, 457-477, doi:10.1002/2015JD023711. 